\title{
Pouvreauren Hiztegiaren antolakuntzaz

\author{
On the organization of Pouvreau's dictionary
}

\author{
Javier Etxagibel \\ Universidad del País Vasco/Euskal Herriko Unibertsitatea UPV/EHU
}

\begin{abstract}
In the research work Silvain Pouvreauren hiztegiaren iturriak eta testukritikaren metodologia (ASJU XLII-2, 2008, 69-118) we studied the Pouvreau's literature and lexical sources with the support of the text criticism. Among the conclusions, we pointed out the need of going deep into the study of the mentioned written sources, and to approach to the aspects of the Pouvreau's lexicography that in the previous works carried out by several researchers had been insufficiently studied or remained unstudied, i.e. the dictionary patterns apart from Voltoire's one (ASJU XLIV-2, 2010, 221-278) on what Pouvreau could based to prepare theirs, the structuration's process of the dictionary, their chronology, the gathered basque spoken testimonies, evolution with the time of dictionary's entries and subentries, and so on. These objectives prompted us to carry out with the aid in this occasion the metalexicography and the text criticism, the doctoral thesis called Pouvreauren hiztegia testukritika eta metalexikografiaren argitan that we defended in november of 2014.

In this number of ASJU we present the section of the thesis Pouvreauren hiztegiaren antolakuntza that is divided in three subsections: i) about dictionary' structure, i.e. macro and microstructure ii) about French lexicography pattern, i.e. traces of the French lexicographers Voltoire, Oudin and Nicot in the Pouvreau's dictionary. iii) about structuration of the dictionary.

The main results we have obtained are the following: the nomenclature is organized in an ethymological order as that Nicot's dictionary has. Regarding the microstructure, our results are not conclusive, because Pouvreau's original manuscript has a lot of marginal entries, Spanish equivalents, proverbes and so on, that difficult to draw out any final conclusion. On the other hand, Nicot's and Oudin's dictionaries were the main patterns that Pouvreau utilized to organize theirs, at a greater extent than Voltoire's one. In efect, it looks like Pouvreau consulted the two dictionaries simultaneously, but choosing the ethymological order of the Nicot's one as the guide. Finally, and according with our hypothesis Pouvreau utilized mainly two starting languages to structure their dictionary: i) French: on one hand looking for the correspondant Basque equivalents to Nicot's and Oudin's entries, and on the other hand, but an a more little extent by incorporating as entries several terms from he himself translated texts from French to Basque, ii) Basque: incorporating Basque authors' and spoken testimonies.
\end{abstract}




\section{Sarrera}

Silvain Pouvreauren XVII. mendeko hiztegiak euskalarien arreta erakarri du gutxienez Humboldt-ek haren eskuizkribuaren berri hedatu zuenetik. Hau dela eta, bertako lekukotasunak xIx. mendetik aurrerako euskal hiztegietan errepikatuak eta euskal idazleek erabiliak izan dira. Ikerketaren aldetik, Urquijok (1909, 1910), Vinson-ek (1910a), Mitxelenak (1961), Bilbaok (1992) eta Lakarrak (1995), besteak beste, hiztegiaren funtsezko alderdiak azaldu dituzte. Hala eta guztiz ere, eskuizkribu garrantzizko horrek gaur egun ere argitaragabe dirau. Bada edizio saio interesgarri bat (Kerejeta 2003), baina, zoritxarrez, egileak ez zuen amaitzerik izan eta bere ahalegina ere isilean gelditu da.

2008ko azaroan defendatu genuen Silvain Pouvreauren hiztegiaren iturriak eta testukritikaren metodologia tesinan, testukritika erabiliaz, Pouvreauren euskal iturri idatziak aztertu genituen. Ikerlan horren ondorioetan adierazi genuenez Pouvreauren hiztegigintzan hainbat alderdi ikertu gabe geratu ziren, eta alderdi horietan sakontzea jarri genuen helburu Pouvreauren hiztegia testukritika eta metalexikografiaren argitan izenburudun tesian. ${ }^{1}$ Oraingo honetan testukritika eta metalexikografiaz baliatuta Pouvreauren iturri idatziak xehekiago miatzeaz eta erabili ahal izan zituen gainerako iturriak arakatzeaz gain, aztertu gabe (edo gutxi aztertuak) diren alderdietan jarri genuen arreta: hiztegiaren eredua(k), gauzatze prozesua, kronologia eta egitura, euskal iturri idatziez bestelako iturriak, hiztegiko lekukotasunen bilakaera denboran zehar, hiztegigilearen iturriekiko jokabidea, etab.

Hasieratik A eskuizkribua hartu genuen gure azterketaren oinarri nagusitzat, hiru eskuizkribuetan osatuena baita eta bertan ageri baitira iturriei buruzko erreferentzia gehienak. Ezarritako helburuetara heltzeko oso luze joko zukeen A eskuizkribuaren edizio osoa egin beharrean, A, B, C, D, I, V eta X letren sarrerek osatutako tamaina handiko lagin batez $(\% 44)$ baliatzea erabaki genuen, horrela jokatuz eskuizkribu osoari estrapolatu geniezazkiokeen datu nahiko fidagarriak lortuko genituela iritzita. Letren aukeraketari dagokionez ondokoa esan behar da: lehenbiziko lau letretan aurkitzen dira Oudinen hiztegitik ateratako gaztelaniazko baliokide gehienak; horrenbestez, letra horiek Pouvreauren balizko hiztegi laukoitzaren eredutik hurbilenak dira. Bestalde, C, I eta V letra bikoitzak dira, hurrenez hurren $\mathrm{C}$ eta $\mathrm{Z}$, I eta J, eta $\mathrm{U}$ eta $\mathrm{V}$ elkarrekin emanak baitira. Azkenik, I eta $\mathrm{V}$ aukeratzeko beste arrazoi bat ere bada: hiztegiaren erdialdeko eta azkenengo letrak direnez, haien azterketaz eskuizkribuaren argazki osoagoa lortzea, kontuan harturik hiztegigileek maiz ez dutela hiztegia hasi eta buka berdin egiten. ${ }^{2}$

$A S J U$-ren ale honetan aurkezten dugun lana «Pouvreauren hiztegiaren antolakuntza» izenburudun tesiaren atalari dagokio, eta hiru azpiatal nagusitan banatzen da: I) Hiztegiaren egituraz; II) Hiztegigile frantsesen ereduaz; III) Hiztegiaren eraketaz.

12014 ko azaroan defendatu nuen doktorego tesi hau Blanca Urgellen zuzendaritzapean burutu nuen. Esan gabe doa nire esker ona Blancari, hala tesia bideratzeagatik, nola eman zizkidan euskarri, laguntza eta aholku guztiengatik.

2 Adibidez, Larramendiren hiztegian alde handia dago A letraren hasiera eta gainerakoaren artean (Urgell 1998: 160). 


\section{Hiztegiaren egituraz}

\section{I.1. Makroegitura}

A eskuizkribuaren nomenklaturak ondoko banaketa du letraz letra: ${ }^{3}$

1. taula

\begin{tabular}{|c|c|c|c|c|}
\hline Letra & Lehehengo sarrera & Azken sarrera & Orrialde tartea & Sarrerak + azpisarrerak guztira \\
\hline A & Abadea & Aztura & $4 r^{o}-30 v^{o}$ & 1.739 \\
\hline B & Baba & Buthoitcea & $31 \mathrm{r}^{0}-49 \mathrm{v}^{\mathrm{o}}$ & 1.386 \\
\hline $\mathrm{C}$ & Çaacoa & Cuzcatcea & $50 \mathrm{r}^{\mathrm{o}}-67 \mathrm{v}^{\mathrm{o}}$ & 1.234 \\
\hline D & Dafailla & Durdoa & $68 \mathrm{r}^{\mathrm{o}}-74 \mathrm{r}^{\mathrm{o}}$ & 434 \\
\hline $\mathrm{E}$ & $\mathrm{Ea}$ & Eztupa & $74 v^{0}-95 v^{0}$ & 1.465 \\
\hline $\mathrm{F}$ & Faça & Futrea & $95 \mathrm{v}^{0}-99 \mathrm{v}^{0}$ & 284 \\
\hline G & Gabea & Gutia & $99 \mathrm{v}^{\mathrm{o}}-115 \mathrm{r}^{\mathrm{o}}$ & 1.123 \\
\hline $\mathrm{H}$ & Habailla & Hutstasuna & $115 \mathrm{v}^{\mathrm{o}}-131 \mathrm{r}^{\mathrm{o}}$ & 1.114 \\
\hline I & Ia & Izpia & $131 \mathrm{r}^{\mathrm{o}}-146 \mathrm{v}^{\mathrm{o}}$ & 1.086 \\
\hline $\mathrm{K}$ & Kaïçua & Kyrieeleisunac & $146 v^{o}-147 v^{o}$ & 93 \\
\hline $\mathrm{L}$ & Labea & Luyza & $148 \mathrm{r}^{\mathrm{o}}-157 \mathrm{v}^{\mathrm{o}}$ & 688 \\
\hline M & Macatcea & Myrrha & $158 \mathrm{r}^{\mathrm{o}}-168 \mathrm{v}^{\mathrm{o}}$ & 747 \\
\hline $\mathrm{N}$ & Nabala & Nuque & $168 \mathrm{v}^{\mathrm{o}}-173 \mathrm{r}^{\mathrm{o}}$ & 296 \\
\hline $\mathrm{O}$ & $\mathrm{Oa}$ & Ozta (hedatu) & $173 \mathrm{r}^{\mathrm{o}}-183 \mathrm{v}^{\mathrm{o}}$ & 668 \\
\hline $\mathrm{P}$ & Pachela & Puxtatcea & $183 \mathrm{v}^{\mathrm{o}}-191 \mathrm{v}^{\mathrm{o}}$ & 567 \\
\hline Q & Quarta & Quitança & $192 \mathrm{r}^{\mathrm{o}}-192 \mathrm{v}^{\mathrm{o}}$ & 41 \\
\hline $\mathrm{R}$ & Refraua & Resuma & $192 \mathrm{v}^{\mathrm{o}}-192 \mathrm{v}^{\mathrm{o}}$ & 3 \\
\hline S & Sabbatoa & Suya & $192 \mathrm{v}^{\mathrm{o}}-201 \mathrm{r}^{\mathrm{o}}$ & 604 \\
\hline $\mathrm{T}$ & Tabacoa & Tutuluya & $201 \mathrm{r}^{\mathrm{o}}-205 \mathrm{r}^{\mathrm{o}}$ & 267 \\
\hline V & Valenta & Vzterra & $205 \mathrm{r}^{\mathrm{o}}-213 \mathrm{r}^{\mathrm{o}}$ & 506 \\
\hline \multirow[t]{2}{*}{$\mathrm{X}$} & Xorhia & Xuxquerrua & $213 \mathrm{r}^{\mathrm{o}}-213 \mathrm{r}^{\mathrm{o}}$ & 3 \\
\hline & & & & 14.348 \\
\hline
\end{tabular}

\section{I.1.1. Antolakuntza orokorra}

Aurreko taulan ikusten denez A eskuizkribuko hiztegia $4 \mathrm{r}^{\mathrm{o}}$ orrialdetik $213 \mathrm{r}^{\mathrm{o}}$ orrialderaino hedatzen da. Guztira 14.348 sarrera ditu; horietarik gure laginari ( $\$ 0$ ) 6.388 dagozkio, hots, \%44,52. Garbi dago behin betiko balizko hiztegiaren zirriborrotzat hartu behar dela. Izan ere, Pouvreauk hasierako zutabe bakarreko euskarafrantses hiztegiari alboetan eta sarrera lerroen artean hiztegi hirukoitz (\$ III) bilakatzeko behar zituen Oudin-en gaztelaniazko ordainak eta errefrauak erantsi zizkion, A eskuizkribua zirriborro bihurtuta. Nomenklaturaren antolakuntzan, oro har, Nicot-en hiztegi etimologikoaren eredua erabili zuen (\$ II.2.4), hots, sarrera buruak alfabeto ordenaren arabera antolatuta eta bakoitzarekin etimologikoki lotutako hitzak eta esapideak azpisarrera modura haren ondoren kokatuta.

${ }^{3}$ Gure zenbaketan testu-zutabean diren sarrerak eta azpisarrerak nahiz orri ertzean direnak kontuan hartu ditugu (\$ I.2.1). 
Nolanahi ere, gure laginean badira alfabetoaren ordenaren aurkako desbideratzeak, oharkabekoak ziurrenik; esaterako, Agaratça ${ }^{4}$ eta Ago-ren artean Agradablea sarrera burua eta haren azpisarrerak dira, eta $A p p$ - hasiera duten Appainkinac eta Appariatu çait macelaco emaitera-ren arteko lerroak $A p$ - sarreren artean sartu zituen oker, nahiz eta geroago konturatu (cf. edizioan Aparta-ri buruzko oharra). Orobat, AzcaraAzpiltasuna (azpiltcea) segidaren ondoren Aza-Aztura sartua da (Ahur bat aza-z hasten den eta Aztura-z bukatzen den orrialdearen testu-zutabea zeharkako marra batez markatuta badago ere).

\section{I.1.2. Aurkezpen grafikoa}

\section{I.1.2.1. Letra aldaketa iragartzeko era}

Eskuizkribua izateagatik edo, Pouvreauk ez zuen arreta berezirik jarri letra baten azken sarrera eta hurrengoaren lehenbizikoa bereizteko. 1. taulan ikus daitekeenez A, B, C, D, H eta L letrek orrialde osoak betetzen dituzte. E, M eta Q letrak orrialde beregain batean hasten dira, baina euren azken sarrerak eta hurrengo letren lehenbizikoak orrialde berean bilduak dira. Gainerakoetan ere letra aldaketa orrialde berberean gertatzen da. Aldaketak nolabait markatzeko bi sarreren arteko tartea ohikoa baino handiagoa da.

\section{I.1.2.2. Orrialde markatzea}

Testua zutabe bakarrean antolatuta dago eta soilik orrien aurkiak Pouvreauren eskutik idatziak ez diren zenbakiz markatuak dira. ${ }^{5}$

\section{I.1.3. Sarrerak}

Sarreren aurkezpen grafikoa ${ }^{6}$ ondoko adibidean ikus daitekeena da:

Behatcea. regarder. 2. so eguitea. mirar. catar. arrostrar.

beha nago. je regarde.

beha nagoca. ie le regarde.

Beha eztagoena aitcinara lerra daite guibelara. O. pr. 77.

Qui ne prend garde en auant est capable de glisser en arriere.

Beha lehenic, minça azkenic. O. pr. 79. Ecoute le premier \& parle

Behaçalea. O. behatçaillea. aguineur. ecouter. espion.

Behaçalea maizago bere gaizquiari ecen ez onguiari beha dago. O. pr. 84. Qui demeure aux ecoutes entend plus souuent son mal que son bien.

\footnotetext{
4 Aurrerantzean aipatuko diren hiztegiko azpisarrera, aipu, adibide, etab. edizioan atzematea errazteko beharrezkoa denean haiei dagozkien sarrera buruak parentesi artean erantsita agertuko dira.

5 Aipatutako zenbakeraz gain, ondoko orrietan bigarren esku batek idatzitako zenbaki desberdinak agertzen dira: 4 / 3; 88 / P. 169; 136 / 265; 148 /289; 160 / 313; 172 / 337; 184 / 361; 196 / 386.

6 Aurkezpen grafikoa deskribatzeko ez ditugu kontuan hartu orri ertzeko eransketak, jakina.
} 
Hau da:

- Sarrera artean hutsunea dago, eransketek tarte hori betetzen dutenean izan ezik.

- Sarrera buruaren hasierako letra larria da, baina baita azpisarrera batzuena ere. Beraz, sarreraren buruan egoteaz beste ezerk ez du bereizten grafikoki.

— Lerrokadak sangraturik gabekoak dira.

- Eskuarki sarrera-azpisarrerak lerro bakarrekoak dira. Salbuespenak dira lerro bat baino gehiago betetzen duten Oihenarten atsotitz elebidun gehienak, Oudin-en errefrauak eta zenbait aipu luze.

\section{I.2. Mikroegitura}

\section{I.2.1. Sarrera kanonikoaren nolakotasuna}

Pouvreauren sarrera kanonikoa sarrera konplexu bat da. Alde batetik, haren antolakuntza etimologikoari dagokionez, sarrera buruaren azpian agertzen dira berak haren familia etimologikotzat jo dituen hitz guztiak. Bestetik, hauek ere lerrokada bana hartuz, sarrera buruaren zein azpisarreren adibideak eta bestelako esapideak, errefrauak barne.

Makrosarrera horren barruko osagai bakoitzaren egiturari dagokionez, A eskuizkribuak dituen eransketak kontuan harturik ezin daiteke sarrera kanoniko orokor batez hitz egin. Eransketarik ez duten sarrerei dagokienez, sarrera kanoniko bakarra jatorriko hiztegi elebidunari legokioke, eta euskal sarrera buruak, haren sinonimo edota aldaerak eta frantsesezko ordainak (edo ordainek) osatuko lukete. Gainerako kasuak haren gainean egindako eransketak dira eta halakoetan soilik joeraz hitz egin daiteke:

- Sarrera edo azpisarrera burua erreferentziaduna bada, erreferentzia haren ondoren izaten da, baina soilik joera da, ez baitago arau finkorik, izan ere, zenbaitetan erreferentziak ordainen ondoren agertzen dira, esaterako, "Alga. fourrage. O.», "Valiostasuna. valeur. a. 136» (valiatcea).

- Sarrera edo azpisarrera buruaren sinonimo, aldaera eta adierak kokatzeko ere ez dago arau finkorik: frantsesezko ordainen aurrean nahiz atzean ager daitezke. Esaterako, «Acheria. aceria. acearia. renard», "Arrogaria. arrogatçailea. voleur. pilleur» (arrogaceria), "Bethaçala. bethespala. bethilleac. paupieres», «Biçuntça. erauntsia. tempesté», baina «Achiruina. La cheuille du pied. 2. apalardotza», "Arrada. raloire. erredola».

- Gaztelaniazko ordainak, agertzekotan, frantsesezko ordainen ondoren ohi dira: «Adina. âge. edad», "Arraina. poisson. pesce. pece», gaztelaniazko baliokideak azken orduko eransketak izan baitziren. Hala ere, badira salbuespenak: esaterako, "Acometamendua. Acometimiento, attaque, aggression, assaut» (acometacea) azpisarrera, baina kasu honetan argi dago hasieran ordainik gabeko sarrera zela eta Pouvreauk eransketa guztiak Oudinen Tresor-eko E/F liburukitik atera zituela.

- Latinezko ordainak oso tarteka baino agertzen ez direnez (Etxagibel 2014: 556-565), ordenan halako anabasa bat gertatzen da: zenbaitetan frantsesezko 
ordainaren ondoren dira: "Arrega. fraise. fragum. maramoa. marruuia. marruuiüa». Bestetan — batez ere, Oihenarten Notitia-tik ateratako sarreretaneuskal sarrera buruak eta latinezko ordainak osatzen dute sarrera, frantsesezko ordainik gabe: "Alquila, Alquilea. O. locatio». Beste batzuetan latinezko ordaina frantsesezkoaren aurrean da: «Anço. 2. sicut, comme. beçala», etab. Badira lau hizkuntzak biltzen dituzten zenbait sarrera, baina salbuespenak dira: ez dago esaterik hiztegi laukoitzaren aztarnak edo aurrekariak direnik. ${ }^{7}$

\section{I.2.2. Aurkezpen grafikoa}

Eskuarki, euskal sinonimoak, aldaerak eta adierak, bai eta beste hizkuntzetako ordainak ere letra xehez idatziak dira, puntuz bananduta beste bereizgarririk gabe.

\section{I.2.3. Forma kanonikoa morfologiaren aldetik}

Sarrera eta azpisarrera buruak, ${ }^{8}$ euren sinonimoak eta aldaerak izenak zein izenondoak direnean ia salbuespenik gabe mugatu singularrean agertzen dira. Berriz, aditzak aditz-izenaz adierazten dira. Jokabide hau ohikoa izan da Iparraldean Leizarragarengandik hasi eta Xahoren hiztegia arte (1855; cf. Urgell 2002a: 74-75).

\section{I.2.4. Sarreren gainerako osagaiak}

\section{I.2.4.1. Azpisarrerak}

Aurkezpen grafikoari dagokionez, A-tik X-raino azpisarreren hasiera letra —sarrera buruenak bezala - letra larriz idaztea joera orokorra da. Salbuespenak dira:

- B: gutxi gorabehera Bachera-tik aurrera azpisarrera gehienak $b$ xehez idatzita daude sarrera burutik bereizteko.

- C: oro har, azpisarrerak $c$ xehez idatziak dira.

— D: Deïa sarrera arte gutxi gorabehera sarrera buru eta azpisarreren hasiera letra larriz idatzia da; handik aurrera joera orokorra azpisarrerak letra xehez idaztea da.

- F: lehenengo sarrera den Faça efe larriz idatzia da. Gainerakoetan sarrera buruak nahiz azpisarrerak efe xehez idatziak dira.

Horietaz gain, I letran Pouvreauk sarrera buruen eta azpisarreren sinonimoak, aldaerak, etab. idazteko $i$ edota $j$ xeheak erabiltzen ditu inolako araurik gabe. Esaterako, «Ichaka. jxeka», "Iduria. jrudia», "Ez jcusi iduri eguitea», "Molça ioria», "Nescato joria» (ioria).

7 Izan ere, C eskuizkribuko Arreba-Aztorea arteko sarrerak A eskuizkribuko tarte bereko sarrerekin alderatuz gero, ondorio kontraesankorrak ateratzen dira: C eskuizkribuan laukoitza den Arrega sarrera A eskuizkribuan hirukoitza da, gaztelaniazko ordainik gabe, hain zuzen. Berriz, A eskuizkribuan laukoitza den Aspidea C eskuizkribuan hirukoitza da, latinezko ordainik gabe.

8 Jakingarria liteke ohiko sarrera buruak zein gramatika kategoriatakoak diren, bai eta zein izan ohi diren azpisarrera gisa agertzen diren kategoria eta atzizkiak, baina gai hau oraingoz aztergai gelditzen da. 


\section{I.2.4.2. Adibideak}

Dagozkien sarrera edo azpisarrera buruen azpian agertzen ohi dira. Ondoko taldeetan sailka ditzakegu:

- Autoreen aipuak: erreferentziadunak edo erreferentzia gabekoak.

- Gainerako adibideak: ematen du haietariko asko Pouvreauk asmatuak direla (Etxagibel 2014: 500-503).

\section{I.2.4.3. Atsotitzak eta errefrauak}

- Oihenarten atsotitzak: oro har, —salbuespenak salbuespen (Etxagibel 2014: 222-225) — Les Prouerbes-en diren bezala agertzen dira hiztegian, hori bai, Oihenarten grafia egokituta (Etxagibel 2014: 529-538).

- Oudinen errefrauak: oro har, Oudin-en Refranes o prouerbios españoles traduzidos en lengua francesa-n diren bezala kopiatu zituen (\$ II.2.2).

— Iturri ezagunik gabeko atsotitzak (Etxagibel 2014: 500-501).

Azpisarrera, adibide eta errefrauen arteko ordenari dagokionez, eredu ideala izango litzateke gorago aurkeztu duguna (\$ I. 1.3), hau da, sarrera zein azpisarrera buru bakoitzaren azpian dagozkion adibide eta errefrauak. Hala ere, Pouvreauk askotan ordena ideal horri ez zion eutsi, agian garrantzirik ez ziolako ematen; nolanahi ere, ez dira gutxi eransketa berriak egiteagatik jatorrizko antolaketa txukuna galdu duten sarrerak:

Bertça. chaudron.

Bertzquina. chaudronnier.

Bertça larratzean, oreina larrean.

Sarrera honetan Pouvreauk Bertça-ri dagokion atsotitza Bertzquina azpisarreraren ondoren bildu zuen.

Beira. verre.

Beira bat vr hotz huts. vn seul verre d'eau froide.

Beiraquia. verre. verrerie.

Beïraquiaren pare gara. a.

Beiraquizco bachera. vaiselle de verre.

Bere etchea beirez daducanac estaliric ezpeça aurtic bertcerenera harriric. O.pr.92.Que celuy qui a sa maison couuerte de vitre ne jette point de pierre sur celle d'autruy.

Sarrera honetan ere Beira-ri dagokion Oihenarten atsotitza lekuz kanpo da, ziurrenik azken orduko eransketa izateagatik. Izan ere, eransketak ahal zituen lekuetan ezartzen zituen, beharbada A eskuizkribua garbira pasatzean berrantolatzeko asmoz.

\section{I.2.5. Markatzea}

\section{I.2.5.1. Gramatika laburdurak}

Pouvreauk ia ez zuen gramatika laburdurarik erabili. ${ }^{9}$ Salbuespen gisa, «aduerbe» marka zein «adu.» laburdura aurkitu dugu ondoko hiru sarreretan: «Azpian.

9 Gramatika laburdurei buruz Urgellek ondokoa dio: «Kategoriaka antolatutako zerrendetan izan ezik (cf. Urte), xIx. mendearen erdialderaino ez dugu aurkitzen euskal hitzen gramatika-kategoria adie- 
2. pian. adu. dessous», "Aurthen. aduerbe. cette année», «Iaz. adu. l'année passé». Bestalde, adizki trinko batzuk «anomal» laburduraz markatuak dira, ziurrenik irregular direla adierazteko, ${ }^{10}$ hala nola "Badacusat. anomal d'icustea», "Badaidit. anomal.», «Badaritçat. anomal.», «Bethor bethoz. anomal d'ethortcea», «Bit. anomal d'emaitea», "Çatchezte hari. anomal d'itchequitcea». Ostera, beste batzuk markatu gabe dira: "Daguidanz. en la gram», "Dançut. en la gram. ençutea», "Darrait. il me suit», etab.

\section{I.2.5.2. Erreferentziadun lekukotasunen laburdurak}

Pouvreauk autoreen erreferentziak ematen ditu, baina ez sistematikoki, hots, zenbaitetan autoreen laburdurak bildu beharrean lekukotasunak testuetan agertzen diren orrialdeen zenbakiak, bertseten erreferentziak edo atsotitzen zenbakiak darabiltza. Vinson-en, Urkijoren, Mitxelenaren eta Kerejetaren ikerlanei esker (Etxagibel 2014: 18-19), salbuespen batzuk izan ezik, ${ }^{11}$ erreferentziak egiaztatuak dira. Laburduren sistema bera ere ez da sistematikoa:

- Axular: a. Eskuarki letra xehez idatzia, baina badira salbuespenak, hala nola "Afentcea. A.", "Bat bedera bere guiçara, ançora eta moldera minço da. Ax." (anço) eta "Borreroa. ax. 304".

- Oihenart:

a) Hitz solteek, oro har, O larria daramate.

b) Atsotitzek «O + pro + zenbakia», "pro + zenbakia» zein "pro» bakarrik.

c) Neurtitzetako hiztegitxoaren hitzek hizkerei dagozkien laburdurak daramatzate $(\$$ I.2.5.4).

- Etxeberri: e.

- Leizarraga:

a) oro har, L, Lç, Liç zein Liz.

b) Testamentu Berria-ko atalei erreferentzia egiten dietenak:

razten duenik, nahiz EHAE-ren egitasmoan jadanik jasota egon ( Se ha de individualizar en cada artículo o voz, qué parte de la oración sea...», $\$ 3^{\circ}, 1^{\circ}$ ). Berrikuntza Salaberriri zor zaio [1856], baina Xahok ere [1855] frantses eta gaztelaniazko ordainak sistematikoki markatzen ditu, eta euskarazkoetarako gramatikazko tauletara bidaltzen. Halere, ez zen orduan orokortu, ezta xx. mendearen zati on batean [...]» (Urgell 2002a: 74).

${ }^{10}$ Ez dago jakiterik «anomal» delako ideia Pouvreaurena berarena den ala beste batengandik hartu zuen. Esaterako, Oihenartengandik badakigu Etxeberri Ziburukoak hiztegi batez gain "conjugaisons» delako idazlana idatzi zuela (Etxagibel 2014: 201). Pouvreauren lekukotasun goiztar hau erantsi behar zaio, beraz, trinkoak irregularrak zirela uste izan zuten gramatikagileen zerrenda luzeari: «Aditz bakunen eta konposatuen - nahiago bada, trinko eta perifrastikoen — antzinatasun eta jatortasunaren arazoan, gauza jakina da, geroztik eta XIX. mendera arte jarrera nagusia izango dena ezartzen du Larramendik (1729: 44-45); hots, adizki konposatuak dira erregularrak eta, beraz, jatorrak, eta bakunak irregularrak» (Gómez 2008: 340).

11 Badira a. laburduradun lekukotasunak Guero-n aurkitzen ez direnak (Etxagibel 2014: 186-187). Halaber, oraingoz ezin izan da frogatu h. laburduradun lekukotasun guztiak Harizmendirenak direnik (Etxagibel 2014: 273-275). 


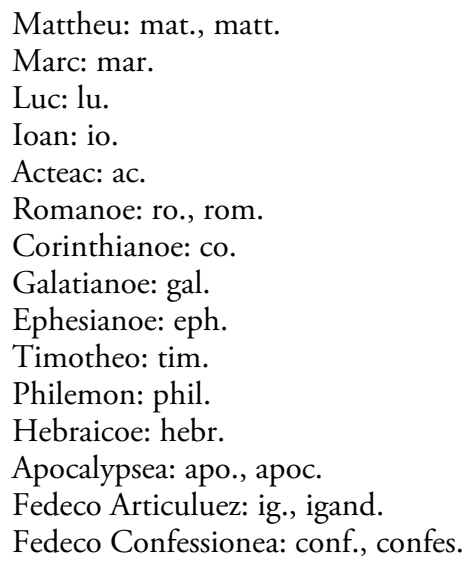

Laburdura horien hasierako letrak larri edo xehe izan daitezke eta dagokien kapitulu edota bertsetaren zenbakiaz lagunduak agertzen dira (zenbaitetan Leizarragaren laburduraren batekin ere).

- Harizmendi: h.

\section{I.2.5.3. «2» ikurra}

Hainbatetan Pouvreauk euskal hitz bati —batzuetan, itxuraz, frantsesezko ordain bati ere- 2 zenbakiaren antza duen ikurra erantsi zion. Gure hipotesiaren arabera ipar-ekialdeko ahozko iturri bati (herri edota pertsona bati) legokioke (Etxagibel 2014: 505-519).

\section{I.2.5.4. Euskalki markak}

Pouvreauk, oro har, ez zuen euskalki markarik erabili. Soilik bi kasutan agertzen dira, baina ez sistematikoki: Oihenarten Les Proverbes basques-eko azkenaldean den hiztegitxotik ateratako hitzetan eta Leizarragaren Çvberoaco Herrian vsançatan eztiraden... hiztegitxotik ateratakoetan. Lehen kasuan, Oihenartek berak erabilitako markez baliatu zen, salbu eta, esanguratsuki, Lapurdiri zegozkienak: ${ }^{12} \mathrm{~B}=$ la Basse Nauarre; $S$ = la Soule; S. M. = Soule Meridionale; N = la Haute-Nauarre. Leizarragaren kasuan, berriz, Oihenartek Zuberoa markatzeko erabili zuen marka bera (S) darabil; esaterako: «Igorçuria, ihorciria. tonerre. durunda S.».

Horietaz gainera, Oihenartek bidalitako hitz zerrendetan agertzen diren euskalki azalpenak ere kopiatu zituen (guk azpimarratuak):

12 Oihenartek Labourt eta Labourt Occidental adierazteko L eta L. Oc. laburdurak erabili zituen, hurrenez hurren. Hala ere, Pouvreauk A eskuizkribuan Oihenarten zerrendatik hartu zituen L edo L. Oc. laburduradunak markarik gabe bildu zituen: hala bada, Ahuz (ahutsa), Araz (aratza), Becoqui, Berretuz (berretcea), Berun, Eredu, Erne, Iguelsu, Iharduquitcea eta Supu Oihenarten frantsesezko azalpenekin agertzen dira, baina laburdurarik gabe. 
«Arimateguia. le manoir des ames, paradis ou enfer. au pais de soule ce terme n'est vsurpé que pour l'enfer».

«Bedatsea. en Soule c'est le printemps O.».

«Behatza. ongle. en basse nauarre le poulce. behatzaçala. açazcuillua».

"Guiçon belatza. en basse n. homme qui a vn visage agreable» (belatza).

«Bethurusta, supercilium. e. bepuruac. en basse nauarre \& soule. O.».

"Betuna. en soule. betoine. O. orhe ondo belharra».

"Çaldarra. en biscain vn clou ou froncle».

«Donguea. O. gaixtoa. mauuais c'est vne mot biscain".

"Gunea, en soule veut dire lieu ou endroit, en labourt geste countenance».

"Gura. desir. c'est vne terme de Biscaye duquel Axular se sert souuent».

«Lambroa. en Ipuzcoa \& biscaye c'est brouée \& lambrozea lors que la brouée s'eleue».

«Lapicoa. tupina. eltcea. en biscaye pot a faire lepotage. en labourt eltcea».

"Lumbratcea. en langage d'Ipuzcoa veut dire nommer».

«Nauea. ordoquia, celhaya. planities. en guipus \& naua en haute \& basse nau. vne grande plaine proche des montagnes».

«Tussuria. le diable. c'est vn mot du vieil basque du quel on se sert encore en soule».

Bestalde, Oihenarten hitz zerrenda ezagunetan ez den euskalki marka bat aurkitu dugu bi aldiz, Gipuz., agian etorki berekoa:

«Ambiltcea, ambilcatcea. precipiter. culbuter en roulant. glisser ou rouler en glissant Gipuz». «Amea. Gipuz. mere. ama»

\section{I.2.5.5. Gramatikaren erreferentziak}

Batzuetan «v. [...] en la gram.» «v. gram.» edo «voyez en la gram.» bezalako laburdurak agertzen dira: «Nekasalea. v. la gram.» (salea), «Noa. je vay. v. ioaitea, en la gram.», "Nuque. j'aurois. Voyez dut en içaitea dans la gram.»

Gramatikari erreferentzia egiten dioten laburdura horiek ez dira aurkitzen B eskuizkribuko gramatikaren ataletan. ${ }^{13}$ Horregatik, ez dago esaterik Pouvreauk A eskuizkribuari ekin baino lehen jadanik Gramatika prestatua zuen edo soilik buruan zuen egitasmoa zen.

\section{I.2.5.6. Bidalketa-deiak}

Bidalketa-deiak eskuarki v. laburdurarekin (Voyez) adierazten dira: «Arbalda v. aluarda. baste d'asne», «Lizlarrua. peau de certain poisson pour polir le bois. v. liça».

Horrezaz gain, oso gutxitan I[nfra] eta S[upra] agertzen dira sarreren baten aldamenean irakurlearen arreta gorago edo beherago eramateko. Esaterako, zutabearen ezkerretara diren "Issuntcea. e. [...]. mulctare» eta "Issuna. issuntza. mulcta» (issuntcea) sarreren azpian $S$ baten zirrimarra agertzen da orrialde bereko lerro batzuen ondoren diren "Isuna. B. amende pecuniaire» eta «Isuntcea» sarreretara bidaltzeko. Agian bere buruarentzako oharrak baino ez dira.

13 Parisko Bibliothèque Nationaleko «Fonds celtique et basque» delakoan gorde den 8. eskuizkribuan Pouvreauren «Grammaire basque»-ren atal batzuk bilduta daude. 


\section{Hiztegigile frantsesen ereduaz}

Hiztegigileen artean kopiaketa oso arrunta izan da. Malkiel-i jarraituta Mitxelenak egindako baieztapena bildu du Lakarrak (1991: 218): «kopiaketa gaitzesgarri bainoago ohitura arrunt da eremu horretan [hiztegigintzan], zintzoenak beren zorrak aitortuz baina, aipamenetara zaletu gabeek nola, mailebatuaz hartzekodunengandik». Ohitura horren adibide bikaina da Oudin-ena, Lakarrak aipatu zuenez:

Bere hiztegia osatzeko Oudinek Pallet, Hornkens eta Covarrubias erabili zituela erakutsi zuten Cooper-ek (1960a, 1962) eta Verdonk-ek (1979); beranduago Guerrerok (1988: 502hh) Nebrija gehitu du haren iturrien zerrendan, izan ere Pallet, Hornkens eta Covarrubiasek Nebrijarengan jaso ez zituztenak hartzen baititu Oudinek (Lakarra 1995: 24-25).

Bestalde, lexikografia frantsesaren hastapentzat hartzen den Nicot-en Le Tresor de la langue françoyse hiztegiak Estienne-engan du jatorri (\$ II.3).

Aurrekari horiek kontuan harturik, ez da harritzekoa Pouvreau ere A eskuizkribua burutzeko kopiaketan aritzea. Izan ere, lehendik bagenekien Pouvreauk A eskuizkribuan diren gaztelaniazko ordainak Oudin-en Tresor des deux Langves Espagnolle et Françoise hiztegitik (aurrerantzean Tresor) bildu zituela (Kerejeta 1991: 869, 12. oh.; Lakarra 1995: 2-3). Oudin-en eragina ez da Tresor-era mugatzen: izan ere, Kerejetaren A, B eta C eskuizkribuen edizioan (2003) Oudin-en Refranes o Proverbios Españoles Traduzidos en Lengua Francesa liburutik Pouvreauk hainbat errefrau jaso zuela erakusten da. Horietaz gainera, Pouvreauk Voltoire-ren L'Interprect ou traduction du françois, espagnol \& basque (aurrerantzean L'Interprect) edota Tresora Hirour Lengvaietaqua, Francesa, Espagnola eta Hasquvara-tik (aurrerantzean Tresora) hainbat sarrera jaso zituela frogatua da (Etxagibel 2010: 221-278). ${ }^{14}$

Gure hipotesiaren arabera, aipatutakoez gain, Pouvreauk Nicot-en Thresor de la langue françoyse (aurrerantzean Thresor) ere usu erabili zuen (\$ II.3).

\section{II.1. Voltoire-ren aztarna Pouvreaurengan}

Aipatu berri dugunez, frogatua da Pouvreauk Voltoire-ren L'Interprect edota Tresora-ko hiztegiaz baliatu zela berea egiteko. Horretarako ondoko metodologia erabili genuen:

- Bi hiztegien arteko erkaketa zuzena lekukotasunen batetortzeak jasotzeko.

- Egitura irizpidea (Lakarra 1996: 32): horren bidez frogatu ahal izan genuen Pouvreauren hiztegian Voltoire-ren hiztegiko alderantzizko ordenaren (frantses-euskara) hainbat aztarna zirela.

— Hiztegi elebidunaren irizpidea (Urgell 2002b: 19): horren arabera, Oudin-en frantses-gaztelania hiztegiaren aurretik Voltoire-ren euskara-frantsesa lehenestekoa zen.

\footnotetext{
${ }^{14}$ L'Interprect (c.a 1620) eta Tresora (1642) liburu beraren izen desberdineko bi edizio dira. Egia esatera, ezin izan ditugu bataren edo bestearen aldeko froga erabakigarriak aurkitu (Etxagibel 2010: 228).
} 
— Literatur iturrien aurretik hiztegi iturrien lehentasunaren irizpidea (Lakarra 1994: 60).

Metodologia hori ezarriaz Pouvreauren hiztegiaren 700dik gorako lekukotasun Voltoire-ri legozkiokeela ondorioztatu genuen. Gure laginari dagozkion 365ak $(\% 5,70)$ Eranskina-n bildu ditugu (\$ VII.1).

\section{II.2. Oudin-en aztarna Pouvreaurengan}

\section{II.2.1. Oudin-en Tresor- $a$}

Marc Zuili-k (2006) azaltzen duenez, Cesar Oudin-ek hiztegigintzaren arloan 1607an Thresor des deux langues espagnolle et françoise. Tesoro de las dos lenguas española y francesa hiztegi elebiduna argitaratu zuen (Marc Orry, Paris). Lehenbiziko argitalpen horrezaz gain xvII. mendean zehar ondoko berrargitalpenak inprimatu ziren:

- 1616koa (Vve. Marc Orry, Paris). Cesar Oudin-ek lehenengo edizioari 5.000 sarrera inguru erantsi zizkion — gehienak Covarrubias-en Tesoro de la lengua castellana o española hiztegitik (1611) atereak-, bai eta Juan Hidalgo-k 1609an argitaratu zuen Vocabulario de Germania hiztegi osoa ere, berak Vocabulaire des mots de jargon, Vocabulario de Gerigonça izenburua emanda bada ere.

- 1621 ekoa (Paris, Adrian Tiffaine-ren eta Pierre Billain-en argitaraldiak). 1616ko edizioarekin alderatuta osatuagoa da eta sarreren alfabeto ordena hobetua du.

- 1625ekoa (Brusela). 1616ko edizioaren berrargitalpena.

- 1645ekoa (Paris, Antoine de Sommaville, Augustin Courbé eta Nicolas \& Jean de la Coste-ren argitaraldiak). Antoine Oudin, Cesar Oudin-en semeak, aita 1625ean hil ondoren 1621eko edizioa eguneratu, zenbait itzulpen zuzendu eta Vocabulaire des mots de jargon-en sarrerak hiztegiaren corpus orokorrean txertatu zituen.

- 1660koa (Paris, Michel Bobin, Simon de Sourd, Antoine de Sommaville, Estienne Maucroy, Jean Depuis, Louis Chamhoudry, Pierre Rocollet, Pierre Moet eta Thomas Jolly, etab.-en argitaraldiak).

- 1660koa (Brusela, Jean Mommarte). Corpusari zenbait sarrera erantsirik eta Vocabulario de las principales ciudades, villas, reynos, prouincias y rios del mundo izeneko hiztegia ere eranskin gisa.

— 1675ekoa (Lyon, J. B. Bourdier \& L. Aubin, M. Mayer eta A. Beaujollin-en argitaraldiak). Edizio guztien artean osotuena da, 1660ko bi edizioen ekarpen berriak bildu baitzituen.

Pouvreauk Oudin-en hiztegia gaztelaniazko ordainak biltzeko erabili zuen. Gehienetan frantses-gaztelania alea erabili zuen arren - gure laginean, bederen-, behin baino gehiagotan soilik gaztelania-frantses alean ziren zenbait sarrera kopiatu zituen, hala nola: 
«Acometamendua. acometimiento. attaque. aggression. assaut» (acometatcea) < "Acometimiento, attaque, aggression, assaut» (E / Fr) vs. "Aggresion, acometimiento», «Assaut, asalto, arremetida» (Fr / E).

"Alcabotatcea. faire maquerelage. alcahuetear» < «Alcahuetear, faire maquerelage»

(E / Fr) vs. «Maquereller, alcahuetear (Fr / E).

«Amiamacoa. heron. garça. aue conocida» < «Garça, aue conocida, heron» (E / Fr) vs. «Heron, garça» $(\mathrm{Fr} / \mathrm{E})$.

Areago, argi dago A eskuizkribua elebidun zenean, hots, euskal sarrerak eta haien frantsesezko ordainak bakarrik bilduta zeudenean, hiztegia antolatzeko Oudin-en Tresor-a erabili zuela (\$ II.4.1). Berriz, azken orduko gaztelaniazko ordainen bilketa hiztegia hirukoitz (\$ III) edo laukoitz (Bilbao 1992: 341-389) bihurtzeko saiakeratzat hartu behar da.

Ez dakigu zein izan zen baliatutako edizioa (edo edizioak). Hala ere, 1607koa, 1616koa eta 1621 ekoa guk erabilitako 1645eko Antoine de Somaville-renarekin alderatuta baiezta dezakegu Oudin-en lehen hiru edizio horien artean ez dagoela A eskuizkribua egiterakoan erabili zuena; ${ }^{15}$ beraz, badirudi hiztegia eratzen ari zenetik gertuago dauden edizioetako bat (1645?, 1660?) izan zela Pouvreauren iturria. ${ }^{16}$

Gure laginean Tresor-en gaztelaniazko ordainak dituzten A eskuizkribuko euskal sarrerak 400 dira (\$ VII.2), gehienak A letran, Oudin-en hiztegiaren erabilera sistematikoari ekin eta bukatu gabe utzi zuelako seinale, beharbada.

Aipatutako horietaz bestalde, Pouvreauk euskal ordainik gabe —ziurrenik haien euskal ordainak bilatzeko asmoz - Tresor-en frantses-espainol aletik beste 21 sarrera jaso zituen (\$ VII.3).

\section{II.2.2. Oudin-en Refranes o Proverbios Españoles Traduzidos en Lengua Francesa}

Pablo-ren arabera (2007) Cesar Oudin Luis XIII.a erregearen idazkari eta aleman, gaztelania eta italierazko interpretea izan zenak Gramática Española eta Tresor liburuez gain Refranes o Proverbios paremiologia bilduma egin zuen, XVII. mendean behin baino gehiagotan argitaratua, are autorea 1625. urtean hil ondoren, ondoan adierazten denez:

- 1604an C. Oudin-ek Parisen argitaratutako Gramática Española-ren eranskineko Prouerbes Espagnoles expliquez en Francois atalean 222 errefrau bildu zituen.

- 1605ean Parisen 2.000 errefrau inguru biltzen diren Refranes o Proverbios-en lehenbiziko edizioa argitaratu zuen 1604ko gehigarrian oinarriturik.

- 1608an Bruselan Roger Velpius-ek bigarren edizioa argitaratu zuen funtsean aldaketarik gabe, baina Blasco Garay-ren Las cartas en refranes eta Rodrigo Cota-ren Dialogos erantsita.

15 Adibidez, Pouvreauk hiztegiko Acheria sarreran Tresor-en 1645eko edizioan diren "renard», «vieux renard», «renarde», «renardeau», «renardiere» eta «renarderie» bildu zituen. Kontuan harturik 1607, 1616 eta 1621ekoan soilik «regnard», «regnarde», "regnardeau» eta "d'vn regnard» direla, ondoriozta daiteke Pouvreauk Tresor-en 1645 edota 1660ko edizioak erabili zituela.

16 Gure ustez, 1675eko edizioa bazter uztekoa da, kontuan hartuta Pouvreauk A eskuizkribuko azken eransketak 1665koak bide direla (Kerejeta 1991: 865). 
- 1609an Parisen inprimatutako hirugarren edizioan 400 errefrau gehiago dira. Horietaz gain, Alonso Fajardo-ren Los Proverbios morales liburutik ateratako 50 «redondillas» eta Distico del juego de la fortuna liburutik ateratako zenbait "coplilla» ere jaso zituen.

- 1610ean Frankfurten Jean Gruter-ek Florilegium ethico-politicum liburuan latinezko, grezierazko, eta abarreko errefrauekin batera 1605 eko edo $1608 \mathrm{ko} \mathrm{Ou}-$ din-enak bildu zituen.

- 1612an Bruselan 1608ko edizioa berrargitaratu zen.

- 1614an Lyonen 1608ko edizioa berrargitaratu zen zenbait errefrau kenduta.

- 1624an 1609ko edizio emendatua argitaratu zen.

- 1634an Bruselan 1608ko edizioa berrargitaratu zen.

- 1659an Parisen hamar argitaratzailek elkarrekin egindako edizioa agertu zen, 1624 ko edizioak zituen errefrau berriak gabekoa.

Pouvreauk erabilitako edizioari (edo edizioei) buruz oraingoz ez dago ezer jakiterik. ${ }^{17}$ A eskuizkribuan Oudin-en errefrau guztiak orri ertzean kokatuak edo zutabean lerro artean txertatuak agertzen dira, hots, hiztegiaren lehen idazketaren ondoren erantsi ziren. Ez dakigu zein izan ziren Pouvreauren irizpideak edota zergatikoak sarrerak eta haiei dagozkien errefrauak aukeratzerakoan, baina kontua da lagin osoan zehar antzeratsu sakabanatuak direla, Oudin-en gaztelaniazko ordainak ez bezala. Eskuarki, errefrauak hitzez hitz kopiatu zituen, nahiz eta zenbaitetan zertxobait aldatu edota laburtu. Laginean 88 sarreratan 144 errefrau jasotzen dira (\$ VII.4); horietarik 48 euskaratuak dira —ziurrenik, Pouvreauk berak itzuliak—.

\section{II.3. Nicot-en aztarna Pouvreaurengan}

Wooldridge-k (1977) Nicot-en Thresor-a frantses lexikografiaren hastapentzat hartzen du:

Le Thresor de la langue françoyse (1606) de Jean Nicot est la clef du développement de la lexicographie française. Somme de quatre éditions du Dictionaire françois-latin de Robert Estienne, oeuvre qui trace le chemin menant du dictionnaire latin à la affirmation du français comme sujet premier d'un dictionnaire françois-latin il revêt, à travers les contributions de Nicot le caractère d'vn dictionnaire français monolingue (Wooldridge 1977, «Matières prèfatoires»: «Avant Propos»).

Ikertzaile berak «Filiation du corpus Estienne-Nicot» delakoan Estienne-ren hiztegien eta Nicot-enaren ondoko filiazio zuhaitza aurkezten du (ib. «Du latin au française: 1 . du dictionnaire latin au dictionnaire française» [3]):

17 Kasu batean bada aldea Pouvreauk A eskuizkribuan kopiatutako errefrauaren eta guk baliatu dugun 1659ko ediziokoaren artean: izan ere, Burla sarrerari dagokion errefrauan 1659ko «cien dias»-en ordez A eskuizkribuan "cien años» agertzen da. Hala ere, hori ez da nahikoa esan ahal izateko Pouvreauk ez zuela 1659ko edizioa erabili, zeren eta kopia hutsa izan baitaiteke. 


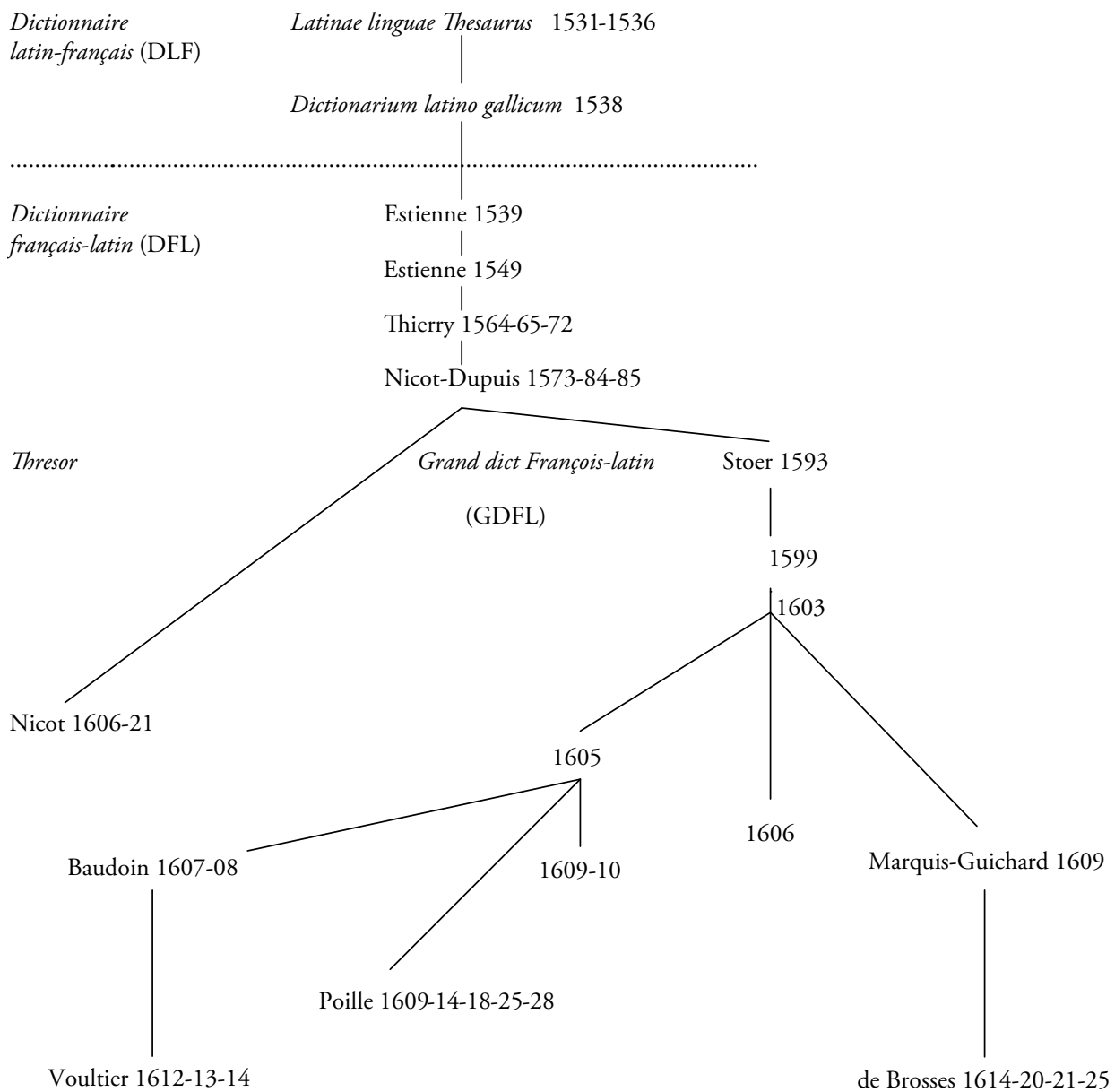

Zuhaitzean ikus daitekeenez, Estienne-rengandik bi adar nagusi zabaltzen dira: Nicot-ena eta Stoer-ek egindako Nicot-en argitalpenarena, bien artean Grand Dictionnaire françois-latin (GDFL) delakoa ${ }^{18}$ izanik.

Beraz, Pouvreauk Oudin-en hiztegiaz gain berea antolatzeko besteren bat erabiltzeko aukera anitz izan zuen, eta horregatik zaila da zehaztea zein izan zuen eskuetan. Nola nahi den, ondoriozta dezakegu Pouvreauk A eskuizkribuan jaso zuen zenbait lekukotasun Nicot-en Thresor-i legozkiokeela. Ondorio horretara heltzeko ondoko konparaketak egin ditugu:

18 Le Grand Dictionaire françois-latin (1593-1628) izenburuaren azpian 1593-1628ko tartean atera ziren Estienne-ren Dictionaire françois-latin hiztegiaren edizioak bildu ditu Wooldridge-k: «Par le Grand Dictionaire françois-latin (GDFL) nous entendons l'ensemble des rééditions du Dictionaire françois-latin de Robert Estienne qui de 1593 à 1628 parurent sous les titres specifiques du Grand Diction(n)aire françois-latin, Nouveau Dictionnaire françois-latin ou Grand Dictionaire françois latin et greo" (Wooldridge 1992, «Introduction»). 


\section{a) Estienne eta Nicot-en hiztegien arteko konparaketa ${ }^{19}$}

Nicot-en Thresor-en erabilpenaz ohartarazi gintuen lehenbiziko lekukotasuna A eskuizkribuko Choria sarreran den «Les passereaux crient, paxaros que pian. pipilant passeres» aipua izan zen. Kontua da Jean Nicot-en Thresor-eko «Passereaux, Passer, Passerculus» sarreran «Les passereaux crient, Pipilant passeres» aipua agertzen den bitartean, Estienne-ren Dictionarium latino gallicum-ean «Passer, passeris. Une passe, Un passereau» baino ez dela agertzen.

Halaber, A eskuizkribuaren ondoko azpisarreren frantsesesko baliokideak soilik Nicot-en hiztegian agertzen dira:

2. taula

\begin{tabular}{|l|l|}
\hline \multicolumn{1}{|c|}{ A eskuizkribuan } & \multicolumn{1}{c|}{ Nicot-en Thresor-en } \\
\hline «Lur argala. terre maigre» (argala) & «Maigre. Terre maigre» \\
\hline $\begin{array}{l}\text { «Arrapoa eltceari edequitea. ecumer le pot» } \\
\text { (arrapoa) }\end{array}$ & $\begin{array}{l}\text { «Escumer [...] Quelques fois actif, comme Escu- } \\
\text { mer le pot» }\end{array}$ \\
\hline «Astalcoa. echeueau de fil» (astalcatcea) & «Escheueau de fil» \\
\hline «Beguiztatcea. Jetter des oeillades» (beguia) & «Oeillades. Jetter des oeillades» \\
\hline «Chinguilca ioaitea. aller à clochepied» (chingil) & «Clochepied. Aller à clochepied» \\
\hline $\begin{array}{l}\text { «Illarac çurkaitztatcea. ramer des poix» (çurkaitz- } \\
\text { tatcea) }\end{array}$ & «Ramer. Ramer des poix» \\
\hline «Vfu hatsa. fi du vilain» (vfu) & «Fi. Fi le vilain» \\
\hline
\end{tabular}

\section{b) Stoer vs. Nicot ${ }^{20}$}

Nicot-en hiztegian diren aipatutako esapideak Stoer-en edizioan ere agertzen dira, bi salbuespenekin: «Escumer» sarreran ez da «Escumer le pot», eta «Fi» sarrera osoki falta da.

Horrenbestez, zilegi da pentsatzea — beste hiztegiren baten erabilera alde batera uztekoa ez izan arren- Pouvreauk Nicot-en Thresor eskuetan izan zuela.

\section{II.4. Oudin-en eta Nicot-en hiztegien eragina Pouvreaurengan}

Puntu honetara heldu eta gero Oudin eta Nicot-en hiztegien eragina zenbatetarainokoa den neurtzea geratzen zaigu. Horretarako, lau zutabedun bi taula antolatu

19 Konparaketa egiteko ondoan aipatzen diren hiztegiekin T. R. Wooldridge-k osatutako «Une base interactive de cinq dictionnaires de Robert E et de Jean Nicot» (1992: "Tablé detaillé: Anexes») base interaktibo delakoaz baliatu gara: Estienne-ren Thesaurus linguae latinae (1531), Thesaurus linguae latinae (1536), Dictionarium latino gallicum (1552) eta Le Grand Dictionaire françois-latin (1593-1628), eta Nicot-en Le Thresor de la langue françoyse (1606).

20 Stoer-ren 1593 ko edizioaz eta aipaturiko Wooldridge-ren base interaktiboaz baliatu gara. 
dugu (\$\$ VII.5 eta VII.6). Lehenbizikoa A eskuizkribuaren sarreren ordenaren arabera antolatua da, hots, aztertutako A eskuizkribuaren sarrera edota azpisarrera bakoitzari Nicot-en edota Oudin-en hiztegietan legozkiekeen frantsesezko ordainak bildu ditugu. Bigarren taula lehenbizikoa bera da, baina Nicot-en orrialde zenbakien arabera antolatua ${ }^{21} \mathrm{~A}$ eskuizkribuaren egituran Nicot-ena islatzen den ikusteko.

$\mathrm{Bi}$ taulak antolatzerakoan ondoko irizpideak erabili ditugu:

— Alde batera utzi ditugu aurreko atalean (\$ II.2.1) ikusitako Oudin-en gaztelaniazko ordainak dituzten sarrerak, egiaztatuak izateagatik.

- Halaber, ez ditugu bildu euskal sarrerei dagozkien frantses ordainak Voltoire-k, Oudin-ek edota Nicot-ek batera dakartzatenean, zeren eta hiztegi elebidunen irizpideari jarraituaz (\$ II.1) Voltoire-ri esleitu baitizkiogu. Soilik azpisarrerak dituzten holako sarreretan —informazio gisa— «(Voltoire)» erantsi dugu. Esaterako, Pouvreauk Voltoire-ren «Prunes, Aranaq" sarrerari legokiokeen Arana sarreran Nicot-en eta Oudin-en hiztegietatik ateratakoak bide diren "prunier» eta «prunaye»-ri dagozkien Aranondoa eta Aranadia bildu zituen; horrenbestez, gure tauletan sarrera burua eta bi azpisarrerak honela agertzen dira:

3. taula

\begin{tabular}{|l|l|c|l|}
\hline \multicolumn{1}{|c|}{ A eskuizkribuko sarrerak } & $\begin{array}{c}\text { Nicot-en } \\
\text { sarrerak }\end{array}$ & $\begin{array}{c}\text { Nicot-en orrialde } \\
\text { zenbakia }\end{array}$ & \multicolumn{1}{|c|}{ Oudin-en sarrerak } \\
\hline Arana. prune. (Voltoire) & Prune. & 524 & Prune. \\
\hline Aranondoa. prunier. & Prunier. & 524 & Prunier. \\
\hline Aranadia, arandeguia. lieu planté de pruniers. & & & Prunaye. lugar de ciruelos. \\
\hline
\end{tabular}

- Guk erabilitako 1645 eko Oudin-en edizioan zenbait orrialde falta dira: "Chambre» eta "Chapeau» sarreren artekoak, Ic-Im artekoak, etab. Horregatik ondoko hitzak 1660ko ediziotik jaso ditugu: "chanure», «chameau», "chancre», "chandelle», "chandelier», «le Chandeleur», "chanteau», «image», «imiter», «imitation», «immortel», «imparfait».

- Adibide gisa jaso ditugun sarrerak batez ere etimologikoak dira, gure ustez haietan ongien islatzen delako Pouvreauren erabilera. ${ }^{22}$

—Zenbaitetan Pouvreauk — batez ere asmatuak bide diren euskal eratorrietanez zituen bildu jatorrizko frantsesezko baliokideak, alegia, A eskuizkribuan frantsesezko hitzei legozkiekeen euskal ordainak bakarrik jaso zituen. ${ }^{23}$ Adibi-

21 Nicot-en hiztegiaren kasuan edozein frantsesezko ordainetarako agertzen den orrialdearen zenbakia jaso dugu; berriz, Oudin-en kasuan ezin izan dugu gauza bera egin erabilitako edizioan orrialdeak zenbakirik gabe agertzen direlako.

22 Horrek ez du esan nahi Nicot edota Oudin-en sarrerei legozkiekeen lagineko sarrera guztiak aztertu ditugunik: ziurrenik banan-banako azterketa eginez gero berriak agertuko lirateke.

23 Hori egiaztatua geratzen da Oudin-en frantsesezko eta gaztelaniazko ordainak dituzten sarreretan. Esaterako, gure terminologian, hurrenez hurren, "hiztegi hitza» eta "agerpen bakaneko" neologismoak (Etxagibel 2014: 313-315) diren Acometatçaillea (acometatcea) eta Bestaguillea euskal sarreren hala frantsesezko ordainak nola gaztelaniazkoak beranduago erantsiak dira. 
dez, Amarra sarreran Pouvreauk Nicot-en eta Oudin-en «lien» frantses ordaina jaso zuen; berriz, haren azpisarrera eta gure terminologian «berezko neologismoa» den Amarradura-n ez zuen hari legokiokeen "liement» jaso. Horrelako kasuetan frantsesezko ordaina [] taketen artean jarri dugu.

- Frantsesezko ordaina soilik Nicot-en hiztegian agertzen bada, letra etzanez markatu dugu. Esaterako, Argala sarreran «Lur argala. terre maigre» azpisarrera Nicot-en "Terre maigre»-ri legokioke, eta ez besteri.

Honela jokatuz A eskuizkribuaren laginean Oudin-en edota Nicot-en hiztegiei legozkiekeen eta soilik frantsesezko ordainik duten 1.246 sarrera edota azpisarrera bildu ditugu $(\% 19,60),{ }^{24}$ nahiz eta aipatu dugun bezala azterketa osoa burutu ez dugun.

\section{II.4.1. Bilketaren ezaugarriak}

Bi taulak aztertu ondoren honakoak dira atera ditugun ondorioak:

a) Egitura irizpidea ( $\$$ II.1) aplikatuz gero, garbi dago Pouvreauk Nicot-en eta Oudin-en hiztegiak berearen hezurdura eraikitzeko erabili zituela. Izan ere, Nicot-en hiztegiaren orrialdeen arabera ordenatutako taulan ondoko hurrenkerak agertzen dira, besteak beste: ${ }^{25}$

«aulne», «aulnage», «auiron», «tirer à l'auiron», «aumosne», «aumosnier», «auorter» (59. or.).

«effronté», «effrontéement», «effacer», «egratigner», «egual», «egualement», «egualer» (220. or.).

«fleute», «joüer de fleute», «fleuue», «flot», «flux de ventre» (290. or.).

«gay», «gayeté», «gayement», «gaule», «gazon», «gelé», «gemissement» (312. or.).

«saoul», «saouler», «sas», «sasser», «sarriete», «sapin», «sarcleur», «sarclet» (581. or.). «vefue», «vefuage», «veloux», vendenge», «vendenger», «veille», «veiller» (652. or.).

b) Nicot-en hiztegian sarreren barneko ordena ia etimologikoa da. Aitzitik, Oudin-enean ordena batez ere alfabetikoa da, eta honek berekin dakar Nicotenean sarrera konplexu beraren barruan agertzen diren hitz familiak Oudin-enean maiz sakabanatuak izatea, bestelako sarrerak alfabetoaren arabera tartekatuak baitira (behin baino gehiagotan tartea orrialde bateko edo gehiagokoa da); esaterako:

Nicot-en «coing, coignier» vs. Oudin-en «coignier [coignoir; coin; coin à battre la monnoye; coin à fendre du bois; marquer ou fendre auec vn coin; se retirer en vn coin; coin de l'oeil; coin de bas; coin de ruë; coins de cheueux; frappé au mesme coin; il n'est pas de bon coin; regarder du coin de l'oeil; coin de beurre; coin de mer; coine] coing».

\footnotetext{
${ }^{24}$ Kopuru horri Oudin-en gaztelaniazko ordaina duten 402 sarrerak erantsi behar zaizkio (\$ II.2.1).

25 Jakina, A eskuizkribu osora zabalduz gero dudarik gabe hurrenkera gehiago eta osoagoak agertuko lirateke.
} 
Halaber gertatzen da ondokoetan, adibidez:

«coudre, cousu, cousture» (Nicot) vs. «coudre [...] cousture [...] cousu» (Oudin) "fondre, fondu» vs. "fondre [...] fondu».

«lire, lecteur» vs. «lecture [...] lire».

«poing, poignet» vs. "poing [...] poignet».

«sale, salir» vs. «sale [...] salir».

Horregatik zilegi da pentsatzea erraztasunez Pouvreauk bere sarrerak antolatzerakoan Nicot-en hiztegia gida bezala erabiltzen ohi zuela aldamenean $\mathrm{Ou}$ din-ena zuelarik; esaterako, Istiltcea sarreran Nicot-en «embouer» eta Oudinen «emplir de boüe» biltzen dira.

c) Gehienetan, Nicot-en eta Oudin-en sarrerak berdinak dira, nahiz eta Pouvreauk Oudin-en grafiak — eguneratuagoak izateagatik, agian- nahiago izan zituen. Adibidez, "Aithorra, aueu» Nicot-enean "Adueu» eta Oudin-enean "Aueu» dira; halaber, "Arhea. herse. occa» Nicot-enean "Herce. Occa» eta Oudin-enean «Herse» (\$ III.1.1, 6. taula).

d) Oudin-en hiztegian Nicot-enean baino eratorri gehiago dira eta hori islatzen da Pouvreaurenean ere; esaterako, ondoko frantses eratorri guztiak Oudinenak dira:

«aduocasserie» (auocatalgoa); «effronterie» (becoquigabetasuna); «rachepteur»(berreroslea, berrerostea); «blanchisseur» (churitçaillea); «destructeur» (deseguillea, deseguitea); «cousturier» (ioslea, iostea).

e) Badirudi Pouvreauk A eskuizkribuan zenbaitetan Oudin-en hiztegitik ateratako frantsesezko ordainaren ordez haren gaztelaniazkoaren itzulpena aukeratu zuela. Gure laginean ondokoak agertu zaizkigu:

«Aranadia. lieu planté de pruniers» vs. Oudin-en «Prunaye, lugar de ciruelas».

«Arramu Igandea. dimanche des rameaux» vs. Oudin-en «Iour des Rameaux, Domingo de Ramos».

«Botika. boutique d'apoticaire» vs. Oudin-en «Apoticairerie, tienda del boticario».

«Cigartsua. pleine de cirons» vs. Oudin-en "Cironniere, cantidad de arados en las manos».

«Credoa. symbole des apostres» vs. Oudin-en «le Credo, el credo, symbolo de Apostoles».

«Dembora igortciritsua. temps pleine de tonnerres» (igorçuria) vs. Oudin-en «Tonnerreux, tiempo de truenos».

«Iguzquiz iguzqui. d'vn soleil a l'autre. du matin au soir» vs. Oudin-en «entre deux Soleils, de sol a sol».

«Iusticia guiçona. homme de iustice» vs. Oudin-en «Iusticier, hombre de justicia».

f) Nicot-en hiztegitik, ondoko motetako lekukotasunak jaso zituen:

— Nicot-en sarrera buruei dagozkien azpisarrerak:

«Cia. gland de chesne» A eskuizkribuko sarrera Nicot-en hiztegian «Gland. Gland de chesne» agertzen da; berriz, Oudin-enean «Gland, castańa». Halaber «Desserta. dessert de table» Nicot-en hiztegian "Dessert, Desserte de table» den bitartean Oudin-enean «Dessert, postre». Orobat, "Illarac çurcaitztatcea. ramer des poix» (çurcaiztatcea) Nicoten hiztegian «Ramer. Ramer des poix»; ordea, Oudin-enean «Ramer, enramar», etab. 
—Nicot-en sarrera buruei dagozkien latinezko ordainak:

«Escuin vssoa. geay. graculus» (vssoa) honela agertzen da Nicot-en hiztegian: «Gay, qu'on prononce Geay. Graccus. gay. Gracculus». Halaber, «Destarta. lourdaut. etourdi. O. rudis. rusticus» Nicot-enean "Lourdaut. Rusticus».

Batzuetan frantsesezko ordaina jaso beharrean latinezko ordaina frantsesez itzuli zuen: «Ioçaçu barrika. percez la barrique» (ioitea) azpisarrerari Nicot-en «Percer. Percer de muiz. Dolia Terebrare» sarrera legokioke, baina ematen du Pouvreauk zuzenki latinezko ordaina frantseseratu zuela. "Bocata. buée. lexiue» sarreran ere itxuraz $\mathrm{Ni}$ cot-en "Buée, Lixiuium» sarreraren latinezko ordaina frantsesez jaso zuen. Berriz, "Chuchurlaria. susurro" sarreran frantsesezko ordaina alde batera utzi zuen eta soilik latinezkoa jaso: «Mesdire. Qui mesdit d'aucun par derriere, Susurro».

- Nicot-en sarreren sinonimoak edo adierak:

Behin baino gehiagotan Pouvreauk Nicot-en sarreretan diren sinonimoak edota adiera desberdinak ere jaso zituen:

«Andrea. dame. maitresse» < «Dame. Dame ou maistresse»; «Arraya. gay. joyeux»< "Gay. Gay et joyeux»; «Arraiqui. gayement. joyeusement» (arraya) < «Gayement. Gayement et joyeusement»; "Atçartcea. eueiller. exciter» < «Exciter. Exciter id est Eueiller»; "Bermea. plege. caution» (bermatcea) < «Caution. Vn pleige et caution»; «Icitcea. faire peur. auoir peur» (icialdura) vs. «Peur. Auoir peur. Faire peur»; «Ikuztea, ikutzea Liz. nettoyer. lauer» vs. «Lauer. Lauer et nettoyer».

g) Guztira A eskuizkribuan 153 dira Nicot-en hiztegian soilik diren frantsesezko ordainak. Haiei Pouvreauk euskal ordaina egokitzerakoan baliatu zituen iturrien arabera ondoko taldeetan banatu ditugu:

— Euskal ordaina literatur lekukotasuna da (62)

A (14): altza; andrea; andrecaria; aratza; artaldea (ardia); arteguia (ardia); arhea; arheatcea; arhatçaillea (arhea); arrapatcea; arratsean; arraya; arraiqui; atçartcea.

B (11): baquetiarra; barka dieçadaçu (barkatcea); beguiztatcea; beguitarte eguitea; elkarganic bereztea; berecia (bereztea); bermea (bermatcea); begui betheriatsuac (betheria); biz hala; bonachera; burlatcea norbaitez (burla).

C (7): çahaguia; çathicatcea; çauria; gende chehea (chehatcea); parra choria; conseillatcea (conseillua); çurmindua.

D (5): desordenatua (desordenua); ene despendioz (despendatcea); ezta deusic (deusa); dolutcea; dolutsua.

I (19): esnearen iaitstea; icerdia; ichiltcea; icitcea (icialdura); ez icusi iduri eguitea (iduria); iduriz; ifinia (ifintcea); igurikitça (igurukitcea); iguzquiztatcea; ihartcea; ikaslea (ikastea); ikuztea; ikuzgarria (ikuztea); imiquia; athea ioitea; irakazlea (irakaztea); vr iraquina (iraquitcea); isuria (isurtcea); ithur vra (ithurria).

V (6): valenta; valiatcea; vhobia (vra); vrrupatcea; vsaintcea; ene vstez.

— Euskal ordaina iturrietan aurki zezakeenaren aldaera da (3)

C (1): vr chort.

D (1): declaratçaillea (declaracionea).

I (1): irakasia (irakaztea). 
— Euskal ordaina ahozkoa da (40)

A (7): andaçaina; argaltasuna; arrega; aspretcea; astalcatcea; astalcoa (astalcatcea); ausartcea.

B (8): baba leka; batayaharria (batayoa); bero hari da; bethaldea; bigarrenecotz (bia); hil biloac; bocata; burdin arrastelua.

C (10): çamuka; chatarra; chinguilca ioaitea; chiquiro ezpalda; chirlac; chirolaria; chopina; churiquetac; churpatcea; cia.

$\mathrm{D}(1)$ : desserta.

I (6): behiaren iaitstea; iaya eguna (iayotcea); ichaka; ilhaintxa; istragalatcea; istiltcea, istillatcea, istilztatcea.

$\mathrm{V}(8)$ : vfu hatsa; vgatz alaba; vrrupa; vrsain eguitea; vsaindua; escuin vssoa; vste gabe; vztartcea (vztarria).

— Euskal ordaina O SP zerrendetakoa ${ }^{26} \mathrm{da}(5)$
A (2): apobelatza; asnaur eguitea.
B (1): bassothea (bassa).
C (1): cipertcea.
D (1): destarta.

—Euskal ordaina Voltoire-ren hiztegiari dagokio ${ }^{27}$

B (3): babaçuça; bassurdea (bassa); billusia (billuzgorria).

C (1): cutchua.

I (1): ikastea.

— Euskal ordainak Pouvreauk asmatutako eratorri, elkartu, esapideak, etab. dira (38)

A (5): adreilluz eguina; lur argala; arrapoa eltceari edequitea; arrastuan; aztietan edo aztiquetan dabilla.

B (8): barrentcea; bederatcitan; berritsua; berrogoytan; bide harritsua; bilhurtcea; billuzgorritcea; bortcharia.

C (9): begui ceiharrez behatcea; chuchurlaria; churiz vestitua; bat banacaco combata; conseillu emaillea; conseillu esque dago; conseilluquetan ibiltea; costumaz; illarac çurkaitztatcea.

D (5): guiçon deliberatua (deliberacionea); desgogara çait; deyadarguillea; distiadura; doluzco arropac.

I (9): iaincotiartcea; iausica; ifintça (ifintcea); iguzqui mina; ikasgaya (ikastea); incontru onez (incontratcea); ioçaçu barrica (ioitea); iruna (irutea); istragala eguitea.

V (2): vrredura; idi vztarri bat.

${ }^{26}$ Horren arabera, baliteke Pouvreauk Nicot-en hitzetarako aurkitu ez zituen euskal ordainak Oihenarti galdetu izana.

${ }_{27}$ Jakina, euskal ordain horiei dagozkien frantsesezko hitzak Nicot-en hiztegian ere agertzen dira, baina adierazi dugunez (\$. II.1) lehentasuna Voltoire-ren hiztegiari eman diogu elebiduna izateagatik. Esaterako, «Gresle» Nicot-en hiztegian da, baina Voltoire-renean euskal ordainarekin agertzen da: «Gresle, Babaçuca». 
h) Guztira 113 lekukotasun dira soilik Oudin-en hiztegian direnak. Nicot-enekin erabilitako irizpide beraren arabera ondoko taldeetan banatu ditugu:

— Euskal ordaina literatur lekukotasuna da (46)

A (4): aisetcea; alleguera; ardianchua; arramu igandea.

B (8): barazcaria (barazcaltcea); bassoilloa (bassa); beiraquia; bekaitztea; belecumeac; bermatcea; bihurria; bruma.

C (7): çahartcea; camutza; chalupa; cimurdura; consolagarria (consolatcea); credoa; curiosqui.

D (8): descargua; deseguillea; desencusatcea; despendatcea; diferenciatcea; diferentqui (diferencia); dotatcea (dotea); dukezza.

I (13): icipera (icialdura); dembora igortciritsua (igorçuria); igorria (igortcea); iguzquiz iguzqui; iharduquitcea; lur ikaratce handia; iraka; iratçartçaillea (iratçartcea); iraunguia (iraunguitcea); irrigarria; irriscua; irriscatcea (irriscua); itchequina (itchequitcea).

$\mathrm{V}(6)$ : visita; vrdaldea (vrdaina); vrdina; vrgoitcea; vrruntcea; vrthetic vrthera.

— Euskal ordaina iturrietan aurki zezakeenaren aldaera da da (1)

A (1): angueruzcoa.

—Euskal ordaina ahozkoa da (23)

A (1): astoqueria.

B (5): balacatçaillea (balacatcea); bandulera, mandulera; belachtea; beraturia; botika.

C (6): chassa; chimignuqueria; chiquiroquia; churiţaillea; çamal cintça; cotilluna.

$\mathrm{D}(2)$ : dentilla; donaberac.

I (7): icicorra (icialdura); idiçaina; iguzqui belharra; ioslea (iostea); iranaslea (iranastea); irrizquina; irulea (irutea).

V (2): vitaillatcea; vnhadura (vnhatcea).

—Euskal ordaina O SP zerrendetakoa da (1)

$\mathrm{V}(1)$ : vdararnoa (vdarea).

— Euskal ordainak Pouvreauk asmatutako eratorri, elkartu eta esapideak dira (44)

A (7): aranadia, arandeguia; armendoladia; arranocumea; atçarţaillea (atçartcea); bere ohoreari atheka eguin dio; auocatalgoa.

B (6): becoquigabetasuna, becoquigaberia; berreroslea (berreroztea); bide celhaya; botoinguillea; buatsua.

C (10): chaflatcea; cantoinatcea; chiribicaria (chiribiria); cigartsua; vrrez eta cilharrez; cithalqui; commaitcea; condicionerequin; chapel cordoina; curchetatcea.

D (9): debauxqueria; desohoramendua (desohorea); desplacergarria; destartqui; disgraciatcea; dobladura (doblea); dohacabetcea; dudacorra; duga.

I (11): igueriketac (iguerea); ikaradura; incensu toquia; irakaztunqueria (irakaztea); irauasçaillea (irauastea); irauastuna (irauastea); iraunguidura (iraunguitcea); irrizquintcea; irrizquintça; itçalgaizqueria; iusticia guiçona.

V (1): vrreztatçaillea. 
Laburbildurik, Pouvreauk Nicot eta Oudin-en hiztegiak — biak batera — gidatzat hartu zituen berea eraikitzeko, ${ }^{28}$ hala frantses, gaztelania zein latinezko ordainak haietatik jasoaz, nola haietan bildutako frantses hitzen euskarazko baliokideak bilatuz eta, antza denez, aurkitu ezean bere kabuz asmatuz. Arakatzea osoa izan zen: izan ere, A-tik V-raino A ezkuizkribuko lagina eta hiztegien artean elkarganako egokitasunak garbiak dira Eranskineko bi tauletan ikus daitekeenez.

\section{Hiztegiaren eraketa}

Bilbaok adierazi duen bezala (1992: 342), ematen du Pouvreauren azken helburua hiztegi laukoitz bat egitea izan zela, B eskuizkribuaren 245. orrialdean den argitaratzeko baimen eskaeraren zirriborroaren arabera:

De la part de Nostre bien-amé Siluain Pouureau, Preste du diocese de Bourge Nous a esté exposé qu'il a traduit en Langue Basque un Liure qu'il jntitule Iesusen Imitacionea sur le latin de Thomas de Kempis [...]. Qu'il a aussi dressé une Grammaire Basque et François auec quelques Dialogues familiers pour le commerce des deux langues, Et de plus un Dictionnaire Basque, François, Espagnol et Latin. Lesquels Liures etant approuuez et iugez utiles au public il desireroit mettre en lumiere, et faire jmprimer (ap. Vinson 1892: 97-99).

Hortik ondoriozta dezakegu Pouvreauk zirriborro hori idatzi zuenerako Iesusen Imitacionea ez beste itzulpenak argitaratuak zituela, bestela baimenaren eskaerak hauetara ere hedatuko baitzukeen. Kontuan harturik Gudu espirituala 1665. urtean argitaratu zela, oso litekeena da zirriborro hori beranduagokoa izatea. Bestalde, elebiduna zen A eskuizkribuko hiztegia 1659-1661 tartean idatzi bide zuen (Etxagibel 2014: 17, 4. oh.), eta B eskuizkribuko kopia 1663an (Etxagibel 2014: 17-18). Tesian erakutsi dugunez (Etxagibel 2014: 334-335) Pouvreauk A eskuizkribuan itzulpenetan esklusiboki erabilitako hainbat hitz bildu zuen, hots, itzulpenak egiten hasi zenean, behintzat, Pouvreauren asmoa euskara-frantses hiztegi elebiduna egitea izan bide zen. Euskara-frantses-gaztelania hirukoitza ${ }^{29}$ eta Bilbaok erakutsi duenez (1992: 341) C eskuizkribuan ${ }^{30}$ den euskara-frantses-gaztelania-latin hiztegi laukoitzaren saiakerak geroagokoak izango lirateke.

${ }^{28}$ Tesia burutu ondoren egindako $\mathrm{H}$ letraren edizioan gure hipotesi hau indartzen duten bi sarrera laueledun agertu zaizkigu, A eskuizkribuan orain arte aurkitutako bakarrak: «Harilcatcea. deuider du fil. ouillar. glomerare» eta "Harilcaïa. deuidet. argadijo. rhombus. girgillus». Hasieran sarrerak elebidunak ziren, hots, euskal sarrera buruak eta frantsesezko ordainak ziren osagai bakarrak, baina ondoren Pouvreauk Oudin-en Tresor-etik gaztelaniazko ordainak eta Nicot-en Thresor-etik latinezkoak erantsi zizkien ondoan adierazten denez: "Ouillar, deuider le fil \& mettre en pelotons» (Oudin-en Tresor 1645 I); «Deuider du fil par pelotons. Glomare. Aglomerare» (Nicot-en Thresor 203); "Argadillo o argadijo, vn deuidoir à deuider de fil ou la lain» (Oudin-en Tresor 1645 I); "Deuidet ou deuidoir, ou deuideau. Rhombus. Girgillus» (Nicot-en Thresor 203).

29 Baliteke hiztegi elebidunaren eta laukoitzaren artean hirukoitz baten saiakera izatea. Batetik, A eskuizkribuan erantsitako gaztelaniazko baliokideek hori iradokiko lukete eta, bestetik, C eskuizkribuko sarrera gehienak hirukoitzak dira, euskara-frantses-gaztelaniazkoak, hots, hiztegi laukoitza egiteko abiapuntua balizko hirukoitz bat izan balitz bezala.

${ }^{30}$ Kontuan harturik Pouvreauren hitzetan (argitaratzeko baimenaren eskaeran eta Alejandro VII.a Aita Sainduari egindako Philotea-ren eskaintzan) Imitacionea latinetik euskaratu zuela (Etxagibel 2014: 15, 3. oh.), esanguratsua da C eskuizkribuan Imitacionea-n esklusiboki erabilitako Asquitcea (asco) lati- 
Hiztegia antolatzen ez dakigu zehazki noiz hasi zen, baina kontuan harturik A eskuizkribuko laginean Guiristinoaren Dotrina liburutik jaso zuen lekukotasun esklusiboen kopuru urria, Philotea-koekin alderatuta (Etxagibel 2014: 334), ematen du 1656. urtetik aurrera, hots, Dotrina argitaratu ondoren ekingo ziola antolaketa lanari. Hiztegiko antolaketa hasi zenean ez dago dudarik Pouvreauren euskarria Voltoire-ren L'Interprect edota Thresora izan zela, ${ }^{31}$ garaiko frantses-euskara hiztegi bakarra izanik, berea antolatzeko oinarrizko hezurduratzat hartu bide baitzuen (\$ II.1), hori bai, euskara-frantses hiztegiaren norabideak eskatu bezala alderantzizko ordenan jarrita, hots, Voltoire-renean xede-hizkuntza zen euskara iturri-hizkuntza bihurtuta. Nomenklatura handiagotzeko, besterik ezean, alderantzizko bideaz baliatu zen, hots, Nicot-en edota Oudin-en frantsesezko nomenklaturari euskal ordainak emateaz, eta horretan dudarik gabe dagoeneko Guiristinoaren Dotrina burutzeko lagungarri izango zitzaion Leizarragaren Testamentu Berria beste euskal autoreen testuak baino askoz funtsezkoagoa suertatuko zitzaion (Etxagibel 2014: 178-179). ${ }^{32}$ Izan ere, euskarazko bertsetak irakurri ahala Testamentu Berria-ren frantsesezko bertsioren batez ${ }^{33}$ edota Vulgata-z lagunduta Nicot-en edota Oudin-en hiztegietako sarreretan Leizarragaren arabera haiei zegozkien euskal ordainak erantsi baitzitzakeen. Hiztegiaren antolakuntzan frantsesezko hiztegiez gain Pouvreauk berak euskaratutako frantsesezko testuak ere erabili zituen helburu berarekin (Etxagibel 2014: 155-157). Baina, frantsesa ez zen abiahizkuntza bakarra izan, euskara, gaztelania eta latina ere erabili baitzituen ondoan azaltzen denez.

nezko ordainik gabe agertzea, eta are esanguratsuagoa da gure laginean agertzen diren Imitacionea-n esklusiboki erabilitako 22 lekukotasun latinezko ordainik gabe izatea (Etxagibel 2014: 321-327). A eskuizkribua antolatzen eta Imitacionea euskaratzen ari zenean Pouvreauren asmoa hiztegi laukoitza egitea izan balitz, zentzuzkoena lirudike latinezko ordainak jasotzeak. Horregatik, pentsatzekoa da hiztegi laukoitzarena beranduago otu zitzaiola. Bilbaoren arabera (1992: 341) ziurrenik C eskuizkribua 1665eko maiatzaren 12a eta abuztua bitartean idatzia izan zen.

31 Gure hipotesiaren ildoan, hiztegia antolatzen hasi zeneko Voltoirerenaz gain soilik Oihenarten Notitia-ko gaztelania-euskara hitz zerrenda etimologikoa ezagutu ahal izan zuen: izan ere, Les Prouerbes euskara-frantsesezko paremiologia bilduma 1657an argitaratu zen, eta ematen du Etxeberriren hiztegia 1663-1665 tartean eskuratu zuela Oihenarten bitartez (Etxagibel 2014: 201-211). Halaber, Jakes de Belaren hiztegia ezagutzekotan (baina galdua da eta, beraz, ez dago egiaztatzerik), beranduago behar izan zen 1660-1666ko tartean idatzi bide baitzuen (Peillen 1983: 127), eta antzeko zerbait gertatzen da Bidegarayrenarekin (Etxagibel 2014: 520).

32 Zenbaki absolututan Leizarraga izan liteke Pouvreauren iturririk oparoena, izan ere: ERL, FHNL, FHL eta FEL motetako 377 lekukotasunez gain (Etxagibel 2014: 260-264) FAL diren 350ek Leizarragaren testuan dute lehen agerpena (Etxagibel 2014: 295).

33 Kontuan harturik Frantses Elizaren Nouveau Testament-en frantsesezko bertsio ofiziala Denis Amelotek 1666an bukatu zuela (Julia 1997: 381) eta Sacy-k prestatutako jansenisten Nouveau Testament -Mons-ekoa izendatua - (ib. 382) 1667an argitaratu zela, ematen du Pouvreau kalbindarrek egindako bertsioren batez baliatu zela. Beste aukera da 1564an frantsesez eta latinez argitaratutako René Benoît-en Bible bilingue edota apaiz berak 1588an imprimarazi zuen Bibliaren bertsio frantsesa eskura izatea (ap. frantsesezko Wikipédia, s.v. René Benoît). Horren harira esanguratsua da Pouvreauk Nicot-en hiztegian eta Oudin-enean aipatzen ez den «rabillure» eratorria Benoît-engandik jaso bide zuela (cf. edizioan Antolatcea sarreran antoladura-ri buruzko oharra). 


\section{III.1. Abiahizkuntza: frantsesa}

\section{III.1.1. Voltoire, Oudin eta Nicot-en hiztegiak}

Pouvreau ez zen Voltoire-ren hiztegitik jasotako sarrerak kopiatzera edo Oudin edota Nicot-en frantsesezko banako sarrerei euskal ordainak ematera mugatu; ordea, bi hiztegigileetan aurkitutako azpisarrera asko (eratorriak, esapideak, etab.) ere euskaraz ematen ahalegindu zen eta, gainera, testuetarik jasotako hitz eta aipuak, atsotitzak, ahozko hitzak, neologismoak, etab. sarrerak osatzeko erabili ohi zituen ondoko adibideek erakusten dutenez:

4. taula

\begin{tabular}{|l|l|l|}
\hline \multicolumn{1}{|c|}{ A eskuizkribua } & \multicolumn{1}{c|}{ Nicot } & \multicolumn{1}{c|}{ Oudin } \\
\hline Alocacera (FHL: Lç). mercenaire. homme de journée. loüager. & Louagier. & Loüagier. \\
\hline Alocärua (FHL: Lç). loüage. prix. salaire. & Louage. & Loüage. \\
\hline Alocaïruan emaitea (FHL: Lç). & Donner a loüage & \\
\hline Alocäruan hartcea. prendre a loüage. & $\begin{array}{l}\text { Louer maison, c'est et bai- } \\
\text { ller et prendre à louage. }\end{array}$ & $\begin{array}{l}\text { Prendre à } \\
\text { loüage. }\end{array}$ \\
\hline Alocatcea (FHL: Lç). & & \\
\hline
\end{tabular}

Alocacera sarreran, «loüagier», «loüage» eta «donner à loüage»-ri Leizarragaren Alocacera, Alocairua eta Alocairuan emaitea esleitu zizkien, hurrenez hurren. Berriz, «prendre à loüage»-rako ez zuen euskal baliokiderik iturrietan aurkitu, nonbait, eta itzultzera mugatu zen. Azkenik, sarrera osatzeko Leizarragaren Alocatcea erantsi zuen.

5. taula

\begin{tabular}{|l|l|l|}
\hline \multicolumn{1}{|c|}{ A eskuizkribua } & \multicolumn{1}{c|}{ Nicot } & \multicolumn{1}{c|}{ Oudin } \\
\hline Aratza (FHL: O). net. nitidus. & Net. Net, Nitidus. & Net. \\
Aratztea (FEL: Harb). & & \\
Aratztasuna (FHL: EZ). netteté. & Netteté. & Netteté. \\
Aratzqui (FHL: EZ). nettement. & Nettement. & Nettement. \\
\hline
\end{tabular}

Aratza sarreran, «net», «netteté» eta «nettement»-i, hurrenez hurren, Oihenarten VocPo-ko Aratza, eta Etxeberriren Aratztasuna eta Aratzqui esleitu zizkien, eta osagarri gisa Haranbururen Aratztea erantsi zuen.

6. taula

\begin{tabular}{|l|l|l|}
\hline \multicolumn{1}{|c|}{ A eskuizkribua } & \multicolumn{1}{c|}{ Nicot } & \multicolumn{1}{c|}{ Oudin } \\
\hline Arhea (FHL: Ax). herse. occa. & Herce, Occa. & Herse. \\
Arheatcea, arhatcea e. herser. occare. & Hercer, Occare. & Herser \\
Arhatçaillea e. occator. & Herceur. Occator. & Herseur \\
\hline
\end{tabular}


«Herse», «herser» eta «herseur»-i Axularren Arhea eta Etxeberriren erreferentziadun Arhatcea eta Arhatçaillea esleitu zizkien.

\section{7. taula}

\begin{tabular}{|l|l|l|}
\hline \multicolumn{1}{|c|}{ A eskuizkribua } & \multicolumn{1}{c|}{ Nicot } & \multicolumn{1}{c|}{ Oudin } \\
\hline Aztea, haztea. nourrir. (Voltoire). & Nourrir. & Nourrir. \\
Az aita (FHL: EZ). pere nourrissier. & Nourrissier. & Nourrisier. \\
Az ama (FHL: Ax). mere nourrice. & Nourrise. & Nourrise. \\
Azcuntça (e). nourriture. & Nourriture. & Nourriture. \\
Azmendua (FAL: EZ, Hm). nourrissement. & Nourrissement. & Nourrissement. \\
\hline
\end{tabular}

«Nourrir» Voltoireren «Nourrir. Haztea» sarrerari legokioke. «Nourrisier», «nourrise», «nourriture» eta "nourrissement» eratorriei, hurrenez hurren, Etxeberriren $A z$ aita, Axularren $A z$ ama, Etxeberriren erreferentziadun Azcuntça eta Etxeberriren edo Harizmendiren Azmendua esleitu zizkien.

\section{8. taula}

\begin{tabular}{|l|l|l|}
\hline \multicolumn{1}{|c|}{ A eskuizkribua } & \multicolumn{1}{|c|}{ Nicot } & \multicolumn{1}{c|}{ Oudin } \\
\hline $\begin{array}{l}\text { Baicen (FHL: EZ). sinon. postponitur. } \\
\text { Ni baicen. sinon moy. }\end{array}$ & Sinon. & $\begin{array}{l}\text { Sinon. } \\
\text { Ezta baicen (FHL: EZ). }\end{array}$ \\
\hline
\end{tabular}

«Sinon»-i Baicen egokitu zion. Berriz, «sinon moy» itzultzera mugatu zen, antza denez. Azkenik, Etxeberriren aipua osagarri sartu zuen.

9. taula

\begin{tabular}{|l|l|l|}
\hline \multicolumn{1}{|c|}{ A eskuizkribua } & \multicolumn{1}{c|}{ Nicot } & \multicolumn{1}{c|}{ Oudin } \\
\hline Banqueta (FAL). banquet. & Banquet. & Banquet. \\
Banquetatcea (FHL: Lç). banqueter. & Banqueter. & Banqueter. \\
Banquecia, bonbacia a. banqueterie. & Banqueterie. & \\
\hline
\end{tabular}

«Banquet», «banqueter» eta «banqueterie»-ri, hurrenez hurren, FAL den Banqueta, Leizarragaren Banquetatcea eta Axularren Banquecia eta Bonbacia esleitu zizkien. 
10. taula

\begin{tabular}{|l|l|l|}
\hline \multicolumn{1}{|c|}{ A eskuizkribua } & \multicolumn{1}{|c|}{ Nicot } & Oudin \\
\hline Beira (FHL: Ax). verre. & Verre. & Verre. \\
\hline Beira bat vr hotz huts (FHL: Ax). & vn seul verre d'eau froide. & \\
\hline Beiraquia (FHL: Ax). verre. verrerie. & & Verrerie. \\
\hline Beïraquiaren pare gara. a. & & \\
\hline Beiraquizco bachera (FHL: Ax). & vaiselle de verre. & \\
\hline $\begin{array}{l}\text { Bere etchea beirez daducanac estaliric ezpeça aurtic ber- } \\
\text { tcerenera harriric. O. pr. 92. Que celuy qui a sa maison } \\
\text { couuerte de vitre ne jette point de pierre sur celle d'au- } \\
\text { truy. }\end{array}$ & & \\
\hline
\end{tabular}

«Verre», "verrerie» eta "vaiselle de verre» Axularren Beira, Beiraquia eta Beiraquizco bachera-z ordezkatu zituen, eta sarrera osatzeko Axularren bi aipu eta Oihenarten atsotiz bat erantsi zituen.

11. taula

\begin{tabular}{|l|l|}
\hline \multicolumn{1}{|c|}{ A eskuizkribua } & \multicolumn{1}{|c|}{ Voltoire } \\
\hline Iaka, gippoina. pourpoint. & pourpoint, Iaqua edo giponya. \\
Oyala jakataco. a. estoffe pour faire vn pourpoint. & \\
Iakagaya (Neolog). de quoy faire vn pourpoint. & \\
\hline
\end{tabular}

Voltoire-ren sarrera osatzeko Axularren aipuaz gainera berak asmatutakoa bide den Iakagaya eta dagokion frantsesezko ordaina erantsi zituen.

\section{2. taula}

\begin{tabular}{|l|l|l|}
\hline \multicolumn{1}{|c|}{ A eskuizkribua } & \multicolumn{1}{|c|}{ Nicot } & \multicolumn{1}{c|}{ Oudin } \\
\hline Içaria, neurria (FHL: Lç). mesure. & Mesure. & Mesure. \\
\hline $\begin{array}{l}\text { Esquerdunari mucurru içari. pr. 154. A celuy qui e[st] } \\
\text { reconnoisea[nt] faut donner la mesure comble. }\end{array}$ & & \\
\hline Isartcea (FHL: Lç). mesurer. & Mesurer. & Mesurer. \\
\hline
\end{tabular}

«Mesure» eta «mesurer»-i, hurrenez hurren, Leizarragaren Içaria eta Isartcea (sic, Içartcea-ren ordez) egokitu zizkien eta adibide gisa Oihenarten atsotitza bildu zuen. 
Testuetan euskal ordainik aurkitu ezean, ahozko hizkuntzara edo neologismoetara jotzen zuen:

13. taula

\begin{tabular}{|l|l|l|}
\hline \multicolumn{1}{|c|}{ A eskuizkribua } & \multicolumn{1}{c|}{ Nicot } & \multicolumn{1}{c|}{ Oudin } \\
\hline $\begin{array}{l}\text { Armendola (Ahoz). amende. fruit. } \\
\text { Armendolondoa (Neolog/Phil), armendolatcea (Neolog). Amendier } \\
\text { Armendoladia (Neolog). lieu planté d'amendiers. }\end{array}$ & $\begin{array}{l}\text { Amande. } \\
\text { Amandier. }\end{array}$ & $\begin{array}{l}\text { Amande. } \\
\text { Amandier. } \\
\text { Amendaye. }\end{array}$ \\
\hline
\end{tabular}

«Amande», «amandier» eta «amendaye»-rako, hurrenez hurren, ahozko Armendola eta berak asmatuak bide diren Armendolondoa / Armendolatcea eta Armendoladia aukeratu zituen.

\section{4. taula}

\begin{tabular}{|l|l|l|}
\hline \multicolumn{1}{|c|}{ A eskuizkribua } & \multicolumn{1}{|c|}{ Nicot } & \multicolumn{1}{c|}{ Oudin } \\
\hline Arrogaceria (Phil/Ahoz.F). volerie. pillerie. rapine. & Volerie & Volerie. \\
Arrogatcea (FEL: EZ). voler. piller. & Voler. & Voler. \\
Arrogaria (Neolog), arrogatçaillea (Phil/Neolog). voleur, pilleur. & Voleur. & Voleur. \\
\hline
\end{tabular}

«Volerie»-rako ahozko fosildua ${ }^{34}$ bide den Arrogaceria aukeratu zuen. «Voler»-en baliokidea Etxeberrirengan aurkitu zuen eta «voleur»-i ziurrenik berak asmatutako Arrogaria eta Arrogatçaillea esleitu zizkion.

\section{5. taula}

\begin{tabular}{|l|c|c|}
\hline \multicolumn{1}{|c|}{ A eskuizkribua } & Nicot & \multicolumn{1}{c|}{ Oudin } \\
\hline $\begin{array}{l}\text { Debauxqueria (Neolog). debauche. } \\
\text { Debauxatcea (Neolog). debaucher. }\end{array}$ & Desbaucher. & $\begin{array}{l}\text { Desbauche. } \\
\text { Desbaucher. }\end{array}$ \\
\hline
\end{tabular}

«Desbauche» eta «desbaucher»-i berak asmatutako Debauxqueria eta Debauxatcea esleitu zizkien, hurrenez hurren.

16. taula

\begin{tabular}{|l|l|l|}
\hline \multicolumn{1}{|c|}{ A eskuizkribua } & \multicolumn{1}{c|}{ Nicot } & \multicolumn{1}{c|}{ Oudin } \\
\hline Dixidua (Ahoz). menace. & Menace. & Menace. \\
Dixidatcea (FAL: EZ, Ax). menacer. & Menacer. & Menacer. \\
Dixidaria (Hizt. Hitza), dixidatçaillea (Hizt. Hitza). menaceur. & Menaceur. & Menaceur. \\
\hline
\end{tabular}

34 «Ahozko fosildua» terminoa Pouvreauren hiztegian gaur egun galduak izan arren Xvir. mendeko mintzairan arruntak bide ziren hitzak izendatzeko darabilgu. Holako hitzak, nolabait esateko, hiztegian fosilduak geratu dira (Etxagibel 2014: 306-307). 
«Menace», «menacer» eta «menaceur»-i, hurrenez hurren, ahozkoa den Dixidua, Etxeberriren edo Axularren Dixidatcea eta berak asmatutako Dixidaria eta Dixidatçaillea esleitu zizkien.

17. taula

\begin{tabular}{|c|l|l|}
\hline A eskuizkribua & \multicolumn{1}{|c|}{ Nicot } & \multicolumn{1}{c|}{ Oudin } \\
\hline Cruxpetac (Ahoz). bignets. & Bignets. & Bignet. \\
\hline
\end{tabular}

«Bignets»-erako ahozkoa den Cruxpetac aukeratu zuen.

18. taula

\begin{tabular}{|c|c|c|}
\hline A eskuizkribua & Nicot & Oudin \\
\hline Dentilla (Ahoz. F). dentelle. & & Dentelles. \\
\hline
\end{tabular}

«Dentelles» itzultzeko ahozko fosildua den Dentilla erabili zuen.

\section{III.1.2. Pouvreauren itzulpenak}

Hiztegigile frantsesengan oinarri hartuta erantsi zituenez gain, euskal hitz eta esapide batzuk zuzenean hartuak dira berak egin zituen itzulpenetatik eta, hortaz, haiek egiteko erabili zituen jatorrizko testuek iradokiak dira. Hala gertatzen da, bada, Richelieu-ren Instruction du Chrestien liburuko itzulpena den Guiristinoaren Doctri$n a-n$ erabili zituen eta hiztegian jaso zituen hainbat hitzetan, bai eta Philotea-renetan edo Daniel de Priezac-ek 1649an idatzitako Privileges de la Sainte Vierge liburuko euskal bertsioa den Andre Dana Maria Pribilegiatua-renetan. Gudu espirituala-ri dagokionez, ez dakigu Pouvreau Il Combattimento Spirituale italierazko testuaz edota haren frantses itzulpena den Le Combat spirituel-ez baliatu zen. ${ }^{35}$

Ondoan aipatzen direnak Pouvreauk — eta berak soilik — direlako itzulpenetako batean erabilitako hitzak dira (Etxagibel 2014: 322-327):

- Guiristinoaren Dotrina-ren esklusiboak ${ }^{36}$

«Ceruraz guero. apres estre arriué au ciel» (cerüa).

Gure Saluatçaillea ceruraz guero, Apostoluen gainera iautsi cenean (Guir 68) < «lorsqu'aprés l'Ascension de Nostre Seigneur il descendit sur les Apostres» (Inst 74).

"Claratuqui. explicite[ment]» (clara).

35 Pouvreauk itzulpena egiteko 1658an Parisen Guillaume de Lvyne-k argitaratutako Le combat spirituel traduit pour le R. P. D. Olympe Massotti edizio elebiduna erabili bide zuen (Vinson 1891: 114). Guk izenburu bera duen 1659an Geoffry Marcher-ek argitaratutako izen bereko edizioaz baliatu gara $G u d u$-ri dagozkion frantsesezko eta italierazko aipuak jasotzeko.

36 Guiristinoaren Dotrina-ri dagozkion frantsesezko aipu guztiak 1642an argitaratutako Instruction $d u$ Chrestien liburutik atereak dira (Imprimerie Royal, Paris). 
Baldin nihorc erraiten badu Esquiritura Sainduac eztuela nihon ere claratuqui erraiten badirela çazpi Sacramendu (Guir 250) < "Que si on dit que l'Escriture ne dit expressément en aucun lieu qu'il y ait sept Sacremens» (Inst 274).

«Bat banacaco combata. duel» (combata).

Cein ere Iusticiaco nausiec pairatcen baitituste Iaincoaren eta munduaren aitcinean madaricatceco diren bat banacaco combatac (Guir 157) < «Les Magistrats qui tolerent les duels detestables deuant Dieu \& deuant les hommes (Inst 172).

- Andre Dana Maria Pribilegiatua-ren esklusiboak direnak ${ }^{37}$

«Berdindura, berdintasuna» (berdina).

Etcheguille Nausi iaquintasunac [...] seinalatcen baititu eta berezten behar diren partimenduac, figuren berdindurac < "Le sçavant architecte [...] il en trace un modele sensible ou il marque la distribution des p[ar]ties, la symmetrie des figures» (POB 36).

"Ethorquizco cutsua. tache d'origine» (cutsua).

eta priuilejio beregaineco batez libratua licen ethorquizco cutsu hartaric < "que par un singulier priuilege, elle fust affranchie de cette contagion originelle» $(P O B 88)$.

«Iaincozqui. diuinement».

Nola Iaincoaren semea Iaincozqui hautatu içan baitcen millaren artean < «Com. Il auoit esté diuinement choisi entre mille» ( $P O B$ 48).

— Philotea-ren esklusiboak direnak: ${ }^{38}$

"Acometadura» (acometatcea).

Vliec ezgaituste penatcen bere acometaduraz (Phil 243) < «Les mouches ne nous inquiétent par leur force» (Intr III, X).

«Bere buruaren afruntatcea. se donner trop de peine» (afruntua).

Contrara gaizqui emaitetasuna hastio duena afruntatuco da bere burua, ceren arinqui minçatu den nihoren contra (Phil 238) < "Au contraire, celui qui hait la médisance se tourmentera d'avoir fait une lègère murmuration» (Intr III, IX).

"Alhargunaiçuna, alhargun itchura».

beraz, placer erguel hetan vici den alharguna, vici delaric hil da, eta ongui erraitera ezta alhargunaicuna edo alhargun itchura baicen (Phil 417) < «La veuve donc qui vit en ces folles delices, vivante est morte, et n'est à proprement parler qu'une idole de viduité (Intr III, XL).

«Arrenez nagotçu. je vous conjure. je vous prie instamment» (arren).

Hargatic arrenez nagotçu haren bessarcatceaz çure bihotz guciaz (Phil 136) < "C'est pourquoi je vous conjure de l'embrasser de tout votre coeur» (Intr II, XIII).

«Biçuntça, erauntsia. tempeste».

tentacionetaco biçuntça eta erauntsia icigarrizco haren erdian eracuzten du bere bihotza eztela garaitua (Phil 438) < «emmi un si terrible orage de tentations et entre tant de voluptés qui sont tout autour de lui, il témoigne que son coeur n'est point vaincu (Intr IV, IV).

«Chamarra. ecreuisse. chancre maladie».

batac du chamarra besoan eta bertceac ahurpeguian (Phil 215) < Un personne a un chancre au bras et l'autre au visage» (Intr III, VI).

\footnotetext{
37 Andre Dana Maria Pribilegiatua-ri dagozkion aipu guztiak Vinsonek 1892an argitaratutako Les Petites Oeuvres Basques de Sylvain Pouvreau liburutik atereak dira.

38 Philotea-ri dagozkion frantsesezko aipu guztiak 1619an Frantzisko Saleskoak idatzitako Introduction á la Vie Dévote liburutik atereak dira (ik. Bibliografia).
} 
"Corapilladura» (corapilloa).

Amurusquerietaco corapilladura guciac bata bertceari datchesco eta darraisco, halanola aimantaren vertute ichilaz (Phil 289) < «Tous les fatras d'amourettes se tiennent l'une à l'autre et s'entresuivent tous, ni plus ni moins qu. Un fer tiré par l'aimant en tire plusieurs autres consécutivement (Intr III, XVIII).

«Dembora idorra. temps sec» (dembora).

Bai Philothe maitea, dembora idorrean gure borondateac eramaiten gaitu Iaincoaren seruitçura (Phil 492) < "Oui chère Philotée, en temps de secheresse notre volonté nous porte au service de Dieu» (Intr IV, XIV).

«Beharri dilindacac. guirguillac. pendans d'oreilles» (dilinda).

edo icusi balu Errebecca Eliezer ganic escumutur-ioyac eta beharri dilindakac hartcen (Phil 349) < «ou qu'il eût vu Rébecca accepter des bracelets et pendants d'oreille d'Eliézer» (Intr III, XXVIII).

—Gudu-ren esklusiboak direnak:

«Bere buruaganaco amorioa. l'amour propre de luy mesme» (burua).

Bertce escatce eta bilha ibilte gucia da batbederaren bere burua ganaco amorioa, superbiotasuna, eta demonioaren sarea (Gudu 37) < «Tout autre demande, tout autre recherche n'est qu'amour propre, orgueil spirituel, piege du demon» < «Ogni altra domanda, \& requisitione è proprio amore, superbia, e laccio del demonio» (Le Combat 1659: 78-79).

«Noizpaiteren buruan. au bout de quelque temps» (burua).

lekat aitcinetic icusten duçunean segur-iduri batez noizpaiteren buruan acometa ahal çaitçaquetela (Gudu 154) < «si ce n'est lors que vous preuoyez vray-semblablement, que dans quelque temp ils pourront vous assaillir» < «se non quando preuedi verisimilmente che da indi à qualche tempo sono per assailirti” (Le Combat 1659: 322-323).

«Veillacoa, mutil veillacoa. mechant garnement. debauché»; «Vhantua. hydropique» (vhantcea).

çarelaric çure etorquiaz sorhayo, maingu, vhantu, itsu, demoniatu, eta largatu çaizcolaric hainitz veillacori (Gudu 283) < «encore que vous soyez de vostre nature lepreuse, boiteuse, hydropique, aueugle, demoniaque, \& que vous soyez abandonnée à beaucoup de débauchez < «benche tù per nature sia leprosa, zoppa, idropica, cieca, indemoniata, e ti habi data à molto fornicatari» (Le Combat 1659: 594-595).

\section{III.2. Abiahizkuntza: euskara}

Pouvreauk, askotan, euskara abiahizkuntza erabili zuen sarrera beregainak jasotzeko. Horren alde da maiz euskal sarrerek ez izatea frantses ordainik, ondoko adibideek erakusten dutenez:

- Testuetarik eratortzen diren sarrera beregain asko erreferentziadun lekukotasunen baten egokitzapenak dira; ohartu behar da euskara-frantses hiztegi elebidunari egokitu gabeko sarrerak direla maiz, jatorrizko hizkuntza edo hizkuntzak bakarrik (euskara, euskara eta latina) ematen baititu:

Axularrenak:

«Cedena» eta hari dagokion aipua: «Cedenac vrdaïa bohatcen du. a. 423».

«Desgouernua. a. mauuais gouuernem[ent]». 
Leizarragarenak:

«Desperiuruac. Liz. cenaren forman».

Etxeberrirenak:

«Diuscuçu. e. nous dites vous».

«Durdoa. e. trochus qui baculo eyectur a pueris».

\section{— Oihenarten Notitia-koak:}

Pouvreauk alderantzizko ordenan jarri zituen Notitia-tik bildutako sarrerak, hots, euskal sarrera lehenik eta latinezko azalpena gero. Batzuetan, latinezko azalpena frantsesez egokitu zuen:

«Bohordoa. O. genus iunci, seu potius capitellu[m], aut bulla quaeda[m] quae in eo[dem] iunco crescit» < «Bohordo $\mathrm{H}$. genus iunci, seu potius capitellum, aut bulla quaedam quae in eodem iunco crescit. V. idem» (Not 49).

«Cecina. O. viande saupoudree, salée» < «Cecina H. caro conditanea, salita. V. idem» (Not 52).

«Corralea. O. ouile subdiale» < "Corral, area subdialis, cohors. V. corrale, ouile subdiale» (Not 51).

\section{- Oihenarten atsotitzak:}

«Boçatcea. O. bouscher vn trou» sarrera Oihenarten pr. 68tik aterea da: «Bata bos, berzea xila ari $d a$. Il ne fait que boucher vn trou \& en ouurir vn autre».

«Duena. qui a. du verbe içaitea, en la gram.» sarrera Oihenarten pr. 120tik aterea da: "Duenac aser biper. Il n'y a que celuy qui en a, qui mette du poivre sur les chous de son potage».

— Oihenarten eta Pouvreauren arteko gutuneriari (Etxagibel 2014: 238-245) dagozkion gehienak, hala nola:

«Bohatcea. souffler» (O SP [14r-17r, 1661?]).

«Bornua. terme de nautonniers» (O SP [12 Mai 1661?]).

«Cornixca. sorte de coiffure des villageoises» (O SP [14r-17r, 1661?]).

"Corromua. espece de poisson» (O SP [12 Mai 1661?]).

«Vspela. le noirceur que causent au corps d'vne personne les coups \& meurtrisseures quelle a souffertes» (O SP [12 Mai 1661?]).

—Oihenarten VocPo hiztegitxotik atereak (Etxagibel 2014: 237-238):

«Aitoralaba. O. aitonen alaba. gentifemme. femme noble».

«Bereterra. O. cler d'eglise. commis. secretaire».

«Duhulatea. S. O. tas d'argent».

«Isuna, B. amende pecuniaire».

— Ahozko hitzak:

«Cimitza. eclisse ou on met le fromage».

«Cincoilla. panse grand. ventre». 


\section{III.3. Abiahizkuntza: gaztelania}

Ikusi dugunez, Pouvreauk Oudin-en frantses-gaztelania norabideko hiztegia erabili ohi zuen. Hala ere, zenbaitetan gaztelania-frantses liburukiaz ere baliatu zen, hala nola Acometamendua (acometatcea), Alcabotatcea (alcabotea) eta Amiamacoa sarreretan ( $\$$ II.2.1). Horrenbestez, horrelako kasuetan abiahizkuntza gaztelania izan zen.

\section{III.4. Abiahizkuntza: latina}

Berak horrela adierazi zuenez gero ( $\$$ III), badakigu Pouvreauk Imitacionea latinetik itzuli zuela. ${ }^{39}$ Beraz, soilik itzulpen horretan erabilitako hiztegiko 45 lekukotasunek (Etxagibel 2014: 334) latinean izango lukete jatorri.

- Imitacionea-ren esklusiboak direnak ${ }^{40}$

"Burfidiadura»

arren çure legueac ikaz detçadan bihotzeco burfidiadurac eta soberaniazco burupeac egoitz detçadan gatic (Imit III, 50, 4, 83. oh.) < «ut discam justificationes tuas \& omnes elationes cordis atque praesumptiones abjiciam (De Imitatione 1754: III, L, IV).

"Chori burutasuna»

Guerthuz loria alferra da, içurri gaixtoa, chori burutasunic handiena apartatcen baigaitu eguiazco loriatic (Imit III, 40, 4) < «Veré inanis gloria, mala pestis, vanitas maxima: quia à verá trahit gloria, caelesti spoliat gratiá» (De Imitatione 1754: III, XL, IV).

«Desconsolamendua» (desconsolacionea)

aitcitic hainitz atsecabe, tarritamendu eta desconsolamendu handi iasan dute (Imit III, 35, 3) < «sed multas gravitates, \& tentationes varias, magnasque desolationes" (De Imitatione 1754: III, XXXV, III).

\section{III.5. Abiahizkuntza: frantsesa? gaztelania?}

Pouvreauk euskaratutako Oudin-en Refranes-etik ( $\$$ II.2.2) ateratako errefrau zenbaitekin ez dago garbi zein bertsio hartu zuen itzulpena egiteko. Esaterako, $B a$ ratchuria sarreran ondoko atsotitza da:

Oguia on çayon mutillari bekatu da emaitea baratchuri. Au garçon que trouue le pain bon c'est peche de l'ail qu'on luy donne. il ne faut pas traiter les valets. Al moço que le sabe bien el pan pecado es el ajo que le dan.

Kontua da ohi ez bezala Pouvreauk gaztelaniazko bertsioa azkenean idatzi zuela. Beraz, baliteke frantses bertsioa erabiltzea berea egokitzeko. Orobat gertatzen da Beharra sarrerari dagokion ondoko atsotitzarekin:

Aberatsari ez prometa beharrari ez falta. Au riche ne promets au pauure ne manque pas. Al rico no prometas, y al pobre no falt[e]s.

\footnotetext{
39 Hala ere, ez dago garbi soilik latinezko testua erabili zuenik, Imitacionea-ren edizioan gaztelaniazko pasarte bat eta haren euskal bertsioa agertzen baitira (Etxagibel 2014: 335, 192. oh.).

40 Imitacionea-ri dagozkion latinezko aipuak De Imitatione Christi-tik (1754) atereak dira.
} 


\section{Ondorioak}

Nomenklaturaren antolakuntzan (\$\$ II.2.4, II. 4.1), oro har, Nicot-en hiztegi etimologikoaren eredua erabili zuen, hots, sarrera buruak alfabeto ordenaren arabera antolatuta eta harekin etimologikoki lotutako hitzak eta esapideak azpisarrera modura haren ondoren kokatuta. Eredu orokor honi, dakigunez, Pouvreauk bere kasa hainbat atsotitz eta adibide erantsi zizkion (\$\$ I.2.4.2, I.2.4.3).

Sarrera eta azpisarreren antolakuntzari dagokionez, (\$ I.2) A eskuizkribuak dituen eransketak kontuan harturik ezin daiteke sarrera kanoniko orokor batez hitz egin. Eransketarik ez duten sarreretan, sarrera kanoniko bakarra jatorrizko hiztegi elebidunari legokioke, eta euskal sarrera buruak, haren sinonimo edota aldaerak eta frantsesezko ordainak (edo ordainek) osatuko lukete. Erantsitako gaztelaniazko ordainek eta errefrauek hiztegi elebidunaren eta laukoitzaren artean azken honen abiapuntua izango zen hirukoitz baten saiakera iradokiko lukete. Horren alde da $\mathrm{C}$ eskuizkribuko sarrera gehienak hirukoitzak izatea ere (\$I.3).

Azterketak bide eman digu Pouvreauk hiztegia eratzeko erabili zuen metodoari buruzko hipotesi bat egiteko. Honen arabera, batez ere bi hizkuntzetatik abiatu zen: frantsesetik eta euskaratik.

Frantsesez hiru iturri nagusi izan zituen: Voltoire, Nicot eta Oudin (\$ III.1.1). Ez dago dudarik Pouvreauren lehenbiziko euskarria Voltoire-ren L'Interprect edota Thresora izan zela, garai hartan eskura zitekeen frantses-euskara hiztegi bakarra izanik, berea antolatzeko oinarrizko hezurduratzat hartu bide baitzuen. Nomenklatura handiagotzeko, batez ere, Nicot-en edota Oudin-en hiztegiez baliatu zen. Izan ere, biak batera gidatzat hartu zituen berea eraikitzeko, hala frantses, gaztelania zein latinezko ordainak haietatik jasoaz, nola haietan bildutako frantses hitzen euskarazko baliokideak bilatuz eta, antza denez, aurkitu ezean bere kabuz asmatuz. Arakatzea osoa izan zen: izan ere, A-tik V-raino A ezkuizkribuko laginaren eta hiztegien artean elkarganako egokitasunak garbiak baitira. Lagineko sarrera eta azpisarreretatik gutxienez \%31,57 frantses hiztegi hauei legokieke (\$\$ II.1, II.4).

Baina, hiru hiztegi horiek ez ziren bere frantses iturri bakarrak izan. Izan ere, euskal hitz eta esapide batzuek euskaratu zituen frantsesezko testuetan dute oinarri, jatorrizkoen egokitzapenak baitira ( $\$$ III.1.2).

Abiahizkuntza gisa euskaraz ere baliatu zen sarrera beregainak jasotzeko. Batetik, testuetako lekukotasunak, Oihenarten Notitia-ko hitz zerrendak, Les Prouerbes-eko atsotitzak, etab. egokituta, eta bestetik, ahozkotik jasotako hitzak hiztegian bilduta (\$ III.2). 


\section{Laburdurak}

Ahoz. : ahozkoa.

Ahoz. F. : ahozko fosildua.

De Imitatione: De Imitatione Christi (Kempis-en testua).

E/Fr: espainol /frantsesa.

ERL: erreferentziadun lekukotasuna.

FAL: fidagarritasun apaleko lekukotasuna.

FEL: fidagarritasun ertaineko lekukotasuna.

FHL: fidagarritasun handiko lekukotasuna.

FHNL: fidagarritasun handieneko lekukotasuna.

$\mathrm{Fr} / \mathrm{E}$ : frantses / espainola.

Hizt. hitza: hiztegi hitza.

Inst: Instruction du Chrestiene (Richelieu-ren testua).

Int: Introduction à la vie devote (Frantzisko Saleskoaren testua).

Le Combat: Le Combat spirituel (Scupoli-ren testua).

Neolog.: Neologismoa

O SP $[\mathrm{xxx}]$ : Oihenartek Pouvreauri bidalitako hitz zerrendak; taket artean zerrendaren data agertzen da.

\section{Bibliografia}

Bilbao, G., 1992, «Pouvreauren hiztegi laukoitza», ASJU 26:2, 341-389.

Etxagibel, J., 2008a, Silvain Pouvreauren iturriak, tesina argitaragabea, Gasteiz: UPV/EHU.

—, 2008b, "Pouvreauren hiztegiaren iturriak eta testukritikaren metodologia», ASJU 42:2, 69-118.

—, 2010, «Silvain Pouvreauren hiztegiaren iturriak eta testukritikaren metodologia: II. Voltoire-ren hiztegiak», $A S J U$ 44:2, 221-278.

-, 2014, Silvain Pouvreauren hiztegia testu kritika eta metalexikografiaren argitan, doktorego tesi argitaragabea, Gasteiz: UPV/EHU.

Gómez, R., 2008, «Euskal gramatikagintza zaharraren historia laburra: XVII-XVIII. mendeak», in X. Artiagoitia \& J.A. Lakarra (arg.), Gramatika Jaietan. Patxi Goenagaren omenez (ASJUren gehigarriak, 51). Bilbo: UPV/EHU \& GFA, 329-349.

Julia, D., 2000 [1997], «Lecturas y Contrarreforma», in G. Cavallo \& R. Chartier, Historia de la lectura en el mundo occidental, Madrid: Taurus, 367-412.

Kempis, T., c. 1441, De Imitatione Christi. Berrarg., Madril: Typografia Regia (vulgó) de la Cazeta, 1754.

Kerejeta, M.J., 1991, "Oihenart Silvain Pouvreauren hiztegian», ASJU 25:3, 865-899.

—, 2003, S. Pouvreauren hiztegiaren edizioa (argitaragabea).

Lakarra, J.A., 1991, «Testukritika eta hiztegiak: Harriet eta Larramendi», in J.A. Lakarra \& I. Ruiz Arzalluz (arg), Memoriae L. Mitxelena Magistri Sacrum (ASJU-ren gehigarriak 14), Donostia: Gipuzkoako Foru Aldundia, 1, 217-258.

—, 1994, "Harrieten gramatikako hiztegiak (1741)», ASJU 28:1, 1-178.

—, 1995, «Pouvreauren hiztegiez eta hiztegigintzaren historiaz», ASJU 29:1, 3-52.

—, 1996, «Iturrien erabilera eta tamainak egitura(z) zehaztuaz: Refranes y Sentencias eta Hiztegi Hirukoitza», Uztaro 16, 21-55. 
—, 1997, «Hizkuntz eskuliburuen tradizioa Euskal Herrian: I. L'Intreprect ou Traduction du François, Espagnol \& Basque ( 1620)», ASJU 31:1, 1-66.

Mitxelena, K., 1961, «Euskal iztegigilleak XVII-XvıIIgarren mendeetan», Euskera 6, 7-22.

Nicot, J, 1606, Thresor de la langue françoyse, Paris: D. Douceur. <http://www. atilf.fr/ dictionnaire/TLF-NICOT/index.htm> [Azken kontsulta: 2014-06-04].

Oihenart, A., 1638, Notitia utriusque Vasconiae tum Ibericae tum Aquitanicae, Paris: S. Cramoisy. 1656ko berrargitalpenaren argit. faks., Gorosterratzuren itzulpenaz, Gasteiz: Eusko Legebiltzarra, 1992.

_, 1657, Les prouerbes basques recuillis par le sr. D'Oihenart plus les poésies basques de mesme auteur, Paris. Berrarg. faks.: Tolosa: Lopez Mendizabal, 1936.

Oudin, C., 1607, Thresor des deux Langves Espagnolle et Françoise, Marc Orry, Paris. <htpp:www.books.google.es/books/about/Tesoro_de_las_dos_lenguas_francesa_y_esp. html > [Azken kontsulta: 2014-06-05].

—, 1616, Paris: Vefve Marc Orry. <htpp:www.books.google.es/books/about/Tesoro_de_ las_dos_lenguas_francesa_y_esp.html> [Azken kontsulta: 2014-06-05].

—, 1621, Paris: Adrian Tiffaine. <http://www.books.google.es/books/about/Tesoro_de_ las_dos_lenguas_francesa_y_esp.html> [Azken kontsulta: 2014-06-05].

—, 1645, A. Oudin (arg.), Paris: Sommaville. Biblioteca Universitat de Barcelona, doc. XVII-7413. Berrarg. elektronikoa [cd-rom].

—, 1660, A. Oudin (arg.), Momart, Brusela. <http://www.books.google.es/books/about/ Tesoro_de_las_dos_lenguas_francesa_y_esp.html> [Azken kontsulta: 2014-06-05].

-, 1659, Refranes o prouerbios españoles traduzidos en lengua francesa = prouerbes espagnols traduits en françois. Paris. Berrarg. elektronikoa: Universitat de Barcelona (Núm. Manuscrit: XVII-7413): R / 7044 [cd-rom].

Pablo Nuñez, L., 2007, "Los Refranes o Proverbios Españoles Traduzidos en lengua francesa, de César Oudin", in VII Congreso Nacional de la Asociación de Jóvenes Investigadores de Historiografía e Historia de la Lengua española (AJIHLE). <hhtp://www.digital.csic. es/.../7AJIHLE_LosRefranesdeCesarOudin.pdf> [Azken kontsulta: 2014-06-04].

Peillen, Tx., 1983, «Bela-ko zaldunaren Zuberotar hiztegia, xviII. mendean», FLV 15, 127 146.

Pouvreau, S., 1648-1659, Les Petites oeuvres basques de Silvain Pouvreau, Vinson-en argit., 1892. Berrarg. faks. Donostia: Hordago, 1979.

—, 1656, Guiristinoaren Dotrina, Paris: Roger. Faks.: <http://www.klasikoak.armiarma. $\mathrm{com} /$ idazlanak/P/PouvreauGiristinoa.htm> [Azken kontsulta: 2014-06-04].

—, 1664, Philotea, Audinet, Paris. Faks: <http://www.klasikoak.armiarma.com/idazlanak/P/ PouvreauFilotea.htm> [Azken kontsulta: 2014-06-04].

—, 1665, Gvdv Espirituala, Audinet, Paris. Faks.: <http://www.klasikoak.armiarma.com/ idazlanak/P/PouvreauGudua.htm.>. [Azken kontsulta: 2014-06-04].

—, c. 1669, Iesusen Imitacionea. J.M. Satrustegiren argit.: Donostia: Hordago, 1979.

—, Eskuizkribuak. Celtique-Basque 7 (R. 31.717), Celtique-Basque 8 (R. 31.718) eta Celtique et Basque 9 (R. 68.519), Bibliothèque National de France, Service Photographique, Paris.

Richelieu, A., 1621, Instruction du Chrestien, Poitiers: A. Mesnier. Berrarg. Paris: Imprimerie Royal, 1642. Edizio elektronikoa: <http://www.gallica.bnf.fr>

Sales, F., 1609, Introduction à la vie devote, Rigaud, Lyon. <http://www.abbaye-saintbenoit.ch/saints/francoisdesales/viedevote> [Azken kontsulta: 2014-06-04]. 
Scupoli, L., 1589, Combat spirituel. Berrarg.: Le combat spirituel composé en italien par le RPD Laurens Scupoli traduit e françois par le R.P. D. Olimpe Massoti, Paris: Marcher, 1659. <http://www.books.google.com/books/about/Le_combat_spirituel traduit par Olympe Massoti/html> [Azken kontsulta: 2014-06-04].

Stoer, J., 1593, Le grand Dictionaire François-Latin (Nicot Jean, Du Puis Jaques), Stoer Jacob (arg.), Geneve. <http://www. le grand dictionaire françois-archive.is/iHeuk> [Azken kontsulta: 2014-06-03].

Urgell, B., 1998, "Hiztegi Hirukoitza eta Diccionario de Autoridades erkatuaz (I): oinarrizko ezaugarri zenbait», ASJU 32: 1 (1998), 109-163.

—, 2002a, Euskal Lexikografia. Irakaskuntza proiektu argitaragabea, Gasteiz: UPV/EHU.

—, 2002b, Larramendiren Hiztegi Hirukoitza-ren Eranskina: Saio bat hiztegigintzaren testukritikaz, Monumenta Linguae Vasconum. Studia et Instrumenta 1 (= ASJU-ren gehigarriak 47), «Julio Urkixo» Euskal Filologia Mintegia \& GFA: Bilbo.

Urquijo, J. de, 1909, «Las citas del Diccionario de Pouvreau», RIEV 3, 504-519.

Vinson, J., 1891-1898, Essai d'une bibliographie de la langue basque. Berrarg. faks. J. Urquijoren oharrekin (ASJU-ren gehigarriak, 9), Donostia: «Julio Urkixo» Euskal Filologia Mintegia \& GFA, 1984.

-, 1892, ik. Pouvreau 1648-1659.

—, 1910a, «Le vocabulaire de Pouvreau», RIEV 4, 139-141.

Voltoire, 1642, Tresora Hirour Lengvaietaqua, Francesa, Espagnola eta Hasquvara. Berrarg. elektronikoa: Euskaltzaindia [cd-rom].

Wikipèdia, L'encyclopédie libre. <http://fr.wikipedia.org>

Wooldridge, T., 1977, Les Debuts de la lexicographie française, Estienne, Nicot et le Thresor de la langue françoyse 1606, Toronto: University of Toronto Press. 2. argit. Toronto: Edicta, 1997. Edizio elektronikoa (2010): <http://www.chass.utoronto.ca/wulfric/ edicta/wooldridge> [Azken kontsulta: 2014-06-03].

-, 1992, Le Grand dictionnaire françoise-latin (1593-1628), Toronto: Editions Paratexte, 2. argit. Toronto: Edicta, 2001. Edizio elektronikoa: <http://www.chass.utoronto.ca/ wulfric/tiden> [Azken kontsulta: 2014-06-03].

Zuili, M., 2006 "Cesar Oudin y la difusión del español en Francia en el siglo Xviı», in M. Bruña et al. (arg.), La cultura del otro: español en Francia, francés en España. La culture de l'autre: espagnol en France, français en Espagne. Actas del Primer encuentro hispanofrancés de investigadores (APFUE-SHF) (Sevilla, 29 noviembre a 2 diciembre de 2005). Sevilla: Universidad, Dpto. de Filología Francesa, APFUE, SHF, 278-289. <http:// www.culturadelotro.us.es /actasehfi/pdf/2zuili/pdf> [Azken kontsulta: 2014-06-03]. 


\section{Eranskina}

\section{VII.1. Voltoire-ren hiztegiari legozkiokeen lekukotasunen zerrenda}

A (99)

abadea
aberatsa
abrea
abuillac
acabatcea
aça
açala
accordatcea
acholatcea
acituna
acusatcea
adarra
adimendua
adina
adisquidea
aditcea
adoratcea
ahaidea (ahaicoa)
abalquea (ahalkatcea)
ahalquegabea (ahalkatcea)
ahantstea
ahoa
abuntça
airea (airatcea)
aita
aitaçoa
aiuta
akerra
alaba
aldamioa
alferra
alfertasuna
allegueratcea
aloeta
allogatcea
alquia
altchatcea (altchagarria)
aluna
ama
amarratcea
anaya

anayatasuna
ançara
angarala
anguira
appaintcea
apartatcea
apeça
appoa
arana
arçaina
arcua
ardietstea
argala
argaltcea
arguia
arina
arinqui
arma
armatcea
armarioa
armierma
arra
arraba
arraçoina
arraina
arrainaren heçurrac
arraintçan haritcea
arrainsalea
arrapoa
arratoina
arraultcearen gorringoa
arrayoa
arribera
arroda
arrosarioa
arţa
asco, asqui
asetcea
gosaltcea (asca)
asmatcea
garratza (asprea)


aste lehena

aste artea

asteazquena

astoa

atço

athea

atheratcea

athorra

auendoa auertitcea

aumoina

aurquitcea (aurquiença)

edireitea (aurquitcea)

aurtiquitcea

ausiquitcea

vrdaï-azpia

haztea (aztea)

B (83)

\begin{tabular}{|c|c|}
\hline$b a b a$ & beltza \\
\hline babaçuça & berantcea \\
\hline bacaillaba & bergatcea \\
\hline bada & berotasuna \\
\hline$b a i$ & berotcea \\
\hline balea & berria \\
\hline balesta & berriz \\
\hline bandera & berrogoy \\
\hline baquea & bertcela \\
\hline baratchuria & beruna \\
\hline baratzea & bessarcatcea \\
\hline barbera & bessoa \\
\hline bare curcuillua & besta egunac \\
\hline barkatcea & bethetcea (bethatcea) \\
\hline barrika & bia \\
\hline barrilla & biçarra \\
\hline barura & bidea \\
\hline bassurdea (bassa) & biharra \\
\hline bassina & bihotza \\
\hline batbedera & bihurtcea (bihurcatcea) \\
\hline bazcoa & bikea \\
\hline becoquia & bildotza \\
\hline beguia & bilhatcea \\
\hline beguiratcea & billusia (billuzgorria) \\
\hline behatzaçala & biltcea (biltçarrea) \\
\hline behera & birazca \\
\hline behia & biribiltcea \\
\hline behorra & biscotcha \\
\hline beldurra & bitina (bitika) \\
\hline beldurtcea & blancheta \\
\hline belea & bolbora \\
\hline belharchuta & bortchatcea \\
\hline belhauna & bortz \\
\hline belhaunicatcea & bortzgarrena \\
\hline
\end{tabular}


botherea

burdina

su burdinac

burgezza

burreba

burua

buruilla

burunçalea bururdia

bustana

busteltcea

bustiña

bustitcea

bustia (bustitcea)

butatcea

C (74)

çabala

cabineta

cablea

cacheta

cadenata

çaharra

çaina

çalduna (çaldia)

caltea

campoa (campatcea)

çangoa

canta

cantaria

cantatcea

capa

capitaina

cargatcea

carneceria

çarpa

casta

çathitcea

cehazca

cerua

chabutcea

chaloina

chapela

charpantera

chehatcea

cherria

chicharia

chilcoa

chipitcea

cuisina

chiquiratcea

chiquiratçaillea (chiquiratçea)

chiquiroa

chitoa

choria

chuchena

churia

churitcea

cigarra

cilhatcea

cilhoa (cilhatcea)

cilharguina

cinçurra

cinetstea

ciria

citroina

clarqui (clara)

cobrea

colera

colorea

colpea

comuna

comunzqui

complitcea

contatcea (condatcea)

copa

çorra

cornadua

çorrotztea (çorrotza)

crisseillua

çubia

cucheta

cucumbrea

cucurusta

çuhaitza

çuhurra (çuhurcia)

cuisinaria 
çurubiac

cusina çutic

cutcha

D (24)

dafalla
dafailluna (dafalla)
dansa
dansatcea
dastatcea
deabrua
deitcea
denda
dendaria
lesxatcea (desserratcea)
desterratcea (desterrua)
desertua

deusa

diamanta

dirua

ditharea

dithia

doatsua

doatsuqui

doblatcea (doblea)

dohacabea

dohacabequi

dostatcea (dostaillua)

dronda erreta (drunda)

I (62)

iadanic (ia)
ianharia
iaka
iaquitea
iarraiquitcea
iartcea
iauna
iautstea (iausia)
iayotcea
ibiltcea
icena
içarra
içorra
içurria
icustea
idequitcea
idia
idortcea
iduquitcea
iduria
ifernua
igandea
iguelsua
igurikitcea
ihardetstea

ihez eguitea (ihesa)

ihiztatcea (ihicia)

ihinça

ikaitea

ikaratcea

ikastea

illabethea (illa)

illarguia

illea

illoba

ilquitcea

imprimatcea

ioitea

iostea

iracequitcea

iragaitea

irakaztea

iraquitcea

irasagarra

iratçartcea

irauastea

iretstea

irina

irutea

isterra (istapea) 


$\begin{array}{ll}\text { itçaina } & \text { itsasoa } \\ \text { itçala } & \text { itsua } \\ \text { itcea } & \text { itsutcea } \\ \text { itçatcea (itcea) } & \text { iugea } \\ \text { itçultcea } & \text { iugeatcea } \\ \text { ithurria } & \text { iuratua }\end{array}$

V (23)

$\begin{array}{ll}\text { vda } & \text { vrrea } \\ \text { vdarea } & \text { vrreztatcea } \\ \text { vestitcea } & \text { vrriquitcea } \\ \text { vkatcea } & \text { vrtharrilla } \\ \text { vlia } & \text { vsaina } \\ \text { vntcia } & \text { vsança } \\ \text { vquitcea } & \text { vsatcea } \\ \text { vra } & \text { vssoa } \\ \text { vrdaya (vrdaina) } & \text { vsso tortoilla } \\ \text { vrdea (vrdaina) } & \text { vstaia } \\ \text { vria } & \text { vtstea } \\ \text { vrratsa } & \end{array}$

\section{VII.2. Oudin-en hiztegiari dagozkion Pouvreauren hiztegian gaztelaniazko ordainak duten sarrera eta azpisarrerak}

A (358)

abadea
abadearena
abadetasuna
abadezza
abadota
abatsa
abeac
abecedea
aberatsa
aberatstasuna
aberatstea
aberatsqui
aberatstura
abrea
abre guiça
abrequeria
abretasuna

ISSN: $0582-6152-e-$ ISSN: 2444-2992

http://www.ehu.es/ojs/index.php/ASJU/

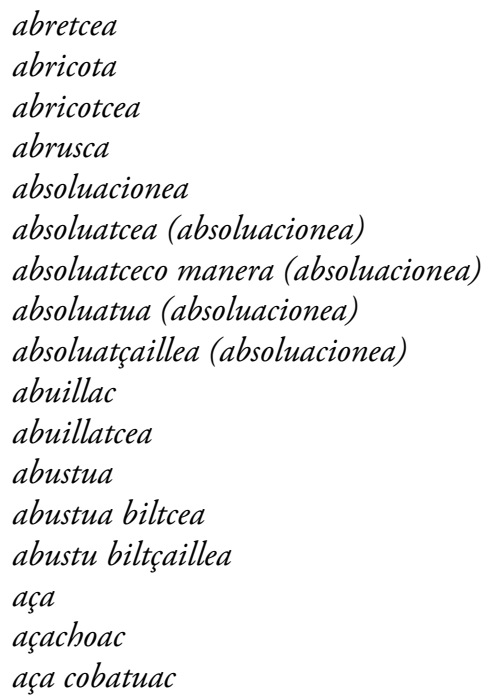




\begin{tabular}{|c|c|}
\hline aça ixurtuac & açotamendua \\
\hline aça gorriac & actea \\
\hline aça loreac & acteac \\
\hline acabatcea & acuillua \\
\hline acabança (acabatcea) & acuillu puntatçaillea \\
\hline açala & acuilluz puntatcea \\
\hline acamaillua & açuna \\
\hline açantça & acusatcea \\
\hline açascuillua & acusatçaillea (acusatcea) \\
\hline açaüa & acusamendua (acusatcea) \\
\hline açaya & acusatceco seinalea \\
\hline accionea & adaquiac \\
\hline accionatcea (accionea) & adarra \\
\hline accordatcea & adarsua \\
\hline accordua (accordatcea) & adartcea \\
\hline accorta & adartchoa \\
\hline guiçon accorta & adatsa \\
\hline acheria & adatsduna \\
\hline aceari çaharra (acheria) & adats izpia \\
\hline acentua & adaussia \\
\hline acentu emaitea & adaussi eguitea \\
\hline acercatcea & adaussiguillea \\
\hline acha & adeçara \\
\hline achelaria & adelatcea \\
\hline achiruina & adimendua \\
\hline achola & adimenduco guiçona \\
\hline acholatcea & adimenduduna \\
\hline acholduria & adimendutsua \\
\hline acholagabea & adina \\
\hline achuria & adinetara helduac \\
\hline acienda & adisquidea \\
\hline acituna & adisquidetasuna \\
\hline acitundia & adisquidetchoa \\
\hline acitun chumea & aditcea \\
\hline acitun-ondoa & adoratcea \\
\hline acitunezcoa & adoratçaillea (adoratcea) \\
\hline acometatcea & adoracionea (adoratcea) \\
\hline acometamendua (acometatcea) & adoratcecoa \\
\hline acometatçaillea (acometatcea) & adoracionerequin (adoratcea) \\
\hline acometatua (acometatcea) & adreillua \\
\hline açorria & adreilluzcoa \\
\hline açot & adreilluztatcea \\
\hline açotatcea & adreilluguillea \\
\hline açotatua & adreillutchoa \\
\hline açotatu beharra & afaria \\
\hline açotatçaillea & afaltcea (afaria) \\
\hline
\end{tabular}




\begin{tabular}{|c|c|}
\hline afentcea & ahaidea (ahaicoa) \\
\hline afendua (afentcea) & Moyseren ahaidea (ahaicoa) \\
\hline afaitatcea & ahaidetasuna (ahaicoa) \\
\hline affaitadura (afaitatcea) & escontçaz ahaidetua (ahaicoa) \\
\hline affaitatasuna (afaitatcea) & ahala \\
\hline affaitaquetac (afaitatcea) & ahal içaitea \\
\hline afaitatçaillea (afaitatcea) & ahalkatcea \\
\hline afruntua & ahalke içaitea (ahalkatcea) \\
\hline afruntatcea (afruntua) & ahalquea (ahalkatcea) \\
\hline afruntatçaillea (afruntua) & ahalqueac narama (ahalkatcea) \\
\hline afrunturequin & ahalquerequin (ahalkatcea) \\
\hline agaratça & ahalquegabea (ahalkatcea) \\
\hline agaratz murcoa & ahalquegaberia (ahalkatcea) \\
\hline agradablea & ahalquegabequi (ahalkatcea) \\
\hline agradamendua (agradablea) & ahalquegabetcea (ahalkatcea) \\
\hline agradatcea (agradablea) & ahalquetia (ahalkatcea) \\
\hline agradablequi & ahalkatçaillea (ahalkatcea) \\
\hline agoargenta & ahantstea \\
\hline agorilla & ahantsia (ahantstea) \\
\hline agorra & ahantscorra (ahantstea) \\
\hline agortcea & ahantscortcea (ahantstea) \\
\hline agortasuna & ahantscortasuna (ahantstea) \\
\hline agortea & ahantslea (ahantstea) \\
\hline agortura & ahantstasuna (ahantstea) \\
\hline agorrean & aharçatça \\
\hline agraça & ahardia \\
\hline agudoa & ahatea \\
\hline agudotcea & ahatsa \\
\hline agudotasuna & liçun ahatsa \\
\hline agudoqui & ahatsqueria \\
\hline agueria & ahia \\
\hline agueriqui & ahoa \\
\hline aguertcea (agueria) & ahoa norbaiti tapatcea \\
\hline aguian & ahagoçoa (ahoa) \\
\hline aguiera & ahalegarra (ahoa) \\
\hline cilharrezco aguiera & ahalegarra edequitea (ahoa) \\
\hline aguilleta & ahal vsaina (ahoa) \\
\hline aguilletaz lotcea & ahal vsain eguitea (ahoa) \\
\hline aguintcea & aharraussia (ahoa) \\
\hline gauça aguindua (aguintcea) & ahasabaya (ahoa) \\
\hline aguintaria (aguintcea) & abolcatcea \\
\hline aguintça (aguintcea) & aholcamendua (aholcatcea) \\
\hline agureac & aholcaria (aholcatcea) \\
\hline agurra & ahotsa \\
\hline agur eguitea norbaiti & ahucua \\
\hline ahaicoa & ahucuratcea \\
\hline
\end{tabular}




\begin{tabular}{|c|c|}
\hline abula & alceiruztatcea (alceiratcea) \\
\hline ahultcea & alcifrea \\
\hline ahuldura & alcifredia \\
\hline ahuntça & alçoa \\
\hline ahuntz biçarra & aldagarria \\
\hline ahuntzcumea & aldamioa \\
\hline ahuntz marruma & aldapa \\
\hline ahuntza marrumaz egoitea & aldarea \\
\hline bassahuntza & aldeteguia \\
\hline ahurpeguia & aldia \\
\hline ahurpegui lucea & aldiria \\
\hline aburra & $a m a$ \\
\hline ahurca & ametsa \\
\hline ahutsa & ametstea \\
\hline ahutz handitacoa (ahutsa) & ameztia \\
\hline ahutcecoa (ahutsa) & amiamacoa \\
\hline ahutzetacoac (ahutsa) & amiamaco-plumac \\
\hline ahutzetacoac emaitea (ahutsa) & amiruina \\
\hline aichturrac & amiruineztatcea \\
\hline aixtur çorrotza (aichturrac) & amurutcha \\
\hline aiduru & anaya \\
\hline aiduru egoitea & anayatasuna \\
\hline aitaçoa & anayazcoa \\
\hline aiuta & anaya guiza \\
\hline aizcora & anayaren hitçaillea \\
\hline aizcora chipia & ançara \\
\hline aizcoraguillea & ansara eguna (ançara) \\
\hline aizpa & apirilla \\
\hline aizpachoa & apiril arraina \\
\hline akerra & arraina \\
\hline akerlarrea & arraintchoa \\
\hline aketza & arrainaren hegalac \\
\hline alaba & arraintça \\
\hline albarda & arraintçan haritcea \\
\hline arbaldaguillea (albarda) & arrainsalea \\
\hline albenia & arrain saltçaillea \\
\hline alcabota & arraintsua \\
\hline alcabotatcea & arrainaren françac \\
\hline alcabotatchoa & arraindia \\
\hline alcabotadorea & arriscatcea \\
\hline alcaboteria & arriscua (arriscatcea) \\
\hline alcaterna & arrochina \\
\hline vntciaren socaquin alcaternatcea & arroka \\
\hline alceiratcea & arroda \\
\hline alceiratua (alceiratcea) & alcabusaren arroda \\
\hline alceirua (alceiratcea) & arrodaren arrayoac \\
\hline
\end{tabular}




arrola
arrondela
arropa
emaztequi arropa
mairu arropa
arrosa
indi arrosa
çapata-arrosac
Andre Dana Maria arrosa
otso arrosa
arrosa ondoa
arrosarioa
arrotza
arrotztea
arruda
arrusina
arrusintsua
arry
artça
artemehin
artoa
aspidea
atabala
atsecabea

arrola

arrondela

arropa

emaztequi arropa

indi arrosa

çapata-arrosac

Andre Dana Maria arrosa

arrosarioa

arrotza

arrotztea

atsecabea atsoa

auantailla

auantaillatcea

auantaillatsua

auantaillatuqui

auaricia

auariciosa (auaricia)

auariciosqui (auaricia)

auarrac

auarrotza

auatza

audiencia

auertimendua

auertitcea (auertimendua)

auertitçaillea (auertimendua)

aubaria

aubenac

auhentcea

auherra

azcuina

azpia

azpiac erabiltea

azpietaric lotcea

gainetic azpira

B (18)

baietz

baka

barura

baruric nago

barurtiarra

barurtcea vrez eta oguiz

bassothea (bassa)

beheititcea

behiaren iaitztea bat

C (16)

çainahoria

ordenaco çalduna (çaldia)

çama

belhar çama

chiminia

chitatcea (chitoa) berega

besta

besta berria

besta egunac

besta eduquitea

besta eguitea

bestaguillea

botatcea

\section{churrua}

cigorra

arçain cigorra

cilhoa (cilhatcea)

cilhochoa (cilhatcea)

cimitxa behatcea 
cinçarrotzac (cinçarria)

cinçurreria (cinçurra) cipertacoa

hari çuntça (çuntça)

D (1)

dauantala

\section{I (3)}

iraquitcea

iraquidura (iraquitcea)

isterra

V (4)

virgula

cearen virgula

vri chehea

vri chehe eguiten du

\section{VII.3. Pouvreauren hiztegian euskal ordainik gabeko Oudin-en hiztegiko sarrerak}

A (21)

«renarde; renardeau; renardiere; renarderie» (acheria) "coup d'ecourgée» (açorria)

«truyette» (açuna)

«branches de cerf; cerf branchu; branches de gard» (adaquiac)

«lauer la brique; briquerie» (adreillua)

«souper de marchand» (afaria)

"parties honteuses» (ahalkatcea)

«donner vn canard a moitié» (ahatea) «beste de bast» (albarda)

«baster vn asne» (albarda)

«acerée» (alceiratcea)

"la petite oye» (ançara)

«faire la rouë» (arroda)

«porter les atabales» (atabala)

«fessée» (azpia)

\section{VII.4. Pouvreauren hiztegian diren Oudin-en errefrauen zerrenda}

— Oudin-en errefrau euskaratuak (48)

$\begin{array}{lc} & \text { A }(5) \\ \begin{array}{l}\text { amora (1) } \\ \text { astoa (2) }\end{array} & \begin{array}{l}\text { atcea (1) } \\ \text { auendoa (1) }\end{array} \\ & \text { B (9) } \\ \text { beguia (1) } & \text { beranta (2) } \\ \text { beharra (1) } & \text { biçarra (1) } \\ \text { behia (1) } \\ \text { bekaitztea (1) } & \text { bidea (1) } \\ \text { bihotza (1) }\end{array}$


caca (1)

capa (1)

ceroni (1)

chiribiria (1)

chirola (1)
C (10)

cilhatcea (1)

çorra (2)

cridac (1)

çuhurcia (1)

D (6)

dembora (1)

deusa (1)

dirua (2)

dixa (2)

\title{
I (15)
}

iaincoa (5)

ibiltcea (1)

idia (1)

iguela (1)

iguerea (1)

\author{
ihardetstea (1) \\ ihicia (1) \\ irina (1) \\ irutea (2) \\ itchura (1)
}

V (3)

vra (2)

vria (1)

— Oudin-en errefrauak gaztelaniaz eta frantsesez (96)

A (41)

abadea (4)

aberatsa (3)

$$
\begin{aligned}
& \text { alharguna (2) } \\
& \text { ama (2) } \\
& \text { amora (1) } \\
& \text { anaya (1) } \\
& \text { apirilla (3) } \\
& \text { astoa (7) } \\
& \text { athorra (1) } \\
& \text { auendoa (1) }
\end{aligned}
$$

aita (1)

B (18)

baba (2)

bahea (1)

barea (1)

beata (1)

balesta (1) 
bekatua (2)

belharra (1)

bermatcea (1)

berria (1)

bihia (1)

cala (1)

capestrua (1)

caritatea (1)

cehazca (1)

chimignua (1)

desdixa (1)

iaincoa (3)

ichilla (3)

içokina (1)

ifernua (1)

iguela (1)

imiquia (1)

vertutea (1)

vrdaina (1)

vria (1) bortha (1)

burfidia (1)

burla (1)

bururdia (1)
C (12)

chiminia (1)

chinhaurria (3)

cicotza (1)

cornadua (1)

çuhurcia (1)

D (2)

dotea (1)

I (16)

iocatcea (1)

iorra (1)

irina (1)

irutea (2)

ixtupa (1)

V (7)

vrka (1)

vstaia (1)

vzta (2) 


\section{VII.5. Nicot edota Oudin-en ordainak A eskuizkribuaren ordenaren arabera} antolatuak

\begin{tabular}{|c|c|c|c|}
\hline $\begin{array}{c}\text { A eskuizkribuko } \\
\text { sarrerak }\end{array}$ & $\begin{array}{l}\text { Nicot-en } \\
\text { sarrerak }\end{array}$ & \begin{tabular}{|c|}
$\begin{array}{c}\text { Nicot-en } \\
\text { or.zenbakia }\end{array}$ \\
\end{tabular} & $\begin{array}{c}\text { Oudin-en } \\
\text { sarrerak }\end{array}$ \\
\hline Abre belharra. foin. (ABREA). & Foin. & 291 & Foin. \\
\hline Adreillua. & Brique. & 92 & Brique. \\
\hline Adreilluz eguina. fait de brique. & Qui est fait de brique. & 92 & \\
\hline AINGURA. ancre de nauire. & Ancre. & 33 & Ancre. \\
\hline AINHARBA, armierma, amaraua. araignée. & Araignée. Araignée et la toile de l'araignée. & 41 & Araignée. \\
\hline AISEA. aisé. facile. & Aisé. & 24 & Aisé. \\
\hline Aisequi. aisement. a l'aise. & Aiséement. & 25 & Aiséement. \\
\hline Aisetasuna. & Aise. & 24 & Aise. \\
\hline Aisetcea. & & & [Aiser]. \\
\hline \begin{tabular}{|l|} 
AITÇAQUIA, atchaquia. excuse. pretexte. \\
\end{tabular} & Pretexte. & 509 & Pretexte. \\
\hline AITHORRA. aueu. confession. & Adueu. & 16 & Aueu. \\
\hline \begin{tabular}{|l|} 
Aithortcea. auoüer. \\
\end{tabular} & Aduoüer. & 18 & Auoüer. \\
\hline \begin{tabular}{|l|} 
AKıLLOA. aiguillé de bouuier. \\
\end{tabular} & Aiguille. & 23 & Aiguille. \\
\hline \begin{tabular}{|l|} 
ALABA. fille. (Voltoire) \\
\end{tabular} & Fille. & 287 & Fille. \\
\hline Alababitchia. filleule. & Filleul. & 287 & Filleule. \\
\hline Alabaiçuna. fillastre. & Filiastre. & 287 & Fillastre. \\
\hline Alabatcea. loüer. & Louer. & 380 & Loüer. \\
\hline Alanbantça. e. louange. & Louange. & 381 & Loüange. \\
\hline ALBA, argui alba. l'aube du jour. & Aube. L'aube et le poinct du jour. & 57 & L'aube. \\
\hline Alentatcea. euenter. & Esuenter. & 267 & Esuenter. \\
\hline \begin{tabular}{|l} 
AlHARGUNA. veuf ou veufue. \\
\end{tabular} & Vefue. & 652 & Veuf. veufue \\
\hline Alharguntasuna. veuuage. & Vefuage. & 652 & Veufuage. \\
\hline ALLARMA. allarme. & Alarme. & 25 & Alarme. \\
\hline ALLEGATCEA. alleguer. & Alleguer. & 26 & Alleguer. \\
\hline ALLEGUERA. allegre. rejouy. plaisant. & & & Allegre. \\
\hline $\begin{array}{l}\text { ALOCACERA. mercenaire. homme de } \\
\text { journée. loüager. }\end{array}$ & Louagier & 380 & Loüagier. \\
\hline \begin{tabular}{|l|} 
Alocaïrua. loüage. prix. salaire. \\
\end{tabular} & Louage & 380 & Loüage. \\
\hline Alocaïruan hartcea. prendre a loüage. & Louer maison, c'est et bailler et prendre à louage. & 380 & Prendre à loüage \\
\hline ALtCHAGARRIA, lemamia. leuain. & Leuain. & 372 & Leuain. \\
\hline Altza. alnus. aune. saule. & Aulne, Alnus. & 59 & Aulne. \\
\hline Altzua. aunaye. saussaye. & Aulnage. Aulnaye. & 59 & Aulnaye. \\
\hline AMARRA. lien. garrot. & Lien. & 374 & Lien. \\
\hline Amarratcea. lier. garroter. (Voltoire) & Lier. & 374 & Lier. \\
\hline Amarradura. & [Liement]. & 375 & [Liement]. \\
\hline
\end{tabular}




\begin{tabular}{|c|c|c|c|}
\hline $\begin{array}{c}\text { A eskuizkribuko } \\
\text { sarrerak }\end{array}$ & $\begin{array}{c}\text { Nicot-en } \\
\text { sarrerak }\end{array}$ & $\begin{array}{c}\text { Nicot-en } \\
\text { or.zenbakia }\end{array}$ & $\begin{array}{c}\text { Oudin-en } \\
\text { sarrerak }\end{array}$ \\
\hline AMOLSUA. aimable. courtois. & Aimable. & 23 & Aimable. \\
\hline AMONTCEA, amuntcea. appriuoiser. & Appriuoiser. & 39 & Appriuoiser. \\
\hline AnÇARA. Oye. (Voltoire) & Oye & 452 & Oye \\
\hline Ançaracumea. oison & Oison. Est une jeune oye. Anserculus & 441 & Oison \\
\hline ANDA. litiere. & Lictiere. & 374 & Lictiere. \\
\hline Andaçaina. & Qui ai doit à porter la lictiere. & 374 & \\
\hline ANDOILLA. andouille. & Andouille. & 33 & Andoüilles. \\
\hline ANDREA. dame. maitresse. & Dame. Dame ou maistresse. & 173 & Dame. \\
\hline Andrecaria. addonné aux femmes. & Femme. Qui est trop addonné aux femmes. & 282 & \\
\hline ANGUEREDERRA. belette. & Belette. & 74 & Belette. \\
\hline ANGUERUA. ange. & Ange. & 34 & Ange. \\
\hline Angueruzcoa. angelique. & & & Angelique. \\
\hline ANimALIA. animal. & Animal. & 34 & Animal. \\
\hline ANIMOA. courage. & Courage. & 157 & Courage. \\
\hline Animotsua. courageux. & Courageux. & 158 & Courageux. \\
\hline AnsIA, artha, coaita. soin. soucy. & Soing. & 597 & Soing. \\
\hline Ansiatcea. & [Soigner]. & 598 & [Soigner]. \\
\hline Ansiatsua. soigneux. soucieux. & Soigneux. & 598 & Soigneux. \\
\hline ANTAPARRAC. ecluses. chaussees. & Chausse. & 118 & Chausse. \\
\hline AnTCEA. industrie. adresse. & Industrie. & 350 & Industrie. \\
\hline Antçatsua. industrieux. & Industrieux. & 350 & Industrieux. \\
\hline ANTCHOA. sorte de poisson. & Anchoye. Est vne espece de poisson [...] & 33 & Anchoie. \\
\hline ANTOLATCEA. accomoder. rabiller. & Rabiller. & 533 & Rabiller \\
\hline Antolatçaillea, antolaria. rabilleur. & Rabilleur. & 533 & Rabilleur \\
\hline $\begin{array}{l}\text { ApalardotZa, achiruina. cheuille du } \\
\text { pied. }\end{array}$ & Cheuille. Les cheuilles des pieds. & 122 & $\begin{array}{l}\text { Cheuilles des } \\
\text { pieds. }\end{array}$ \\
\hline ApIOA. ache, herbe. & $\begin{array}{l}\text { Ache. Tantost signifie vne herbe que les La- } \\
\text { tins apellent Apium }\end{array}$ & 11 & Ache, herbe. \\
\hline AровеLAтZA. O. butor, oyseau. cresserele. & Butor. Butor, Oiseau. & 95 & Butor. \\
\hline APPURRA. petit. peu. & Peu. & 478 & Peu. \\
\hline Appurca. peu a peu. & Peu à peu. & 478 & Peu à peu. \\
\hline ARANA. prune. (Voltoire) & Prune. & 524 & Prune. \\
\hline Aranondoa. prunier. & Prunier. & 524 & Prunier. \\
\hline $\begin{array}{l}\text { Aranadia, arandeguia. lieu planté de pru- } \\
\text { niers. }\end{array}$ & & & $\begin{array}{l}\text { Prunaye. lugar } \\
\text { de ciruelos. }\end{array}$ \\
\hline ARANCEA. epine. le piqueron. & Espine. & 258 & Espine. \\
\hline ARARTECOA. entremetteur. mediateur. & Entremetteur. Vn entremetteur et moyenneur. & 239 & Entremetteur. \\
\hline Ararteco iartcea. interceder. s'entremettre. & Entremettre. S'entremettre. & 239 & S'entremettre. \\
\hline
\end{tabular}




\begin{tabular}{|c|c|c|c|}
\hline $\begin{array}{c}\text { A eskuizkribuko } \\
\text { sarrerak }\end{array}$ & $\begin{array}{l}\text { Nicot-en } \\
\text { sarrerak }\end{array}$ & \begin{tabular}{|c|} 
Nicot-en \\
or.zenbakia
\end{tabular} & $\begin{array}{c}\text { Oudin-en } \\
\text { sarrerak }\end{array}$ \\
\hline ARATZA. net. nitidus. & Net. Net, Nitidus. & 429 & Net. \\
\hline Aratztasuna. netteté. & Netteté. & 429 & Netteté. \\
\hline Aratzqui. nettement. & Nettement. & 429 & Nettement. \\
\hline ARAUA. proportion. & Proportion. & 520 & Proportion. \\
\hline Araueratcea. proportionner. & Proportioner. & 520 & Proportionner. \\
\hline ARBUYUA, arbuïoa. mepris. rebut. & Mespris. & 406 & Mespris. \\
\hline Arbuyamendua. l'action du mepris. & Mesprisement. & 406 & Mesprisement. \\
\hline Arbuyatcea. mepriser. rebuter. & Mespriser. & 406 & Mespriser. \\
\hline Arbuyatçaillea. & [Mespriseur] & 406 & [Mespriseur] \\
\hline ARCHIPOTEA. etourneau. & Estourneau. & 265 & Estourneau. \\
\hline ARDIA. brebis. & Brebis. & 90 & Brebis. \\
\hline Ardianchua, ardiantcha. brebis d'vn an. & & & Brebis d'vn an. \\
\hline Artaldea. troupeau de brebis. & Brebis. Troupeau de brebis. & 90 & \\
\hline Arteguia. ouile. bergeriè. & Brebis. Estable à brebis, Ouile. & 90 & \\
\hline ARDITA. liard. & Liard. & 373 & Liard. \\
\hline Aretzea. veau. & Veau. & 652 & Veau. \\
\hline ARGALA. maigre. & Maigre. & 385 & Maigre. \\
\hline Lur argala. terre maigre. & Maigre. Terre maigre. & 385 & \\
\hline Argaldura. & [Maigreur]. & 385 & [Maigreur]. \\
\hline Argaltasuna. & [Maigreté]. & 385 & \\
\hline ARGIBOA. bossu. courbé. & Bossu & 84 & Bossu. \\
\hline ARHEA. herse. occa. & Herce, Occa. & 333 & Herse. \\
\hline Arheatcea, arhatcea e. herser. occare. & Hercer, Occare. & 333 & Herser \\
\hline Arhatçaillea e. occator. & Herceur. Occator. & 333 & Herseur \\
\hline ARIMA. ame. & Ame. & 30 & Ame. \\
\hline ARINA. leger. & Legier. & 370 & Leger. \\
\hline Arinqui. legerement. & Legierement. & 370 & Legerement \\
\hline Arintasuna. legereté. gaillardise. & Legiereté. & 370 & Legereté \\
\hline ARMENDOLA. amende. fruit. & Amande. & 29 & Amande \\
\hline Armendol-ondoa, armendolatcea. amandier & Amandier. & 29 & Amandier. \\
\hline Armendoladia. lieu planté d'amendiers. & & & Amendaye. \\
\hline ARNEGATCEA. renier. & Renier. & 556 & Renier. \\
\hline Arnegaria, arnegatçaillea. renieur. & Renieur. & 556 & Renieur. \\
\hline Arnegua. reniement. & Reniement. & 556 & Reniement. \\
\hline AROA, sasoina. saison. & Saison. & 579 & Saison. \\
\hline ARRABA, abiroina. auiron. (Voltoire) & Auiron. & 59 & Auiron. \\
\hline Arrauquetan haritcea. tirer a l'auiron. & Tirer à l'auiron. & 59 & Tirer à l'auiron. \\
\hline ARrABOtA. rabot. & Rabot. & 533 & Rabot. \\
\hline
\end{tabular}




\begin{tabular}{|c|c|c|c|}
\hline $\begin{array}{l}\text { A eskuizkribuko } \\
\text { sarrerak }\end{array}$ & $\begin{array}{c}\text { Nicot-en } \\
\text { sarrerak }\end{array}$ & $\begin{array}{c}\text { Nicot-en } \\
\text { or.zenbakia }\end{array}$ & $\begin{array}{c}\text { Oudin-en } \\
\text { sarrerak }\end{array}$ \\
\hline ARRAÇATCEA. raser. & Raser. & 539 & Raser. \\
\hline ARRAÇOINA. raison. (Voltoire) & Raison. & 535 & Raison. \\
\hline Arraçoinamendua. raisonnement. & Raisonnement. & 536 & Raisonnement. \\
\hline Arraçoinezcoa. raisonnable. & Raisonnable. & 536 & Raisonable. \\
\hline ARRAILLATCEA. fendre. & Fendre. & 283 & Fendre. \\
\hline Arrailladura. fente. & Fente. & 283 & Fente. \\
\hline ARRAYA. gay. joyeux. & Gay. Gay et joyeux. & 312 & Gay. \\
\hline Arraytasuna. gayeté. & Gayeté. & 312 & Gayeté. \\
\hline Arraïqui. gayement. joyeusement. & Gayement. Gayement et joyeusement. & 312 & Gayement. \\
\hline ARRAMBERRITCEA. renouueler. & Renouueler. & 557 & Renouueller. \\
\hline ARRAMUA. rameau. & Rameau. & 537 & Rameau. \\
\hline $\begin{array}{l}\text { Arramu Igandea. Le dimanche des ra- } \\
\text { meaux. }\end{array}$ & & & $\begin{array}{l}\text { Jour des Ra- } \\
\text { meaux, Domingo } \\
\text { de Ramos. } \\
\end{array}$ \\
\hline ARRANOA. aigle. & Aigle. & 22 & Aigle. \\
\hline Arranocumea. aiglon. & & & $\begin{array}{l}\text { Aigleron ou ai- } \\
\text { glon. }\end{array}$ \\
\hline ARRAPATCEA. rauir. emporter par force. & Rauir. Rauir et emporter le bien d'autruy. & 539 & Rauir. \\
\hline Arrapaceria. & [Rauissement]. & 540 & [Rauissement]. \\
\hline Arraparia. & [Rauisseur]. & 540 & [Rauisseur]. \\
\hline ARRAPOA, habuina. ecume. (Voltoire) & Escume. & 250 & Escume. \\
\hline Arrapoa eltceari edequitea. ecumer le pot. & Escumer [...] comme escumer le pot. & 250 & \\
\hline ARRASTA edo arresta. arrest. & Arrest. & 46 & Arrest. \\
\hline ARRASTELUA. rasteau. & Rasteau. & 539 & \\
\hline Arrastuan. enuiron. circum circa. (ARRASTUA) & Enuiron. Tout à l'enuiron, Circumcirca. & 242 & Enuiron. \\
\hline ARRATSA. le soir. & Soir. le soir. & 596 & Soir. \\
\hline Arratsean. au soir. & Soir. Au soir. & 596 & \\
\hline Arratsaldea. soirée. & Soirée. & 596 & Soirée. \\
\hline ARRAULtCEA. oeuf. & Oeuf. & 439 & Oeuf. \\
\hline ARRAUTZA. forgeron. marechal. & Forgeron. & 294 & Forgeron. \\
\hline ARRAYOA. rayon. & Rayons. & 540 & Rayon. \\
\hline $\begin{array}{l}\text { ARREGA. maramoa. marruuia. marruuiüa. } \\
\text { fraise. fragum. }\end{array}$ & Fraise, Fragum. & 299 & Fraise. \\
\hline ARRENCURA. plainte. & Plainte. & 485 & Plainte. \\
\hline Arrencuratcea. se plaindre. & Se plaindre ou complaindre. & 485 & Se plaindre. \\
\hline Arrencuratia. plaintif. qui se plaint toujours. & Plainte ou plaintif. & 485 & Plaintif. \\
\hline ARROGACERIA. volerie. pillerie. rapine. & Volerie & 667 & Volerie. \\
\hline Arrogaria, arrogatçaillea. voleur, pilleur. & Voleur. & 667 & Voleur. \\
\hline
\end{tabular}




\begin{tabular}{|c|c|c|c|}
\hline $\begin{array}{l}\text { A eskuizkribuko } \\
\text { sarrerak }\end{array}$ & $\begin{array}{c}\text { Nicot-en } \\
\text { sarrerak }\end{array}$ & \begin{tabular}{|c|} 
Nicot-en \\
or.zenbakia
\end{tabular} & $\begin{array}{c}\text { Oudin-en } \\
\text { sarrerak }\end{array}$ \\
\hline Arrogatcea. voler. piller. & Voler. & 667 & Voler. \\
\hline ARRUTA. route. & Route. & 575 & Route. \\
\hline ARTHA, ansia, achola. soin. soucy. & Soing. & 597 & Soing. \\
\hline Arthatsua. soigneux & Soigneux. & 597 & Soigneux. \\
\hline ARTHEÇA. droit. & Droict. & 215 & Droict. \\
\hline ARTICULUA. article. & Article. & 48 & Article. \\
\hline Articulatcea. articuler. & Articuler. & 48 & Articuler. \\
\hline ARTINA belharra. plant[a]in. & Plantain. & 487 & Plantain. \\
\hline ArTORIA. O. aube du iour. & Aube. L'Aube et poinct du iour. & 57 & $\begin{array}{l}\text { l'Aube. alua del } \\
\text { dia. }\end{array}$ \\
\hline $\begin{array}{l}\text { AsALDATCEA. fascher. irriter. detourner. } \\
\text { importuner. }\end{array}$ & Fascher. & 279 & Fascher. \\
\hline Asaldua. fascherie. & Fascherie. & 279 & Fascherie. \\
\hline AsCA, makina, ortera. auge. & Auge. & 58 & Auge. \\
\hline AsEA. saoul. remply. & Saoul. & 581 & Saoul. \\
\hline Asetcea. saouler. remplir. (Voltoire) & Saouler. & 581 & Saouler. \\
\hline $\begin{array}{l}\text { AsNaUR eguitea. O. ruminer comme font } \\
\text { les bestes. }\end{array}$ & $\begin{array}{l}\text { Ruminer. Ruminer comme quand les bestes re- } \\
\text { maschent ce qu'elles ont ja mangé. }\end{array}$ & 576 & Ruminer. \\
\hline AsPREA. aspre. aigre. & Aspre. & 49 & Aspre. \\
\hline Aspretasuna. âpreté. & Aspreté. & 49 & Aspreté. \\
\hline Aspretcea. rendre ou deuenir âpre & Aspre. Deuenir aspre par succession du temp. & 49 & \\
\hline Asprequi. âprement & Asprement. & 49 & Asprement. \\
\hline AssautA. assaut. & Assaut. & 49 & Assaut. \\
\hline AssuCREA. sucre. & Succre. & 609 & Sucre. \\
\hline Assucreztatcea. sucrer. & & & Sucrer. \\
\hline AstalCatcea. deuider du fil. & Deuider. Deuider du fil par pelotons. & 203 & Deuider. \\
\hline Astalcayac. deuidet. trauoil. & Deuidet. & 203 & Deuidet. \\
\hline Astalcoa. echeueau de fil. & Escheueau. Escheueau de fil. & 246 & \\
\hline AstoA. asne. (Voltoire) & Asne. & 49 & Asne. \\
\hline Astocumea. asnon ou asnine. & Asnon. & 49 & Asnon. \\
\hline Astoqueria. asnerie. & & & Asnerie. \\
\hline ATÇARTCEA. eueiller. exciter. & Exciter. Exciter id est Eueiller. & 269 & Exciter. \\
\hline Atçartçaillea. excitateur. & & & Excitateur. \\
\hline Atçarmendua. excitation. & Excitation. & 269 & Excitation. \\
\hline ATCHETERA, midicua, dotora. medecin. & Medecin. & 399 & Medecin. \\
\hline ATHEA, bortha. porte. (Voltoire) & Porte. & 495 & Porte. \\
\hline Athalçaina. portier. & Portier. & 495 & Portier. \\
\hline Атнека. bréche. & Breche. & 90 & Breche. \\
\hline
\end{tabular}




\begin{tabular}{|c|c|c|c|}
\hline $\begin{array}{l}\text { A eskuizkribuko } \\
\text { sarrerak }\end{array}$ & $\begin{array}{l}\text { Nicot-en } \\
\text { sarrerak }\end{array}$ & $\begin{array}{c}\text { Nicot-en } \\
\text { or.zenbakia }\end{array}$ & $\begin{array}{l}\text { Oudin-en } \\
\text { sarrerak }\end{array}$ \\
\hline $\begin{array}{l}\text { Bere ohoreari atheka eguin dio. Il a fait } \\
\text { bréche a son honneur. }\end{array}$ & & & $\begin{array}{l}\text { faire Breche à } \\
\text { son honneur. }\end{array}$ \\
\hline ATRAPATCEA. attraper. & Attraper. & 55 & Attraper. \\
\hline $\begin{array}{l}\text { Atseguina. plaisir. delice. contente- } \\
\text { ment. }\end{array}$ & Plaisir. & 486 & Plaisir. \\
\hline Atseguintsua. & [Plaisant]. & 486 & [Plaisant]. \\
\hline Atseguintasuna. & [Plaisanteries]. & 486 & [Plaisanterie]. \\
\hline AuIsuA. auis. conseil. & Aduis. & 16 & Aduis. \\
\hline Auisatcea. auiser. conseiller. & Aduiser. & 16 & Aduiser. \\
\hline $\begin{array}{l}\text { Auisatçaillea, auisu emaillea. qui donne } \\
\text { auis. }\end{array}$ & & & $\begin{array}{l}\text { Donneur d'a- } \\
\text { duis. }\end{array}$ \\
\hline $\begin{array}{l}\text { AumoIna, limosna, erremusina. aumône. } \\
\text { (Voltoire) }\end{array}$ & Aumosne. & 59 & Aumosne. \\
\hline $\begin{array}{l}\text { Aumoinera, limosnaria, erremusinaria, } \\
\text { aumônier. }\end{array}$ & Aumosnier. & 59 & Aumosnier. \\
\hline AUOCATA. auocat. & Aduocat. & 17 & Aduocat. \\
\hline Auocatalgoa. office $\&$ exercise d'auocat. & & & Aduocasserie. \\
\hline AuSARTA. hardy. & Hardi & 329 & Hardi. \\
\hline $\begin{array}{l}\text { Ausartcea. prendre, donner hardiesse. } \\
\text { s'enhardir. }\end{array}$ & Hardiesse. Donner hardiesse et asseurance. & 330 & \\
\hline Ausartcia. hardiesse. & Hardiesse. & 330 & Hardiesse. \\
\hline AusiQUia. morsure. & Morsure. & 418 & Morsure. \\
\hline Ausiquitcea. mordre. (Voltoire) & Mordre. & 418 & Mordre. \\
\hline Autemaitea. a. visiter. & Visiter. & 664 & Visiter. \\
\hline Autemaillea. qui visite. & Visiteurs. & 664 & Visiteur. \\
\hline AXTIGARRA. erable, arbre. & Erable. & 243 & Erable. \\
\hline AzPILTCEA. orler. & Orler. & 447 & Orler. \\
\hline Azpilçuna. orlet. & Orlet. & 447 & Orlet. \\
\hline Azpildura. orlure. & Orlure. & 447 & Orlure. \\
\hline Azpila O. cormier. & Cormier. & 151 & Cormier. \\
\hline AzTEA, haztea. nourrir. (Voltoire) & Nourrir. & 433 & Nourrir. \\
\hline Az aita. pere nourricier. & Nourrissier. & 433 & Nourrisier. \\
\hline Az ama. mere nourrice. & Nourrise. & 433 & Nourrise. \\
\hline Azcuntça. nourriture. & Nourriture. & 433 & Nourriture. \\
\hline Azmendua. nourriture. & Nourrissement. & 434 & Nourrissement. \\
\hline AzTiA. deuin. & Deuin. & 203 & Deuin. \\
\hline $\begin{array}{l}\text { Aztietan edo aztiketan dabilla. il va aux } \\
\text { deuins. }\end{array}$ & $\begin{array}{l}\text { Deuin. Aller aux deuin, et luy compter son af- } \\
\text { faire, et demand conseil. }\end{array}$ & 203 & \\
\hline BABA, ekosaria. feuue. & Febue. & 282 & Feue. \\
\hline
\end{tabular}




\begin{tabular}{|c|c|c|c|}
\hline $\begin{array}{l}\text { A eskuizkribuko } \\
\text { sarrerak }\end{array}$ & $\begin{array}{c}\text { Nicot-en } \\
\text { sarrerak }\end{array}$ & $\begin{array}{c}\text { Nicot-en } \\
\text { or.zenbakia }\end{array}$ & $\begin{array}{l}\text { Oudin-en } \\
\text { sarrerak }\end{array}$ \\
\hline Baba leka. gosse de feuue. & Febue. L'escosse d'vne febue. & 282 & $\begin{array}{l}\text { Gosse. hollejo } \\
\text { de haua. }\end{array}$ \\
\hline $\begin{array}{l}\text { BABAÇUÇA, arrabarra, chichera, chicherra } \\
\text { Liz. gresle. grando }\end{array}$ & Gresle. La Gresle. Grando. & 321 & Gresle. \\
\hline BABILLERA. meche de lampe. & Meiche. & 400 & Meche. \\
\hline BACHATCEA. mettre bas. abbaisser. auilir. & Abbaisser. & 2 & Abbaisser. \\
\hline Bachoa. bas. & Bas ou bassement. & 69 & Bassement. \\
\hline Bachotasuna. bassesse. & Bassese. & 70 & Bassese. \\
\hline BAHEA. sas. tamis. crible. van. & Sas. & 581 & Sas. \\
\hline Bahatcea. sasser. tamiser. cribler. vanner. & Sasser. & 581 & Sasser. \\
\hline BAHIA. gage. saisi. & Gage. & 306 & Gage. \\
\hline $\begin{array}{l}\text { Bahitcea. engager. saisir. mettre a } \\
\text { l'amende. }\end{array}$ & Engager. & 230 & Engager. \\
\hline Bahimendua. engagement. saisie. & Engagement. & 230 & Engagement. \\
\hline BAICEN. sinon. postponitur. & Sinon. & 596 & Sinon. \\
\hline Ni baicen. sinon moy. & & & $\begin{array}{l}\text { Sinon moy, que } \\
\text { moy. }\end{array}$ \\
\hline BAILLIA. baillif. & Bailli. & 64 & Bailli. \\
\hline $\begin{array}{l}\text { Bailliatasuna. charge, office de baillif, bai- } \\
\text { lliage. }\end{array}$ & Baillage, office de Bayle. & 65 & Baillage. \\
\hline $\begin{array}{l}\text { BaINo. est vne particule qui e[s]pliq[ue] } \\
\text { la que du comparatif. }\end{array}$ & Plus. Magis. & 490 & Plus. \\
\hline BALACATCEA. mignarder. flatter. amignoter. & Mignarder. & 411 & Mignarder. \\
\hline Balacatçaillea. & & & [Mignardeur]. \\
\hline Balacua. mignardise. & Mignardise. & 411 & Mignardise. \\
\hline BALENÇA. balance. & Balance. & 65 & Balance. \\
\hline BALESTA. arbaleste. (Voltoire) & Arbaleste. & 41 & Arbaleste. \\
\hline Balestaria. arbalestrier. & Arbalestrier. & 41 & $\begin{array}{l}\text { Arbalestier, ar- } \\
\text { balestrier. }\end{array}$ \\
\hline BALSAMUA. baume. & Bausme. & 73 & Baulme. \\
\hline BANDATCEA. bander quelque chose. & Bander. & 66 & Bander. \\
\hline BANDERA. baniere. etandart. & Baniere. & 66 & Banniere. \\
\hline Banderiça. bande, ligue. & Bande. Vne bande et ligue. & 66 & Bande, ligue. \\
\hline BANDULERA, mandulera. bandoulier. & & & $\begin{array}{l}\text { Bandolier, ban- } \\
\text { doulier. }\end{array}$ \\
\hline BANQUETA. banquet. & Banquet. & 67 & Banquet. \\
\hline Banquetatcea. banqueter. & Banqueter. & 67 & Banqueter. \\
\hline Banquecia, bonbacia. banqueterie. & Banqueterie. & 67 & \\
\hline BAQUEA. paix. & Paix. & 453 & Paix. \\
\hline
\end{tabular}




\begin{tabular}{|c|c|c|c|}
\hline $\begin{array}{l}\text { A eskuizkribuko } \\
\text { sarrerak }\end{array}$ & $\begin{array}{c}\text { Nicot-en } \\
\text { sarrerak }\end{array}$ & $\begin{array}{c}\text { Nicot-en } \\
\text { or.zenbakia }\end{array}$ & $\begin{array}{c}\text { Oudin-en } \\
\text { sarrerak }\end{array}$ \\
\hline Baquetcea. mettre la paix. & Paix. Mettre paix. & 453 & Mettre en paix. \\
\hline Baquetiarra. qui aime la paix. pacifique. & Paix. Qui aime paix. & 454 & \\
\hline Baquetsua, baquezcoa. paisible. & Paisible. & 454 & Paisible. \\
\hline BARA. O. berga. aune. & Aulne. & 59 & Aulne à mesurer. \\
\hline BARATZEA. iardin. (Voltoire) & Iardin. & 343 & Iardin. \\
\hline Baratzeçaina. & Iardinier. & 344 & Iardinier. \\
\hline BARAZCALTCEA. disner. & Disner. & 208 & Disner. \\
\hline Barazcaria. le disné. & & & Disné. \\
\hline BAREA. la ratte. & Rate. La Rate. & 539 & Rate. \\
\hline BARKA, barkua. barque. & Barque. & 69 & Barque. \\
\hline BARKATCEA. pardonner. (Voltoire) & Pardonner. & 457 & Pardonner. \\
\hline Barka diaçadaçu. pardonnez moy. & Pardonner. Pardonne moy cette faut. & 457 & \\
\hline Barkacinoa, barkamendua. pardon. & Pardon. & 457 & Pardon. \\
\hline Barkaquiçuna. digne de pardon. & Pardonnable. & 457 & Pardonnable. \\
\hline BARRAYATCEA. publier. diuulguer. dissiper. & Dissiper. & 208 & Dissiper. \\
\hline $\begin{array}{l}\text { Barrayaria, barreïaria, barrayatçaillea. dis- } \\
\text { sipateur. }\end{array}$ & Dissipateur. & 209 & Dissipateur. \\
\hline BARRENA. dedans. & Dedans. & 179 & Dedans. \\
\hline Barrentcea. mettre dedans. & Mettre. Mettre dedans. & 408 & \\
\hline Bassastoa. asne sauuage. (BASSA) & Vn asne sauuage. & 49 & Asne sauuage. \\
\hline Basoillarra. faisan. & Faisan. & 277 & Faisan. \\
\hline Bassoilloa. faisane. & & & Faisanne. \\
\hline Basoillazcoa. faisandeau. & Faisanneaux. & 277 & Faisandeau. \\
\hline Bassothea. O., orria. genieure. juniperus. & Geneure. Juniperus. & 313 & Geneure. \\
\hline Bassurdea. porc sanglier. aper. (Voltoire) & Porc. Porc sanglier, Aper apris. & 494 & Porc sanglier. \\
\hline BASTA, arbalda. bast. & Bast. & 70 & Bast. \\
\hline Bastatcea. baster. & Baster. & 70 & Baster vn asne. \\
\hline $\begin{array}{l}\text { BASTARTA, borth, haur ixila, bertceren } \\
\text { vmea. bastard. }\end{array}$ & Bastard. & 70 & Bastard. \\
\hline BATAYOA. bateme. & Baptesme. & 67 & Baptesme. \\
\hline Batayatcea. batiser. & Baptizer. & 67 & Baptiser. \\
\hline $\begin{array}{l}\text { Batayaharria, batayaherria. fons baptis- } \\
\text { maux. }\end{array}$ & Baptizer. Les fons à baptizer. & 67 & \\
\hline BATELA. bateau. & Bateau. & 71 & Bateau. \\
\hline BAZCA. pasture. & Pasture. & 468 & Pasture. \\
\hline Bazcatcea. paistre. & Paistre. & 453 & Paistre. \\
\hline BEBERINA. sariette. & Sarriette. & 581 & Sarriette. \\
\hline BeCOA. bec. & Bec. & 74 & Bec. \\
\hline
\end{tabular}




\begin{tabular}{|c|c|c|c|}
\hline $\begin{array}{l}\text { A eskuizkribuko } \\
\text { sarrerak }\end{array}$ & $\begin{array}{c}\text { Nicot-en } \\
\text { sarrerak }\end{array}$ & $\begin{array}{c}\text { Nicot-en } \\
\text { or.zenbakia }\end{array}$ & $\begin{array}{l}\text { Oudin-en } \\
\text { sarrerak }\end{array}$ \\
\hline Becoquigabea. effronte. (BECOQUiA) & Effronté. & 220 & Effronté. \\
\hline $\begin{array}{l}\text { Becoquigabetasuna, becoquigaberia. ef- } \\
\text { fronterie. }\end{array}$ & & & Effronterie. \\
\hline Becoquigabequi. effrontement. & Effrontéement. & 220 & Effrontement. \\
\hline BEDERATCI. neuf. & Neuf. & 429 & Neuf. \\
\hline Bederatcigarrena. neufiéme. & Neufiesme. & 429 & Neufiesme. \\
\hline Bederatci vrruna. neufaine. & Neufaine. & 429 & Neufuaine. \\
\hline Bederatcitan. neuf fois. & Neuf. Neuf fois. & 429 & \\
\hline $\begin{array}{l}\text { Beguiztatcea. ietter des oeillades. mugueter } \\
\text { des yeux. ensorceler. (BEGUIA) }\end{array}$ & Oeillades. Oeillades, id est, jetter des oeillades. & 439 & \\
\hline BEgUitARTEA. visage. accueil. carresse. & Visage. & 663 & Visage. \\
\hline $\begin{array}{l}\text { Beguitarte eguitea. faire beau visage, bon } \\
\text { accueil. carresser. }\end{array}$ & Visage. Faire bon visage. & 663 & \\
\hline BeHACuna. e. spectacle. & Spectacle. & 607 & Spectacle. \\
\hline BeHAÇUnA, mina, guibel mina Liz. fiel. & Fiel. & 286 & Fiel. \\
\hline BEIRA. verre. & Verre. & 657 & Verre. \\
\hline Beiraquia. verre. verrerie. & & & Verrerie. \\
\hline $\begin{array}{l}\text { BEKAITZTEA. regarder de mauuais oeil. } \\
\text { enuier. estre jaloux. }\end{array}$ & & & Envier. \\
\hline Bekaitztia. enuieux. jaloux. & Enuieux. & 242 & Enuieux. \\
\hline $\begin{array}{l}\text { Bekaitzcoa, beltçuria. enuie. ialousie. } \\
\text { mauuais regard. }\end{array}$ & Enuie. & 241 & Enuie. \\
\hline BEKATUA. peché. & Peché. & 469 & Peché. \\
\hline Bekatorea. pecheur. & Pecheur. & 469 & Pecheur. \\
\hline Bekatorezza. pecheresse. & Pecheresse. & 469 & Pecheresse. \\
\hline Bekatu eguitea. & Pecher. & 469 & Pecher. \\
\hline BELA. voile. & Voile. & 666 & Voile de nauir. \\
\hline BeLACHTEA. neud coulant. & & & Neud courant. \\
\hline BELARRA. front. & Front. & 303 & Front. \\
\hline BELDURRA. crainte. craintif. (Voltoire) & Crainte. & 164 & Crainte. \\
\hline Beldur içaitea. & Craindre. & 163 & Craindre. \\
\hline Beldurrez. de crainte. par crainte. & Craintiuement. & 164 & Craintiuement. \\
\hline Beldurtia. craintif. & Craintif. & 164 & Craintif. \\
\hline Belecumeac. cornillaux. (BELEA) & & & Cornillat. \\
\hline BELHAQUiA, ogaça. gasteau. & Gasteau. & 311 & Gasteau. \\
\hline Belharra. herbe. & Herbe. & 333 & Herbe. \\
\hline Erle belharra. thym. & Thym. & 629 & Thim. \\
\hline Belhartcea, belhastea. printemps. & Printemps. & 511 & Printemps. \\
\hline
\end{tabular}




\begin{tabular}{|c|c|c|c|}
\hline $\begin{array}{l}\text { A eskuizkribuko } \\
\text { sarrerak }\end{array}$ & $\begin{array}{c}\text { Nicot-en } \\
\text { sarrerak }\end{array}$ & $\begin{array}{c}\text { Nicot-en } \\
\text { or.zenbakia }\end{array}$ & $\begin{array}{c}\text { Oudin-en } \\
\text { sarrerak }\end{array}$ \\
\hline BeLOSA. velours. & Veloux. & 652 & $\begin{array}{l}\text { Velours, vee ve- } \\
\text { loux. }\end{array}$ \\
\hline Beltza. noir. (Voltoire) & Noir. & 430 & Noir. \\
\hline Beltztasuna, beltztura. noirceur. & Noircisseur ou noirceur. & 431 & Noircisseur. \\
\hline Beltztea. noircir. & Noircir. & 430 & Noircir. \\
\hline Benedicatcea. benir. & Benir. & 75 & Benir. \\
\hline BENEDICIONEA, benedicinoa. benediction. & Benediction. & 74 & Bendiction. \\
\hline BERA. tendre. mol. & Mol. & 415 & Mol. \\
\hline $\begin{array}{l}\text { Beratcea. amollir. rendre souple. tremper. } \\
\text { mouiller. }\end{array}$ & Mollir. & 415 & Mollir. \\
\hline $\begin{array}{l}\text { BERATURIA. vrille. instrum[ent] de me- } \\
\text { nuisier. }\end{array}$ & & & Vrille. \\
\hline BERDINA. egal. & Egual. & 221 & Egal. \\
\hline Berdinqui. egalement. & Egualement. & 221 & Egalement. \\
\hline Berdintcea. egaler. & Egualer. & 221 & Egaler. \\
\hline BERDOGALA. pourpier. & Pourpier. & 501 & Pourpier. \\
\hline BEREHALA. bertan. incontinent. & Incontinent. & 349 & \\
\hline BEREZTEA, berecitcea. separer. distinguer. & Separer. & 590 & Separer. \\
\hline Elkar ganic bereztea. separer l'vn de l'autre. & Separer. Separer l'vn auec dé l'autre. & 590 & \\
\hline Berecia. separé. distingué. & Separer. Separé. & 591 & \\
\hline BERMATCEA. cautionner. pleger. & & & Cautionner. \\
\hline Bermea. plege. caution. & Caution. Vn pleige et caution. & 104 & \\
\hline BEROA. chaud. chaleur. & Chaud. & 118 & Chaud. \\
\hline Bero hari da. il fait chaud. & Chaud. Il fait chaud. & 118 & \\
\hline Berotasuna. chaleur. & Chaleur. & 109 & Chaleur. \\
\hline Berotcea. chauffer. echauffer. & Chauffer. & 109 & Chauffer. \\
\hline Beroqui. chaudement. & Chaudement. & 118 & Chaudement. \\
\hline Berreguindura. (BERREGUINA). & [Attifement]. & 55 & [Attifement]. \\
\hline Berreguintcea. attifer. enioliuer. & Attifer. & 55 & Attifer. \\
\hline BerReroztea, berriz erostea. racheter. & Racheter. & 534 & Rachepter. \\
\hline Berrerospena. rachet. & Rachapt. & 534 & Rachapt. \\
\hline Berreroslea. racheteur. redempeur. & & & Rachepteur. \\
\hline Berretçaillea. (Berretcea). & [Augmentateur]. & 58 & [Augmentateur]. \\
\hline Berretura. a. augmentation. & Augmentation. & 58 & Augmentation. \\
\hline BERRIA. nouueau. recent. nouuelle. & Nouuelle. & 434 & Nouuelle. \\
\hline Berriro, berrirozqui. nouuellem[ent]. & Nouuuellement. & 434 & Nouuellement. \\
\hline Berritsua. conteur de nouuelles, rapporteur. & $\begin{array}{l}\text { Nouuelle. Rapporteur ou controueur de fausse } \\
\text { nounelle. }\end{array}$ & 434 & \\
\hline
\end{tabular}




\begin{tabular}{|c|c|c|c|}
\hline $\begin{array}{l}\text { A eskuizkribuko } \\
\text { sarrerak }\end{array}$ & $\begin{array}{c}\text { Nicot-en } \\
\text { sarrerak }\end{array}$ & $\begin{array}{c}\text { Nicot-en } \\
\text { or.zenbakia }\end{array}$ & $\begin{array}{c}\text { Oudin-en } \\
\text { sarrerak }\end{array}$ \\
\hline BERROA, saparra, sassia. hallier. & Haillier ou hallier. & 327 & Haillier. \\
\hline BERROGOY, berriz hogoy. quarante. & Quarante. & 528 & Quarante. \\
\hline Berrogoygarrena. quarantiéme. & Quarantieme. & 528 & Quarantiesme. \\
\hline Berrogoytan, berrogoy aldiz. quarante fois. & Quarant. Quarante fois. & 528 & \\
\hline BerRogoya $\mathrm{O}$, gariçuma. caresme. & Quaresme. & 528 & Quaresme. \\
\hline BERTÇA. chaudron. & Chauderon. & 117 & Chauderon. \\
\hline Bertzquina. chaudronnier. & Chauderonnier. & 117 & Chauderonnier. \\
\hline BERUINA. vendange. & Vendenge. & 652 & Vendange. \\
\hline Beruinatcea. vendanger. & Vendenger. & 652 & Vendanger. \\
\hline Beruinsalea. vendangeur. & Vendangeur. & 653 & Vendangeur. \\
\hline BERUNA. plomb. & Plomb. & 489 & Plomb. \\
\hline $\begin{array}{l}\text { Berunztatcea, beruneztatcea, berundat- } \\
\text { cea. plomber. garnir de plomb. }\end{array}$ & Plomber. & 489 & Plomber. \\
\hline BETHAÇALA, bethespala, bethilleac. paupieres. & Paulpieres. & 469 & Paulpieres. \\
\hline BETHALDEA, acienda. troupeau de bestail. & Trouppeau. Troupeau de bestiail. & 646 & \\
\hline Bethacorra. fertile. (BетHATCEA) & Fertile. & 284 & Fertile. \\
\hline Bethacortcea. fertiliser. & Fertiliser. & 284 & Fertile. \\
\hline BETHERIA. chassie. & Chacie. & 108 & Chassie. \\
\hline Begui betheriatsuac. yeux chassieux. & Chacieux. Chacieux. Yeux chacieux. & 108 & \\
\hline Bethiere. continuellement. (BETHI). & Continuellement. & 116 & Continuellement. \\
\hline $\begin{array}{l}\text { Bethicoa, bethierecoa. qui e }[\mathrm{st}] \text { pour } \\
\text { touiours. perpetuel. continuel. }\end{array}$ & Continuel. & 116 & Continuel. \\
\hline Bethieretcea. continuer. perpetuer. & Continuer. & 116 & Continuer. \\
\hline BEYTHA. appas. & Appas. & 36 & Appas. \\
\hline Beytatcea. appaster. & Appaster. & 36 & Appaster. \\
\hline Bigarrena. deuxiéme. second (BIA). & Second. & 585 & Second. \\
\hline Bigarrenean. secondement. & Secondement. & 585 & Secondement. \\
\hline Bigarrenecotz. pour la second fois. & Second. Consul pour la second fois. & 585 & \\
\hline Bigarrentcea. secundare, ari. & Seconder. & 585 & Seconder. \\
\hline Guiçon biçarra. homme libera.l (BIÇARRA) & Liberal. & 373 & Liberal. \\
\hline Biçartasuna. liberalité. & Liberalité. & 373 & Liberalité. \\
\hline Biçarqui. liberalement. & Liberalement. & 373 & Liberalement. \\
\hline Bide celhaya. chemin battu. (BIDEA) & & & $\begin{array}{l}\text { Chemin battu } \\
\text { ou frayé. }\end{array}$ \\
\hline Bide harritsua. chemin pierreux. & Chemin. Chemin pierreux et mal aisé. & 118 & \\
\hline Biga. O., miga. genisse. & Genisse. & 313 & Genisse. \\
\hline BiHIA. grain. bled. & Grain. & 318 & Grain. \\
\hline Bihiteguia. grenier. grange. & Grenier. & 321 & Grenier. \\
\hline
\end{tabular}




\begin{tabular}{|c|c|c|c|}
\hline $\begin{array}{c}\text { A eskuizkribuko } \\
\text { sarrerak }\end{array}$ & $\begin{array}{c}\text { Nicot-en } \\
\text { sarrerak }\end{array}$ & \begin{tabular}{|c|} 
Nicot-en \\
or.zenbakia
\end{tabular} & $\begin{array}{c}\text { Oudin-en } \\
\text { sarrerak }\end{array}$ \\
\hline BIHURRIA. bigearre. malin. acariatre. & & & Bigearre. \\
\hline Bihurritcea. rendre ou deuenir bigearre. & Bigarrer. & 78 & Bigarrer. \\
\hline BiKEA. poix. & Poix. & 493 & Poix. \\
\hline Bikeztatcea. poisser. & Poisser. & 493 & Poisser. \\
\hline BilCUA. amas. & Amas. & 29 & Amas. \\
\hline BILHURA, bihurra. garrot. rote. & Garrot. & 311 & Garrot. \\
\hline Bilhurtcea. garroter. lier. & Garotter. Lier et garotter vn homme. & 311 & Garroter. \\
\hline BilligarROA. etourneau. & Estourneau. & 265 & Estourneau. \\
\hline Billuzgorria. tout fin nud. & Nud. & 434 & Nud. \\
\hline Billuzgorritasuna. nudité. & Nudité. & 434 & Nudité. \\
\hline $\begin{array}{l}\text { Billuzgorritcea. mettre tont a nud. se de- } \\
\text { poüiller tout a fait. }\end{array}$ & Nud. Mettre nud. & 434 & \\
\hline Billusia. nud. depoüillé. & Despouillé. & 199 & \\
\hline Billuztea. depoüiller. & Despouiller. & 199 & Despouiller. \\
\hline BilOA, ille izpia. cheueuil. & Cheueul. & 122 & Cheueul. \\
\hline Hil biloac. poil folet. lanugo. & Poil. Poil folet [...]. Lanugo. & 490 & Poil folet. \\
\hline BIPERRA. poiure. & Poyvre. & 503 & Poivre. \\
\hline Biperztatcea. poiurer. & Poyvrer. & 503 & Poivrer. \\
\hline BipILTCEA. plumer. & Plumer. & 490 & Plumer. \\
\hline BIR EZCONTCEA. remarier. & Remarier. & 552 & Remarier. \\
\hline BIRIAC, hauscoac. poumons. & Poulmon. & 498 & Poumon. \\
\hline BiRIBILLA. rond. & Rond. & 573 & Rond. \\
\hline $\begin{array}{l}\text { Biribiltcea, biribillatcea. arrondir, mettre } \\
\text { en rond. (Voltoire) }\end{array}$ & Arrondir. & 47 & Arrondir. \\
\hline Biribildura. arrondissement. & Arrondissement. & 47 & Arrondissement. \\
\hline Biribiltasuna. rondeur. & Rondeur. & 573 & Rondeur. \\
\hline Biribilqui. rondem[ent]. en rond. & Rondement. & 573 & Rondement. \\
\hline BIRITCHIA. pair. & Paire. & 453 & Pair. \\
\hline Birlandatcea. transplanter. (BIRLANDA) & Transplanter. & 640 & Transplanter. \\
\hline Bista. la veuë. & Veue. & 656 & Veuë. \\
\hline Bitartea. espace. & Espace. & 254 & Espace. \\
\hline BitzTEA, pitztea. allumer. & Allumer. & 28 & Allumer. \\
\hline Biz hala, hala biz. ainsi soit il. (BIz) & Ainsi. Ainsi soit il. & 24 & \\
\hline BIZCARRA. echine. dos. & Eschine. & 247 & Eschine. \\
\hline BoçA, voça. voix. & Voix. & 667 & Voix. \\
\hline Bocata. buée. lexiue. & Buée, Lixiuium. & 94 & Bueé. \\
\hline Bocatatcea. & [Buer]. & 94 & [Buer]. \\
\hline Bola. boule. & Boule. & 86 & Boule. \\
\hline
\end{tabular}




\begin{tabular}{|c|c|c|c|}
\hline $\begin{array}{c}\text { A eskuizkribuko } \\
\text { sarrerak }\end{array}$ & $\begin{array}{l}\text { Nicot-en } \\
\text { sarrerak }\end{array}$ & $\begin{array}{c}\text { Nicot-en } \\
\text { or.zenbakia }\end{array}$ & $\begin{array}{l}\text { Oudin-en } \\
\text { sarrerak }\end{array}$ \\
\hline Boletan haritcea. ioüer a la boule. & Bouler. & 86 & $\begin{array}{l}\text { Bouler. jugar } \\
\text { bolas. }\end{array}$ \\
\hline BOLATCEA. voler. emporter la vole. & Voler. & 667 & Voler. \\
\hline BONACHERA. bonne chere. & Chere. Bonne chere. & 120 & \\
\hline BORDA. borde. metairie. & Borde. & 83 & Borde. \\
\hline Bordaçaina, bordaria. bordier. metayer. & Bordier. & 84 & Bordier. \\
\hline BORONDATEA. volonté. & Volonté. & 669 & Volonté. \\
\hline $\begin{array}{l}\text { Borondatez, borondatezqui. volontai- } \\
\text { rem[ent]. }\end{array}$ & Volontairement. & 669 & Volontairement. \\
\hline BORRATCEA. effacer. & Effacer. & 220 & Effacer. \\
\hline BORREROA ax. 304 , burreba. bourreau. & Bourreau. & 87 & Bourreau. \\
\hline Borroca. luitte. & Luicte. & 383 & Luitte. \\
\hline Borrocaria. luiteur. & Luicteur. & 383 & Luitteur. \\
\hline Borrocatcea. luiter. & Luicter. & 383 & Luitter. \\
\hline BORTCHA. force. contrainte. & Contrainte. & 147 & Contrainte. \\
\hline Bortcharia, bortchatçaillea. qui contraint. & Contraindre. Celle qui contraint. & 147 & \\
\hline Bortchatcea. forcer. contraindre. & Contraindre. & 147 & Containdre. \\
\hline BоRтна. 2. athea. porte. & Porte. & 495 & Port. \\
\hline Borthaçaina, athalçaina. portier. & Portier. & 495 & Portier. \\
\hline BORTHITZA. fort. valeureux. rude. & Fort. & 295 & Fort. \\
\hline Borthizqui. fortement. & Fortement. & 295 & Fortement. \\
\hline BОТНАТСЕA. bourgeonner. boutonner. & Bourjonner. & 87 & Bourjonner. \\
\hline Bothea. bourgeon. bouton. & Bourjon. & 87 & Bourjon. \\
\hline $\begin{array}{l}\text { Botherea. puissance. pouuoir. (Vol- } \\
\text { toire) }\end{array}$ & Puissance. & 525 & Puissance. \\
\hline Botheretsua. puissant. & Puissant. & 525 & Puissant. \\
\hline Bотіка. boutique d'apoticaire. & & & $\begin{array}{l}\text { Apoticairerie. tien- } \\
\text { da del Boticario. }\end{array}$ \\
\hline Botikaria. apoticaire. & Apoticaire. & 35 & Apoticaire. \\
\hline BотоINA. bouton. & Bouton. & 88 & Bouton. \\
\hline Botoinguillea. boutonnier. & & & Boutonnier. \\
\hline Botoinatcea. boutonner. & Boutonner. & 88 & Boutonner. \\
\hline BRAGAMIOA. parchemin. & Parchemin. & 457 & Parchemin. \\
\hline BrAUOA. & Braue. & 89 & Braue. \\
\hline Brauotcea. & Brauer. & 89 & Brauer. \\
\hline Brauoqui. & Brauement. & 90 & Brauement. \\
\hline BRIDA. bride. & Bride. & 91 & Bride. \\
\hline Bridatcea. brider. & Brider. & 91 & Brider. \\
\hline
\end{tabular}




\begin{tabular}{|c|c|c|c|}
\hline $\begin{array}{l}\text { A eskuizkribuko } \\
\text { sarrerak }\end{array}$ & $\begin{array}{l}\text { Nicot-en } \\
\text { sarrerak }\end{array}$ & $\begin{array}{c}\text { Nicot-en } \\
\text { or.zenbakia }\end{array}$ & $\begin{array}{c}\text { Oudin-en } \\
\text { sarrerak }\end{array}$ \\
\hline BRIYUA. reliquaire. & Reliquaire. & 552 & Reliquaire. \\
\hline BRODATCEA. broder. & Border. & 83 & $\begin{array}{l}\text { Border pour } \\
\text { broder. }\end{array}$ \\
\hline Brodadura. brodure. & Bordure. & 83 & $\begin{array}{l}\text { Bordeure, bro- } \\
\text { deure. }\end{array}$ \\
\hline Brodaria, brodatçaillea. & Bordeur. & 83 & Bordeur. \\
\hline BRUITA, aharra, açantça, auarrotza. bruit. & Bruit. & 92 & Bruit. \\
\hline BRUMA. & & & [Brume]. \\
\hline $\begin{array}{l}\text { BRUSCAMBILLAC, bassa mahatzac. lam- } \\
\text { brusches. racheboches. }\end{array}$ & Lambrunche. & 366 & Lambruche. \\
\hline BuA. grosse verole. & Verole. La grosse verole. & 657 & grosse Verole. \\
\hline Buatsua. verolé. & & & Verolé. \\
\hline Buhescatcea. bourdonner. (BuHEZCA) & Bourdonner. & 86 & Bourdonner. \\
\hline Burdin arrastelua. (BURDINA) & Rasteau. Vne sorte de rasteau de fer. & 539 & \\
\hline BuRGEZZA. ratean de fer. bourgeois. & Bourgeois. & 87 & Bourgeois. \\
\hline Burgezia. bourgeoisie. & Bourgeoisie. & 87 & Bourgeoisie. \\
\hline Burhostatcea. maudire. (BURHOA). & Mauldir. & 398 & Maudire. \\
\hline BURLA, trufa. gausserie. moquerie. & Mocquerie. & 413 & Mocquerie. \\
\hline Burlaria, burlatçaillea, trufaria. moqueur. & Mocqueur. & 413 & Mocqueur. \\
\hline $\begin{array}{l}\text { Burlatcea norbaitez. se moquer de quel- } \\
\text { qu'vn. }\end{array}$ & Mocquer. Se mocquer de quelqu'vn. & 413 & \\
\hline $\begin{array}{l}\text { Burua. teste, chef, bout, commen- } \\
\text { cem[ent]. (Voltoire) }\end{array}$ & Teste. & 627 & Teste. \\
\hline Bur-heçur. caluaria. caluaire. & Caluaire, ou le Tez de la teste. Caluaria. & 98 & Caluaire. \\
\hline Buruz buru. teste a teste. & Teste à teste. & 627 & Teste à teste. \\
\hline BussoA. plongeur. & Plongeur. & 489 & Plongeur. \\
\hline Bussotcea. plonger. & Plonger. & 489 & Plonger. \\
\hline $\begin{array}{l}\text { BuSTELTCEA, vsteltcea, pusteltcea, vmatcea. } \\
\text { pourrir. chopir. mollir. (Voltoire) }\end{array}$ & Pourrir. & 502 & Pourrir. \\
\hline Busteldua. pourri. & Pourri. & 502 & Pourry. \\
\hline Busteldura. pourriture. & Porriture. & 502 & Pourriture. \\
\hline ÇABALA, çauala. large. (Voltoire) & Large. & 368 & Large. \\
\hline Çabaltcea. elargir. etendre. & Eslargir. & 252 & Eslargir. \\
\hline Çabaldua. elargy. & Eslargi. & 252 & Eslargy. \\
\hline Çabaltasuna. largeur. & Largeur. & 368 & Largeur. \\
\hline CaBilla. cheuille. & Cheuille. & 122 & Cheuille. \\
\hline Cabillaztatcea. cheuiller. & Cheuiller. & 122 & Cheuiller. \\
\hline Caca eguitea. (Caca) & Chier. & 123 & Chier. \\
\hline CACHETA, siguillua. cachet. & Cachet. & 97 & Cachet. \\
\hline
\end{tabular}




\begin{tabular}{|c|c|c|c|}
\hline $\begin{array}{c}\text { A eskuizkribuko } \\
\text { sarrerak }\end{array}$ & $\begin{array}{l}\text { Nicot-en } \\
\text { sarrerak }\end{array}$ & $\begin{array}{c}\text { Nicot-en } \\
\text { or.zenbakia }\end{array}$ & $\begin{array}{c}\text { Oudin-en } \\
\text { sarrerak }\end{array}$ \\
\hline $\begin{array}{l}\text { Cachetatcea, chingolatcea. cacheter. cor- } \\
\text { deler les cheueux a trois cordons. }\end{array}$ & Cacheter. & 97 & Cacheter. \\
\hline CADIRA. chaire. & Chaire. & 109 & Chaire. \\
\hline CAFIA, ohatcea, habia. cage. & Cage. & 97 & Cage. \\
\hline $\begin{array}{l}\text { ÇAHAGUIA. peau de cuir a mettre vin ou } \\
\text { huile. outre. }\end{array}$ & $\begin{array}{l}\text { Peau. Peau de bouc ou de cheure cuir a mettre } \\
\text { vin ou huile. }\end{array}$ & 469 & \\
\hline ÇAHAROA. 2. cigorra. gaule. & Gaule. & 312 & Gaule. \\
\hline ÇAHARra. vieil. ancien. (Voltoire) & Vieil. & 660 & Vieil. \\
\hline Çahartcea. vieillir. & & & Vieillir. \\
\hline Çahartasuna. vieillesse. & Vieillesse. & 660 & Vieillese. \\
\hline ÇAINA. nerf. vene. racine. (Voltoire) & Nerf. & 429 & Nerf. \\
\hline ÇAKARRA. crouste de gale. teigne. & Teigne. & 619 & Teigne. \\
\hline Çakartsua. teigneux. & Teigneux. & 619 & Teigneux. \\
\hline CALAMUA, garsandea. chanure. roseau. & Chanure. & 112 & Chanure. \\
\hline ÇALDIA, çamaria. cheual. & Cheual. & 120 & Cheual. \\
\hline CALITÇA. calitça copa. calice. & Calice. & 98 & Calice. \\
\hline CALITCHA, marroca. verruë. & Verrüe. & 657 & Verrüe. \\
\hline CAlsada. paué. & Paué. & 468 & Paué. \\
\hline Calsadatcea. pauer. & Pauer. & 469 & Pauer. \\
\hline ÇALUA, çaluya. souple. & Soupple. & 606 & Soupple. \\
\hline $\begin{array}{l}\text { Çamarikina, irrincirina. henissem[ent]. } \\
\text { (ÇAMARIA) }\end{array}$ & Henissement. & 332 & Henissement. \\
\hline CAMASTRA a., ohea, etçauntça. lit. couche. & Lict. & 374 & Lict. \\
\hline CAMELOTA. camelot. & Camelot. & 98 & Camelot. \\
\hline CAMElUa. a. 304. chameau. & Chameau. & 110 & Chameau. \\
\hline ÇAMINA, kiratsa, karmina. amer. & Amer. & 30 & Amer. \\
\hline Çamintcea. rendre ou deuenir amer. & Deuenir amer. & 30 & Deuenir amer. \\
\hline Çamintasuna. amertume. aigreur. colere. & Amertume. & 30 & Amertume. \\
\hline ÇAмUKA. bast d'asne, clitella. & Bast (Baster, Clitella). & 70 & Bast. \\
\hline CAMUTZA. emoussé. camus. & & & Esmoussié. \\
\hline Camutztea. emousser. & Esmousser. & 253 & Esmousser. \\
\hline CANABERA. roseau. & Roseau. & 573 & Roseau. \\
\hline CANALA, gottera, ithaiçura. canal & Canal. & 99 & Canal. \\
\hline CANCERIA, chamarra. chancre & Chancre. & 111 & Chancre. \\
\hline CANDELa. chandelle. & Chandelle. & 111 & Chandelle. \\
\hline Candelera. chandelier. & Chandelier. & 111 & Chandelier. \\
\hline $\begin{array}{l}\text { Candelerua, candeleroa, ganderalu } \mathrm{O}, \\
\text { candelairua h. la chandeleur. }\end{array}$ & Chandeleur. La feste de la chandeleur. & 111 & la Chandeleur. \\
\hline
\end{tabular}




\begin{tabular}{|c|c|c|c|}
\hline $\begin{array}{l}\text { A eskuizkribuko } \\
\text { sarrerak }\end{array}$ & $\begin{array}{c}\text { Nicot-en } \\
\text { sarrerak }\end{array}$ & $\begin{array}{c}\text { Nicot-en } \\
\text { or.zenbakia }\end{array}$ & $\begin{array}{c}\text { Oudin-en } \\
\text { sarrerak }\end{array}$ \\
\hline Çangartea. jambette. (ÇANGARDIA) & Iambette. & 343 & Iambette. \\
\hline CANTALA. chanteau. quarrie. & Chanteau. & 112 & Chanteau. \\
\hline CANTOINA. canton. quarrie. quartier. & Cantons. & 100 & Canton. \\
\hline Cantoinatcea. quantonner. se cantonner. & & & $\begin{array}{l}\text { Cantonner. se } \\
\text { Cantonner. }\end{array}$ \\
\hline ÇAPARRA. buisson. & Buisson. & 95 & Buisson. \\
\hline ÇAРATCEA. presser. enfoncer. entasser. & Presser. & 508 & Presser. \\
\hline Capestrua. licol. & Licol. & 374 & Licol. \\
\hline ÇAPPOREA. a. saueur. goust. & Saueur. & 582 & Saueur. \\
\hline Çapporatcea. sauourer. gouster. & Sauourer. & 582 & Sauourer. \\
\hline CAPUTXA. capuçon. & Capuchon. & 101 & Capuchon. \\
\hline $\begin{array}{l}\text { ÇARAGOILLA. O., galçac. haut de chaus- } \\
\text { ses. }\end{array}$ & Haut de chausses. & 118 & $\begin{array}{l}\text { Chausses, haut } \\
\text { de chausses. }\end{array}$ \\
\hline ÇARAMICATCEA, çarrapocatcea. egratigner. & Egratigner. & 220 & Esgratigner. \\
\hline CARCAINATCEA. 2. arraillatcea. fendre. & Fendre. & 283 & Fendre. \\
\hline Carcainadura, arrailladura. fente. & Fente. & 283 & Fente. \\
\hline CARCELA, garcela. prison. & Prison. & 512 & Prison. \\
\hline CARGUA. charge. office. & Charge. & 114 & $\begin{array}{l}\text { Charge, oficio, } \\
\text { cargo. }\end{array}$ \\
\hline CARIOA, garestia. cher. & Cher. & 120 & Cher. \\
\hline CARITATEA. charité. & Charité. & 115 & Charité. \\
\hline CARLOA. chardon. & Chardon. & 114 & Chardon. \\
\hline CARPETA. 2. tapisseria. tapisserie. & Tapisserie. & 617 & Tapisserie. \\
\hline CARSOILLA. chauue. & Chauue. & 118 & Chauue. \\
\hline Carsoiltcea. & [Deuenir chauue]. & 118 & $\begin{array}{l}\text { [ } \mathrm{d} \text { e u e n i r } \\
\text { Chauue]. }\end{array}$ \\
\hline Carsoildura. & [Chauueté]. & 118 & [Chauueté]. \\
\hline ÇATHIA. morceau. piece. & Morceau. & 418 & Morceau. \\
\hline $\begin{array}{l}\text { Çathicatcea. çathitcea. mettre a mor- } \\
\text { ceaux. rompre. dechirer. }\end{array}$ & Morceau. Mettre en morceaux. & 418 & \\
\hline CAUARDILLA. pourpre. rougeole. & Pourpre. & 501 & Pourpre,maladie. \\
\hline ÇAURIA. playe. blessure. & Blessure. & 81 & \\
\hline Çauritcea edo çaurtcea. blesser. & Blesser. & 81 & Blesser. \\
\hline ÇAURNEA. pus. ordure. & & & Pus. \\
\hline CAUTERA. chaudronnier. & Chauderonnier. & 117 & Chauderonnier. \\
\hline CeCEnA. taureau. & Taureau. & 619 & Taureau. \\
\hline CEDARRIA, mugarria. borne. limite. & Borne. & 84 & Borne. \\
\hline Cegúta. cigue. & Cigue. & 124 & Cigüe. \\
\hline CенATCEA. battre. frapper. & Batre. & 71 & Battre. \\
\hline
\end{tabular}




\begin{tabular}{|c|c|c|c|}
\hline $\begin{array}{l}\text { A eskuizkribuko } \\
\text { sarrerak }\end{array}$ & $\begin{array}{l}\text { Nicot-en } \\
\text { sarrerak }\end{array}$ & $\begin{array}{c}\text { Nicot-en } \\
\text { or.zenbakia }\end{array}$ & $\begin{array}{c}\text { Oudin-en } \\
\text { sarrerak }\end{array}$ \\
\hline Cehatçaillea. batteur. & Bateur. & 72 & Batteur. \\
\hline $\begin{array}{l}\text { Begui ceiharrez behatcea, ceihar behatcea } \\
\text { norbaiti. de trauers. (Ceiharra) }\end{array}$ & Trauers. Regarder de trauers. & 641 & \\
\hline CenenA. chiche. taquin. & Chiche. & 123 & Chiche. \\
\hline Cekentasuna. & [Chicheté]. & 123 & [Chicheté]. \\
\hline Cekenqui. chichement. & Chichement. & 123 & Chichement. \\
\hline Celata. guet. epie. embusche. & Espies. & 258 & Espie. \\
\hline Celataria. espion. & Espion. & 258 & Espion. \\
\hline Celatacea. espier. & Espier. & 258 & Espier. \\
\hline Celhaïtcea. applanir. (CELHAї̈) & Applanir. & 38 & Applanir. \\
\hline CEPOA. lien. menotte. & Lien. & 374 & Lien. \\
\hline Chafla, herscaillua. O. emplastre. & Emplastre. & 224 & Emplastre. \\
\hline Chaflatcea. & & & $\begin{array}{l}\text { [mettre vn Em- } \\
\text { plastre]. }\end{array}$ \\
\hline CHAнUA, garbia. net. & Net. & 429 & Net. \\
\hline Chahutcea. nettoyer. (Voltoire) & Nettoyer. & 429 & Nettoyer. \\
\hline Chahutasuna. netteté. & Netteté. & 429 & Netteté. \\
\hline Chahuqui, chauroqui. nettement. & Nettement. & 429 & Nettement. \\
\hline Chaincua. 2. maingua. boiteux. & Boiteux. & 83 & Boiteux. \\
\hline Chaincutcea. & [Boiter]. & 83 & [Boiter]. \\
\hline Chalupa. chaloupe. & & & Chaloupe. \\
\hline CHAMARRA. ecreuisse. chancre, maladie. & Escreuice. & 249 & $\begin{array}{l}\text { Escreuice, esc- } \\
\text { reuisse. }\end{array}$ \\
\hline CHAPIGNAC, galzoinac. chaussons. & Chaussons. & 118 & Chausson. \\
\hline CHARDANGOA. 2. felderacoa. leurier. & Leurier. & 372 & Leurier. \\
\hline Charitatea. charité. & Charité. & 115 & Charité. \\
\hline Charitatetsua, charitatosa. charitable. & Charitable. & 115 & Charitable. \\
\hline CHARPA, xarpa. echarpe. & Escharpe. & 245 & Escharpe. \\
\hline СHARPOTA. serpoulet. thym. & Serpolet. & 592 & $\begin{array}{l}\text { Serpolet, ser- } \\
\text { poulet. }\end{array}$ \\
\hline CHARRAMPIGNA. rougeole. & Rougeolle. & 574 & Rougeolle. \\
\hline ChARRANTCHA. seran. & Seran. & 591 & Seran. \\
\hline Charrantchatcea. & [Serancer]. & 591 & [Serancer]. \\
\hline Chassa. chasse au jeu. & & & $\begin{array}{l}\text { Chasse ou jeu du } \\
\text { paulme, chaça. }\end{array}$ \\
\hline Chatarra. paquet. & Paquet. & 456 & Pacquet. \\
\hline Chatarrac. drapeaux d'enfans, maillots. & Maillot. Le maillot des petites enfans. & 385 & Maillot. \\
\hline Chatarratcea. enmailloter. & Emmailloter. & 223 & Emmailloter. \\
\hline
\end{tabular}




\begin{tabular}{|c|c|c|c|}
\hline $\begin{array}{l}\text { A eskuizkribuko } \\
\text { sarrerak }\end{array}$ & $\begin{array}{c}\text { Nicot-en } \\
\text { sarrerak }\end{array}$ & $\begin{array}{c}\text { Nicot-en } \\
\text { or.zenbakia }\end{array}$ & $\begin{array}{c}\text { Oudin-en } \\
\text { sarrerak }\end{array}$ \\
\hline Chedea. but. visée. objet. & But. & 95 & But. \\
\hline Chedatcea. viser. buter. & Buter. & 95 & Buter. \\
\hline $\begin{array}{l}\text { Chenatcea. hacher, mettre a menu. } \\
\text { (Voltoire) }\end{array}$ & Hacher. & 327 & Hacher. \\
\hline Chehea. menu. & Menu. & 402 & Menu. \\
\hline Gende chehea. le menu peuple. & Menu. Le menu peuple. & 402 & \\
\hline $\begin{array}{l}\text { Chehero, cheheroqui. separem[ent], par } \\
\text { le menu, en detail. }\end{array}$ & Par le menu. & 402 & Par le menu. \\
\hline $\begin{array}{l}\text { Chercatcea, cercatcea. 2. bilhatcea. } \\
\text { chercher. }\end{array}$ & Cercher. & 106 & Chercher. \\
\hline Chercatçaillea. chercheur. & Cercheur. & 106 & Chercheur. \\
\hline $\begin{array}{l}\text { Chertatcea, chartatcea, empeldatzea. } \\
\text { enter. }\end{array}$ & Enter. & 236 & Enter. \\
\hline Chertoa. ente. & Ente. & 236 & Ente. \\
\hline $\begin{array}{l}\text { CHICHITERA, chichitola, pimpirina, as- } \\
\text { toaren arima. papillon. }\end{array}$ & Papillon. & 456 & Papillon. \\
\hline CHILIABILIAC, chizqui bizquiac. haillons. & Haillon. & 327 & Haillon. \\
\hline Chilintcha. clochette. & Clochete. & 127 & Clochette. \\
\hline ChimicatCeA, cimicatcea. pinser. & Pincer. & 481 & Pinser. \\
\hline Chimignua. singe. & Singe. & 596 & Singe. \\
\hline Chimignuqueria. singerie. & & & Singerie. \\
\hline CHINCHINBAREA. 2. itçaina. sansuë. & Sansuë. & 580 & Sansuë. \\
\hline $\begin{array}{l}\text { Chinguilca ioaitea. aller a la clochepied. } \\
\text { (CHINGUIL iausia). }\end{array}$ & Clochepied. Aller a la clochepied. & 127 & \\
\hline ChinguilLac. lentilles. & Lentilles. & 370 & Lentilles. \\
\hline ChinHAURRIA, inhurria O. fourmy. & Fourmi. & 298 & Fourmi. \\
\hline Chiperaillua. seche, poisson. & Seche. & 585 & Seche. \\
\hline ChipIA, chiquia. petit. & Petit. & 477 & Petit. \\
\hline Chipitcea. appetisser. (Voltoire) & Appetisser. & 38 & Appetisser. \\
\hline Chipidura. appettissement. & Appetissement. & 38 & Appetissement. \\
\hline Chipitasuna. petitesse. & Petitesse. & 477 & Petitesse. \\
\hline ChIQUiroA. mouton. (Voltoire) & Mouton. & 421 & Mouton \\
\hline Chiquiroquia. chair de mouton. & & & $\begin{array}{l}\text { Mouton, chair } \\
\text { du mouton. }\end{array}$ \\
\hline Chiquiro ezpalda. & [Espaule de mouton]. & 421 & \\
\hline ChIRIBIRIA. violon. & Violles, Viollons & 663 & Violon. \\
\hline Chiribicaria. joueur de violon. & & & $\begin{array}{l}\text { Violon, joüeur } \\
\text { de Violon. }\end{array}$ \\
\hline CHIRIÜA. cierge. & Cierge. & 124 & Cierge. \\
\hline
\end{tabular}




\begin{tabular}{|c|c|c|c|}
\hline $\begin{array}{l}\text { A eskuizkribuko } \\
\text { sarrerak }\end{array}$ & $\begin{array}{c}\text { Nicot-en } \\
\text { sarrerak }\end{array}$ & \begin{tabular}{|c|} 
Nicot-en \\
or.zenbakia
\end{tabular} & $\begin{array}{c}\text { Oudin-en } \\
\text { sarrerak }\end{array}$ \\
\hline $\begin{array}{l}\text { CHIRLAC, maxcorrac. coquilles de mer, } \\
\text { de S. Iaques. }\end{array}$ & $\begin{array}{l}\text { Coquille. Coquille de Saint Iacques ou Large } \\
\text { coquille. }\end{array}$ & 150 & \\
\hline Chirola. fluste. fluteau. & Fleute. & 290 & Fleute. \\
\hline Chirolaria. ioüeur de la flute. & Fleute. Joüeur de fleute. & 290 & \\
\hline Chirripa. ruisseau. & Ruisseau. & 576 & Ruisseau. \\
\hline Chirrixtatcea. rinsser. (CHIRRIXTA) & Rinser. & 571 & Rinser. \\
\hline Chixterra, chisterra. gousse. & Gousse. & 317 & Gousse. \\
\hline Chizpiltcea. griller. & Griller. & 322 & Griller. \\
\hline Chizpildua. grillé. & Grillé. & 322 & Grillé. \\
\hline СHopina. le hoquet. & Hoquet. Le hoquet. & 339 & \\
\hline Choria. oiseau. (Voltoire) & Oiseau. & 440 & Oiseau. \\
\hline Parra-choria, eliça choria. passer, passerculus. & Passereau, Passer, Passerculus. & 467 & \\
\hline $\begin{array}{l}\text { Les passereaux crient, paxaros que pian, } \\
\text { pipilant passeres }\end{array}$ & $\begin{array}{l}\text { Passereau. Les passereaux crient, Pipilant pas- } \\
\text { seres. }\end{array}$ & 467 & \\
\hline СHorta. goute de quelque liqueur. & Goutte. & 317 & Goutte. \\
\hline Vr chorta bat. vne goute d'eau. & $\begin{array}{l}\text { Goutte. Vne goutte d'eaüe, ou d'autre liqueur } \\
\text { qui chet. }\end{array}$ & 317 & \\
\hline Chortaca. goute a goute. & Goutte a goutte. & 317 & Goutte a goutte. \\
\hline Chuchurlaria. susurro. (СhuchurLaC) & $\begin{array}{l}\text { Mesdire. Qui mesdit d'aucun par derriere, } \\
\text { Susurro. }\end{array}$ & 405 & \\
\hline Chumetcea. appetisser. (СнuмеA) & Appetisser. & 38 & Appetisser. \\
\hline Churia. blanc. but. (Voltoire) & Blanc. & 79 & Blanc. \\
\hline Churiz vestitua. vestu de blanc. & Blanc. Vestu de blanc. & 79 & \\
\hline $\begin{array}{l}\text { Churitcea. blanchir. tromper. enjoller. } \\
\text { (Voltoire) }\end{array}$ & Blanchir. & 79 & Blanchir. \\
\hline Churitasuna. blancheur. & Blancheur. & 79 & Blancheur. \\
\hline Churitçaillea. blanchisseur. trompeur. & & & Blanchisseur. \\
\hline $\begin{array}{l}\text { Churiquetac edo churiquetacoac. linges } \\
\text { a blanchir }\end{array}$ & Blanchissage. Blanchissage de linges. & 79 & \\
\hline Churpailla. blesme. haue. & Blesme. & 81 & Blesme. \\
\hline Churpailtcea. & [Blesmir]. & 81 & [Blesmir]. \\
\hline Churpailtasuna. & Blesmissement. & 81 & [Blesmissement]. \\
\hline Churpatcea. se courber. & Courber. Se courber. & 158 & \\
\hline CiA. gland de chesne. & Gland. gland de chesne. & 315 & Gland. \\
\hline Piñu cia, meluis sagarra. pomme de pin. & Pomme. Pommes de pin. & 493 & Pomme de pin. \\
\hline Cicotza. O. chiche. & Chiche. & 123 & Chiche. \\
\hline Cicotztasuna. & [Chicheté]. & 123 & [Chicheté]. \\
\hline Cicotzqui. & [Chichement]. & 123 & [Chichement]. \\
\hline Cigarra. ciron. (Voltoire) & Ciron. & 125 & Ciron. \\
\hline
\end{tabular}




\begin{tabular}{|c|c|c|c|}
\hline $\begin{array}{c}\text { A eskuizkribuko } \\
\text { sarrerak }\end{array}$ & $\begin{array}{c}\text { Nicot-en } \\
\text { sarrerak }\end{array}$ & $\begin{array}{c}\text { Nicot-en } \\
\text { or.zenbakia }\end{array}$ & $\begin{array}{c}\text { Oudin-en } \\
\text { sarrerak }\end{array}$ \\
\hline Cigartsua. plein de cirons. & & & $\begin{array}{l}\text { Cironniere. can- } \\
\text { tidad de arados } \\
\text { en las manos. }\end{array}$ \\
\hline Ciguillua, cigulua, sagetta. 2. sceau. & Seau. & 585 & Sceau. \\
\hline Cikina. crasse. & Crasse. & 164 & Crasse. \\
\hline Cikintsua. & [Crasseux]. & 164 & [Crasseux]. \\
\hline Cikultcea. herisser. & Herisser. & 334 & Herisser. \\
\hline CilHARRA. argent non monnoyé. & Argent. & 42 & Argent, matiere. \\
\hline Vrrez eta cilharrez. d'or \& d'argent. & & & $\begin{array}{l}\text { Argent meslé } \\
\text { d'or. }\end{array}$ \\
\hline Cilharreztatcea. & Argenter. & 43 & Argenter. \\
\hline Cimendua. fondement. & Fondement. & 292 & Fondement. \\
\hline Cimendatcea. cimenter. fonder. & Fonder. & 292 & Fonder. \\
\hline Cimurra. ride. & Rides. & 570 & Ride. \\
\hline Cimurtcea. rider. soupir. & Rider. & 570 & Rider. \\
\hline Cimurdura. & & & [Ridement]. \\
\hline Cincuria. O. gemissement. & Gemissement. & 312 & Gemissement. \\
\hline CInçURRA. gorge. gosier. & Gorge. & 316 & Gorge. \\
\hline $\begin{array}{l}\text { Cinçurrac norbaiti eguitea. couper la } \\
\text { gorge a quelqu'vn. }\end{array}$ & Couper la gorge à aucun. & 316 & Couper la gorge. \\
\hline CINETSTEA. croire. & Croire. & 168 & Croire. \\
\hline Cinetsbera. cinetscorra. credule. & Credule. & 165 & Credule. \\
\hline $\begin{array}{l}\text { Cinetsberatasuna. cinetscortasuna. facilité } \\
\text { a croire. credulité. }\end{array}$ & Credulité. & 165 & Credulité. \\
\hline CINTÇA. morue. gourme. & Morue. & 419 & Morve. \\
\hline Çamal cintça. gourme de cheual. & & & Morve de cheual. \\
\hline Cipertcea. creuer de depit. & $\begin{array}{l}\text { Creuer. Creuer de despit qu'on a d'aucuns qui } \\
\text { ne laissent rien à faire. }\end{array}$ & 166 & \\
\hline Circilla. dechiré en ses habits. & Deschiré. & 192 & Deschiré. \\
\hline Circiltcea. & [Deschirer]. & 192 & [Deschirer]. \\
\hline Circildura. & [Deschirure]. & 192 & [Deschireure]. \\
\hline Circiltasuna. & [Deschirement]. & 192 & [Deschirement]. \\
\hline CIRIA. cheuille. coing. & Cheuille. & 122 & Cheuille. \\
\hline Ciriztatcea. cheuiller. & Cheuiller. & 122 & Cheuiller. \\
\hline Citthala, liçuna. sale, vilain. & Sale. & 579 & Sale. \\
\hline Cithalqueria. & [Saleté] & 579 & [Saleté]. \\
\hline Cithalqui. & & & [Salement]. \\
\hline CiXtapurrac. festus. buchettes. & Festu. & 284 & Festus. \\
\hline Clara, agueria. clair. & Cler. & 126 & Clair \\
\hline
\end{tabular}




\begin{tabular}{|c|c|c|c|}
\hline $\begin{array}{l}\text { A eskuizkribuko } \\
\text { sarrerak }\end{array}$ & $\begin{array}{l}\text { Nicot-en } \\
\text { sarrerak }\end{array}$ & $\begin{array}{c}\text { Nicot-en } \\
\text { or.zenbakia }\end{array}$ & $\begin{array}{c}\text { Oudin-en } \\
\text { sarrerak }\end{array}$ \\
\hline Clartasuna. & [Clerté ou Clarté]. & 126 & [Clairté]. \\
\hline Clarqui. (Voltoire). claroqui. & [Clerement]. & 126 & [Clairement]. \\
\hline Clauera. marguillier. clauier. & Clauier. & 126 & Clauier. \\
\hline Cleda. craye. & Craye. & 164 & Craye. \\
\hline COBERATCEA a. 167 . cobratcea. recouurer. & Recouurer. & 544 & Recouurer. \\
\hline COÇATCEA. O, cutsatcea. corrompre. infecter. & Corrompre. & 152 & Corrompre. \\
\hline Coconico iartcea. s'accroupir. & Accroupir. S'accroupir. & 10 & s'Accroupir. \\
\hline Cocotza. menton. & Menton. & 402 & Menton. \\
\hline Cofia. coüeffe. & Coeffe. & 128 & Coiffe. \\
\hline Cofiatcea. & Coeffer. & 128 & [Coiffer]. \\
\hline COFrea. cofre. & Coffre. & 128 & Coffre. \\
\hline ÇонIA. gazon. motte. & Gazon. & 312 & Gazon. \\
\hline Cola, amiruina. cole. empois. & Colle. & 129 & Colle. \\
\hline Colatcea. & [Coller]. & 129 & [Coller]. \\
\hline Colera. colere. (Voltoire) & Cholere. & 124 & Colere. \\
\hline Coleracorra. & [Cholerique]. & 124 & [Coleric]. \\
\hline Coleratcea. & [Cholerer]. & 124 & \\
\hline ColOreA. couleur. (Voltoire) & Couleur. & 154 & Couleur. \\
\hline Coloratcea. & [Coulourer]. & 155 & \\
\hline Columbrina. couleurine. & Couleuurine. & 156 & Couleurine. \\
\hline CомватA, gudua. combat. & Combat. & 130 & Combat. \\
\hline Bat banacaco combata. duel. & $\begin{array}{l}\text { Combat. Combat d'homme à homme ou } \\
\text { corps à corps. }\end{array}$ & 130 & \\
\hline COMMAYA. commere. & Commerre. & 133 & Commere \\
\hline Commaitasuna. commerage. & Commerage. & 133 & Commerage \\
\hline Commaïtcea. & & & [Commerer]. \\
\hline CoMpainia. compagnie. & Compagnie. & 135 & Compagnie. \\
\hline $\begin{array}{l}\text { COMPARACIONEA, Comparacinoa. com- } \\
\text { paraison. }\end{array}$ & Comparaison. & 135 & Comparaison. \\
\hline Comparatcea. comparer. & Comparer. & 135 & Comparer. \\
\hline COMPAYA. compere. (Voltoire) & Comperes. & 135 & Compere. \\
\hline Compaitasuna. comperage. & Comperage. & 135 & Comperage. \\
\hline Conclusionea. conclusion. & Conclusion. & 138 & Conclusion. \\
\hline Condea. comte. & Conte. & 145 & Comte. \\
\hline Condetasuna. comté. & Conté. & 145 & Comté. \\
\hline Condezza. & [Contesse]. & 145 & [Comtesse]. \\
\hline CONDICIONEA, condicinoa. condition & Condition. & 139 & Condition. \\
\hline Condicionerequin. a. condition & & & A condition que \\
\hline
\end{tabular}




\begin{tabular}{|c|c|c|c|}
\hline $\begin{array}{c}\text { A eskuizkribuko } \\
\text { sarrerak }\end{array}$ & $\begin{array}{c}\text { Nicot-en } \\
\text { sarrerak }\end{array}$ & $\begin{array}{c}\text { Nicot-en } \\
\text { or.zenbakia }\end{array}$ & $\begin{array}{c}\text { Oudin-en } \\
\text { sarrerak }\end{array}$ \\
\hline CONFESSATCEA. confesser. & Confesser. & 140 & Confesser. \\
\hline Confessora. confesseur. & Confesseur. & 140 & Confesseur. \\
\hline Confessionea. confession. & Confession. & 140 & Confession. \\
\hline Congita. congé. & Congé. & 141 & Congé. \\
\hline Consciencia. conscience. & Conscience. & 142 & Conscience. \\
\hline Conseillua. conseil. & Conseil. & 142 & Conseil. \\
\hline Conseillu emaillea. qui donne conseil. & Conseil. Qui donne conseil. & 143 & \\
\hline Conseillaria. vn conseiller. & Conseiller. & 143 & Vn conseiller. \\
\hline $\begin{array}{l}\text { Conseillatcea, conseillu emaitea. consei- } \\
\text { ller. donner conseil. }\end{array}$ & $\begin{array}{l}\text { Conseiller. C'est donner advis et conseil à } \\
\text { quelqu'vn. }\end{array}$ & 143 & Conseiller. \\
\hline Conseilluquetan ibiltea. aller au conseil. & $\begin{array}{l}\text { Conseil. Aller au conseil apres les plaidoyez } \\
\text { des parties. }\end{array}$ & 142 & \\
\hline Conseillu esque dago. il demande conseil. & Conseil. Demander conseil. & 142 & \\
\hline CONSOLATCEa. consoler. & Consoler. & 144 & Consoler. \\
\hline Consolacionea, consolamendua. consolation. & Consolation. & 144 & Consolation \\
\hline Consolagarria. & & & [Consolatoire]. \\
\hline Consolatçaillea. & [Consolateur]. & 144 & [Consolateur]. \\
\hline Contra. & [Contre]. & 147 & [Contre]. \\
\hline Contracarra, contresta & [Contrecarre]. & 147 & [Contrecarre]. \\
\hline CONTRICIONEA, vrriquimendua. contrition. & Contrition. & 149 & Contrition. \\
\hline Contua. compte. & Compte. & 137 & Compte. \\
\hline Copia. copie. & Copie. & 150 & Copie. \\
\hline Copiatcea. copier. & Copier. & 150 & Copier. \\
\hline Corapilloa. neud. & Neud. & 429 & Neud. \\
\hline Corapillatcea. noüer. & Noüer. & 429 & Noüer. \\
\hline Corapilladura. & [Noüement]. & 429 & [Noüement]. \\
\hline ÇOROA. fol. extrauagué. & Fol. & 291 & Fol. \\
\hline Çoratcea. & [Folier]. & 291 & [Folier]. \\
\hline Çoramendua. & [Folie]. & 291 & [Folie]. \\
\hline CoRdoIna. cordon. & Cordon & 151 & Cordon. \\
\hline Chapel cordoina. cordon de chapeau. & & & $\begin{array}{l}\text { Cordon de cha- } \\
\text { peau. }\end{array}$ \\
\hline CORDUANA. marroquin. & $\begin{array}{l}\text { Marroquin [...] car s'il estoit passé en Tan, } \\
\text { ce seroit Cordoüan. }\end{array}$ & 397 & Marroquin. \\
\hline ÇORHIA. meur. & Meur. & 410 & Meur. \\
\hline Çorhitcea. meurir. & Meurir. & 410 & Meurir. \\
\hline ÇORHOA. preau. herbe verte. & Preau. & 504 & Preau. \\
\hline Çorra. debte. (Voltoire) & Debte. & 178 & Debte. \\
\hline
\end{tabular}




\begin{tabular}{|c|c|c|c|}
\hline $\begin{array}{c}\text { A eskuizkribuko } \\
\text { sarrerak }\end{array}$ & $\begin{array}{c}\text { Nicot-en } \\
\text { sarrerak }\end{array}$ & $\begin{array}{c}\text { Nicot-en } \\
\text { or.zenbakia }\end{array}$ & $\begin{array}{c}\text { Oudin-en } \\
\text { sarrerak }\end{array}$ \\
\hline Çorduna. debiteur. & Debteur. & 178 & Debteur. \\
\hline ÇORROA. sac. poche. & Sac. & 577 & Sac. \\
\hline CORSUA. course. & Course. & 159 & Course. \\
\hline $\begin{array}{l}\text { CORTEA, gortea. cour, palais royal, lieu } \\
\text { ou on plaide }\end{array}$ & Court & 160 & Court \\
\hline Cortesalea. courtisan. & Courtisan. & 161 & Courtisan \\
\hline CORTEZA. courtois. & Courtois. & 161 & Courtois. \\
\hline Cortezia. courtoisie. & Courtoisie. & 161 & Courtoisie. \\
\hline ÇORTHEA. sort. & Sort. & 601 & Sort. \\
\hline Costuma. coutume. & Coustume. & 162 & Coustume. \\
\hline Costumatcea. accoutumer. & Accoutumer. & 9 & Accoustumer. \\
\hline Costumatua. accoutumé. & Accoutumé. & 9 & Accoustumé. \\
\hline Costumaz. par coutume. & Coustume. Par coustume. & 162 & \\
\hline Cotilluna. cotillon & & & Cottillon \\
\hline ÇOTINA. 2. chopina. hoquet. & Hoquet. & 339 & Hoquet. \\
\hline CRACOAC, macoac. croc. crochet. & Croc. & 167 & Croc. \\
\hline CREDITA. credit. & Credit. & 165 & Credit. \\
\hline CREDOA. symbole des apostres. & & & $\begin{array}{l}\text { le Credo, el credo } \\
\text { o symbolo de } \\
\text { Apostoles. }\end{array}$ \\
\hline CRISMOA, crisuma. créme. & Cresme. & 165 & Cresme. \\
\hline Croscatcea. frotter. battre. (CROSCA) & Frotter. & 303 & Frotter. \\
\hline CRUXPETAC. bignets. & Bignets. & 78 & Bignet. \\
\hline ÇU, çuc. vous. & Vous. & 669 & Vous. \\
\hline CuBA. cuue. & Cuve. & 172 & Cuue. \\
\hline ÇuCENA. le droit. ius. & Droit et raison, Ius. & 215 & Droict. \\
\hline ÇUHURCIA. sagesse. & Sagesse. & 578 & Sagesse. \\
\hline Çuhurra. sage. sobre. discret. & Sage. & 578 & Sage. \\
\hline Çuhurqui. sagem[ent]. & Sagement. & 578 & Sagement. \\
\hline CuILlidA. cuilliere. & Cuilliere. & 171 & Cuiller. \\
\hline ÇUNKURRa. bossu. courbé. & Bossu. & 84 & Bossu. \\
\hline Çunkurtcea. & [Bossuer]. & 84 & [Bossuer]. \\
\hline $\begin{array}{l}\text { Illarac çurkaitztatcea. ramer les pois. } \\
\text { (ÇURKAITZTATCEA) }\end{array}$ & Ramer. Ramer des poix. & 536 & \\
\hline Curiosa. curieux. & Curieux. & 172 & Curieux. \\
\hline Curiostasuna. & [Curiosité]. & 172 & [Curiosité]. \\
\hline Curiosqui. & & & [Curieusement]. \\
\hline ÇURMINDUA. moisi. vermoulu. & Moisi. & 415 & \\
\hline
\end{tabular}




\begin{tabular}{|c|c|c|c|}
\hline $\begin{array}{l}\text { A eskuizkribuko } \\
\text { sarrerak }\end{array}$ & $\begin{array}{c}\text { Nicot-en } \\
\text { sarrerak }\end{array}$ & $\begin{array}{c}\text { Nicot-en } \\
\text { or.zenbakia }\end{array}$ & $\begin{array}{c}\text { Oudin-en } \\
\text { sarrerak }\end{array}$ \\
\hline Çurmindura. & [Moissisure]. & 415 & [Moissiseur] \\
\hline Çurmintcea. & [Moisir]. & 415 & Moisir. \\
\hline $\begin{array}{l}\text { Curchetatcea. fermer de crochets. } \\
\text { (Curchetac) }\end{array}$ & & & Corcheter. \\
\hline $\begin{array}{l}\text { Cutchua, oha eltcea. pot de chambre. } \\
\text { matula. }\end{array}$ & Pot. Pot à pissser, Matula. & 497 & $\begin{array}{l}\text { Pot de chambre, } \\
\text { \& Pot a pisser. }\end{array}$ \\
\hline Cutsua. tache. & Tache. & 615 & Tache. \\
\hline Cutsatcea. tacher. & Tacher. & 615 & Tacher. \\
\hline $\begin{array}{l}\text { Oguia cuzcatcea. chapeller le pain. (Cuz- } \\
\text { CATCEA) }\end{array}$ & Chapeler. chapeler du pain. & 113 & Chapeler le pain. \\
\hline DAINUA. pert. dommage. degast. & Dommage. & 210 & Dommage. \\
\hline DAMUA. douleur. regret. fascherie. & Regret. & 549 & Regret. \\
\hline Damugarria. & [Regretable]. & 549 & [Regretable]. \\
\hline Damutcea. & [Regretter]. & 549 & [Regretter]. \\
\hline DANSA. (Voltoire) & Danse. & 175 & Danse. \\
\hline Dansaria. & [Danseur]. & 175 & [Danseur]. \\
\hline DARDOA. dard. & Dard. & 175 & Dard. \\
\hline Dardatcea. darder. & Darder. & 175 & Darder. \\
\hline DebauXqueria. debauche. & & & Desbauche. \\
\hline Debauxatcea. debaucher. & Desbaucher. & 191 & Desbaucher. \\
\hline Deвecua. defense. prohibition. & Defense. & 181 & Deffense. \\
\hline Debecatcea. defendre. prohiber. & Defendre. & 180 & Deffendre. \\
\hline Debecatçaillea. & [Defenseur ou defendeur]. & 181 & [Deffendeur]. \\
\hline DECLARACIONEA, declaracinoa. declaration. & Declaration. & 179 & Declaration. \\
\hline Declaratcea. declarer. & Declarer. & 179 & Declarer. \\
\hline Declaratçaillea. qui declare. & Declarer. Qui declare et donne à entendre [...]. & 179 & Declarant. \\
\hline Deliberacionea. deliberation. resolution. & Resolution. & 563 & Resolution. \\
\hline Deliberatua. & [Resolu]. & 563 & [Resolu]. \\
\hline Guiçon deliberatua. & [Resolu. Vn homme resolu]. & 563 & \\
\hline DELIENÇA, agudotasuna. diligence. & Diligence. & 206 & Diligence. \\
\hline Delienta, agudo. diligent. & Diligent. & 206 & Diligent. \\
\hline Dentilla. dentelle. & & & Dentelles. \\
\hline DesafiOA. defi. & Desfi & 194 & Defy. \\
\hline Desafiatcea. defier. & Desfier & 194 & Desfier. \\
\hline Descargua. decharge. & & & Descharge. \\
\hline Descargatcea. decharger. & Descharger. & 191 & Descharger. \\
\hline Deseguitea. defaire. detruire. & Destruire. & 201 & Destruire. \\
\hline Deseguina. defait. detruit. & Destruict. & 201 & Destruit. \\
\hline
\end{tabular}


JAVIER ETXAGIBEL

\begin{tabular}{|c|c|c|c|}
\hline $\begin{array}{l}\text { A eskuizkribuko } \\
\text { sarrerak }\end{array}$ & $\begin{array}{l}\text { Nicot-en } \\
\text { sarrerak }\end{array}$ & $\begin{array}{c}\text { Nicot-en } \\
\text { or.zenbakia }\end{array}$ & $\begin{array}{c}\text { Oudin-en } \\
\text { sarrerak }\end{array}$ \\
\hline Deseguillea. qui defait. destructeur. & & & Destructeur. \\
\hline Desenguidura, deseguintça. destruction. & Destruction. & 202 & Destruction. \\
\hline Desencusa. excuse. & Excuse. & 270 & Excuse. \\
\hline Desencusamendua. & [Excusation]. & 270 & [Excusation]. \\
\hline Desencusatcea. & & & [Excuser] \\
\hline Desgogara çait. il me deplaist. (DESGOGARA) & Desplaire. Il me desplait grandement. & 199 & \\
\hline Desira. desir. & Desir. & 195 & Desir. \\
\hline Desiratcea. desirer. & Desirer. & 195 & Desirer. \\
\hline Desirosa. & [Desireux] & 195 & [Desireux]. \\
\hline DesOHOREA, desondra. deshonneur. & Deshonneur. & 195 & Deshonneur. \\
\hline Desohoratcea. & [Deshonnorer]. & 195 & [Deshonnorer]. \\
\hline Desohoramendua. & & & $\begin{array}{l}\text { [Deshonnora- } \\
\text { tion]. }\end{array}$ \\
\hline DesORDENUA. desordre. dereglement. & Desordre. & 197 & Desordre. \\
\hline Desordenatua. desordonné. & Desordonné. & 197 & \\
\hline DespendatCEA. gastatzea depenser. & & & Despenser. \\
\hline Despendioa, gastua. depens. & Despens. & 197 & Despense \\
\hline Ene despendioz, ene gastuz. a mes depens. & $\begin{array}{l}\text { Despens. Il sent le vnguens à mes despens et de } \\
\text { mon bien. }\end{array}$ & 197 & \\
\hline Despendaria. depensier. & Despensier. & 198 & Despensier. \\
\hline Despita. depit. & Despit. & 198 & Despit. \\
\hline Despitatcea, despitcea. depiter. & Despiter. & 199 & Despiter. \\
\hline Desplacera. deplaisir. & Desplaisir. & 199 & Desplaisir. \\
\hline Desplacermendua. & [Desplaisance]. & 199 & [Desplaisance]. \\
\hline Desplacergarria. & & & [Desplaisant]. \\
\hline Desserta. dessert de table. & Dessert. Desserte de table. & 200 & Dessert. \\
\hline $\begin{array}{l}\text { DESTARTA, erreueza. lourdaut. etourdi O. } \\
\text { rudis. rusticus. }\end{array}$ & Lourdaut. Rusticus. & 381 & Lourdaut. \\
\hline Destartcea. & [Estourdir]. & 265 & [Estourdir]. \\
\hline Destartqui. & & & [Estourdiement] \\
\hline Desterrua. exil. & Exil. & 271 & Exile. \\
\hline Desterratcea. exiler. bannir. & Exiler. & 271 & Exhiler. \\
\hline DETCHUMAC, hamarrenac. dismes. & Dismes. & 208 & Dismes. \\
\hline Detchumaria. dismeur. & Dismeur. & 208 & Dismeur. \\
\hline Detchumatcea. dismer. & Dismer. & 208 & Dismer. \\
\hline Deuersatcea 2. ehoitea. digerer. & Digerer. & 206 & Digerer. \\
\hline Deuocionea. deuocion. & Deuotion. & 204 & Deuotion. \\
\hline Deuocionetsua, deuota. deuot. & Deuot. & 204 & Deuot. \\
\hline
\end{tabular}




\begin{tabular}{|c|c|c|c|}
\hline $\begin{array}{c}\text { A eskuizkribuko } \\
\text { sarrerak }\end{array}$ & $\begin{array}{l}\text { Nicot-en } \\
\text { sarrerak }\end{array}$ & \begin{tabular}{|c|} 
Nicot-en \\
or.zenbakia
\end{tabular} & $\begin{array}{c}\text { Oudin-en } \\
\text { sarrerak }\end{array}$ \\
\hline Ezta deusic. il n'y a rien. (DeusA) & Rien. Il n'y a rien que. & 570 & \\
\hline Ezdeusa. le rien. & Rien. & 570 & Rien. \\
\hline DEYADARRA. alarme. & Alarme. & 25 & Alarme. \\
\hline Deyadarguillea. qui donne l'alarme. & Alarme. On a donné l'alarme au camp. & 25 & \\
\hline DifERENCIA. difference. & Difference. & 205 & Difference. \\
\hline Diferenciatcea. & & & [Differencier]. \\
\hline Diferenta. & [Different]. & 205 & [Different]. \\
\hline Diferentqui. & & & [Differement]. \\
\hline Disciflina. discipline. & Discipline. & 208 & Discipline. \\
\hline Discipulua. disciple. & Disciple. & 208 & Disciple. \\
\hline Disgracia. disgrace. & Disgrace. & 208 & Disgrace. \\
\hline Disgraciatcea. & & & [Disgratier]. \\
\hline Distia handiaz. & Splendeur. & 608 & Splendeur. \\
\hline Distiatcea. reluire. briller. & Reluire. & 552 & Reluire. \\
\hline Distiadura. lueur. brillant. fulgor. & Lueur, Fulgor. & 383 & Lueur. \\
\hline Ditharea. dé a coudre. & Dé. Dé à coudre. & 176 & Dé a coudre. \\
\hline DixiduA. menace. & Menace. & 401 & Menace. \\
\hline Dixidatcea. menacer. & Menacer. & 401 & Menacer. \\
\hline Dixidaria, dixidatçaillea. menaceur. & Menaceur. & 401 & Menaceur. \\
\hline Doatsua. bienheureux. & Bienheureux. & 78 & Bien-heureux. \\
\hline Doatsutcea. bienheurer. & Bienheurer. & 78 & Bien-heurer. \\
\hline Doatsutasuna. bonheur. felicité. & Heur. De bon Heur. & 335 & Bon-heur. \\
\hline Doblea. double. & Double. & 212 & Double. \\
\hline Doblatcea. doubler. & Doubler. & 213 & Doubler. \\
\hline Dobladura. & & & [Doubleure]. \\
\hline DOHACABEA. malheureux. (Voltoire) & Malheureux. & 391 & Mal-heureux. \\
\hline Dohacabetcea. rendre malheureux. & & & [Mal-heurer]. \\
\hline Dohacabetasuna. malheur. & Malheur. & 391 & Mal-heur. \\
\hline Dohacabequi. malheureusement. (Voltoire) & Malheureusement. & 391 & $\begin{array}{l}\text { Mal-heureuse- } \\
\text { ment. }\end{array}$ \\
\hline DoHAINA, emaitça, donua. don. present. & Don. & 212 & Don. \\
\hline DOLAMENA. doleance. & Doleance. & 210 & Doleance. \\
\hline DOLOREA. douleur. & Doleur. & 210 & Douleur. \\
\hline Dolorezcoa. & Doloureux. & 210 & Douloureux. \\
\hline Dolorezqui. & [Doloureusement]. & 210 & $\begin{array}{l}\text { [Doloureuse- } \\
\text { ment]. }\end{array}$ \\
\hline Doloratcea. & [Doloir]. & 210 & [Douloir]. \\
\hline Dolva. deüil. & Dueil. & 217 & Deüil. \\
\hline
\end{tabular}




\begin{tabular}{|c|c|c|c|}
\hline $\begin{array}{c}\text { A eskuizkribuko } \\
\text { sarrerak }\end{array}$ & $\begin{array}{l}\text { Nicot-en } \\
\text { sarrerak }\end{array}$ & \begin{tabular}{|c|}
$\begin{array}{c}\text { Nicot-en } \\
\text { or.zenbakia }\end{array}$ \\
\end{tabular} & $\begin{array}{c}\text { Oudin-en } \\
\text { sarrerak }\end{array}$ \\
\hline Doluzco arropa. robe de deuil. & Dueil. Robbe, chapperon et habit de dueil. & 217 & \\
\hline Dolutcea. & [Dueil. Faire dueil]. & 217 & \\
\hline Dolutsua. & [Dueil. Pleine de dueil]. & 217 & \\
\hline $\begin{array}{l}\text { DONABERAC edo tonaberac. les tenebres, } \\
\text { offices de la Semaine Sante. }\end{array}$ & & & $\begin{array}{l}\text { les Tenebres que } \\
\text { l'on chante la se- } \\
\text { maine Saincte. }\end{array}$ \\
\hline Donceilla. demoiselle. & Damoiselle. & 173 & $\begin{array}{l}\text { Damoiselle, de- } \\
\text { moiselle. }\end{array}$ \\
\hline DoteA. dot. & Dost. & 212 & Dot. \\
\hline Dotatcea. doter. & & & Doter. \\
\hline DraGoINA. dragon. & Dragon. & 214 & Dragon. \\
\hline DuDA. doute. & Doubte. & 213 & Doute. \\
\hline Dudatcea. douter. & Doubter. & 213 & Douter. \\
\hline Dudacorra. & & & [Doutant]. \\
\hline $\begin{array}{l}\text { Dudatsua. } \\
\text { Dudosa. }\end{array}$ & [Douteux]. & 213 & [Douteux $]$. \\
\hline Duga. douelle de tonneau. & & & Douuelle. \\
\hline Dugata. vn ducat. & Ducat. & 217 & Ducat. \\
\hline DukEa. duc. & Duc. & 217 & Duc. \\
\hline Duketasuna. & [Duché]. & 217 & [Duché]. \\
\hline Dukezza. & & & [Duchesse]. \\
\hline Dulcea. eztia. doux. & Doulx. & 213 & Doux. \\
\hline Dulcetasuna. & [Doulceur]. & 214 & [Douceur]. \\
\hline Dulcequi. & [Doulcement]. & 214 & [Doucement]. \\
\hline Durdusia. menace. & Menace. & 401 & Menace. \\
\hline $\begin{array}{l}\text { Durdusiatcea, induriatcea. menacer. fro- } \\
\text { ller. }\end{array}$ & Menacer. & 401 & Menacer. \\
\hline Durdusiadura. & Menacement. & 401 & Menacement. \\
\hline Durdusiatçaillea. & [Menaceur]. Qui menace. & 401 & [Menaceur]. \\
\hline Iagoiti, iagoitic. desormais. ( $\left.\mathrm{IA}_{\mathrm{A}}\right)$ & Desormais. & 197 & Desormais. \\
\hline IABEA. maistre. possesseur. & Posseseur. & 496 & Posseseur. \\
\hline Iabetcea. posseder. entre en possession. & Posseder. & 496 & Posseder. \\
\hline Iabetasuna. & [Possession]. & 496 & [Possession]. \\
\hline IAINCOA, Iaungoicoa. Dieu. & Dieu. & 204 & Dieu. \\
\hline Iaincossa. deesse. & Deesse. & 180 & Deesse. \\
\hline Iaincotasuna. diuinité. & Diuinité. & 209 & Diuinité. \\
\hline Iaincotcea. rendre ou deuenir Dieu. deifier. & Deifier. & 182 & Deifier. \\
\hline Iaincortiartasuna. pieté. deuotion. & Deuotion. & 204 & Deuotion. \\
\hline
\end{tabular}




\begin{tabular}{|c|c|c|c|}
\hline $\begin{array}{c}\text { A eskuizkribuko } \\
\text { sarrerak }\end{array}$ & $\begin{array}{l}\text { Nicot-en } \\
\text { sarrerak }\end{array}$ & $\begin{array}{c}\text { Nicot-en } \\
\text { or.zenbakia }\end{array}$ & $\begin{array}{c}\text { Oudin-en } \\
\text { sarrerak }\end{array}$ \\
\hline Iaincortiartcea. deuenir deuot. & Deuot. Il denient denot. & 204 & \\
\hline Iaincozqui. diuinem[ent]. & Diuinement. & 209 & Diuinement. \\
\hline IAIQUITCEA, jaiquitea. se leuer. & Leuer. Se leuer. & 372 & Se leuer. \\
\hline IAITSTEA. tirer. pressurer. & Tirer. & 630 & Tirer. \\
\hline Behiaren iaitstea. traire vne vache. & Traire. Traire vne vache [...] & 639 & \\
\hline Esnearen jaitstea. tirer du laict. & Tirer. Tirer le laict d'vne mamelle. & 630 & \\
\hline IALGUITEA 2, jlkitcea. sortir. mettre dehors. & Sortir. & 601 & Sortir. \\
\hline IANHARIA. viande. mangeaille. & Mangeaille. & 392 & Mangeaille \\
\hline IAQUITEA. sçauoir. & Sçauoir. & 583 & Sçauoir. \\
\hline Iaquilegoa $\mathrm{O}$, lecucotasuna. temoignage. & Tesmoinage. & 627 & Tesmoinage. \\
\hline Iaquinsuna. sçauant. & Sçauant. & 584 & Sçaüant. \\
\hline Iaquintasuna. science. & Science. & 584 & Science. \\
\hline IARRAIQUITCEA. suiure. (Voltoire) & Suyure. & 613 & Suiure. \\
\hline Iarraiquitça. suite. poursuite. & Suite. & 613 & Suitte. \\
\hline IASARTCEA. frapper. battre. & Frapper. & 300 & Frapper. \\
\hline IATEA. manger. & Manger. & 392 & Manger. \\
\hline Ialea. mangeur. & Mangeur. & 392 & Mangeur. \\
\hline IAUGUITEA. 2. ethortcea. venir. & Venir. & 653 & Venir. \\
\hline IAUNSTEA. vestir. & Vestir. & 658 & Vestir. \\
\hline Iauntsaldia, aldagarria. habit. & Habit. & 326 & Habit. \\
\hline Iauntscura, iauntscuïa. habillem[ent]. & Habillement. & 326 & Habillement. \\
\hline IAUSIA. saut. & Sault. & 582 & Sault. \\
\hline Iausi eguitea. sauter. & Saulter. & 582 & Saulter. \\
\hline Iausica. & [Saulter. En saultant]. & 582 & \\
\hline Iautstea. sauter. descendre. (Voltoire) & Descendre. & 191 & Descendre. \\
\hline $\begin{array}{l}\text { Iautzapena. a. 140. cheute, descendant, } \\
\text { descente. }\end{array}$ & Descente. & 191 & Descente. \\
\hline Iautzcalaria, iautscaria. sauteur. & Saulteur. & 582 & Saulteur. \\
\hline IAYOTCEA, sortcea. naistre. & Naistre. & 425 & Naistre. \\
\hline Iaya eguna. jour natal. & $\begin{array}{l}\text { Natiuité. Le jour de la natiuité d'vn chascun } \\
\text { [...] Die natalis. }\end{array}$ & 425 & \\
\hline IвAYA. cours d'eau. riuiere. & Riuiere. & 571 & Riuiere. \\
\hline IBENTCEA. mettre. poser. & Mettre. & 408 & Mettre. \\
\hline IBILTCEA, ibiltea. aller. marcher. se promener. & Aller. & 26 & Aller. \\
\hline IBIRIA, ipidia, iuia. O. gué. & Gué. & 323 & Gué. \\
\hline IÇARIA, neurria. mesure. & Mesure. & 407 & Mesure. \\
\hline Isartcea. mesurer. & Mesurer. & 407 & Mesurer. \\
\hline ICEBA. tante. & Tante. & 617 & Tante. \\
\hline
\end{tabular}




\begin{tabular}{|c|c|c|c|}
\hline $\begin{array}{l}\text { A eskuizkribuko } \\
\text { sarrerak }\end{array}$ & $\begin{array}{c}\text { Nicot-en } \\
\text { sarrerak }\end{array}$ & $\begin{array}{c}\text { Nicot-en } \\
\text { or.zenbakia }\end{array}$ & $\begin{array}{l}\text { Oudin-en } \\
\text { sarrerak }\end{array}$ \\
\hline ICENA. nom. (Voltoire) & Nom. & 431 & Nom. \\
\hline Icendatcea. nommer. & Nommer. & 431 & Nommer. \\
\hline Icengoitia. surnom, sobriquet. & Surnom. & 612 & Surnom. \\
\hline Icenguillatcea. surnommer. & $\begin{array}{l}\text { Surnommer. Estre surnommé et auoir vn } \\
\text { sotbriquet. }\end{array}$ & 612 & Surnommer. \\
\hline ICERDIA. sueur. qui suë. & Sueur. Sueur, Qui sue. & 610 & Sueur. \\
\hline Icerditcea, icertcea. suer. & Suer. & 610 & Suer. \\
\hline ICEYA. sapin. & Sapin. & 581 & Sapin. \\
\hline $\begin{array}{l}\text { IсHAKA, jxeka. sillon pour faire ecou- } \\
\text { ler l'eau. }\end{array}$ & $\begin{array}{l}\text { Seillon. Vn seillon ou rayon pour esgoutter } \\
\text { l'eaue. }\end{array}$ & 587 & \\
\hline ICHILLA. & [Taire.Qui se taist]. & 616 & \\
\hline Ichiltcea. se taire, faire taire. & Taire. Se taire. Faire taire. & 616 & Taire. Se taire. \\
\hline ICHUCATCEA. essuyer. torcher. & Essuyer. & 260 & Essuyer. \\
\hline ICIALDURA, icidura. peur. & Peur. & 478 & Peur. \\
\hline Icicorra. peureux. & & & Peureux. \\
\hline Icipera. peureux. & & & Peureux. \\
\hline Icitcea. faire peur. auoir peur. & Peur. Auoir peur. Faire peur. & 478 & \\
\hline IÇOKINA. saumon. & Salmon. & 582 & Saumon. \\
\hline Içorratcea. engrosser. (IÇORRA) & Engrossir. & 231 & Engrosser. \\
\hline IçOTZA. gelée. & Gelée. & 312 & Gelée. \\
\hline $\begin{array}{l}\text { IÇURPIDEA, jtçurpidea. 2. itçulbidea. } \\
\text { echapatoire. }\end{array}$ & Eschappatoire. & 245 & Eschappatoire. \\
\hline IÇURRIA. peste. (Voltoire) & Peste. & 477 & Peste. \\
\hline Içurritea. pestilence. & Pestilence. & 477 & Pestilence. \\
\hline IDIA. beuf. (Voltoire) & Beuf. & 77 & Beuf. \\
\hline Idiquia, guehelia. chair de beuf. & Chaire de beufs. & 77 & $\begin{array}{l}\text { Du Beuf, chair } \\
\text { de beuf. }\end{array}$ \\
\hline Idiçaina. nerf de beuf. & & & Nerf de boeuf. \\
\hline IDORRA. sec. & Sec. & 586 & Sec. \\
\hline Idortcea. secher. (Voltoire) & Seicher. & 586 & Secher. \\
\hline Idortea. secheresse. & Seicheresse. & 586 & Secheresse. \\
\hline Idorqui. & [Seichement] & 586 & Sechement. \\
\hline $\begin{array}{l}\text { IDURIA, jrudia. 2. semblant. semblance. } \\
\text { (Voltoire) }\end{array}$ & Semblant. Semblance. & 588 & $\begin{array}{l}\text { Semblant. Sem- } \\
\text { blance. }\end{array}$ \\
\hline $\begin{array}{l}\text { Ez jcusi iduri eguitea. faire semblant de } \\
\text { ne voir pas. }\end{array}$ & $\begin{array}{l}\text { Semblant. Faire semblant de ne veoir ou ap- } \\
\text { perceuoir point quelque chose. }\end{array}$ & 588 & \\
\hline Iduriz. a la semblance. & $\begin{array}{l}\text { Semblance. A la semblance, ou à la façon et } \\
\text { maniere. }\end{array}$ & 588 & \\
\hline IЕÏA. 2. jaïa. feste. & Feste. & 284 & Feste. \\
\hline
\end{tabular}




\begin{tabular}{|c|c|c|c|}
\hline $\begin{array}{l}\text { A eskuizkribuko } \\
\text { sarrerak }\end{array}$ & $\begin{array}{c}\text { Nicot-en } \\
\text { sarrerak }\end{array}$ & $\begin{array}{c}\text { Nicot-en } \\
\text { or.zenbakia }\end{array}$ & $\begin{array}{c}\text { Oudin-en } \\
\text { sarrerak }\end{array}$ \\
\hline Iaïa iduquitea, hautstea. fester. & Fester. & 284 & Fester. \\
\hline Ieloscorra. jaloux. (IELOSIA) & Ialoux. & 343 & Ialoux. \\
\hline Ieloscortasuna. jalousie. & Ialousie. & 343 & Ialousie. \\
\hline Ieloscorqui. & [Ialousement]. & 343 & [Ialousement]. \\
\hline IELOSIAC. treillis. & Treillis. & 641 & Treillis. \\
\hline $\begin{array}{l}\text { IFINTCEA, landatcea. planter. piquer. } \\
\text { ficher. attacher. }\end{array}$ & Planter. & 487 & Planter. \\
\hline Ifinia. mis. planté. & Planté. & 487 & \\
\hline Ifintça. plantatio. & Plantement. Plantatio. & 488 & \\
\hline IGORÇURIA, ihorciria, durunda S. tonnerre. & Tonnairre. & 633 & Tonnerre. \\
\hline $\begin{array}{l}\text { Dembora igortciritsua. temps plein de } \\
\text { tonnerres. }\end{array}$ & & & $\begin{array}{l}\text { Tonnerreux,tiem- } \\
\text { po de trueno. }\end{array}$ \\
\hline IGORTCEA. enuoyer. & Enuoyer. & 242 & Enuoyer. \\
\hline Igorria. enuoyé. & & & Enuoyé. \\
\hline IguALA, berdina. egal. & Egual. & 221 & Egal. \\
\hline Igualatcea, berdintcea. egaler. & Egualer. & 221 & Egaler. \\
\hline IgueLA, jhela. grenouille. & Grenouille. & 321 & Grenoüille. \\
\hline IgUeLSUA, guilsua e. plastre. & Plastre. & 488 & Plastre. \\
\hline Iguelsuztatcea, guilsatcea. plastrer. & Plastrer. & 488 & Plastrer. \\
\hline Iguericatcea. nager. (IgUEREA) & Nager. & 425 & Nager. \\
\hline Iguericaria, iguericatçaillea. nageur. & Nageur. & 425 & Nageur. \\
\hline Igueriketac. & & & [Nageure]. \\
\hline IGURIKITCEA. attendre. & Attendre. & 54 & Attendre. \\
\hline Igurikitça. attente. expectatio. & Attente. Attente et desir, Expectatio. & 54 & Attente. \\
\hline IGUZQUiA, ekia. soleil. & Soleil. & 598 & Soleil. \\
\hline Iguzqui jlkitea. l'orient. & Soleil leuant, Oriens sol. & 598 & Soleil leuant. \\
\hline Iguzqui sartcea. l'occident. & Soleil couchant, Occidens sol. & 598 & Soleil couchant. \\
\hline Iguzqui mina. soleil ardent. & Soleil. Le soleil est fort ardant. & 598 & \\
\hline $\begin{array}{l}\text { Iguzqui belharra, iguzqui lorea. tourne- } \\
\text { sol. solsequium. }\end{array}$ & & & $\begin{array}{l}\text { Soleil fleur, tor- } \\
\text { nasol. }\end{array}$ \\
\hline $\begin{array}{l}\text { Iguzquiz iguzqui. d'vn soleil a l'autre. du } \\
\text { matin au soir. }\end{array}$ & & & $\begin{array}{l}\text { Entre deux So- } \\
\text { leils, de sol a sol. }\end{array}$ \\
\hline Iguzquiztatcea. mettre, etendre au soleil. & Soleil. Mettre au soleil. & 598 & \\
\hline $\begin{array}{l}\text { IHARDETSTEA, inhardetstea. repondre a } \\
\text { vne demande. }\end{array}$ & Respondre. & 564 & Respondre. \\
\hline Ihardetspena O. reponse. & Response. & 564 & Response. \\
\hline $\begin{array}{l}\text { IHARDUQUITCEA. contester. disputer sur } \\
\text { quelque chose. }\end{array}$ & & & Quereller. \\
\hline Iharduquitçaillea. qui conteste. & Querelleux. & 530 & Querelleux. \\
\hline
\end{tabular}




\begin{tabular}{|c|c|c|c|}
\hline $\begin{array}{c}\text { A eskuizkribuko } \\
\text { sarrerak }\end{array}$ & $\begin{array}{l}\text { Nicot-en } \\
\text { sarrerak }\end{array}$ & $\begin{array}{c}\text { Nicot-en } \\
\text { or.zenbakia }\end{array}$ & $\begin{array}{c}\text { Oudin-en } \\
\text { sarrerak }\end{array}$ \\
\hline Iharduquitça. querelle. disension. & Querelle. & 530 & Querelle. \\
\hline IHARRA. etincelle. & Estincelle. & 264 & Estincelle. \\
\hline IHARTCEA, eihartcea. deuenir sec, aride. & Sec. deuenir sec, et se seicher. & 586 & \\
\hline IHARROZTEA, inharroztea. secouer. ebranler. & Secouer. & 585 & Secoüer. \\
\hline IHETCEA, higatua. vsé. & Vsé. & 670 & Vsé. \\
\hline Ihetcetcea. vser. & Vser. & 670 & Vser. \\
\hline IHIA. jonc. & Ionc. & 355 & Ionc. \\
\hline IHICIA. chasse. & Chasse. & 117 & Chasse. \\
\hline Ihiztaria. chasseur. & Chasseur. & 117 & Chasseur. \\
\hline Ihiztatcea. chasser. & Chasser. & 116 & Chasser. \\
\hline IHINÇA. rosée. & Rosée. & 573 & Rosée. \\
\hline IKAITEA. monter. (Voltoire) & Monter. & 417 & Monter. \\
\hline Ikaitça. montée. l'action de monter. & Montée. & 418 & Montée. \\
\hline IKARA. tremblement. & Tremblement. & 641 & Tremblement. \\
\hline Ikaratcea. trembler. (Voltoire) & Trembler. & 641 & Trembler. \\
\hline Lur ikaratce handia. grand trembleterre. & & & Trembleterre. \\
\hline Ikaradura. & & & $\begin{array}{l}\text { [Tremblotte- } \\
\text { ment]. }\end{array}$ \\
\hline IKARTCEA. regarder. regard. & Regarder. Regard. & 548 & Regarder. \\
\hline IKASTEA. aprendre. (Voltoire). discere. & Apprendre, Discere. & 39 & Apprendre. \\
\hline Ikasgaya. capable d'aprendre. & Apprendre. Qui aprend aisement, Docilis. & 39 & \\
\hline Ikastuna. aprenty. & Apprenti. & 39 & Apprenty. \\
\hline Ikaslea. qui aprend. & $\begin{array}{l}\text { Apprendre. Celuy ou celle qui apprend d'vn } \\
\text { autre. }\end{array}$ & 39 & \\
\hline Ikazgoa. aprentissage. & Apprentissage. & 39 & Apprentissage. \\
\hline IKATZA. charbon. & Charbon. & 114 & Charbon. \\
\hline IKEA. montée. colline. & Coline. & 130 & Colline. \\
\hline IKUСATCEA. O., vrhentcea. acheuer. & Acheuer. & 11 & Acheuer. \\
\hline IKUZTEA, ikutzea Liz. nettoyer. lauer. & Lauer. Lauer et nettoyer. & 369 & Lauer. \\
\hline Ikuzgarria. Io. 5.4. lauoir. lauacrum. & Lauer. Vn lieu à se lauer, Lauacrum. & 369 & Lauoir. \\
\hline IlHAintXa. 2. mirua. (Voltoire) miluus. & Milan. Vn Milan, Miluus. & 411 & Milan. \\
\hline ILHORTCEA. 2. jlhor eguitea. auorter. & Auorter. faire auorter. & 59 & Auorter. \\
\hline ILHUNA. brun. noir. obscur. & Obscur. & 437 & Obscur. \\
\hline Ilhuntcea. obscurcir. & Obscurcir. & 437 & Obscurcir. \\
\hline Ilhuntasuna. obscurité. & Obscurité. & 437 & Obscurité. \\
\hline IMAGINA. image. & Image. & 346 & Oudin 1660. \\
\hline IMIQUia. coeffure de femme. couurechef. & $\begin{array}{l}\text { Coeffure. Coeffure, Ancienne coeffure de } \\
\text { femme.. }\end{array}$ & 346 & Coiffeure. \\
\hline
\end{tabular}




\begin{tabular}{|c|c|c|c|}
\hline $\begin{array}{l}\text { A eskuizkribuko } \\
\text { sarrerak }\end{array}$ & $\begin{array}{c}\text { Nicot-en } \\
\text { sarrerak }\end{array}$ & \begin{tabular}{|c|} 
Nicot-en \\
or.zenbakia
\end{tabular} & $\begin{array}{l}\text { Oudin-en } \\
\text { sarrerak }\end{array}$ \\
\hline IMITATCEA. jmiter. & Imiter. & 346 & Oudin 1660. \\
\hline Imitacionea. jmitation. & Imitation. & 346 & Imitation. \\
\hline $\begin{array}{l}\text { IMMERECIENTA, merecigabea, mereciga- } \\
\text { becoa. indigne. }\end{array}$ & Indigne. & 349 & Indigne. \\
\hline IMMORTALA, ecin hillezcoa. inmmortel. & Immortel. & 347 & Oudin 1660. \\
\hline IMPERFETA, escasa, makurra. jmparfait. & Imparfait. & 347 & Oudin 1660. \\
\hline Imperfeccionea, escasia. jmperfection. & Imperfection. & 347 & Imperfection. \\
\hline IMPRIMATCEA. imprimer. (Voltoire) & Imprimir. & 348 & Imprimir. \\
\hline Imprimatçaillea. imprimeur. & Imprimeur. & 348 & Imprimeur. \\
\hline $\begin{array}{l}\text { Imprimatçaillearena. la maison de l'jm- } \\
\text { primeur. }\end{array}$ & Imprimerie. & 348 & Imprimerie. \\
\hline INCENSUA. encens. & Encens. & 426 & Encens. \\
\hline Incensu toquia. encensoir. & & & Encensoir. \\
\hline INCIRINA. gemissement. & Gemissement. & 312 & Gemissement. \\
\hline INCONTRATCEA. rencontrer. & Rencontrer. & 555 & Rencontrer. \\
\hline Incontrua. rencontre. & Rencontre. & 555 & Rencontre. \\
\hline Incontru onez. par bon rencontre. & Rencontre. Par bonne rencontre. & 555 & \\
\hline INDARRA. force. & Force. & 293 & Force. \\
\hline Indartsua. fort. valereux. & Fort. & 295 & Fort. \\
\hline INDURIA, mehatchua. menace. & Menace. & 401 & Menace. \\
\hline Induriatcea. menacer. & Menacer. & 401 & Menacer. \\
\hline Induriosa. & [Menaçant] & 401 & [Menaçant]. \\
\hline INFORMACIONEA. jnformation. & Information. & 350 & Information. \\
\hline Informatcea. & [Informer]. & 350 & [Informer]. \\
\hline INGUDEA, jngura. enclume. & Enclume. & 227 & Enclume. \\
\hline INGURATCEA. enuironner. & Enuironner. & 242 & Enuironner. \\
\hline Ingurua. l'enuiron. & Enuiron. & 242 & les Enuirons. \\
\hline INHAURTCEA. etendre. & Estendre. & 263 & Estendre. \\
\hline INHURRIA, chinhaurria. fourmi. & Fourmi. & 298 & Fourmi. \\
\hline Inhurritcea. fourmiller. & Fourmiller. & 298 & Fourmiller. \\
\hline IOCATCEA. joüer. & Ioüer. & 355 & Ioüer. \\
\hline Iocaria. joüeur. & Ioueur. & 356 & Ioüeur. \\
\hline Iocoa. jeu. & Ieu. & 345 & Ieu. \\
\hline IOITEA. frapper. percer. pousser. (Voltoire) & Percer. & 473 & Percer. \\
\hline Ioçaçu barrika. percez la barrique. & Percer. Percer de muiz, Dolia terebrare. & 473 & \\
\hline Athea ioitea, bulcatcea. frapper a la porte. & Frapper. Frapper à la porte. & 300 & \\
\hline Iorralea. sarcleur. (IORRA) & Sarcleur. & 581 & Sarcleur. \\
\hline Iorratcea, jorran haritcea. sarcler. & Sarcler. & 581 & Sarcler. \\
\hline
\end{tabular}




\begin{tabular}{|c|c|c|c|}
\hline $\begin{array}{c}\text { A eskuizkribuko } \\
\text { sarrerak }\end{array}$ & $\begin{array}{l}\text { Nicot-en } \\
\text { sarrerak }\end{array}$ & $\begin{array}{c}\text { Nicot-en } \\
\text { or.zenbakia }\end{array}$ & $\begin{array}{c}\text { Oudin-en } \\
\text { sarrerak }\end{array}$ \\
\hline Iorraya. sarclet. & Sarclet. & 581 & Sarclet. \\
\hline IOSTEA. coudre. attacher. (Voltoire) & Coudre. & 154 & Coudre. \\
\hline Iosia. cousu. & Cousu. & 154 & Cousu. \\
\hline Ioslea. couturier, qui coud. & & & Cousturier. \\
\hline Iostura. vne couture. & Cousture. & 154 & Cousture. \\
\hline IPIZPICUA, apezpicua. euesque. & Euesque. & 268 & Euesque. \\
\hline Ipizpicutasuna. euesché. & Euesché. & 268 & Euesché. \\
\hline IRACURTCEa. 2. leitcea. lire. & Lire. & 377 & Lire. \\
\hline Iracurlea, jracurtçaillea. lecteur, qui lit. & Lecteur. & 377 & Lecture. \\
\hline IRAKAZTEA. enseigner. (Voltoire) & Enseigner. & 234 & Enseigner. \\
\hline Irakasia. enseigné. & Enseigner. Enseigné. & 235 & \\
\hline Irakazlea, irakastuna. qui enseigne. & Enseigner. Qui enseigne. & 235 & \\
\hline Irakazmendua. enseignement. & Enseignement. & 235 & Enseignement \\
\hline Irakaztunqueria. pedanterie. & & & Pedanterie. \\
\hline Irakaztunlaria. pedant. & Pedante. & 470 & Pedant. \\
\hline IRAKA. yuraïe. & & & Iuraye. \\
\hline $\begin{array}{l}\text { IRAQUITCEA. bouillir. heruer. heruir. } \\
\text { (Voltoire) }\end{array}$ & Bouillir. & 86 & Boüillir. \\
\hline Vr iraquina. eau bouillante. & Bouillir. Eau bouillant. & 86 & \\
\hline IRASAGARRA. coing, fruit. & Coing, Fruict. & 129 & Coing, fruit. \\
\hline Irasagaronoda. coignier. & Coignier. & 129 & Coignier. \\
\hline IRASTEA. pressurer. & Pressurer. & 509 & Pressurer. \\
\hline IRATÇARTCEA. eueiller. (Voltoire) & Esueiller. & 267 & Esueiller. \\
\hline Iratçarria. eueillé. & Esueillé. & 267 & Esueillé. \\
\hline Iratçargarria. & & & [Esueilleur]. \\
\hline Iratçartçaillea. & [Esueiller]. & 267 & [Esueilleur]. \\
\hline IRAUASTEA. gaigner. (Voltoire) & Gaigner. & 307 & Gaigner. \\
\hline $\begin{array}{l}\text { Irauaslea, irauasçaillea, irauastuna. gaig- } \\
\text { neur. qui gaigne. }\end{array}$ & & & Gaigneur. \\
\hline IRAUNGUITCEA. eteindre. mortifier. & Esteindre. & 262 & Esteindre. \\
\hline Iraunguia. eteint. & & & Esteint. \\
\hline Iraunguidura. extinction. & & & Extinction. \\
\hline IRAUTEA. durer. perseuerer. durée. & Durer. & 218 & Durer. \\
\hline Iraupea, jraupena, irautea. durée. & Durée. & 218 & Durée. \\
\hline IRAZEA. fougere. & Fougiere. & 297 & Fougere. \\
\hline IREQUITCEA, idequitcea. ouurir. & Ouurir. & 451 & Ouurir. \\
\hline IRETSTEA. & Aualler. & 56 & Aualler. \\
\hline Iretslea. & Aualleur. & 56 & Aualleur. \\
\hline
\end{tabular}




\begin{tabular}{|c|c|c|c|}
\hline $\begin{array}{c}\text { A eskuizkribuko } \\
\text { sarrerak }\end{array}$ & $\begin{array}{l}\text { Nicot-en } \\
\text { sarrerak }\end{array}$ & \begin{tabular}{|c|} 
Nicot-en \\
or.zenbakia
\end{tabular} & $\begin{array}{c}\text { Oudin-en } \\
\text { sarrerak }\end{array}$ \\
\hline IRIOITEA. enuoyer. & Enuoyer. & 242 & Enuoyer. \\
\hline IROA. O., handitsua, çaurnea. apostume. & Apostume. & 35 & Apostume. \\
\hline IRRIA. ris. & Ris. & 571 & Ris. \\
\hline Irri eguitea. rire. & Rire. & 571 & Rire. \\
\hline Irribera. & [Rieur]. & 571 & [Rieur]. \\
\hline Irrigarria. & & & [Risible]. \\
\hline IRRIZKINA. ecornifleur. & & & \begin{tabular}{|l|} 
Escorniffleur. \\
\end{tabular} \\
\hline Irrizkintcea. & & & [Escorniffler]. \\
\hline Irrizkintça. & & & [Escornifflerie]. \\
\hline IRRISCUA, erriscua. risque. & & & Risque. \\
\hline Irriscatcea. risquer. & & & Risquer. \\
\hline IRUA. fascheux. depiteux. & Fascheux. & 279 & Fascheux. \\
\hline IRUTEA. filer. (Voltoire) & Filer. & 287 & Filer. \\
\hline Irulea. qui file. & & & [Fileur]. \\
\hline Iruna. filé. & Filé. & 287 & \\
\hline Irulaga. quenoüille. & Quenoüille. & 530 & Quenoüille. \\
\hline IsATSA. balay. & Balay. & 65 & Balay. \\
\hline IsPILLUA. malotru. gueux. & Malotru. & 391 & Malotru. \\
\hline IsQuILIMBA. epingle. & Espingle. & 258 & Espingle. \\
\hline Istape eguitea. enjamber. (ISTAPEA) & Enjamber. & 232 & $\begin{array}{l}\text { Enjamber. hazer } \\
\text { piernas. }\end{array}$ \\
\hline IstiLlA, lohia. boüe. & Boüe. & 85 & Boüe. \\
\hline $\begin{array}{l}\text { Istiltcea, istillatcea, istiltatcea. embouer. } \\
\text { remplir de boüe. }\end{array}$ & Embouer. & 222 & Emplir de Boüe. \\
\hline $\begin{array}{l}\text { IsTRAGALATCEA, jstelgatcea, jstragaltcea. } \\
\text { trousser sa robe. }\end{array}$ & Trousser. Trousser sa robe. & 647 & \\
\hline Istragala eguitea. se trousser. & Trousser. Se trousser. & 647 & \\
\hline IsURTCEA. verser. & Verser. & 658 & Verser. \\
\hline Isuria. versé. & Verser. Versé. & 658 & \\
\hline ITÇAINA idien çaina. bouuier. & Bouuier. & 77 & Bouuier. \\
\hline ITÇALA. ombre. (Voltoire) & Ombre. & 441 & Ombre. \\
\hline Itçaltcea. ombrager. & Ombrager. & 441 & Ombrager. \\
\hline Itçalgaizqueria. dissimulation. palliation. & Dissimulation. & 208 & Dissimulation. \\
\hline ITCHAINA, chinchinbarea. sangsuë. & Sansue. & 580 & Sangsuë. \\
\hline ITCHENDIA. 2. jlhetia. tison de feu. & Tison. & 631 & Tison. \\
\hline ITCHEQUITCEA. tenir. & Tenir. & 623 & Tenir. \\
\hline Itchequina. tenace. & & & Tenace. \\
\hline ITHAUNTCEA O. jnterroger. & Interroguer. & 353 & Interroger. \\
\hline
\end{tabular}




\begin{tabular}{|c|c|c|c|}
\hline $\begin{array}{c}\text { A eskuizkribuko } \\
\text { sarrerak }\end{array}$ & $\begin{array}{l}\text { Nicot-en } \\
\text { sarrerak }\end{array}$ & \begin{tabular}{|c|}
$\begin{array}{c}\text { Nicot-en } \\
\text { or.zenbakia }\end{array}$ \\
\end{tabular} & $\begin{array}{c}\text { Oudin-en } \\
\text { sarrerak }\end{array}$ \\
\hline ІтНОТСЕА. etouffer. noyer. etrangler. & Estouffer. & 265 & Estouffer. \\
\hline ITHURRIA. fontaine. (Voltoire) & Fontaine. & 292 & Fontaine. \\
\hline Ithur vra. eau de fontaine. & Fontaine. Eauë de fontaine. & 292 & \\
\hline ITsusia. sale. vilain. laid. jnfame. & Sale. & 579 & Sale. \\
\hline Itsustasuna. saleté. deformité. & Saleté. & 579 & Saleté. \\
\hline Itsustea. salir. deuenir sale, laid. & Salir. & 579 & Salir. \\
\hline IUDUA. & [Iuif]. & 362 & [Iuif]. \\
\hline IUGEA. juge. (Voltoire) & Iuge. & 359 & Iuge. \\
\hline Iugeatcea, julgatcea a. juger. & Iuger. & 360 & Iuger. \\
\hline Iugeamendua, julgamendua a. jugement. & Iugement. & 361 & Iugement. \\
\hline IULUFREA. oeillet. & Oeillet. & 439 & Oeillet, fleur. \\
\hline IUNTA. complot. assemblée. & Complot. & 136 & Complot. \\
\hline Iunta eguitea. comploter. & Comploter. & 136 & Complotter. \\
\hline Iuntatcea. joindre. & Ioindre. & 355 & Ioindre. \\
\hline Iunturac. jointures. & Ioincture. & 355 & Ioincture. \\
\hline IURAMENTUA, cina. jurement, serment. & Iurement. & 362 & Iurement. \\
\hline Iuramentu eguitea, cin eguitea. jurer. & Iurer. & 362 & Iurer. \\
\hline Iuramentutsua. a. jureur. & Iureur. & 362 & Iureur. \\
\hline Iusticia. justice. & Iustice. & 363 & Iustice. \\
\hline \multicolumn{4}{|l|}{ Iusticia guiçona. ho[mm]e de iustice. } \\
\hline \multicolumn{4}{|l|}{ Iusticier, hombre de justicia. } \\
\hline Iustua. juste. equitable. & Equitable. & 243 & Iuste. \\
\hline Iustutasuna. equité. & Equité. & \begin{tabular}{|r|} 
(Equita- \\
blement).
\end{tabular} & 243 \\
\hline IXTUPA, eztupa. etoupe. filasse. & Estoupe. & 265 & Estoupe. \\
\hline VALENTA. vaillant, valereux. & Valereux. Valereux id est Vaillant. & 651 & Vaillant. \\
\hline Valentia. vaillantise. & Vaillantise & 651 & Vaillantise. \\
\hline VALIATCEA. se seruir. faire valoir. & $\begin{array}{l}\text { Valoir. Valoir et seruir de ce qu'vn autre chose } \\
\text { sert. }\end{array}$ & 650 & \\
\hline Valioa. valeur. prix. & Valeur. & 651 & Valeur. \\
\hline Valio içaitea. valoir. & Valoir. & 650 & Valoir. \\
\hline Vbeldura. meurtrisseure. (VBELA) & Meurtrissure. & 650 & Meurtrisseure. \\
\hline Vbeltcea. & Meurtrir. & 410 & Meurtrir. \\
\hline VCHADA, vxada. dissenterie. flux de ventre. & Flux. Flux de ventre. & 290 & Flux de ventre \\
\hline VDAGARA, vhadera. loutre. leurre. & Loutre. & 381 & Loutre. \\
\hline VDAREA. poire. (Voltoire) & Poire. & 492 & Poire. \\
\hline Vdareondoa. poirier. & Poirier. & 492 & Poirier. \\
\hline Vdar arnoa. poiré. & & & Poiré. \\
\hline
\end{tabular}




\begin{tabular}{|c|c|c|c|}
\hline $\begin{array}{c}\text { A eskuizkribuko } \\
\text { sarrerak }\end{array}$ & $\begin{array}{c}\text { Nicot-en } \\
\text { sarrerak }\end{array}$ & $\begin{array}{c}\text { Nicot-en } \\
\text { or.zenbakia }\end{array}$ & $\begin{array}{c}\text { Oudin-en } \\
\text { sarrerak }\end{array}$ \\
\hline VeILla. veille qu'on fait dans l'eglise. & Veilla. & 652 & Veilla. \\
\hline Veillatcea. veiller. & Veiller. & 652 & Veiller. \\
\hline VENTURA. auenture. & Aduenture. & 16 & Aduenture. \\
\hline Venturaz. par auenture, peut estre. & Par auenture. & 16 & Par aduenture. \\
\hline VERNIÇA. vernis. fard. & Vernis. & 657 & Vernis. \\
\hline Verniztatcea, verniçatcea. farder. & [Vernisser]. & 657 & [Vernisser]. \\
\hline VeRTUTEA. vertu. force. & Vertu. & 658 & Vertu. \\
\hline Vertutetsua. vertueux. & Vertueux. & 658 & Vertueux. \\
\hline VESPERA. vespre. veille. & Vespre. & 658 & Vespre. \\
\hline VestitCEA. vestir. (Voltoire) & Vestir. & 658 & Vestir. \\
\hline Vestidura. & [Vesture]. & 658 & [Vesture]. \\
\hline Vfu hatsa. fi du vilain. (VFu) & $\begin{array}{l}\text { Fi. est interjection rejectiue }[. . .] \text { comme, } F i \\
\text { le vilain. }\end{array}$ & 285 & \\
\hline VGATZA, bulharra. laict de femme. le sein. & Sein. & 587 & Sein. \\
\hline Vgaz aita. beau pere. paratre. & Beau. Beau pere. & 73 & Pere. beau Pere. \\
\hline Vgaz ama, amaiçuna. belle mere. maratre. & Belle mere. & 73 & Belle mere. \\
\hline Vgatz alaba. priuigna. & $\begin{array}{l}\text { Fille. La fille de ma femme ou de mon mari. } \\
\text { Prinigna. }\end{array}$ & 287 & \\
\hline VhAITZA, vharca, ibaya. riuiere, fleuue. & Fleuue. Fleuue ou riuiere. & 290 & Fleuue. \\
\hline Vhantua. (VhANTCEA) & Hydropique. & 342 & Hydropique. \\
\hline Vhantura. & [Hydropisie]. & 342 & [Hydropisie]. \\
\hline $\begin{array}{l}\text { VHARREA, vholdea. torrent, impetuosité } \\
\text { d'eaux. }\end{array}$ & Torrent. & 663 & Torrent. \\
\hline VHEA, makilla. baston. & Baston. & 70 & Baston. \\
\hline VHERRA. gris. sombre. & Gris. & 322 & Gris. \\
\hline VhiLLADA. arrousement. & Arrousement. & 47 & Arrousement. \\
\hline VHina, hola. onde. flot. & Flot. & 290 & Flot. \\
\hline Vновіа. embouchure. golfe. & Embouchure. & 222 & \\
\hline $\begin{array}{l}\text { VIANDA, iaquia, ianharia. viande. man- } \\
\text { geaille. }\end{array}$ & Viande. & 659 & Viande. \\
\hline VICIA, bicia. vie. vif. & Vie. Vif. & 660 & \begin{tabular}{|l} 
Vie. Vif. \\
\end{tabular} \\
\hline VICIOA. vice. & Vice. & 659 & Vice. \\
\hline Viciosa, viciotsua. vicieux. & Vicieux. & 659 & Vicieux. \\
\hline VigiLIA. vigile de feste. jour de jeusne. & Vigile. & 660 & Vigile. \\
\hline Violeta. & [Violette]. & 663 & [Violette]. \\
\hline VIRATCEA, itçultcea. virer. & Virer. & 663 & Virer. \\
\hline VIRGINA. & [Vierge]. & 660 & [Vierge]. \\
\hline VISAYA, beguitartea. visage. & Visage. & 663 & Visage. \\
\hline
\end{tabular}




\begin{tabular}{|c|c|c|c|}
\hline $\begin{array}{l}\text { A eskuizkribuko } \\
\text { sarrerak }\end{array}$ & $\begin{array}{l}\text { Nicot-en } \\
\text { sarrerak }\end{array}$ & \begin{tabular}{|c|} 
Nicot-en \\
or.zenbakia
\end{tabular} & $\begin{array}{l}\text { Oudin-en } \\
\text { sarrerak }\end{array}$ \\
\hline VISITA. visite. & & & Visite. \\
\hline Visitatcea. visiter. & Visiter. & 664 & Visiter. \\
\hline Vitaillatcea. auitailler. & & & Auitailler. \\
\hline VkaBILLA. poing. & Poing. & 492 & Poing. \\
\hline Vkaldia. coup. & Coup. & 156 & Coup. \\
\hline Vkaraya. muineca O. le poignet. & Poignet. & 492 & Poignet. \\
\hline VKATCEA. nier. & Nier. & 430 & Nier. \\
\hline VMUA, vmoa. a. meur. mol. & Meur. & 410 & Meur. \\
\hline Vmatcea, vmotcea a. meurir. mollir. & Meurir. & 410 & Meurir. \\
\hline VNÇA. once. poids. & Once. & 441 & Once. \\
\hline VNGUENTA, vnguentua. onguent. & Onguent. & 440 & Onguent. \\
\hline Vnguenztatcea, vnguentatcea. Io. 12 . oindre. & Oindre. & 440 & Oindre. \\
\hline VNHAIA, vnhaina. vacher. & Vachier. & 649 & Vacher. \\
\hline VNHATCEA. lasser. & Lasser. & 369 & Lasser. \\
\hline Vnhadura. lassitude. & & & Lassitude. \\
\hline VNHIDEA. nourrice. & Nourrise ou Nourrice. & 433 & Nourrise. \\
\hline Vnhit haurra. nourriçon. & Nourrison. & 433 & Nourrison. \\
\hline VNILLA, imitua, ardanazca. entonnoir. & Entonnoir. & 237 & Entonnoir. \\
\hline VNTATCEA. oindre. & Oindre. & 440 & Oindre. \\
\hline VOLONDREZ, a. borondatez. volontairement. & Volontairement. & 669 & Volontairement. \\
\hline Volondrezcoa. borondatezcoa. volontaire. & Voluntaire. & 668 & Volontaire. \\
\hline VQUITCEA, hunquitcea. 2. toucher. & Toucher. & 634 & Toucher. \\
\hline $\begin{array}{l}\text { VRÇAPALA. O, vsso apala, vsso tortoilla. } \\
\text { tourterelle. }\end{array}$ & Tourte ou Tourterelle. & 637 & Tourterelle. \\
\hline VRDAINA. porcher. & Porcher. & 494 & Porcher. \\
\hline Vrdaldea. tropeau de porcs. & & & Porcherie. \\
\hline Vrdea. porc, porceau. (Voltoire) & Porc ou Porceau. & 494 & Porc. \\
\hline VRDINA. grison. moisi. & & & Grison. \\
\hline Vrdintcea. grissoner. & Griser. Griser ou Grissoner. & 322 & Grisonner. \\
\hline VRDINCHAC. potirons. & Potiron. & 498 & Potiron. \\
\hline VRGOÏA. reproche. & Reproche. & 561 & Reproche. \\
\hline Vrgoitcea. & & & [Reprocher] \\
\hline VRGUILLUA. orgueilleux. & Orgueilleux. & 447 & Orgueilleux. \\
\hline Vrguillutcea. s'enorgueillir. enorgueilir. & Orgueillir. S’orgueillir. & 447 & S'orgueillir. \\
\hline Vrguilluqui. orgueilleusem[ent]. & Orgueilleusement. & 447 & $\begin{array}{l}\text { Orgueilleuse- } \\
\text { ment. }\end{array}$ \\
\hline VRIÑA. graisse. & Gresse. & 319 & Graisse. \\
\hline VRKA. fourche. & Fourche. & 297 & Fourche. \\
\hline
\end{tabular}




\begin{tabular}{|c|c|c|c|}
\hline $\begin{array}{l}\text { A eskuizkribuko } \\
\text { sarrerak }\end{array}$ & $\begin{array}{c}\text { Nicot-en } \\
\text { sarrerak }\end{array}$ & \begin{tabular}{|c|} 
Nicot-en \\
or.zenbakia
\end{tabular} & $\begin{array}{c}\text { Oudin-en } \\
\text { sarrerak }\end{array}$ \\
\hline VRKABEA. gibet. potence. & Gibbet. & 314 & Gibet. \\
\hline Vrkatcea. pendre. & Pendre. & 471 & Pendre. \\
\hline Vrredura. dorure. (VRREA) & Dorure. & 212 & \\
\hline Vrreztatcea. dorer. & Dorer. & 212 & Dorer. \\
\hline Vrreztatçaillea. doreur. & & & Doreur. \\
\hline $\begin{array}{l}\text { Vrricalmendua. compassion. pitié. (VRRI- } \\
\text { CALTCEA) }\end{array}$ & Pitié. & 483 & Pitié. \\
\hline Vrricalmendutsua. compassif. pitoyable. & Pitoyable. & 483 & Pitoyable. \\
\hline VRRICHA, vrrixa. genisse. taure. & Genisse. & 313 & Genisse. \\
\hline VRRINA. senteur. graisse. & Senteur. & 590 & Senteur. \\
\hline Vrrindatcea, vrrinztatcea. parfumer. & Parfumer. & 458 & Parfumer. \\
\hline Galz vrrinac, asta corotzac. roignons. & Roignon. & 572 & Roignon. \\
\hline VRRIQUITCEA. se repentir. (Voltoire) & Repentir. & 559 & Se repentir. \\
\hline Vrriquimendua. repentance. contrition. & Repentance. & 559 & Repentance. \\
\hline VRRITZA. coudriere. & Couldre. & 154 & Vn coudre. \\
\hline VRRUNA. loing. eloigné. & Loing. & 379 & Loing. \\
\hline Vrruntcea. eloigner. s'eloigner. & & & Esloigner. \\
\hline Vrruititic. de loing. & De loing. & 379 & De loing. \\
\hline VRRUPA. gorgée. sorbitio. & Humement. sorbitio. & 342 & Gorgée. \\
\hline Vrrupatcea. humer. aualer a gorgées. & Aualler. humer et aualler. & 56 & Aualler. \\
\hline Vrruparia. humeur. aualeur. & Aualleur. & 56 & Aualleur. \\
\hline VRSAINA, vrsaiztea. eternum[ent]. & Esternuement. & 263 & Esternüement. \\
\hline Vrsain eguitea. vrsaizte eguitea. & [Esternuer. Faire esternuer]. & 263 & \\
\hline VRTCEA. fondre. & Fondre. & 292 & Fondre. \\
\hline Vrtua. fondu. & Fondu. & 292 & Fondu. \\
\hline Nigarretan vrtcea. fondre en larmes. & Fondre en larmes. & 292. & Fondre en larmes. \\
\hline VRTHEA. an. année. & An. & 33 & An. \\
\hline Vrthetic vrthera. d'an en an. & & & D'An en an. \\
\hline VRTZA. 2. taula. aix. table. & Table. & 614 & Table. \\
\hline $\begin{array}{l}\text { Vsaintcea. deuenir puant. empuantir. } \\
\text { (Vsaina) }\end{array}$ & $\begin{array}{l}\text { Empuantir. S'empuantir ou s'empunaisir et } \\
\text { deuenir puant. }\end{array}$ & 225 & $\begin{array}{l}\text { E mpuantir. } \\
\text { s'Empuantir. }\end{array}$ \\
\hline Vsaindua. qui a mauuaise senteur. & [Empuanti]. & 225 & \\
\hline VsQUEA, arto chehea. millet. & Millet. & 412 & Millet. \\
\hline $\begin{array}{l}\text { VssoA. 2. vrsoa. pigeon. palomme. (Vol- } \\
\text { toire) }\end{array}$ & Pigeon. & 481 & Pigeon. \\
\hline Vssocumea. pigeonneau. & Pigeonneau. & 481 & Pigeonneau. \\
\hline Vssoteguia. pigeonnier. & Pigeonnier ou Colombier. & 481 & Pigeonnier. \\
\hline Vsso dorrea. colombier. & Pigeonnier ou Colombier. & 481 & Colombier. \\
\hline
\end{tabular}




\begin{tabular}{|l|l|c|l|}
\hline \multicolumn{1}{|c|}{$\begin{array}{c}\text { A eskuizkribuko } \\
\text { sarrerak }\end{array}$} & \multicolumn{1}{|c|}{$\begin{array}{c}\text { Nicot-en } \\
\text { sarrerak }\end{array}$} & $\begin{array}{c}\text { Nicot-en } \\
\text { or.zenbakia }\end{array}$ & \multicolumn{1}{c|}{$\begin{array}{c}\text { Oudin-en } \\
\text { sarrerak }\end{array}$} \\
\hline Escuin vssoa. geay. graculus. & $\begin{array}{l}\text { Gay qu'on prononce Geay, Graccus, Graccu- } \\
\text { lus. }\end{array}$ & 312 & Gay. \\
\hline VstEa. opinion. penser. & Penser. & 472 & Penser. \\
\hline Ene vstez. selon mon opinion. & Opinion. Selon mon opinion. & 442 & \\
\hline $\begin{array}{l}\text { Vste gabe, vste gabez, vste gaberic. sans } \\
\text { y penser. }\end{array}$ & Penser. Sans y penser. & 472 & \\
\hline VzTA. moisson. & Moison. & 415 & Moisson. \\
\hline $\begin{array}{l}\text { Vzta biltçailleac, ogui eppailleac. mois- } \\
\text { sonneurs. }\end{array}$ & Moissonneur. & 415 & Moissonneur. \\
\hline VzTARRIA. ioug. & Ioug. & 356 & Ioug. \\
\hline Idi vztarri bat. vne paire de beufs. & Beuf. Vne couple de beufs, Iugum. & 77 & \\
\hline Vztartcea. mettre au joug. & Ioug. Mettre les beufs sous le ioug. & 356 & \\
\hline XusQUerRUa. 2. musquerra. lezard. & Laisarde. & 365 & Lezard. \\
\hline
\end{tabular}

\section{VII.6. Nicot edota Oudin-en ordainak Nicot-en hiztegiko orrialdeen arabera ordenatuak}

\begin{tabular}{|c|c|c|c|}
\hline $\begin{array}{l}\text { A eskuizkribuko } \\
\text { sarrerak }\end{array}$ & $\begin{array}{l}\text { Nicot-en } \\
\text { sarrerak }\end{array}$ & $\begin{array}{c}\text { Nicot-en } \\
\text { orrialde } \\
\text { zenbakia }\end{array}$ & $\begin{array}{l}\text { Oudin-en } \\
\text { sarrerak }\end{array}$ \\
\hline Aisetcea. & - & - & [Aiser]. \\
\hline AlLEGUERA. allegre. rejouy. plaisant. & - & - & Allegre. \\
\hline Angueruzcoa. angelique. & - & - & Angelique. \\
\hline Aranadia, arandeguia. lieu planté de pruniers. & - & - & Prunaye. lugar de ciruelos. \\
\hline Ardianchua, ardiantcha. brebis d'vn an. & - & - & Brebis d'vn an. \\
\hline Armendoladia. lieu planté d'amendiers. & - & - & Amendaye. \\
\hline Arramu Igandea. Le dimanche des rameaux. & - & - & $\begin{array}{l}\text { Jour des Rameaux, Do- } \\
\text { mingo de Ramos. }\end{array}$ \\
\hline Arranocumea. aiglon. & - & - & Aigleron ou aiglon. \\
\hline Assucreztatcea. sucrer. & - & - & Sucrer. \\
\hline Astoqueria. asnerie. & - & - & Asnerie. \\
\hline Atçartçaillea. excitateur. & - & - & Excitateur. \\
\hline $\begin{array}{l}\text { Bere ohoreari atheka eguin dio. Il a fait bréche } \\
\text { a son honneur. }\end{array}$ & - & - & faire Breche à son honneur. \\
\hline Auisatçaillea, auisu emaillea. qui donne auis. & - & - & Donneur d'aduis \\
\hline Auocatalgoa. office \& exercise d'auocat. & - & - & Aduocasserie. \\
\hline Ni baicen. sinon moy. & - & - & Sinon moy, que moy. \\
\hline Balacatçaillea. & - & - & [Mignardeur]. \\
\hline BANDULERA, mandulera. bandoulier. & - & - & Bandolier, bandoulier. \\
\hline Barazcaria. le disné. & - & - & Disné. \\
\hline
\end{tabular}




\begin{tabular}{|c|c|c|c|}
\hline $\begin{array}{l}\text { A eskuizkribuko } \\
\text { sarrerak }\end{array}$ & $\begin{array}{l}\text { Nicot-en } \\
\text { sarrerak }\end{array}$ & $\begin{array}{c}\begin{array}{c}\text { Nicot-en } \\
\text { orrialde } \\
\text { zenbakia }\end{array} \\
\end{array}$ & $\begin{array}{c}\text { Oudin-en } \\
\text { sarrerak }\end{array}$ \\
\hline Bassoilloa. faisane. & - & - & Faisanne. \\
\hline Becoquigabetasuna, becoquigaberia. effronterie. & - & - & Effronterie. \\
\hline Beiraquia. verre. verrerie. & - & - & Verrerie. \\
\hline $\begin{array}{l}\text { BEKAITZTEA. regarder de mauuais oeil. enuier. } \\
\text { estre jaloux. }\end{array}$ & - & - & Envier. \\
\hline BELACHTEA. neud coulant. & - & - & Neud courant. \\
\hline Belecumeac. cornillaux. (BELEA) & - & - & Cornillat. \\
\hline BERATURIA. vrille. instrum[ent] de menuisier. & - & - & Vrille. \\
\hline BERMATCEA. cautionner. pleger. & - & - & Cautionner. \\
\hline Berreroslea. racheteur. redempeur. & - & - & Rachepteur. \\
\hline Bide celhaya. chemin battu. (BIDEA) & - & - & Chemin battu ou frayé. \\
\hline BIHURRIA. bigearre. malin. acariatre. & - & - & Bigearre. \\
\hline Bотіка. boutique d'apoticaire. & - & - & $\begin{array}{l}\text { Apoticairerie. tienda del } \\
\text { Boticario. }\end{array}$ \\
\hline Botoinguillea. boutonnier. & - & - & Boutonnier. \\
\hline BRUMA. & - & - & [Brume]. \\
\hline Buatsua. verolé. & - & - & Verolé. \\
\hline Çahartcea. vieillir. & - & - & Vieillir. \\
\hline CAMUTZA. emoussé. camus. & - & - & Esmoussié. \\
\hline Cantoinatcea. quantonner. se cantonner. & - & - & Cantonner. se Cantonner. \\
\hline ÇAURNEA. pus. ordure. & - & - & Pus. \\
\hline Chaflatcea. & - & - & [mettre vn Emplastre]. \\
\hline Chalupa. chaloupe. & - & - & Chaloupe. \\
\hline Chassa. chasse au jeu. & - & - & $\begin{array}{l}\text { Chasse ou jeu du paulme, } \\
\text { chaça. }\end{array}$ \\
\hline Chimignuqueria. singerie. & - & - & Singerie. \\
\hline Chiquiroquia. chair de mouton. & - & - & Mouton, chair du mouton. \\
\hline Chiribicaria. joueur de violon. & - & - & Violon, joüeur de Violon. \\
\hline Churitçaillea. blanchisseur. trompeur. & - & - & Blanchisseur. \\
\hline Cigartsua. plein de cirons. & - & - & $\begin{array}{l}\text { Cironniere. cantidad de } \\
\text { arados en las manos. }\end{array}$ \\
\hline Vrrez eta cilharrez. d'or $\&$ d'argent. & - & - & Argent meslé d'or. \\
\hline Cimurdura. & - & - & [Ridement]. \\
\hline Çamal cintça. gourme de cheual. & - & - & Morve de cheual. \\
\hline Cithalqui. & - & - & [Salement]. \\
\hline Commaïtcea. & - & - & [Commerer]. \\
\hline Condicionerequin. a condition. & - & - & A condition que. \\
\hline Consolagarria. & - & - & [Consolatoire]. \\
\hline
\end{tabular}




\begin{tabular}{|c|c|c|c|}
\hline $\begin{array}{l}\text { A eskuizkribuko } \\
\text { sarrerak }\end{array}$ & $\begin{array}{l}\text { Nicot-en } \\
\text { sarrerak }\end{array}$ & \begin{tabular}{|c|}
$\begin{array}{c}\text { Nicot-en } \\
\text { orrialde } \\
\text { zenbakia }\end{array}$ \\
\end{tabular} & $\begin{array}{l}\text { Oudin-en } \\
\text { sarrerak }\end{array}$ \\
\hline Chapel cordoina. cordon de chapeau. & - & - & Cordon de chapeau. \\
\hline Cotilluna. cotillon & - & - & Cottillon \\
\hline CredoA. symbole des apostres. & - & - & $\begin{array}{l}\text { le Credo, el credo o sym- } \\
\text { bolo de Apostoles. }\end{array}$ \\
\hline Curiosqui. & - & - & [Curieusement]. \\
\hline Curchetatcea. fermer de crochets. (CURCHETAC) & - & - & Corcheter. \\
\hline DEBAUXQUeria. debauche. & - & - & Desbauche. \\
\hline Dentilla. dentelle. & - & - & Dentelles. \\
\hline DESCARGUA. decharge. & - & - & Descharge \\
\hline Deseguillea. qui defait. destructeur. & - & - & Destructeur. \\
\hline Desencusatcea. & - & - & [Excuser]. \\
\hline Desohoramendua. & - & - & [Deshonnoration]. \\
\hline DESPENDATCEA. gastatzea. depenser. & - & - & Despenser. \\
\hline Desplacergarria. & - & - & [Desplaisant]. \\
\hline Destartqui. & - & - & [Estourdiement]. \\
\hline Diferenciatcea. & - & - & [Differencier]. \\
\hline Diferentqui. & - & - & [Differement]. \\
\hline Disgraciatcea. & - & - & [Disgratier]. \\
\hline Dobladura. & - & - & [Doubleure]. \\
\hline Dohacabetcea. rendre malheureux. & - & - & [Mal-heurer]. \\
\hline $\begin{array}{l}\text { DonabERAC edo tonaberac. les tenebres, offices } \\
\text { de la Semaine Sante. }\end{array}$ & - & - & $\begin{array}{l}\text { les Tenebres que l'on } \\
\text { chante la semaine Saincte. }\end{array}$ \\
\hline Dotatcea. doter. & - & - & Doter. \\
\hline Dudacorra. & - & - & [Doutant]. \\
\hline Duga. douelle de tonneau. & - & - & Douuelle. \\
\hline Dukezza. & - & - & [Duchesse]. \\
\hline Icicorra. peureux. & - & - & Peureux. \\
\hline Icipera. peureux. & - & - & Peureux. \\
\hline Idiçaina. nerf de beuf. & - & - & Nerf de boeuf. \\
\hline $\begin{array}{l}\text { Dembora igortciritsua. temps plein de tonne- } \\
\text { rres. }\end{array}$ & - & - & $\begin{array}{l}\text { Tonnerreux, tiempo de } \\
\text { trueno. }\end{array}$ \\
\hline Igorria. enuoyé. & - & - & Enuoyé. \\
\hline Igueriketac. & - & - & [Nageure]. \\
\hline $\begin{array}{l}\text { Iguzqui belharra, iguzqui lorea. tournesol. sol- } \\
\text { sequium. }\end{array}$ & - & - & Soleil fleur, tornasol. \\
\hline $\begin{array}{l}\text { Iguzquiz iguzqui. d'vn soleil a l'autre. du ma- } \\
\text { tin au soir. }\end{array}$ & - & - & $\begin{array}{l}\text { Entre deux Soleils, de sol } \\
\text { a sol. }\end{array}$ \\
\hline $\begin{array}{l}\text { IHARDUQUITCEA. contester. disputer sur quel- } \\
\text { que chose. }\end{array}$ & - & - & Quereller. \\
\hline
\end{tabular}




\begin{tabular}{|c|c|c|c|}
\hline $\begin{array}{l}\text { A eskuizkribuko } \\
\text { sarrerak }\end{array}$ & $\begin{array}{l}\text { Nicot-en } \\
\text { sarrerak }\end{array}$ & $\begin{array}{l}\text { Nicot-en } \\
\text { orrialde } \\
\text { zenbakia }\end{array}$ & $\begin{array}{l}\text { Oudin-en } \\
\text { sarrerak }\end{array}$ \\
\hline Lur ikaratce handia. grand trembleterre. & - & - & Trembleterre. \\
\hline Ikaradura. & - & - & [Tremblottement]. \\
\hline Incensu toquia. encensoir. & - & - & Encensoir. \\
\hline Ioslea. couturier, qui coud. & - & - & Cousturier. \\
\hline Irakaztunqueria. pedanterie. & - & - & Pedanterie. \\
\hline IRAKA. yuraïe. & - & - & Iuraye. \\
\hline Iratçargarria. & - & - & [Esueilleur]. \\
\hline $\begin{array}{l}\text { Irauaslea, irauasçaillea, irauastuna. gaigneur. } \\
\text { qui gaigne. }\end{array}$ & - & - & Gaigneur. \\
\hline Iraunguia. eteint. & - & - & Esteint. \\
\hline Iraunguidura. extinction. & - & - & Extinction. \\
\hline Irrigarria. & - & - & [Risible]. \\
\hline IRRIZKINA. ecornifleur. & - & - & Escorniffleur. \\
\hline Irrizkintcea. & - & - & [Escorniffler]. \\
\hline Irrizkintça. & - & - & [Escornifflerie]. \\
\hline IRRISCUA, erriscua. risque. & - & - & Risque. \\
\hline Irriscatcea. risquer. & - & - & Risquer. \\
\hline Irulea. qui file. & - & - & [Fileur]. \\
\hline Itchequina. tenace. & - & - & Tenace. \\
\hline Iusticia guiçona. ho[mm]e de iustice. & - & - & $\begin{array}{l}\text { Iusticier, hombre de jus- } \\
\text { ticia. }\end{array}$ \\
\hline Vdar arnoa. poiré. & - & - & Poiré. \\
\hline VISITA. visite. & - & - & Visite. \\
\hline VitAILLATCEA. auitailler. & - & - & Auitailler. \\
\hline Vnhadura. lassitude. & - & - & Lassitude. \\
\hline Vrdaldea. tropeau de porcs. & - & - & Porcherie. \\
\hline VRDINA. grison. moisi. & - & - & Grison. \\
\hline Vrgoitcea. & - & - & [Reprocher]. \\
\hline Vrreztatçaillea. doreur. & - & - & Doreur. \\
\hline Vrruntcea. eloigner. s'eloigner. & - & - & Esloigner. \\
\hline Vrthetic vrthera. d'an en an. & - & - & D'An en an. \\
\hline BACHATCEA. mettre bas. abbaisser. auilir. & Abbaisser. & 2 & Abbaisser. \\
\hline Costumatcea. accoutumer. & Accoutumer. & 9 & Accoustumer. \\
\hline Costumatua. accoutumé. & Accoutumé. & 9 & Accoustumé. \\
\hline Cocorico iartcea. s'accroupir. & Accroupir. S'accroupir. & 10 & s'Accroupir. \\
\hline ApIOA. ache, herbe. & $\begin{array}{l}\text { Ache. Tantost signifie vne } \\
\text { herbe que les Latins ape- } \\
\text { llent Apium. }\end{array}$ & 11 & Ache, herbe. \\
\hline
\end{tabular}




\begin{tabular}{|c|c|c|c|}
\hline $\begin{array}{c}\text { A eskuizkribuko } \\
\text { sarrerak }\end{array}$ & $\begin{array}{l}\text { Nicot-en } \\
\text { sarrerak }\end{array}$ & $\begin{array}{c}\begin{array}{c}\text { Nicot-en } \\
\text { orrialde } \\
\text { zenbakia }\end{array} \\
\end{array}$ & $\begin{array}{l}\text { Oudin-en } \\
\text { sarrerak }\end{array}$ \\
\hline IKUCATCEA. O., vrhentcea. acheuer. & Acheuer. & 11 & Acheuer. \\
\hline AItHORRA. aueu. confession. & Adueu. & 16 & Aueu. \\
\hline Auisua. auis. conseil. & Aduis & 16 & Aduis. \\
\hline Auisatcea. auiser. conseiller. & Aduiser & 16 & Aduiser. \\
\hline Ventura. auenture. & Aduenture. & 16 & Aduenture. \\
\hline Venturaz. par auenture, peut estre. & Par auenture. & 16 & Par aduenture. \\
\hline AuOCATA. auocat. & Aduocat. & 17 & Aduocat. \\
\hline Aithortcea. auoüer. & Aduoüer. & 18 & Auoüer. \\
\hline ARRANOA. aigle. & Aigle. & 22 & Aigle. \\
\hline AKILLOA. aiguille de bouuier. & Aiguille. & 23 & Aiguille. \\
\hline AMOLsua. aimable. courtois. & Aimable. & 23 & Aimable. \\
\hline AiseA. aisé. facile. & Aisé. & 24 & Aisé. \\
\hline Aisetasuna. & Aise. & 24 & Aise. \\
\hline Biz hala, hala biz. ainsi soit il. (Bız) & Ainsi. Ainsi soit il. & 24 & \\
\hline Aisequi. aisement. a l'aise. & Aiséement. & 25 & Aiséement. \\
\hline AlLARMA. allarme. & Alarme. & 25 & Alarme. \\
\hline DEYADARRA. alarme. & Alarme. & 25 & Alarme. \\
\hline Deyadarguillea. qui donne l'alarme. & $\begin{array}{l}\text { Alarme. On a donné l'alar- } \\
\text { me au camp. }\end{array}$ & 25 & \\
\hline Allegatcea. alleguer. & Alleguer. & 26 & Alleguer. \\
\hline IвILTCEA, ibiltea. aller. marcher. se promener. & Aller. & 26 & Aller. \\
\hline BitzTEA, pitztea. allumer. & Allumer. & 28 & Allumer. \\
\hline ARMENDOLA. amende. fruit. & Amande. & 29 & Amande \\
\hline Armendol-ondoa, armendolatcea. amandier. & Amandier. & 29 & Amandier. \\
\hline BilcuA. amas. & Amas. & 29 & Amas. \\
\hline Arima. ame. & Ame. & 30 & Ame. \\
\hline ÇAMINA, kiratsa, karmina. amer. & Amer. & 30 & Amer. \\
\hline Çamintcea. rendre ou deuenir amer. & Deuenir amer. & 30 & Deuenir amer. \\
\hline Çamintasuna. amertume. aigreur. colere. & Amertume. & 30 & Amertume. \\
\hline AINGURA. ancre de nauire. & Ancre. & 33 & Ancre. \\
\hline ANDOILLA. andouille. & Andouille. & 33 & Andoüilles. \\
\hline ANTCHOA. sorte de poisson. & $\begin{array}{l}\text { Anchoye. Est vne espece } \\
\text { de poisson }[\ldots]\end{array}$ & 33 & Anchoie. \\
\hline VRTHEA. an. année. & An. & 33 & An. \\
\hline ANGUERUA. ange. & \begin{tabular}{|l|} 
Ange. \\
\end{tabular} & 34 & Ange. \\
\hline ANIMALIA. animal. & Animal. & 34 & Animal. \\
\hline Botikaria. apoticaire. & Apoticaire. & 35 & Apoticaire. \\
\hline
\end{tabular}




\begin{tabular}{|c|c|c|c|}
\hline $\begin{array}{l}\text { A eskuizkribuko } \\
\text { sarrerak }\end{array}$ & $\begin{array}{l}\text { Nicot-en } \\
\text { sarrerak }\end{array}$ & $\begin{array}{c}\text { Nicot-en } \\
\text { orrialde } \\
\text { zenbakia }\end{array}$ & $\begin{array}{c}\text { Oudin-en } \\
\text { sarrerak }\end{array}$ \\
\hline IrOA. O., handitsua, çaurnea. apostume. & Apostume. & 35 & Apostume. \\
\hline BEYTHA. appas. & Appas. & 36 & Appas. \\
\hline Beytatcea. appaster. & Appaster. & 36 & Appaster. \\
\hline Celhaïtcea. applanir. (СеLHAÏA) & Applanir. & 38 & Applanir. \\
\hline Chipitcea. appetisser. (Voltoire) & Appetisser. & 38 & Appetisser. \\
\hline Chipidura. appettissement. & Appetissement. & 38 & Appetissement. \\
\hline Chumetcea. appetisser. (СнuмеA) & Appetisser. & 38 & Appetisser. \\
\hline AMONTCEA, amuntcea. appriuoiser. & Appriuoiser. & 39 & Appriuoiser. \\
\hline IKASTEA. aprendre. (Voltoire). discere. & Apprendre, Discere. & 39 & Apprendre. \\
\hline Ikasgaya. capable d'aprendre. & $\begin{array}{l}\text { Apprendre. Qui aprend ai- } \\
\text { sement, Docilis. }\end{array}$ & 39 & \\
\hline Ikastuna. aprenty. & Apprenti. & 39 & Apprenty. \\
\hline Ikaslea. qui aprend. & $\begin{array}{l}\text { Apprendre. Celuy ou celle } \\
\text { qui apprend d'vn autre. }\end{array}$ & 39 & \\
\hline Ikazgoa. aprentissage. & Apprentissage. & 39 & Apprentissage. \\
\hline AINHARBA, armierma, amaraua. araignée. & $\begin{array}{l}\text { Araignée. Araignée et la } \\
\text { toile de l'araignée. }\end{array}$ & 41 & Araignée. \\
\hline BaLesta. arbaleste. (Voltoire) & Arbaleste. & 41 & Arbaleste. \\
\hline Balestaria. arbalestrier. & Arbalestrier. & 41 & Arbalestier, arbalestrier. \\
\hline Cilharra. argent non monnoyé. & Argent. & 42 & Argent, matiere. \\
\hline Cilharreztatcea. & Argenter. & 43 & Argenter. \\
\hline ARRASTA edo arresta. arrest. & Arrest. & 46 & Arrest. \\
\hline $\begin{array}{l}\text { Biribiltcea, biribillatcea. arrondir, mettre en } \\
\text { rond. (Voltoire) }\end{array}$ & Arrondir. & 47 & Arrondir. \\
\hline Biribildura. arrondissement. & Arrondissement. & 47 & Arrondissement. \\
\hline VHILLADA. arrousement. & Arrousement. & 47 & Arrousement. \\
\hline Articulua. article. & Article. & 48 & Article. \\
\hline Articulatcea. articuler. & Articuler. & 48 & Articuler. \\
\hline AsPreA. aspre. aigre. & Aspre & 49 & Aspre. \\
\hline Aspretasuna. âpreté. & Aspreté & 49 & Aspreté. \\
\hline Aspretcea. rendre ou deuenir âpre & $\begin{array}{l}\text { Aspre. Deuenir aspre par } \\
\text { succession du temp. }\end{array}$ & 49 & \\
\hline Asprequi. âprement & Asprement & 49 & Asprement. \\
\hline Assauta. assaut. & Assaut. & 49 & Assaut. \\
\hline AstoA. asne. (Voltoire) & Asne. & 49 & Asne. \\
\hline Asto emea. asnesse. & Asnesse. & 49 & Asnesse. \\
\hline Astocumea. asnon ou asnine. & Asnon. & 49 & Asnon. \\
\hline Bassastoa. asne sauuage. (BASSA) & Vn asne sauuage. & 49 & Asne sauuage. \\
\hline
\end{tabular}




\begin{tabular}{|c|c|c|c|}
\hline $\begin{array}{l}\text { A eskuizkribuko } \\
\text { sarrerak }\end{array}$ & $\begin{array}{l}\text { Nicot-en } \\
\text { sarrerak }\end{array}$ & $\begin{array}{l}\text { Nicot-en } \\
\text { orrialde } \\
\text { zenbakia }\end{array}$ & $\begin{array}{l}\text { Oudin-en } \\
\text { sarrerak }\end{array}$ \\
\hline IGURIKITCEA. attendre. & Attendre. & 54 & Attendre. \\
\hline Igurikitça. attente. expectatio. & $\begin{array}{l}\text { Attente. Attente et desir, } \\
\text { Expectatio. }\end{array}$ & 54 & Attente. \\
\hline ATRAPATCEA. attraper. & Attraper. & 55 & Attraper. \\
\hline Berreguindura. (BERREguina) & [Attifement]. & 55 & [Attifement]. \\
\hline Berreguintcea. attifer. enioliuer. & Attifer. & 55 & Attifer. \\
\hline IRETSTEA. & Aualler. & 56 & Aualler. \\
\hline Iretslea. & Aualleur. & 56 & Aualleur. \\
\hline Vrrupatcea. humer. aualer a gorgées. & Aualler. humer et aualler. & 56 & Aualler. \\
\hline Vrruparia. humeur. aualeur. & Aualleur. & 56 & Aualleur. \\
\hline AlBA, argui alba. l'aube du jour. & $\begin{array}{l}\text { Aube. L'aube et le poinct } \\
\text { du jour. }\end{array}$ & 57 & L'aube. \\
\hline Artoria. O. aube du iour. & $\begin{array}{l}\text { Aube. L'Aube et poinct du } \\
\text { iour. }\end{array}$ & 57 & l'Aube. alua del dia. \\
\hline AscA, makina, ortera. auge. & Auge. & 58 & Auge. \\
\hline Berretçaillea. (BERRETCEA) & [Augmentateur]. & 58 & [Augmentateur]. \\
\hline Berretura. a. augmentation. & Augmentation. & 58 & Augmentation. \\
\hline Altza. alnus. aune. saule. & Aulne, Alnus. & 59 & Aulne. \\
\hline Altzua. aunaye. saussaye. & Aulnage. Aulnaye. & 59 & Aulnaye. \\
\hline ARrABA, abiroina. auiron. (Voltoire) & Auiron. & 59 & Auiron \\
\hline Arrauquetan haritcea. tirer a l'auiron. & Tirer à l'auiron. & 59 & Tirer à l'auiron. \\
\hline $\begin{array}{l}\text { Aumoina, limosna, erremusina. aumône. (Vol- } \\
\text { toire) }\end{array}$ & Aumosne. & 59 & Aumosne. \\
\hline Aumoinera, limosnaria, erremusinaria, aumônier. & Aumosnier. & 59 & Aumosnier. \\
\hline BARA. O. berga. aune. & Aulne. & 59 & Aulne à mesurer. \\
\hline ILHORTCEA. 2. jlhor eguitea. auorter. & Auorter. faire auorter. & 59 & Auorter. \\
\hline BAILLIA. baillif. & Bailli. & 64 & Bailli. \\
\hline Bailliatasuna. charge, office de baillif, bailliage. & Baillage, office de Bayle. & 65 & Baillage. \\
\hline BALENÇA. balance. & Balance. & 65 & Balance. \\
\hline IsATSA. balay. & Balay. & 65 & Balay. \\
\hline BANDATCEA. bander quelque chose. & Bander. & 66 & Bander. \\
\hline BANDERA. baniere. etandart. & Baniere. & 66 & Banniere. \\
\hline Banderiça. bande, ligue. & Bande. Vne bande et ligue. & 66 & Bande, ligue. \\
\hline BANQUETA. banquet. & Banquet. & 67 & Banquet. \\
\hline Banquetatcea. banqueter. & Banqueter. & 67 & Banqueter. \\
\hline Banquecia, bonbacia. banqueterie. & Banqueterie. & 67 & \\
\hline BATAYOA. bateme. & Baptesme. & 67 & Baptesme. \\
\hline Batayatcea. batiser. & Baptizer. & 67 & Baptiser. \\
\hline
\end{tabular}




\begin{tabular}{|c|c|c|c|}
\hline $\begin{array}{l}\text { A eskuizkribuko } \\
\text { sarrerak }\end{array}$ & $\begin{array}{l}\text { Nicot-en } \\
\text { sarrerak }\end{array}$ & \begin{tabular}{|c|}
$\begin{array}{c}\text { Nicot-en } \\
\text { orrialde } \\
\text { zenbakia }\end{array}$ \\
\end{tabular} & $\begin{array}{c}\text { Oudin-en } \\
\text { sarrerak }\end{array}$ \\
\hline Batayaharria, batayaherria. fons baptismaux. & Baptizer. Les fons à baptizer. & 67 & \\
\hline Bachoa. bas. & Bas ou bassement. & 69 & Bassement. \\
\hline BARKA, barkua. barque. & Barque. & 69 & Barque. \\
\hline Bachotasuna. bassesse. & Bassese. & 70 & Bassese. \\
\hline BASTA, arbalda. bast. & Bast. & 70 & Bast. \\
\hline Bastatcea. baster. & Baster. & 70 & Baster vn asne. \\
\hline $\begin{array}{l}\text { BASTARTA, borth, haur ixila, bertceren vmea. } \\
\text { bastard. }\end{array}$ & Bastard. & 70 & Bastard. \\
\hline ÇAмUKA. bast d'asne, clitella. & Bast (Baster, Clitella). & 70 & Bast. \\
\hline VHEA, makilla. baston. & Baston. & 70 & Baston. \\
\hline BATELA. bateau. & Bateau. & 71 & Bateau. \\
\hline CенAтCEA. battre. frapper. & Batre. & 71 & Battre. \\
\hline Cehatçaillea. batteur. & Bateur. & 72 & Batteur. \\
\hline BaLsamua. baume. & Bausme. & 73 & Baulme. \\
\hline Vgaz aita. beau pere. paratre. & Beau. Beau pere. & 73 & Pere. beau Pere \\
\hline Vgaz ama, amaiçuna. belle mere. maratre. & Belle mere. & 73 & Belle mere. \\
\hline ANGUEREDERRA. belette. & Belette. & 74 & Belette. \\
\hline BECOA. bec. & Bec. & 74 & Bec. \\
\hline BENEDICIONEA, benedicinoa. benediction. & Benediction. & 74 & Bendiction. \\
\hline Benedicatcea. benir. & Benir. & 75 & Benir. \\
\hline IDIA. beuf. (Voltoire) & Beuf. & 77 & Beuf. \\
\hline Idiquia, guehelia. chair de beuf. & Chaire de beufs. & 77 & Du Beuf, chair de beuf. \\
\hline ITÇAINA. idien çaina. bouuier. & Bouuier. & 77 & Bouuier. \\
\hline Idi vztarri bat. vne paire de beufs. & $\begin{array}{l}\text { Beuf. Vne couple de beufs, } \\
\text { Ingum. }\end{array}$ & 77 & \\
\hline Bihurritcea. rendre ou deuenir bigearre. & Bigarrer. & 78 & Bigarrer. \\
\hline CruXPeTAC. bignets. & Bignets. & 78 & Bignet. \\
\hline Doatsua. bienheureux. & Bienheureux. & 78 & Bien-heureux. \\
\hline Doatsutcea. bienheurer. & Bienheurer. & 78 & Bien-heurer. \\
\hline CHURIA. blanc. but. (Voltoire) & Blanc. & 79 & Blanc. \\
\hline Churiz vestitua. vestu de blanc. & Blanc. Vestu de blanc. & 79 & \\
\hline Churitcea. blanchir. tromper. enjoller. (Voltoire) & Blanchir. & 79 & Blanchir. \\
\hline Churitasuna. blancheur. & Blancheur. & 79 & Blancheur. \\
\hline $\begin{array}{l}\text { Churiquetac edo churiquetacoac. linges a } \\
\text { blanchir. }\end{array}$ & $\begin{array}{l}\text { Blanchissage. Blanchissage } \\
\text { de linges. }\end{array}$ & 79 & \\
\hline ÇAURIA. playe. blessure. & Blessure. & 81 & \\
\hline Çauritcea edo çaurtcea. blesser. & Blesser. & 81 & Blesser. \\
\hline
\end{tabular}




\begin{tabular}{|c|c|c|c|}
\hline $\begin{array}{c}\text { A eskuizkribuko } \\
\text { sarrerak }\end{array}$ & $\begin{array}{l}\text { Nicot-en } \\
\text { sarrerak }\end{array}$ & $\begin{array}{c}\text { Nicot-en } \\
\text { orrialde } \\
\text { zenbakia }\end{array}$ & $\begin{array}{l}\text { Oudin-en } \\
\text { sarrerak }\end{array}$ \\
\hline Churpailla. blesme. haue. & Blesme. & 81 & Blesme. \\
\hline Churpailtcea. & [Blesmir]. & 81 & [Blesmir]. \\
\hline Churpailtasuna. & Blesmissement. & 81 & [Blesmissement]. \\
\hline BORDA. borde. metairie. & Borde. & 83 & Borde. \\
\hline BRODATCEA. broder. & Border. & 83 & Border pour broder \\
\hline Brodadura. brodure. & Bordure. & 83 & Bordeure, brodeure \\
\hline Brodaria, brodatçaillea. & Bordeur. & 83 & Bordeur. \\
\hline Chaincua. 2. maingua. boiteux. & Boiteux. & 83 & Boiteux. \\
\hline Chaincutcea. & [Boiter]. & 83 & [Boiter]. \\
\hline ARgIBOA. bossu. courbé. & Bossu & 84 & Bossu. \\
\hline Bordaçaina, bordaria. bordier. metayer. & Bordier. & 84 & Bordier. \\
\hline CEDARRIA, mugarria. borne. limite. & Borne. & 84 & Borne. \\
\hline ÇUNKuRRA. bossu. courbé. & Bossu. & 84 & Bossu. \\
\hline Çunkurtcea. & [Bossuer]. & 84 & [Bossuer]. \\
\hline IstiLLA, lohia. boüe. & Boüe. & 85 & Boüe. \\
\hline Bola. boule. & Boule. & 86 & Boule. \\
\hline Boletan haritcea. ioüer a la boule. & Bouler. & 86 & Bouler. jugar bolas. \\
\hline Buhescatcea. bourdonner. (BuHEZCA) & Bourdonner. & 86 & Bourdonner. \\
\hline IRAQUITCEA. bouillir. heruer. heruir. (Voltoire) & Bouillir. & 86 & Boüillir. \\
\hline Vr iraquina. eau bouillante. & Bouillir. Eau bouillant. & 86 & \\
\hline BORREROA. ax. 304. burreba. bourreau. & Bourreau. & 87 & Bourreau. \\
\hline ВОТНАТСЕA. bourgeonner. boutonner. & Bourjonner. & 87 & Bourjonner. \\
\hline Bothea. bourgeon. bouton. & Bourjon. & 87 & Bourjon. \\
\hline BuRgEZZA. bourgeois. & Bourgeois. & 87 & Bourgeois. \\
\hline Burgezia. bourgeoisie. & Bourgeoisie. & 87 & Bourgeoisie. \\
\hline BотоіNA. bouton. & Bouton. & 88 & Bouton. \\
\hline Botoinatcea. boutonner. & Boutonner. & 88 & Boutonner. \\
\hline BrauOA. & Braue. & 89 & Braue. \\
\hline Brauotcea. & Brauer. & 89 & Brauer. \\
\hline ARDIA. brebis. & Brebis. & 90 & Brebis. \\
\hline Artaldea. troupeau de brebis. & Brebis. Troupeau de brebis. & 90 & \\
\hline Arteguia. ouile. bergeriè. & $\begin{array}{l}\text { Brebis. Estable à brebis, } \\
\text { Ouile. }\end{array}$ & 90 & \\
\hline Атнека. bréche. & Breche. & 90 & Breche. \\
\hline Brauoqui. & Brauement. & 90 & Brauement. \\
\hline BRIDA. bride. & Bride. & 91 & Bride. \\
\hline Bridatcea. brider. & Brider. & 91 & Brider. \\
\hline
\end{tabular}




\begin{tabular}{|c|c|c|c|}
\hline $\begin{array}{l}\text { A eskuizkribuko } \\
\text { sarrerak }\end{array}$ & $\begin{array}{l}\text { Nicot-en } \\
\text { sarrerak }\end{array}$ & \begin{tabular}{|c|}
$\begin{array}{c}\text { Nicot-en } \\
\text { orrialde } \\
\text { zenbakia }\end{array}$ \\
\end{tabular} & $\begin{array}{l}\text { Oudin-en } \\
\text { sarrerak }\end{array}$ \\
\hline Adreillua. & Brique. & 92 & Brique. \\
\hline Adreilluz eguina. fait de brique. & Qui est fait de brique. & 92 & \\
\hline BRUITA, aharra, açantça, auarrotza. bruit. & Bruit. & 92 & Bruit. \\
\hline BосатA. buée. lexiue. & Buée, Lixiuium. & 94 & Bueé. \\
\hline Bocatatcea. & [Buer]. & 94 & [Buer]. \\
\hline AровеLATZa. O. butor, oyseau. cresserele. & Butor. Butor, Oiseau. & 95 & Butor. \\
\hline ÇAPARRA. buisson. & Buisson. & 95 & Buisson. \\
\hline Chedea. but. visée. objet. & But. & 95 & But. \\
\hline Chedatcea. viser. buter. & Buter. & 95 & Buter. \\
\hline CACHETA, siguillua. cachet. & Cachet. & 97 & Cachet. \\
\hline $\begin{array}{l}\text { Cachetatcea, chingolatcea. cacheter. cordeler } \\
\text { les cheueux a trois cordons. }\end{array}$ & Cacheter. & 97 & Cacheter. \\
\hline CAFIA, ohatcea, habia. cage. & Cage. & 97 & Cage. \\
\hline Bur-heçur. caluaria. caluaire. & $\begin{array}{l}\text { Caluaire, ou le Tez de la } \\
\text { teste. Caluaria. }\end{array}$ & 98 & Caluaire. \\
\hline CALITÇA. calitça copa. calice. & Calice. & 98 & Calice. \\
\hline CAMELOTA. camelot. & Camelot. & 98 & Camelot. \\
\hline CANALA, gottera, ithaiçura. canal & Canal. & 99 & Canal. \\
\hline CANTOINA. canton. quarrie. quartier. & Cantons. & 100 & Canton. \\
\hline CAPUTXA. capuçon. & Capuchon. & 101 & Capuchon. \\
\hline Bermea. plege. caution. & $\begin{array}{l}\text { Caution. Vn pleige et cau- } \\
\text { tion. }\end{array}$ & 104 & \\
\hline Chercatcea, cercatcea. 2. bilhatcea. chercher. & Cercher. & 106 & Chercher. \\
\hline Chercatçaillea. chercheur. & Cercheur. & 106 & Chercheur. \\
\hline BetHeria. chassie. & Chacie. & 108 & Chassie. \\
\hline Begui betheriatsuac. yeux chassieux. & $\begin{array}{l}\text { Chacieux. Chacieux.Yeux } \\
\text { chacieux. }\end{array}$ & 108 & \\
\hline Berotasuna. chaleur. & Chaleur. & 109 & Chaleur. \\
\hline Berotcea. chauffer. echauffer. & Chauffer. & 109 & Chauffer. \\
\hline CADIRA. chaire. & Chaire. & 109 & Chaire. \\
\hline CAMELUA. a. 304. chameau. & Chameau. & 110 & Chameau. \\
\hline CANCERIA, chamarra. chancre & Chancre. & 111 & Chancre. \\
\hline CANDELA. chandelle. & Chandelle. & 111 & Chandelle. \\
\hline Candelera. chandelier. & Chandelier. & 111 & Chandelier. \\
\hline $\begin{array}{l}\text { Candelerua, candeleroa, ganderalu } \mathrm{O} \text {, cande- } \\
\text { lairua h. la chandeleur. }\end{array}$ & $\begin{array}{l}\text { Chandeleur. La feste de la } \\
\text { chandeleur. }\end{array}$ & 111 & la Chandeleur. \\
\hline CALAMUA, garsandea. chanure. roseau. & Chanure. & 112 & Chanure. \\
\hline CANTALA. chanteau. quarrie. & Chanteau. & 112 & Chanteau. \\
\hline
\end{tabular}




\begin{tabular}{|c|c|c|c|}
\hline $\begin{array}{c}\text { A eskuizkribuko } \\
\text { sarrerak }\end{array}$ & $\begin{array}{c}\text { Nicot-en } \\
\text { sarrerak }\end{array}$ & \begin{tabular}{|c|}
$\begin{array}{c}\text { Nicot-en } \\
\text { orrialde } \\
\text { zenbakia }\end{array}$ \\
\end{tabular} & $\begin{array}{l}\text { Oudin-en } \\
\text { sarrerak }\end{array}$ \\
\hline $\begin{array}{l}\text { Oguia cuzcatcea. chapeller le pain. (CuzcA- } \\
\text { TCEA) }\end{array}$ & Chapeler. chapeler du pain. & 113 & Chapeler le pain. \\
\hline CARGUA. charge. office. & Charge. & 114 & Charge, oficio, cargo. \\
\hline CARLOA. chardon. & Chardon. & 114 & Chardon. \\
\hline IKATZA. charbon. & Charbon. & 114 & Charbon. \\
\hline Caritatea. charité. & Charité. & 115 & Charité. \\
\hline ChARITATEA. charité. & Charité. & 115 & Charité. \\
\hline Charitatetsua, charitatosa. charitable. & Charitable. & 115 & Charitable. \\
\hline BEтHI, bethiere. touiours. continuellement. & Continuellement. & 116 & Continuellement. \\
\hline $\begin{array}{l}\text { Bethicoa, bethierecoa. qui e[st] pour toujours. } \\
\text { perpetuel. continuel. }\end{array}$ & Continuel. & 116 & Continuel. \\
\hline Bethieretcea. continuer. perpetuer. & Continuer. & 116 & Continuer. \\
\hline Ihiztatcea. chasser. & Chasser. & 116 & Chasser. \\
\hline BERTÇA. chaudron. & Chauderon. & 117 & Chauderon. \\
\hline Bertzquina. chaudronnier. & Chauderonnier. & 117 & Chauderonnier. \\
\hline CAUTERA. chaudronnier. & Chauderonnier. & 117 & Chauderonnier. \\
\hline IHICIA. chasse. & Chasse. & 117 & Chasse. \\
\hline Ihiztaria. chasseur. & Chasseur. & 117 & Chasseur. \\
\hline ANTAPARRAC. ecluses. chaussees. & Chausse. & 118 & Chausse. \\
\hline BEROA. chaud. chaleur. & Chaud. & 118 & Chaud. \\
\hline Bero hari da. il fait chaud. & Chaud. Il fait chand. & 118 & \\
\hline Beroqui. chaudement. & Chaudement. & 118 & Chaudement. \\
\hline Bide harritsua. chemin pierreux. & $\begin{array}{l}\text { Chemin. Chemin pierreux } \\
\text { et mal aisé. }\end{array}$ & 118 & \\
\hline ÇARAGoilla. O., galçac. haut de chausses. & Haut de chausses. & 118 & Chausses, haut de chausses. \\
\hline Carsollla. chauue. & Chauue. & 118 & Chauue. \\
\hline Carsoiltcea. & [Deuenir chauue]. & 118 & [deuenir Chauue]. \\
\hline Carsoildura. & [Chauueté]. & 118 & [Chauueté]. \\
\hline CHAPIGNAC, galzoinac. chaussons. & Chaussons. & 118 & Chausson. \\
\hline BONACHERA. bonne chere. & Chere. Bonne chere. & 120 & \\
\hline ÇALDIA, çamaria. cheual. & Cheual. & 120 & Cheual. \\
\hline CARIOA, garestia. cher. & Cher. & 120 & Cher. \\
\hline ApALARDOTZA, achiruina. cheuille du pied. & $\begin{array}{l}\text { Cheuille. Les cheuilles des } \\
\text { pieds. }\end{array}$ & 122 & Cheuilles des pieds. \\
\hline BiLOA, ille izpia. cheueuil. & Cheueul. & 122 & Cheueul. \\
\hline CaBilla. cheuille. & Cheuille. & 122 & Cheuille. \\
\hline Cabillaztatcea. cheuiller. & Cheuiller. & 122 & Cheuiller. \\
\hline CIRIA. cheuille. coing. & Cheuille. & 122 & Cheuille. \\
\hline
\end{tabular}




\begin{tabular}{|c|c|c|c|}
\hline $\begin{array}{l}\text { A eskuizkribuko } \\
\text { sarrerak }\end{array}$ & $\begin{array}{l}\text { Nicot-en } \\
\text { sarrerak }\end{array}$ & \begin{tabular}{|c|}
$\begin{array}{c}\text { Nicot-en } \\
\text { orrialde } \\
\text { zenbakia }\end{array}$ \\
\end{tabular} & $\begin{array}{c}\text { Oudin-en } \\
\text { sarrerak }\end{array}$ \\
\hline Ciriztatcea. cheuiller. & Cheuiller. & 122 & Cheuiller. \\
\hline Caca eguitea. (Caca) & Chier. & 123 & Chier. \\
\hline Cenenna. chiche. taquin. & Chiche. & 123 & Chiche. \\
\hline Cekentasuna. & [Chicheté]. & 123 & [Chicheté]. \\
\hline Cekenqui. chichement. & Chichement. & 123 & Chichement. \\
\hline Сicotza. O. chiche. & Chiche. & 123 & Chiche. \\
\hline Cicotztasuna. & [Chicheté]. & 123 & [Chicheté]. \\
\hline Cicotzqui. & [Chichement]. & 123 & [Chichement]. \\
\hline Cegúta. cigue. & Cigue. & 124 & Cigüe. \\
\hline CHIRIÜA. cierge. & Cierge. & 124 & Cierge. \\
\hline ColERA. colere. (Voltoire) & Cholere. & 124 & Colere. \\
\hline Coleracorra. & [Cholerique]. & 124 & [Coleric]. \\
\hline Coleratcea. & [Cholerer]. & 124 & \\
\hline Cigarra. ciron. (Voltoire) & Ciron. & 125 & Ciron. \\
\hline ClaRA, agueria. clair. & Cler. & 126 & Clair \\
\hline Clartasuna. & [Clerté ou Clarté]. & 126 & [Clairté]. \\
\hline Clarqui, (Voltoire). claroqui. & [Clerement]. & 126 & [Clairement]. \\
\hline Clauera. marguillier. clauier. & Clauier. & 126 & Clauier. \\
\hline CHILINTcha. clochette. & Clochete. & 127 & Clochette. \\
\hline $\begin{array}{l}\text { Chinguilca ioaitea. aller a la clochepied. (CHIN- } \\
\text { GUIL iausia) }\end{array}$ & $\begin{array}{l}\text { Clochepied. Aller a la } \\
\text { clochepied. }\end{array}$ & 127 & \\
\hline Cofia. coüeffe. & Coeffe. & 128 & Coiffe. \\
\hline Cofiatcea. & Coeffer. & 128 & [Coiffer]. \\
\hline COFrea. cofre. & Coffre. & 128 & Coffre. \\
\hline ColA, amiruina. cole. empois. & Colle. & 129 & Colle. \\
\hline Colatcea. & [Coller]. & 129 & [Coller]. \\
\hline IRASAGARRA. coing, fruit. & Coing, Fruict. & 129 & Coing, fruit. \\
\hline Irasagaronoda. coignier. & Coignier. & 129 & Coignier. \\
\hline CомватA, gudua. combat. & Combat. & 130 & Combat. \\
\hline Bat banacaco combata. duel. & $\begin{array}{l}\text { Combat. Combat d'homme } \\
\text { à homme ou corps à corps. }\end{array}$ & 130 & \\
\hline IKEA. montée. colline. & Coline. & 130 & Colline. \\
\hline COMMAYA. commere. & Commerre. & 133 & Commere. \\
\hline Commaitasuna. commerage. & Commerage. & 133 & Commerage. \\
\hline CoMpainia. compagnie. & Compagnie. & 135 & Compagnie. \\
\hline COMPARACIONEA, comparacinoa. comparaison. & Comparaison. & 135 & Comparaison. \\
\hline Comparatcea. comparer. & Comparer. & 135 & Comparer. \\
\hline
\end{tabular}




\begin{tabular}{|c|c|c|c|}
\hline $\begin{array}{l}\text { A eskuizkribuko } \\
\text { sarrerak }\end{array}$ & $\begin{array}{l}\text { Nicot-en } \\
\text { sarrerak }\end{array}$ & $\begin{array}{l}\text { Nicot-en } \\
\text { orrialde } \\
\text { zenbakia }\end{array}$ & $\begin{array}{l}\text { Oudin-en } \\
\text { sarrerak }\end{array}$ \\
\hline Сомрауа. compere. (Voltoire) & Comperes & 135 & Compere. \\
\hline Compaitasuna. comperage. & Comperage. & 135 & Comperage. \\
\hline IUNTA. complot. assemblée. & Complot. & 136 & Complot. \\
\hline Iunta eguitea. comploter. & Comploter. & 136 & Complotter. \\
\hline Contua. compte. & Compte. & 137 & Compte. \\
\hline ConClusionea. conclusion. & Conclusion. & 138 & Conclusion. \\
\hline Condicionea, condicinoa. condition. & Condition. & 139 & Condition. \\
\hline CONFEssatcea. confesser. & Confesser. & 140 & Confesser. \\
\hline Confessora. confesseur. & Confesseur. & 140 & Confesseur. \\
\hline Confessionea. confession. & Confession. & 140 & Confession. \\
\hline Congita. congé. & Congé. & 141 & Congé. \\
\hline Consciencia. conscience. & Conscience. & 142 & Conscience. \\
\hline Conseilluua. conseil. & Conseil. & 142 & Conseil. \\
\hline Conseilluquetan ibiltea. aller au conseil. & $\begin{array}{l}\text { Conseil. Aller au conseil } \\
\text { apres les plaidoyez des par- } \\
\text { ties. }\end{array}$ & 142 & \\
\hline Conseillu esque dago. il demande conseil. & Conseil. Demander conseil. & 142 & \\
\hline Conseillu emaillea. qui donne conseil. & Conseil. Qui donne conseil. & 143 & \\
\hline Conseillaria. vn conseiller. & Conseiller. & 143 & Vn conseiller. \\
\hline $\begin{array}{l}\text { Conseillatcea, conseillu emaitea. conseiller. } \\
\text { donner conseil. }\end{array}$ & $\begin{array}{l}\text { Conseiller. C'est donner } \\
\text { advis et conseil à quelqu'vn. }\end{array}$ & 143 & Conseiller. \\
\hline Consolatcea. consoler. & Consoler. & 144 & Consoler. \\
\hline Consolacionea, consolamendua. consolation. & Consolation. & 144 & Consolation \\
\hline Consolatçaillea. & [Consolateur]. & 144 & [Consolateur]. \\
\hline Condea. comte. & Conte. & 145 & Comte. \\
\hline Condetasuna. comté. & Conté. & 145 & Comté. \\
\hline Condezza. & [Contesse]. & 145 & [Comtesse]. \\
\hline BORTCHA. force. contrainte. & Contrainte. & 147 & Contrainte. \\
\hline Bortcharia, bortchatçaillea. qui contraint. & $\begin{array}{l}\text { Contraindre. Celle qui } \\
\text { contraint. }\end{array}$ & 147 & \\
\hline Bortchatcea. forcer. contraindre. & Contraindre. & 147 & Containdre. \\
\hline Contra. & [Contre]. & 147 & [Contre]. \\
\hline Contracarra, contresta & [Contrecarre]. & 147 & [Contrecarre]. \\
\hline CONTRICIONEA, vrriquimendua. contrition. & Contrition. & 149 & Contrition. \\
\hline $\begin{array}{l}\text { CHIRLAC, maxcorrac. coquilles de mer, de S. } \\
\text { Iaques. }\end{array}$ & $\begin{array}{l}\text { Coquille. Coquille de Saint } \\
\text { Iacques ou Large coquille. }\end{array}$ & 150 & \\
\hline Copia. copie. & Copie. & 150 & Copie. \\
\hline Copiatcea. copier. & Copier. & 150 & Copier. \\
\hline
\end{tabular}




\begin{tabular}{|c|c|c|c|}
\hline $\begin{array}{l}\text { A eskuizkribuko } \\
\text { sarrerak }\end{array}$ & $\begin{array}{l}\text { Nicot-en } \\
\text { sarrerak }\end{array}$ & \begin{tabular}{|c|}
$\begin{array}{c}\text { Nicot-en } \\
\text { orrialde } \\
\text { zenbakia }\end{array}$ \\
\end{tabular} & $\begin{array}{l}\text { Oudin-en } \\
\text { sarrerak }\end{array}$ \\
\hline AzPILA. O. cormier. & Cormier. & 151 & Cormier. \\
\hline CoRdoIna. cordon. & Cordon & 151 & Cordon. \\
\hline COÇATCEA. O, cutsatcea. corrompre. infecter. & Corrompre. & 152 & Corrompre. \\
\hline Colorea. couleur. (Voltoire) & Couleur. & 154 & Couleur. \\
\hline IOSTEA. coudre. attacher. (Voltoire) & Coudre. & 154 & Coudre. \\
\hline Iosia. cousu. & Cousu. & 154 & Cousu. \\
\hline Iostura. vne couture. & Cousture. & 154 & Cousture. \\
\hline VRRITZA. coudriere. & Couldre. & 154 & Vn coudre. \\
\hline Coloratcea. & [Coulourer]. & 155 & \\
\hline Columbrina. couleurine. & Couleuurine. & 156 & Couleurine. \\
\hline Vkaldia. coup. & Coup. & 156 & Coup. \\
\hline ANIMOA. courage. & Courage. & 157 & Courage. \\
\hline Animotsua. courageux. & Courageux. & 158 & Courageux. \\
\hline Churpatcea. se courber. & Courber. Se courber. & 158 & \\
\hline Corsua. course. & Course. & 159 & Course. \\
\hline $\begin{array}{l}\text { CORTEA, gortea. cour, palais royal, lieu ou on } \\
\text { plaide. }\end{array}$ & Court & 160 & Court. \\
\hline Cortesalea. courtisan. & Courtisan. & 161 & Courtisan. \\
\hline CORTEZA. courtois. & Courtois. & 161 & Courtois. \\
\hline Cortezia. courtoisie. & Courtoisie. & 161 & Courtoisie. \\
\hline Costuma. coutume. & Coustume. & 162 & Coustume. \\
\hline Costumaz. par coutume. & Coustume. Par coustume. & 162 & \\
\hline BELDUR içaitea. & Craindre. & 163 & Craindre. \\
\hline BELDURRA. crainte. craintif. (Voltoire) & Crainte. & 164 & Crainte. \\
\hline Beldurrez. de crainte. par crainte. & Craintiuement. & 164 & Craintiuement. \\
\hline Beldurtia. craintif. & Craintif. & 164 & Craintif. \\
\hline Cikina. crasse. & Crasse. & 164 & Crasse. \\
\hline Cikintsua. & [Crasseux]. & 164 & [Crasseux]. \\
\hline Clenda. craye. & Craye. & 164 & Craye. \\
\hline Cinetsbera. cinetscorra. credule. & Credule. & 165 & Credule. \\
\hline $\begin{array}{l}\text { Cinetsberatasuna. cinetscortasuna. facilité a } \\
\text { croire. credulité. }\end{array}$ & Credulité. & 165 & Credulité. \\
\hline Credita. credit. & Credit. & 165 & Credit. \\
\hline CRISMOA, crisuma. créme. & Cresme. & 165 & Cresme. \\
\hline Cipertcea. creuer de depit. & $\begin{array}{l}\text { Creuer. Creuer de des- } \\
\text { pit qu'on a d'aucuns qui ne } \\
\text { laissent rien à faire. }\end{array}$ & 166 & \\
\hline CracoA, macoa. croc. crochet. & Croc. & 167 & Croc. \\
\hline
\end{tabular}




\begin{tabular}{|c|c|c|c|}
\hline $\begin{array}{c}\text { A eskuizkribuko } \\
\text { sarrerak }\end{array}$ & $\begin{array}{l}\text { Nicot-en } \\
\text { sarrerak }\end{array}$ & \begin{tabular}{|c|}
$\begin{array}{c}\text { Nicot-en } \\
\text { orrialde } \\
\text { zenbakia }\end{array}$ \\
\end{tabular} & $\begin{array}{l}\text { Oudin-en } \\
\text { sarrerak }\end{array}$ \\
\hline Cinetstea. croire. & Croire. & 168 & Croire. \\
\hline CuIllidd. cuilliere. & Cuilliere. & 171 & Cuiller. \\
\hline Cuba. cuue. & Cuve. & 172 & Cuue. \\
\hline CuRIOSA. curieux. & Curieux. & 172 & Curieux. \\
\hline Curiostasuna. & [Curiosité]. & 172 & [Curiosité]. \\
\hline AnDREA. dame. maitresse. & Dame. Dame ou maistresse. & 173 & Dame. \\
\hline Donceilla. demoiselle. & Damoiselle. & 173 & Damoiselle, demoiselle. \\
\hline DANSA. (Voltoire) & Danse. & 175 & Danse. \\
\hline Dansaria. & [Danseur]. & 175 & [Danseur]. \\
\hline DARDOA. dard. & Dard. & 175 & Dard. \\
\hline Dardatcea. darder. & Darder. & 175 & Darder. \\
\hline Ditharea. dé a coudre. & Dé. Dé à coudre. & 176 & Dé a coudre. \\
\hline ÇOrRa. debte. (Voltoire) & Debte. & 178 & Debte. \\
\hline Çorduna. debiteur. & Debteur. & 178 & Debteur. \\
\hline BARRENA. dedans. & Dedans. & 179 & Dedans. \\
\hline DeClaracionea, declaracinoa. declaration. & Declaration. & 179 & Declaration. \\
\hline Declaratcea. declarer. & Declarer. & 179 & Declarer. \\
\hline Declaratçaillea. qui declare. & $\begin{array}{l}\text { Declarer. Qui declare et } \\
\text { donne à entendre [...] }\end{array}$ & 179 & Declarant. \\
\hline Debecatcea. defendre. prohiber. & Defendre. & 180 & Deffendre. \\
\hline Iaincossa. deesse. & Deesse. & 180 & Deesse. \\
\hline Debecua. defense. prohibition. & Defense. & 181 & Deffense. \\
\hline Debecatçaillea. & [Defenseur ou defendeur]. & 181 & [Deffendeur]. \\
\hline Iaincotcea. rendre ou deuenir Dieu. deifier. & Deifier. & 182 & Deifier. \\
\hline Debauxatcea. debaucher. & Desbaucher. & 191 & Desbaucher. \\
\hline Descargatcea. decharger. & Descharger. & 191 & Descharger. \\
\hline Iautstea. sauter. descendre. (Voltoire) & Descendre. & 191 & Descendre. \\
\hline Iautzapena, a. 140. cheute, descendant, descente. & Descente. & 191 & Descente. \\
\hline Circilla. dechiré en ses habits. & Deschiré. & 192 & Deschiré. \\
\hline Circiltcea. & [Deschirer]. & 192 & [Deschirer]. \\
\hline Circildura. & [Deschirure]. & 192 & [Deschireure]. \\
\hline Circiltasuna. & [Deschirement]. & 192 & [Deschirement]. \\
\hline DesafiOA. defi. & Desfi & 194 & Defy. \\
\hline Desafiatcea. defier. & Desfier & 194 & Desfier. \\
\hline Desira. desir. & Desir. & 195 & Desir. \\
\hline Desiratcea. desirer. & Desirer. & 195 & Desirer. \\
\hline Desirosa. & [Desireux]. & 195 & [Desireux]. \\
\hline
\end{tabular}




\begin{tabular}{|c|c|c|c|}
\hline $\begin{array}{l}\text { A eskuizkribuko } \\
\text { sarrerak }\end{array}$ & $\begin{array}{l}\text { Nicot-en } \\
\text { sarrerak }\end{array}$ & \begin{tabular}{|c|}
$\begin{array}{c}\text { Nicot-en } \\
\text { orrialde } \\
\text { zenbakia }\end{array}$ \\
\end{tabular} & $\begin{array}{l}\text { Oudin-en } \\
\text { sarrerak }\end{array}$ \\
\hline DesoHOREA, desondra. deshonneur. & Deshonneur. & 195 & Deshonneur. \\
\hline Desohoratcea. & [Deshonnorer]. & 195 & [Deshonnorer]. \\
\hline Desordenua. desordre. dereglement. & Desordre. & 197 & Desordre. \\
\hline Desordenatua. desordonné. & Desordonné. & 197 & \\
\hline Despendioa, gastua. depens. & Despens. & 197 & Despense \\
\hline Ene despendioz, ene gastuz. a mes depens. & $\begin{array}{l}\text { Despens. Il sent le vnguens à } \\
\text { mes despens et de mon bien. }\end{array}$ & 197 & \\
\hline Iagoiti, iagoitic. desormais. $\left(\mathrm{I}_{\mathrm{A}}\right)$ & Desormais. & 197 & Desormais. \\
\hline Despendaria. depensier. & Despensier. & 198 & Despensier. \\
\hline Despita. depit. & Despit. & 198 & Despit. \\
\hline Billusia. nud. depoüillé. & Despouillé. & 199 & \\
\hline Billuztea. depoüiller. & Despouiller. & 199 & Despouiller. \\
\hline Desgogara çait. il me deplaist. (DESGOGARA) & $\begin{array}{l}\text { Desplaire. Il me desplait } \\
\text { grandement. }\end{array}$ & 199 & \\
\hline Despitatcea, despitcea. depiter. & Despiter. & 199 & Despiter. \\
\hline Desplacera. deplaisir. & Desplaisir. & 199 & Desplaisir. \\
\hline Desplacermendua. & [Desplaisance]. & 199 & [Desplaisance]. \\
\hline Desserta. dessert de table. & Dessert. Desserte de table. & 200 & Dessert. \\
\hline Deseguitea. defaire. detruire. & Destruire. & 201 & Destruire. \\
\hline Deseguina. defait. detruit. & Destruict. & 201 & Destruit. \\
\hline Desenguidura, deseguintça. destruction. & Destruction. & 202 & Destruction. \\
\hline Astalcatcea. deuider du fil. & \begin{tabular}{|l|}
$\begin{array}{l}\text { Deuider. Deuider du fil } \\
\text { parpelotons. }\end{array}$ \\
\end{tabular} & 203 & Deuider. \\
\hline Astalcayac. deuidet. trauoil. & Deuidet. & 203 & Deuidet. \\
\hline Aztia. deuin. & Deuin. & 203 & Deuin. \\
\hline Aztietan edo aztiketan dabilla. il va aux deuins. & $\begin{array}{l}\text { Deuin. Aller aux deuin, et } \\
\text { luy compter son affaire, et } \\
\text { demand conseil. }\end{array}$ & 203 & \\
\hline Deuocionea. deuocion. & Deuotion. & 204 & Deuotion. \\
\hline Deuocionetsua, deuota. deuot & Deuot. & 204 & Deuot. \\
\hline IAINCOA, Iaungoicoa. Dieu. & Dieu. & 204 & Dieu. \\
\hline Iaincortiartasuna. pieté. deuotion. & Deuotion. & 204 & Deuotion. \\
\hline Iaincortiartcea. deuenir deuot. & Deuot. Il deuient deuot. & 204 & \\
\hline DifERENCIA. difference. & Difference. & 205 & Difference. \\
\hline Diferenta. & [Different]. & 205 & [Different]. \\
\hline DeliEnÇA, agudotasuna. diligence. & Diligence. & 206 & Diligence. \\
\hline Delienta, agudo. diligent. & Diligent. & 206 & Diligent. \\
\hline Deuersatcea 2, ehoitea. digerer. & Digerer. & 206 & Digerer. \\
\hline
\end{tabular}




\begin{tabular}{|c|c|c|c|}
\hline $\begin{array}{l}\text { A eskuizkribuko } \\
\text { sarrerak }\end{array}$ & $\begin{array}{l}\text { Nicot-en } \\
\text { sarrerak }\end{array}$ & \begin{tabular}{|c|}
$\begin{array}{c}\text { Nicot-en } \\
\text { orrialde } \\
\text { zenbakia }\end{array}$ \\
\end{tabular} & $\begin{array}{l}\text { Oudin-en } \\
\text { sarrerak }\end{array}$ \\
\hline BARAZCALTCEA. disner. & Disner. & 208 & Disner. \\
\hline BARRAYATCEA. publier. diuulguer. dissiper. & Dissiper. & 208 & Dissiper. \\
\hline Detchumac, hamarrenac. dismes. & Dismes. & 208 & Dismes. \\
\hline Detchumaria. dismeur. & Dismeur. & 208 & Dismeur. \\
\hline Detchumatcea. dismer. & Dismer. & 208 & Dismer. \\
\hline Disciflina. discipline. & Discipline. & 208 & Discipline. \\
\hline Discipulua. disciple. & Disciple. & 208 & Disciple. \\
\hline DisgraCia. disgrace. & Disgrace. & 208 & Disgrace. \\
\hline Itçalgaizqueria. dissimulation. palliation. & Dissimulation. & 208 & Dissimulation. \\
\hline Barrayaria, barreïaria, barrayatçaillea. dissipateur. & Dissipateur. & 209 & Dissipateur. \\
\hline Iaincotasuna. diuinité. & Diuinité. & 209 & Diuinité. \\
\hline Iaincozqui. diuinem[ent]. & Diuinement. & 209 & Diuinement. \\
\hline DAINUA. pert. dommage. degast. & Dommage. & 210 & Dommage. \\
\hline Dolamena. doleance. & Doleance. & 210 & Doleance. \\
\hline DOLOREA. douleur. & Doleur. & 210 & Douleur. \\
\hline Dolorezcoa. & Doloureux. & 210 & Douloureux. \\
\hline Dolorezqui. & [Doloureusement]. & 210 & [Doloureusement]. \\
\hline Doloratcea. & [Doloir]. & 210 & [Douloir]. \\
\hline Doblea. double. & Double. & 212 & Double. \\
\hline DoHAINA, emaitça, donua. don. present. & Don. & 212 & Don. \\
\hline DoteA. dot. & Dost. & 212 & Dot. \\
\hline Vrredura. dorure. (VRREA) & Dorure. & 212 & \\
\hline Vrreztatcea. dorer. & Dorer. & 212 & Dorer. \\
\hline Doblatcea. doubler. & Doubler. & 213 & Doubler. \\
\hline DudA. doute. & Doubte. & 213 & Doute. \\
\hline Dudatcea. douter. & Doubter. & 213 & Douter. \\
\hline Dudatsua. Dudosa. & [Douteux]. & 213 & [Douteux]. \\
\hline Dulcea. eztia. doux. & Doulx. & 213 & Doux. \\
\hline DraGoINA. dragon. & Dragon. & 214 & Dragon. \\
\hline Dulcetasuna. & [Doulceur]. & 214 & [Douceur]. \\
\hline Dulcequi. & [Doulcement]. & 214 & [Doucement]. \\
\hline ARTHEÇA. droit. & Droict. & 215 & Droict. \\
\hline ÇuCENA. le droit. ius. & Droit et raison, Ius. & 215 & Droict. \\
\hline Dolua. deüil. & Dueil. & 217 & Deüil. \\
\hline Doluzco arropa. robe de deuil. & $\begin{array}{l}\text { Dueil. Robbe, chapperon et } \\
\text { habit de dueil. }\end{array}$ & 217 & \\
\hline Dolutcea. & [Dueil. Faire dueil]. & 217 & \\
\hline
\end{tabular}




\begin{tabular}{|c|c|c|c|}
\hline $\begin{array}{l}\text { A eskuizkribuko } \\
\text { sarrerak }\end{array}$ & $\begin{array}{l}\text { Nicot-en } \\
\text { sarrerak }\end{array}$ & \begin{tabular}{|c|}
$\begin{array}{c}\text { Nicot-en } \\
\text { orrialde } \\
\text { zenbakia }\end{array}$ \\
\end{tabular} & $\begin{array}{l}\text { Oudin-en } \\
\text { sarrerak }\end{array}$ \\
\hline Dolutsua. & [Dueil. Pleine de dueil]. & 217 & \\
\hline Dugata. vn ducat. & Ducat. & 217 & Ducat. \\
\hline Dukea. duc. & Duc. & 217 & Duc. \\
\hline Duketasuna. & [Duché]. & 217 & [Duché]. \\
\hline IRAUTEA. durer. perseuerer. durée. & Durer. & 218 & Durer. \\
\hline Iraupea, jraupena, irautea. durée. & Durée. & 218 & Durée. \\
\hline Becoquigabea. effronte. (BECOQUIA) & Effronté. & 220 & Effronté. \\
\hline Becoquigabequi. effrontement. & Effrontéement. & 220 & Effrontement. \\
\hline BORRATCEA. effacer. & Effacer. & 220 & Effacer. \\
\hline ÇARAMICATCEA, çarrapocatcea. egratigner. & Egratigner. & 220 & Esgratigner. \\
\hline BERDINA. egal. & Egual. & 221 & Egal. \\
\hline Berdinqui. egalement. & Egualement. & 221 & Egalement. \\
\hline Berdintcea. egaler. & Egualer. & 221 & Egaler. \\
\hline IgUALA, berdina. egal. & Egual. & 221 & Egal. \\
\hline Igualatcea, berdintcea. egaler. & Egualer. & 221 & Egaler. \\
\hline $\begin{array}{l}\text { Istiltcea, istillatcea, istiltatcea. embouer. rem- } \\
\text { plir de boüe. }\end{array}$ & Embouer. & 222 & Emplir de Boüe. \\
\hline VновіA. embouchure. golfe. & Embouchure. & 222 & \\
\hline Chatarratcea. enmailloter. & Emmailloter. & 223 & Emmailloter. \\
\hline CHAFLA, herscaillua. O. emplastre. & Emplastre. & 224 & Emplastre. \\
\hline Vsaintcea. deuenir puant. empuantir. (VsaINA) & $\begin{array}{l}\text { Empuantir. S'empuantir } \\
\text { ou s'empunaisir et deue- } \\
\text { nir puant. }\end{array}$ & 225 & Empuantir. s'Empuantir. \\
\hline Vsaindua. qui a mauuaise senteur. & [Empuanti]. & 225 & \\
\hline INGUDEA, jngura. enclume. & Enclume. & 227 & Enclume. \\
\hline Bahitcea. engager. saisir. mettre a l'amende. & Engager. & 230 & Engager. \\
\hline Bahimendua. engagement. saisie. & Engagement. & 230 & Engagement. \\
\hline Içorratcea. engrosser. (IçORRA) & Engrossir. & 231 & Engrosser. \\
\hline Istape eguitea. enjamber. (ISTAPEA) & Enjamber. & 232 & Enjamber. hazer piernas. \\
\hline IRAKAZTEA. enseigner. (Voltoire) & Enseigner. & 234 & Enseigner. \\
\hline Irakasia. enseigné. & Enseigner. Enseigné. & 235 & \\
\hline Irakazlea, irakastuna. qui enseigne. & Enseigner. Qui enseigne. & 235 & \\
\hline Irakazmendua. enseignement. & Enseignement. & 235 & Enseignement. \\
\hline Chertatcea, chartatcea, empeldatzea. enter. & Enter. & 236 & Enter. \\
\hline Chertoa. ente. & Ente. & 236 & Ente. \\
\hline VNILLA, imitua, ardanazca. entonnoir. & Entonnoir. & 237 & Entonnoir. \\
\hline ARARTECOA. entremetteur. mediateur. & $\begin{array}{l}\text { Entremetteur. Vn entre- } \\
\text { metteur et moyenneur. }\end{array}$ & 239 & Entremetteur. \\
\hline
\end{tabular}




\begin{tabular}{|c|c|c|c|}
\hline $\begin{array}{l}\text { A eskuizkribuko } \\
\text { sarrerak }\end{array}$ & $\begin{array}{l}\text { Nicot-en } \\
\text { sarrerak }\end{array}$ & $\begin{array}{c}\begin{array}{c}\text { Nicot-en } \\
\text { orrialde } \\
\text { zenbakia }\end{array} \\
\end{array}$ & $\begin{array}{l}\text { Oudin-en } \\
\text { sarrerak }\end{array}$ \\
\hline Ararteco iartcea. interceder. s'entremettre. & Entremettre. S'entremettre. & 239 & S'entremettre. \\
\hline $\begin{array}{l}\text { Bekaitzcoa, beltçuria. enuie. ialousie. mauuais } \\
\text { regard. }\end{array}$ & Enuie. & 241 & Enuie. \\
\hline Arrastuan. enuiron. circum circa. (ARRASTUA) & $\begin{array}{l}\text { Enuiron. Tout à l'enuiron, } \\
\text { Circumcirca. }\end{array}$ & 242 & Enuiron. \\
\hline Bekaitztia. enuieux. jaloux. & Enuieux. & 242 & Enuieux. \\
\hline IGORTCEA. enuoyer. & Enuoyer. & 242 & Enuoyer. \\
\hline INGURATCEA. enuironner. & Enuironner. & 242 & Enuironner. \\
\hline Ingurua. l'enuiron. & Enuiron. & 242 & les Enuirons. \\
\hline IRIOITEA. enuoyer. & Enuoyer. & 242 & Enuoyer. \\
\hline Axtigarra. erable, arbre. & Erable. & 243 & Erable. \\
\hline IUstuA. juste. equitable. & Equitable. & 243 & Iuste. \\
\hline Iustutasuna. equité. & Equité. (Equitablement). & 243 & Equité. \\
\hline Charpa, xarpa. echarpe. & Escharpe. & 245 & Escharpe. \\
\hline IÇURPIDEA, jtçurpidea, 2. itçulbidea. echapatoire. & Eschappatoire. & 245 & Eschappatoire. \\
\hline Astalcoa. echeueau de fil. & Escheueau. Escheneau de fil. & 246 & \\
\hline Bizcarra. echine. dos. & Eschine. & 247 & Eschine. \\
\hline CHAMARRA. ecreuisse. chancre, maladie. & Escreuice. & 249 & Escreuice, escreuisse. \\
\hline ARRAPOA, habuina. ecume. (Voltoire) & Escume. & 250 & Escume. \\
\hline Arrapoa eltceari edequitea. ecumer le pot. & $\begin{array}{l}\text { Escumer }[\ldots] \text { comme escu- } \\
\text { mer le pot. }\end{array}$ & 250 & \\
\hline Çabaltcea. elargir. etendre. & \begin{tabular}{|l|} 
Eslargir. \\
\end{tabular} & 252 & Eslargir. \\
\hline Çabaldua. elargy. & Eslargi. & 252 & Eslargy. \\
\hline Camutztea. emousser. & Esmousser. & 253 & Esmousser. \\
\hline BITARTEA. espace. & Espace. & 254 & Espace. \\
\hline ARANCEA. epine. le piqueron. & Espine. & 258 & Espine. \\
\hline Celata. guet. epie. embusche. & Espies. & 258 & Espie. \\
\hline Celataria. espion. & Espion. & 258 & Espion. \\
\hline Celatacea. espier. & Espier. & 258 & Espier. \\
\hline IsQUILIMBA. epingle. & Espingle. & 258 & Espingle. \\
\hline ICHUCATCEA. essuyer. torcher. & Essuyer. & 260 & Essuyer. \\
\hline IRAUNGUITCEA. eteindre. mortifier. & Esteindre. & 262 & Esteindre. \\
\hline INHAURTCEA. etendre. & Estendre. & 263 & Estendre. \\
\hline VRSAINA, vrsaiztea. eternum[ent]. & Esternuement. & 263 & Esternüement. \\
\hline Vrsain eguitea, vrsaizte eguitea. & [Esternuer. Faire esternuer]. & 263 & \\
\hline IHARRA. etincelle. & Estincelle. & 264 & Estincelle. \\
\hline ARCHIPOTEA. etourneau. & Estourneau. & 265 & Estourneau. \\
\hline
\end{tabular}




\begin{tabular}{|c|c|c|c|}
\hline $\begin{array}{l}\text { A eskuizkribuko } \\
\text { sarrerak }\end{array}$ & $\begin{array}{l}\text { Nicot-en } \\
\text { sarrerak }\end{array}$ & \begin{tabular}{|c|}
$\begin{array}{c}\text { Nicot-en } \\
\text { orrialde } \\
\text { zenbakia }\end{array}$ \\
\end{tabular} & $\begin{array}{l}\text { Oudin-en } \\
\text { sarrerak }\end{array}$ \\
\hline BILLIGARROA. etourneau. & Estourneau. & 265 & Estourneau. \\
\hline Destartcea. & [Estourdir]. & 265 & [Estourdir]. \\
\hline IтнОтСЕА. etouffer. noyer. etrangler. & Estouffer. & 265 & Estouffer. \\
\hline IXTUPA, eztupa. etoupe. filasse. & Estoupe. & 265 & Estoupe. \\
\hline AlENTATCEA. euenter. & Esuenter. & 267 & Esuenter. \\
\hline IRATÇARTCEA. eueiller. (Voltoire) & Esueiller. & 267 & Esueiller. \\
\hline Iratçarria. eueillé. & Esueillé. & 267 & Esueillé. \\
\hline Iratçartçaillea. & [Esueiller]. & 267 & [Esueilleur]. \\
\hline IPIZPICUA, apezpicua. euesque. & Euesque. & 268 & Euesque. \\
\hline Ipizpicutasuna. euesché. & Euesché. & 268 & Euesché. \\
\hline AtÇARTCEA. eueiller. exciter. & $\begin{array}{l}\text { Exciter. Exciter id est Euei- } \\
\text { ller. }\end{array}$ & 269 & Exciter. \\
\hline Atçarmendua. excitation. & Excitation. & 269 & Excitation. \\
\hline Desencusa. excuse. & Excuse. & 270 & Excuse. \\
\hline Desencusamendua. & [Excusation]. & 270 & [Excusation]. \\
\hline Desterrua. exil. & Exil. & 271 & Exile. \\
\hline Desterratcea. exiler. bannir. & Exiler. & 271 & Exhiler. \\
\hline Basoillarra. faisan. & Faisan. & 277 & Faisan. \\
\hline Basoillazcoa. faisandeau. & Faisanneaux. & 277 & Faisandeau. \\
\hline $\begin{array}{l}\text { ASALDATCEA. fascher. irriter. detourner. im- } \\
\text { portuner. }\end{array}$ & Fascher & 279 & Fascher. \\
\hline Asaldua. fascherie. & Fascherie & 279 & Fascherie. \\
\hline IRUA. fascheux. depiteux. & Fascheux. & 279 & Fascheux. \\
\hline Andrecaria. addonné aux femmes. & $\begin{array}{l}\text { Femme. Qui est trop ad- } \\
\text { donné aux femmes. }\end{array}$ & 282 & \\
\hline BABA, 2. Sam. 17. 28, 2. ekosaria. feuue. & Febue. & 282 & Feue. \\
\hline Baba leka. gosse de feuue. & Febue. L'escosse d'vne febue. & 282 & Gosse. hollejo de haua. \\
\hline Arraillatcea. fendre. & Fendre. & 283 & Fendre. \\
\hline Arrailladura. fente. & Fente. & 283 & Fente. \\
\hline CARCAinatcea, 2. arraillatcea. fendre. & Fendre. & 283 & Fendre. \\
\hline Carcainadura, arrailladura. fente. & Fente. & 283 & Fente. \\
\hline Bethacorra. fertile. (BETHATCEA) & Fertile. & 284 & Fertile. \\
\hline Bethacortcea. fertiliser. & Fertiliser. & 284 & Fertile. \\
\hline Cixtapurrac. festus. buchettes. & Festu. & 284 & Festus. \\
\hline IEÏA, 2. jaïa. feste. & Feste. & 284 & Feste. \\
\hline Iaïa iduquitea, hautstea. fester. & Fester. & 284 & Fester. \\
\hline Vfu hatsa. fi du vilain. (VFu) & $\begin{array}{l}\text { Fi. est interjection rejectiue } \\
{[\ldots] \text { comme, Fi le vilain. }}\end{array}$ & 285 & \\
\hline
\end{tabular}




\begin{tabular}{|c|c|c|c|}
\hline $\begin{array}{l}\text { A eskuizkribuko } \\
\text { sarrerak }\end{array}$ & $\begin{array}{l}\text { Nicot-en } \\
\text { sarrerak }\end{array}$ & \begin{tabular}{|c|}
$\begin{array}{c}\text { Nicot-en } \\
\text { orrialde } \\
\text { zenbakia }\end{array}$ \\
\end{tabular} & $\begin{array}{l}\text { Oudin-en } \\
\text { sarrerak }\end{array}$ \\
\hline BEHAÇUNA, mina, guibel mina Liz. fiel. & Fiel. & 286 & Fiel. \\
\hline Alaba. fille. (Voltoire) & Fille. & 287 & Fille. \\
\hline Alababitchia. filleule. & Filleul. & 287 & Filleule. \\
\hline Alabaiçuna. fillastre. & Filiastre. & 287 & Fillastre. \\
\hline IRUTEA. filer. (Voltoire) & Filer. & 287 & Filer. \\
\hline Iruna. filé. & Filé. & 287 & \\
\hline Vgatz alaba. priuigna. & $\begin{array}{l}\text { Fille. La fille de ma femme } \\
\text { ou de mon mari. Priuigna. }\end{array}$ & 287 & \\
\hline Chirola. fluste. fluteau. & Fleute. & 290 & Fleute. \\
\hline Chirolaria. ioüeur de la flute. & Fleute. Joüeur de fleute. & 290 & \\
\hline VCHADA, vxada. dissenterie. flux de ventre. & Flux. Flux de ventre. & 290 & Flux de ventre. \\
\hline VHAITZA, vharca, ibaya. riuiere, fleuue. & Fleuue. Fleuue ou riuiere. & 290 & Fleuue. \\
\hline Vhina, hola. onde. flot. & Flot. & 290 & Flot. \\
\hline Abre belharra. foin. (ABREA) & Foin. & 291 & Foin. \\
\hline ÇOROA. fol. extrauagué. & Fol. & 291 & Fol. \\
\hline Çoratcea. & [Folier]. & 291 & [Folier]. \\
\hline Çoramendua. & [Folie]. & 291 & [Folie]. \\
\hline Cimendua. fondement. & Fondement. & 292 & Fondement. \\
\hline Cimendatcea. cimenter. fonder. & Fonder. & 292 & Fonder. \\
\hline ITHURRIA. fontaine. (Voltoire) & Fontaine. & 292 & Fontaine. \\
\hline Ithur vra. eau de fontaine. & Fontaine. Eauë de fontaine. & 292 & \\
\hline VRTCEA. fondre. & Fondre. & 292 & Fondre. \\
\hline Vrtua. fondu. & Fondu. & 292 & Fondu. \\
\hline Nigarretan vrtcea. fondre en larmes & Fondre en larmes. & 292. & Fondre en larmes. \\
\hline INDARRA. force. & Force. & 293 & Force. \\
\hline ARRAUTZA. forgeron. marechal. & Forgeron. & 294 & Forgeron. \\
\hline BorTHITZA. fort. valeureux. rude. & Fort. & 295 & Fort. \\
\hline Borthizqui. fortement. & Fortement. & 295 & Fortement. \\
\hline Indartsua. fort. valereux. & Fort. & 295 & Fort. \\
\hline IRAZEA. fougere. & Fougiere. & 297 & Fougere. \\
\hline VRKA. fourche. & Fourche. & 297 & Fourche. \\
\hline ChInHAURRIa, inhurria O. fourmy. & Fourmi. & 298 & Fourmi. \\
\hline INHURRIA, chinhaurria. fourmi. & Fourmi. & 298 & Fourmi. \\
\hline Inhurritcea. fourmiller. & Fourmiller. & 298 & Fourmiller. \\
\hline $\begin{array}{l}\text { ARREGA. maramoa. marruuia. marruuiüa. fraise. } \\
\text { fragum. }\end{array}$ & Fraise, Fragum. & 299 & Fraise. \\
\hline IASARTCEA. frapper. battre. & Frapper. & 300 & Frapper. \\
\hline
\end{tabular}




\begin{tabular}{|c|c|c|c|}
\hline $\begin{array}{c}\text { A eskuizkribuko } \\
\text { sarrerak }\end{array}$ & $\begin{array}{c}\text { Nicot-en } \\
\text { sarrerak }\end{array}$ & \begin{tabular}{|c|}
$\begin{array}{c}\text { Nicot-en } \\
\text { orrialde } \\
\text { zenbakia }\end{array}$ \\
\end{tabular} & $\begin{array}{l}\text { Oudin-en } \\
\text { sarrerak }\end{array}$ \\
\hline Athea ioitea, bulcatcea. frapper a la porte. & Frapper. Frapper à la porte. & 300 & \\
\hline BELARRA. front. & Front. & 303 & Front. \\
\hline Croscatcea. frotter. battre. (CROSCA) & Frotter. & 303 & Frotter. \\
\hline BAHIA. gage. saisi. & Gage. & 306 & Gage. \\
\hline IRAUASTEA. gaigner. (Voltoire) & Gaigner. & 307 & Gaigner. \\
\hline BelHAQUiA, ogaça. gasteau. & Gasteau. & 311 & Gasteau. \\
\hline BILHURA, bihurra. garrot. rote. & Garrot. & 311 & Garrot. \\
\hline Bilhurtcea. garroter. lier. & $\begin{array}{l}\text { Garotter. Lier et garotter } \\
\text { vn homme. }\end{array}$ & 311 & Garroter. \\
\hline ARrAYA. gay. joyeux. & Gay. Gay et joyeux. & 312 & Gay. \\
\hline Arraytasuna. gayeté. & Gayeté. & 312 & Gayeté. \\
\hline Arraïqui. gayement. joyeusement. & $\begin{array}{l}\text { Gayement. Gayement et jo- } \\
\text { yeusement. }\end{array}$ & 312 & Gayement. \\
\hline ÇAHAROA, 2. cigorra. gaule. & Gaule. & 312 & Gaule. \\
\hline Cincuria. O. gemissement. & Gemissement. & 312 & Gemissement. \\
\hline ÇoHIA. gazon. motte. & Gazon. & 312 & Gazon. \\
\hline IçOTZA. gelée. & Gelée. & 312 & Gelée. \\
\hline InCIRINA. gemissement. & Gemissement. & 312 & Gemissement. \\
\hline Escuin vssoa. geay. graculus. & $\begin{array}{l}\text { Gay qu'on prononce Geay, } \\
\text { Graccus, Gracculus. }\end{array}$ & 312 & Gay. \\
\hline Bassothea. O., orria. genieure. juniperus. & Geneure. Juniperus. & 313 & Geneure. \\
\hline Biga. O., miga. genisse. & Genisse. & 313 & Genisse. \\
\hline VRRICHA, vrrixa. genisse. taure. & Genisse. & 313 & Genisse. \\
\hline VRKABEA. gibet. potence. & Gibbet. & 314 & Gibet. \\
\hline CiA. gland de chesne. & Gland. gland de chesne. & 315 & Gland. \\
\hline CinçURRA. gorge. gosier. & Gorge. & 316 & Gorge. \\
\hline $\begin{array}{l}\text { Cinçurrac norbaiti eguitea. couper la gorge a } \\
\text { quelqu'vn. }\end{array}$ & Couper la gorge à aucun. & 316 & Couper la gorge. \\
\hline Chixterra, chisterra. gousse. & Gousse. & 317 & Gousse. \\
\hline Сhorta. goute de quelque liqueur. & Goutte. & 317 & Goutte. \\
\hline Vr chort bat. vne goute d'eau. & $\begin{array}{l}\text { Goutte. Vne goutte d'eauë, } \\
\text { ou d'autre liqueur qui chet. }\end{array}$ & 317 & \\
\hline Chortaca. goute a goute. & Goutte a goutte. & 317 & Goutte a goutte. \\
\hline BiнIA. grain. bled. & Grain. & 318 & Grain. \\
\hline VRIÑA. graisse. & Gresse. & 319 & Graisse. \\
\hline $\begin{array}{l}\text { BABAÇUÇA, arrabarra, chichera, chicherra Liz. } \\
\text { gresle. grando. }\end{array}$ & Gresle. La Gresle. Grando. & 321 & Gresle. \\
\hline Bihiteguia. grenier. grange. & Grenier. & 321 & Grenier. \\
\hline
\end{tabular}




\begin{tabular}{|c|c|c|c|}
\hline $\begin{array}{c}\text { A eskuizkribuko } \\
\text { sarrerak }\end{array}$ & $\begin{array}{l}\text { Nicot-en } \\
\text { sarrerak }\end{array}$ & \begin{tabular}{|c|}
$\begin{array}{c}\text { Nicot-en } \\
\text { orrialde } \\
\text { zenbakia }\end{array}$ \\
\end{tabular} & $\begin{array}{l}\text { Oudin-en } \\
\text { sarrerak }\end{array}$ \\
\hline IguELA, jhela. grenouille. & Grenouille. & 321 & Grenoüille. \\
\hline Chizpiltcea. griller. & Griller. & 322 & Griller. \\
\hline Chizpildua. grillé. & Grillé. & 322 & Grillé. \\
\hline VHERRA. gris. sombre. $^{\circ}$ & Gris. & 322 & Gris. \\
\hline Vrdintcea. grissoner. & Griser. Griser ou Grissoner. & 322 & Grisonner. \\
\hline IBIRIA, ipidia, iuia. O. gué. & Gué. & 323 & Gué. \\
\hline Iauntsaldia, aldagarria. habit. & Habit. & 326 & Habit. \\
\hline Iauntscura, iauntscuïa. habillem[ent]. & Habillement. & 326 & Habillement. \\
\hline BERROA, saparra, sassia. hallier. & Haillier ou hallier. & 327 & Haillier. \\
\hline CHEHATCEA. hacher, mettre a menu. (Voltoire) & Hacher. & 327 & Hacher. \\
\hline CHILIABILIAC, chizqui bizquiac. haillons. & Haillon. & 327 & Haillon. \\
\hline AUSARTA. hardy. & Hardi & 329 & Hardi. \\
\hline Ausartcea. prendre, donner hardiesse. s'enhardir. & $\begin{array}{l}\text { Hardiesse. Donner har- } \\
\text { diesse et asseurance. }\end{array}$ & 330 & \\
\hline Ausartcia. hardiesse. & Hardiesse. & 330 & Hardiesse. \\
\hline Çamarikina, irrincirina. henissem[ent]. (ÇAMARIA) & Henissement. & 332 & Henissement. \\
\hline ARHEA. herse. occa. & Herce, Occa. & 333 & Herse. \\
\hline Arheatcea, arhatcea e. herser. occare. & Hercer, Occare. & 333 & Herser. \\
\hline Arhatçaillea e. occator. & Herceur. Occator. & 333 & Herseur. \\
\hline Belharra. herbe. & Herbe. & 333 & Herbe. \\
\hline Cikultcea. herisser. & Herisser. & 334 & Herisser. \\
\hline Doatsutasuna. bonheur. felicité. & Heur. De bon Heur. & 335 & Bon-heur. \\
\hline Chopina. le hoquet. & Hoquet. Le hoquet. & 339 & \\
\hline Çotina, 2. chopina. hoquet. & Hoquet. & 339 & Hoquet. \\
\hline Vhantua. (Vhantcea) & Hydropique. & 342 & Hydropique. \\
\hline Vhantura. & [Hydropisie]. & 342 & [Hydropisie]. \\
\hline VRRUPA. gorgée. sorbitio. & Humement. sorbitio. & 342 & Gorgée. \\
\hline BARATZEa. iardin. (Voltoire) & Iardin. & 343 & Iardin. \\
\hline Çangartea. jambette. (ÇANGARDIA) & Iambette. & 343 & Iambette. \\
\hline Ieloscorra. jaloux. (Ielosia) & Ialoux. & 343 & Ialoux. \\
\hline Ieloscortasuna. jalousie. & Ialousie. & 343 & Ialousie. \\
\hline Ieloscorqui. & [Ialousement]. & 343 & [Ialousement]. \\
\hline Baratzeçaina. & Iardinier. & 344 & Iardinier. \\
\hline Iocoa. jeu. & Ieu. & 345 & Ieu. \\
\hline IMAGINA. image. & Image. & 346 & Oudin 1660. \\
\hline IMIQUIA. coeffure de femme. couurechef. & $\begin{array}{l}\text { Coeffure. Coeffure, An- } \\
\text { cienne coeffure de femme. }\end{array}$ & 346 & Coiffeure. \\
\hline
\end{tabular}




\begin{tabular}{|c|c|c|c|}
\hline $\begin{array}{l}\text { A eskuizkribuko } \\
\text { sarrerak }\end{array}$ & $\begin{array}{l}\text { Nicot-en } \\
\text { sarrerak }\end{array}$ & $\begin{array}{c}\text { Nicot-en } \\
\text { orrialde } \\
\text { zenbakia }\end{array}$ & $\begin{array}{l}\text { Oudin-en } \\
\text { sarrerak }\end{array}$ \\
\hline IMITATCEA. jmiter. & Imiter. & 346 & Oudin 1660. \\
\hline Imitacionea. jmitation. & Imitation. & 346 & Imitation. \\
\hline IMMORTALA, ecin hillezcoa. inmmortel. & Immortel. & 347 & Oudin 1660. \\
\hline IMPERFETA, escasa, makurra. jmparfait. & Imparfait. & 347 & Oudin 1660. \\
\hline Imperfeccionea, escasia. jmperfection. & Imperfection. & 347 & Imperfection. \\
\hline IMPRIMATCEA. imprimer. (Voltoire) & Imprimir. & 348 & Imprimir. \\
\hline Imprimatçaillea. imprimeur. & Imprimeur. & 348 & Imprimeur. \\
\hline Imprimatçaillearena. la maison de l'imprimeur. & Imprimerie. & 348 & Imprimerie. \\
\hline BEREHALA. incontinent. & Incontinent. & 349 & \\
\hline $\begin{array}{l}\text { IMMERECIENTA, merecigabea, merecigabecoa. } \\
\text { indigne. }\end{array}$ & Indigne. & 349 & Indigne. \\
\hline ANTCEA. industrie. adresse. & Industrie. & 350 & Industrie. \\
\hline Antçatsua. industrieux. & Industrieux. & 350 & Industrieux. \\
\hline INFORMACIONEA. jnformation. & Information. & 350 & Information. \\
\hline Informatcea. & [Informer]. & 350 & [Informer]. \\
\hline ITHAUNTCEA O. jnterroger. & Interroguer. & 353 & Interroger. \\
\hline IHIA. jonc. & Ionc. & 355 & Ionc. \\
\hline IOCATCEA. joüer. & Ioüer. & 355 & Ioüer. \\
\hline Iuntatcea. joindre. & Ioindre. & 355 & Ioindre. \\
\hline Iunturac. jointures. & Ioincture. & 355 & Ioincture. \\
\hline Iocaria. joüeur. & Ioueur. & 356 & Ioüeur. \\
\hline VZTARRIA. ioug. & Ioug. & 356 & Ioug. \\
\hline Vztartcea. mettre au joug. & $\begin{array}{l}\text { Ioug. Mettre les beufs sous } \\
\text { le ioug. }\end{array}$ & 356 & \\
\hline IugEa. juge. (Voltoire) & Iuge. & 359 & Iuge. \\
\hline Iugeatcea, julgatcea a. juger. & Iuger. & 360 & Iuger. \\
\hline Iugeamendua, julgamendua a. jugement. & Iugement. & 361 & Iugement. \\
\hline IUduA. & [Iuif]. & 362 & [Iuif]. \\
\hline IURAMENTUA, cina. jurement, serment. & Iurement. & 362 & Iurement. \\
\hline Iuramentu eguitea, cin eguitea. jurer. & Iurer. & 362 & Iurer. \\
\hline Iuramentutsua. a. jureur. & Iureur. & 362 & Iureur. \\
\hline Iusticia. justice. & Iustice. & 363 & Iustice. \\
\hline Xusquerrua, 2. musquerra. lezard. & Laisarde. & 365 & Lezard. \\
\hline $\begin{array}{l}\text { BRUSCAMBILLAC, bassa mahatzac. lambrusches. } \\
\text { racheboches. }\end{array}$ & Lambrunche. & 366 & Lambruche. \\
\hline ÇABALA, çauala. large. (Voltoire) & Large. & 368 & Large. \\
\hline Çabaltasuna. largeur. & Largeur. & 368 & Largeur. \\
\hline
\end{tabular}




\begin{tabular}{|c|c|c|c|}
\hline $\begin{array}{l}\text { A eskuizkribuko } \\
\text { sarrerak }\end{array}$ & $\begin{array}{l}\text { Nicot-en } \\
\text { sarrerak }\end{array}$ & $\begin{array}{c}\text { Nicot-en } \\
\text { orrialde } \\
\text { zenbakia }\end{array}$ & $\begin{array}{c}\text { Oudin-en } \\
\text { sarrerak }\end{array}$ \\
\hline IKUZTEA, ikutzea Liz. nettoyer. lauer. & Lauer. Lauer et nettoyer. & 369 & Lauer. \\
\hline Ikuzgarria. Io 5.4. lauoir. lauacrum. & $\begin{array}{l}\text { Lauer. Vn lieu à se lauer, } \\
\text { Lauacrum. }\end{array}$ & 369 & Lauoir. \\
\hline VNHATCEA. lasser. & Lasser. & 369 & Lasser. \\
\hline ARINA. leger. & Legier. & 370 & Leger. \\
\hline Arinqui. legerement. & Legierement. & 370 & Legerement \\
\hline Arintasuna. legereté. gaillardise. & Legiereté. & 370 & Legereté \\
\hline ChinguilLac. lentilles. & Lentilles. & 370 & Lentilles. \\
\hline Altchagarria, lemamia. leuain. & Leuain. & 372 & Leuain. \\
\hline CHARDANGOA, 2. felderacoa. leurier. & Leurier. & 372 & Leurier. \\
\hline IAIQUITCEA, jaiquitea. se leuer. & Leuer. Se leuer. & 372 & Se leuer. \\
\hline ARDItA. liard. & Liard. & 373 & Liard. \\
\hline Guiçon biçarra. homme liberal. (BIÇARRA) & Liberal. & 373 & Liberal. \\
\hline Biçartasuna. liberalité. & Liberalité. & 373 & Liberalité. \\
\hline Biçarqui. liberalement. & Liberalement. & 373 & Liberalement. \\
\hline AMARRA. lien. garrot. & Lien. & 374 & Lien. \\
\hline Amarratcea. lier. garroter. (Voltoire) & Lier. & 374 & Lier. \\
\hline AnDA. litiere. & Lictiere. & 374 & Lictiere. \\
\hline Andaçaina. & $\begin{array}{l}\text { Qui ai doit à porter la lic- } \\
\text { tiere. }\end{array}$ & 374 & \\
\hline CAMASTRA a., ohea, etçauntça. lit. couche. & Lict. & 374 & Lict. \\
\hline CAPESTRUA. licol. & Licol. & 374 & Licol. \\
\hline CEPOA. lien. menotte. & Lien. & 374 & Lien. \\
\hline Amarradura. & [Liement]. & 375 & [Liement]. \\
\hline IRACURTCEA, 2. leitcea. lire. & Lire. & 377 & Lire. \\
\hline Iracurlea, jracurtçaillea. lecteur, qui lit. & Lecteur. & 377 & Lecture. \\
\hline VRRUNA. loing. eloigné. & Loing. & 379 & Loing. \\
\hline Vrruititic. de loing. & De loing. & 379 & De loing. \\
\hline Alabatcea. loüer. & Louer. & 380 & Loüer. \\
\hline ALOCACERA. mercenaire. homme de journée. loüager. & Louagier. & 380 & Loüagier. \\
\hline Alocaïrua. loüage. prix. salaire. & Louage. & 380 & Loüage. \\
\hline Alocaïruan hartcea. prendre a loüage. & $\begin{array}{l}\text { Louer maison, c'est et bai- } \\
\text { ller et prendre à louage. }\end{array}$ & 380 & Prendre à loüage. \\
\hline Alanbantça. e. louange. & Louange. & 381 & Loüange. \\
\hline $\begin{array}{l}\text { DESTARTA, erreueza. lourdaut. etourdi O. ru- } \\
\text { dis. rusticus. }\end{array}$ & Lourdaut. Rusticus. & 381 & Lourdaut. \\
\hline VDAGARA, vhadera. loutre. leurre. & Loutre. & 381 & Loutre. \\
\hline BORROCA. luitte. & Luicte. & 383 & Luitte. \\
\hline
\end{tabular}




\begin{tabular}{|c|c|c|c|}
\hline $\begin{array}{l}\text { A eskuizkribuko } \\
\text { sarrerak }\end{array}$ & $\begin{array}{l}\text { Nicot-en } \\
\text { sarrerak }\end{array}$ & $\begin{array}{c}\text { Nicot-en } \\
\text { orrialde } \\
\text { zenbakia }\end{array}$ & $\begin{array}{c}\text { Oudin-en } \\
\text { sarrerak }\end{array}$ \\
\hline Borrocaria. luiteur. & Luicteur. & 383 & Luitteur. \\
\hline Borrocatcea. luiter. & Luicter. & 383 & Luitter. \\
\hline Distiadura. lueur. brillant. fulgor. & Lueur, Fulgor. & 383 & Lueur. \\
\hline ARgala. maigre. & Maigre. & 385 & Maigre. \\
\hline Lur argala. terre maigre. & Maigre. Terre maigre. & 385 & \\
\hline Argaldura. & [Maigreur]. & 385 & [Maigreur]. \\
\hline Argaltasuna. & [Maigreté]. & 385 & \\
\hline Chatarrac. drapeaux d'enfans, maillots. & $\begin{array}{l}\text { Maillot. Le maillot des pe- } \\
\text { tites enfans. }\end{array}$ & 385 & Maillot. \\
\hline DOHACABEA. malheureux. (Voltoire) & Malheureux. & 391 & Mal-heureux. \\
\hline Dohacabetasuna. malheur. & Malheur. & 391 & Mal-heur. \\
\hline Dohacabequi. malheureusement. (Voltoire) & Malheureusement. & 391 & Mal-heureusement. \\
\hline IsPILLUA. malotru. gueux. & Malotru. & 391 & Malotru. \\
\hline IANHARIA. viande. mangeaille. & Mangeaille. & 392 & Mangeaille. \\
\hline IATEA. manger. & Manger. & 392 & Manger. \\
\hline Ialea. mangeur. & Mangeur. & 392 & Mangeur. \\
\hline CORDUANA. marroquin. & $\begin{array}{l}\text { Marroquin [...] car s'il es- } \\
\text { toit passé en Tan, ce seroit } \\
\text { Cordoüan. }\end{array}$ & 397 & Marroquin. \\
\hline Burhostatcea. maudire. (BuRHOA) & Mauldir. & 398 & Maudire. \\
\hline ATCHETERA, midicua, dotora. medecin. & Medecin. & 399 & Medecin. \\
\hline BabiLlera. meche de lampe. & Meiche. & 400 & Meche. \\
\hline DixiduA. menace. & Menace. & 401 & Menace. \\
\hline Dixidatcea. menacer. & Menacer. & 401 & Menacer. \\
\hline Dixidaria, dixidatçaillea. menaceur. & Menaceur. & 401 & Menaceur. \\
\hline Durdusia. menace. & Menace. & 401 & Menace. \\
\hline Durdusiatcea, induriatcea. menacer. froller. & Menacer. & 401 & Menacer. \\
\hline Durdusiadura. & Menacement. & 401 & Menacement. \\
\hline Durdusiatçaillea. & [Menaceur]. Qui menace. & 401 & [Menaceur]. \\
\hline INDURIA, mehatchua. menace. & Menace. & 401 & Menace. \\
\hline Induriatcea. menacer. & Menacer. & 401 & Menacer. \\
\hline Induriosa. & [Menaçant]. & 401 & [Menaçant]. \\
\hline Chehea. menu. & Menu. & 402 & Menu. \\
\hline Gende chehea. le menu peuple. & Menu. Le menu peuple. & 402 & \\
\hline $\begin{array}{l}\text { Chehero, cheheroqui. separem [ent], par le } \\
\text { menu, en detail. }\end{array}$ & Par le menu. & 402 & Par le menu. \\
\hline Cocotza. menton. & Menton. & 402 & Menton. \\
\hline
\end{tabular}




\begin{tabular}{|c|c|c|c|}
\hline $\begin{array}{c}\text { A eskuizkribuko } \\
\text { sarrerak }\end{array}$ & $\begin{array}{l}\text { Nicot-en } \\
\text { sarrerak }\end{array}$ & \begin{tabular}{|c|}
$\begin{array}{c}\text { Nicot-en } \\
\text { orrialde } \\
\text { zenbakia }\end{array}$ \\
\end{tabular} & $\begin{array}{c}\text { Oudin-en } \\
\text { sarrerak }\end{array}$ \\
\hline Chuchurlaria. susurro. (CHUChurLac) & $\begin{array}{l}\text { Mesdire. Qui mesdit d'au- } \\
\text { cun par derriere, Susurro. }\end{array}$ & 405 & \\
\hline ARBUYUA, arbuïoa. mepris. rebut. & Mespris. & 406 & Mespris. \\
\hline Arbuyamendua. l'action du mepris. & Mesprisement. & 406 & Mesprisement. \\
\hline Arbuyatcea. mepriser. rebuter. & Mespriser. & 406 & Mespriser. \\
\hline Arbuyatçaillea. & [Mespriseur]. & 406 & [Mespriseur]. \\
\hline IÇARIA, neurria. mesure. & Mesure. & 407 & Mesure. \\
\hline Isartcea. mesurer. & Mesurer. & 407 & Mesurer. \\
\hline Barrentcea. mettre dedans. & Mettre. Mettre dedans. & 408 & \\
\hline IBENTCEA. mettre. poser. & Mettre. & 408 & Mettre. \\
\hline ÇORHIA. meur. & Meur. & 410 & Meur. \\
\hline Çorhitcea. meurir. & Meurir. & 410 & Meurir. \\
\hline Vbeltcea. & Meurtrir. & 410 & Meurtrir. \\
\hline VMUA, vmoa. a. meur. mol. & Meur. & 410 & Meur. \\
\hline Vmatcea, vmotcea a. meurir. mollir. & Meurir. & 410 & Meurir. \\
\hline BALACATCEA. mignarder. flatter. amignoter. & Mignarder. & 411 & Mignarder. \\
\hline Balacua. mignardise. & Mignardise. & 411 & Mignardise. \\
\hline IlHaintXa, 2. mirua. (Voltoire) miluus. & Milan. Vn Milan, Miluus. & 411 & Milan. \\
\hline VSQUEA, arto chehea. millet. & Millet. & 412 & Millet. \\
\hline BuRLA, trufa. gausserie. moquerie. & Mocquerie. & 413 & Mocquerie. \\
\hline Burlaria, burlatçaillea, trufaria. moqueur. & Mocqueur. & 413 & Mocqueur. \\
\hline Burlatcea norbaitez. se moquer de quelqu'vn. & $\begin{array}{l}\text { Mocquer. Se mocquer de } \\
\text { quelqu'vn. }\end{array}$ & 413 & \\
\hline BERA. tendre. mol. & Mol. & 415 & Mol. \\
\hline $\begin{array}{l}\text { Beratcea. amollir. rendre souple. tremper. } \\
\text { mouiller. }\end{array}$ & Mollir. & 415 & Mollir. \\
\hline ÇURMINDUA. moisi. vermoulu. & Moisi. & 415 & \\
\hline Çurmindura. & [Moissisure]. & 415 & [Moissiseur]. \\
\hline Çurmintcea. & [Moisir]. & 415 & Moisir. \\
\hline VzTA. moisson. & Moison. & 415 & Moisson. \\
\hline Vzta biltçailleac, ogui eppailleac. moissonneurs. & Moissonneur. & 415 & Moissonneur. \\
\hline IKAITEA. monter. (Voltoire) & Monter. & 417 & Monter. \\
\hline AusIQUiA. morsure. & Morsure. & 418 & Morsure. \\
\hline Ausiquitcea. mordre. (Voltoire) & Mordre. & 418 & Mordre. \\
\hline ÇATHIA. morceau. piece. & Morceau. & 418 & Morceau. \\
\hline $\begin{array}{l}\text { Çathicatcea. çathitcea. mettre a morceaux. } \\
\text { rompre. dechirer. }\end{array}$ & $\begin{array}{l}\text { Morceau. Mettre en mor- } \\
\text { ceaux. }\end{array}$ & 418 & \\
\hline Ikaitça. montée. l'action de monter. & Montée. & 418 & Montée. \\
\hline
\end{tabular}




\begin{tabular}{|c|c|c|c|}
\hline $\begin{array}{c}\text { A eskuizkribuko } \\
\text { sarrerak }\end{array}$ & $\begin{array}{l}\text { Nicot-en } \\
\text { sarrerak }\end{array}$ & $\begin{array}{c}\text { Nicot-en } \\
\text { orrialde } \\
\text { zenbakia }\end{array}$ & $\begin{array}{l}\text { Oudin-en } \\
\text { sarrerak }\end{array}$ \\
\hline CinTÇA. morue. gourme. & Morue. & 419 & Morve. \\
\hline ChIQUiroA. mouton. (Voltoire) & Mouton. & 421 & Mouton. \\
\hline Chiquiro ezpalda. & [Espaule de mouton]. & 421 & \\
\hline IAYOTCEA, sortcea. naistre. & Naistre. & 425 & Naistre. \\
\hline Iaya eguna. jour natal. & $\begin{array}{l}\text { Natiuité. Le jour de la na- } \\
\text { tiuité d'vn chascun [...] Die } \\
\text { natalis. }\end{array}$ & 425 & \\
\hline Iguericatcea. nager. (IgueREA) & Nager. & 425 & Nager. \\
\hline Iguericaria, iguericatçaillea. nageur. & Nageur. & 425 & Nageur. \\
\hline INCENSUA. encens. & Encens. & 426 & Encens. \\
\hline ARATZA. net. nitidus. & Net. Net, Nitidus. & 429 & Net. \\
\hline Aratztasuna. netteté. & Netteté. & 429 & Netteté. \\
\hline Aratzqui. nettement. & Nettement. & 429 & Nettement. \\
\hline BEDERATCI. neuf. & Neuf. & 429 & Neuf. \\
\hline Bederatcigarrena. neufiéme. & Neufiesme. & 429 & Neufiesme. \\
\hline Bederatci vrruna. neufaine. & Neufaine. & 429 & Neufuaine. \\
\hline Bederatcitan. neuf fois. & Neuf. Neuffois. & 429 & \\
\hline ÇAINA. nerf. vene. racine. (Voltoire) & Nerf. & 429 & Nerf. \\
\hline Снанua, garbia. net. & Net. & 429 & Net. \\
\hline Chahutcea. nettoyer. (Voltoire) & Nettoyer. & 429 & Nettoyer. \\
\hline Chahutasuna. netteté. & Netteté. & 429 & Netteté. \\
\hline Chahuqui, chauroqui. nettement. & Nettement. & 429 & Nettement. \\
\hline Corapilloa. neud. & Neud. & 429 & Neud. \\
\hline Corapillatcea. noüer. & Noüer. & 429 & Noüer. \\
\hline Corapilladura. & [Noüement]. & 429 & [Noüement]. \\
\hline BeltzA. noir. (Voltoire) & Noir. & 430 & Noir. \\
\hline Beltztea. noircir. & Noircir. & 430 & Noircir. \\
\hline VKaTCEA. nier. & Nier. & 430 & Nier. \\
\hline Beltztasuna, beltztura. noirceur. & Noircisseur ou noirceur. & 431 & Noircisseur. \\
\hline ICENA. nom. (Voltoire) & Nom. & 431 & Nom. \\
\hline Icendatcea. nommer. & Nommer. & 431 & Nommer. \\
\hline AzTEA, haztea. nourrir. (Voltoire) & Nourrir. & 433 & Nourrir. \\
\hline Az aita. pere nourricier. & Nourrissier. & 433 & Nourrisier. \\
\hline Az ama. mere nourrice. & Nourrise. & 433 & Nourrise. \\
\hline Azcuntça. nourriture. & Nourriture. & 433 & Nourriture. \\
\hline VNHIDEA. nourrice. & Nourrise ou Nourrice. & 433 & Nourrise. \\
\hline Vnhit haurra. nourriçon. & Nourrison. & 433 & Nourrison. \\
\hline
\end{tabular}




\begin{tabular}{|c|c|c|c|}
\hline $\begin{array}{l}\text { A eskuizkribuko } \\
\text { sarrerak }\end{array}$ & $\begin{array}{l}\text { Nicot-en } \\
\text { sarrerak }\end{array}$ & $\begin{array}{c}\text { Nicot-en } \\
\text { orrialde } \\
\text { zenbakia }\end{array}$ & $\begin{array}{l}\text { Oudin-en } \\
\text { sarrerak }\end{array}$ \\
\hline Azmendua. nourriture. & Nourrissement. & 434 & Nourrissement. \\
\hline BERRIA. nouueau. recent. nouuelle. & Nouuelle. & 434 & Nouuelle. \\
\hline Berriro, berrirozqui. nouuellem[ent]. & Nouuuellement. & 434 & Nouuellement. \\
\hline Berritsua. conteur de nouuelles, rapporteur. & $\begin{array}{l}\text { Nounelle. Rapporteur ou } \\
\text { controueur de fausse noune- } \\
\text { lle. }\end{array}$ & 434 & \\
\hline BilluzgorRia. tout fin nud. & Nud. & 434 & Nud. \\
\hline Billuzgorritasuna. nudité. & Nudité. & 434 & Nudité. \\
\hline $\begin{array}{l}\text { Billuzgorritcea. mettre tout a nud. se depoüi- } \\
\text { ller tout a fait. }\end{array}$ & Nud. Mettre nud. & 434 & \\
\hline ILHUNA. brun. noir. obscur. & Obscur. & 437 & Obscur. \\
\hline Ilhuntcea. obscurcir. & Obscurcir. & 437 & Obscurcir. \\
\hline Ilhuntasuna. obscurité. & Obscurité. & 437 & Obscurité. \\
\hline Arraultcea. oeuf. & Oeuf. & 439 & Oeuf. \\
\hline $\begin{array}{l}\text { Beguiztatcea. ietter des oeillades. mugueter des } \\
\text { yeux. ensorceler. (Beguia) }\end{array}$ & $\begin{array}{l}\text { Oeillades. Oeillades, id est, } \\
\text { jetter des oeillades. }\end{array}$ & 439 & \\
\hline IULUFREA. oeillet. & Oeillet. & 439 & Oeillet, fleur. \\
\hline CHORIA. oiseau. (Voltoire) & Oiseau. & 440 & Oiseau. \\
\hline VNGUENTA, vnguentua. onguent. & Onguent. & 440 & Onguent. \\
\hline Vnguenztatcea, vnguentatcea. Io. 12. oindre. & Oindre. & 440 & Oindre. \\
\hline VNTATCEA. oindre. & Oindre. & 440 & Oindre. \\
\hline Ançaracumea. oison & $\begin{array}{l}\text { Oison. Est une jeune oye. } \\
\text { Anserculus. }\end{array}$ & 441 & Oison. \\
\hline ITÇALA. ombre. (Voltoire) & Ombre. & 441 & Ombre. \\
\hline Itçaltcea. ombrager. & Ombrager. & 441 & Ombrager. \\
\hline VNÇA. once. poids. & Once. & 441 & Once. \\
\hline Ene vstez. selon mon opinion. & $\begin{array}{l}\text { Opinion. Selon mon opi- } \\
\text { nion. }\end{array}$ & 442 & \\
\hline AzPILtCEA. orler. & Orler. & 447 & Orler. \\
\hline Azpilçuna. orlet. & Orlet. & 447 & Orlet. \\
\hline Azpildura. orlure. & Orlure. & 447 & Orlure. \\
\hline VRGUILLUA. orgueilleux. & Orgueilleux. & 447 & Orgueilleux. \\
\hline Vrguillutcea. s'enorgueillir. enorgueilir. & Orgueillir. S'orgueillir. & 447 & S'orgueillir. \\
\hline Vrguilluqui. orgueilleusem[ent]. & Orgueilleusement. & 447 & Orgueilleusement. \\
\hline IREQUITCEA, idequitcea. ouurir. & Ouurir. & 451 & Ouurir. \\
\hline AnçAra. Oye. (Voltoire) & Oye & 452 & Oye. \\
\hline BAQUEA. paix. & Paix. & 453 & Paix. \\
\hline Baquetcea. mettre la paix. & Paix. Mettre paix. & 453 & Mettre en paix. \\
\hline
\end{tabular}




\begin{tabular}{|c|c|c|c|}
\hline $\begin{array}{l}\text { A eskuizkribuko } \\
\text { sarrerak }\end{array}$ & $\begin{array}{l}\text { Nicot-en } \\
\text { sarrerak }\end{array}$ & \begin{tabular}{|c|}
$\begin{array}{c}\text { Nicot-en } \\
\text { orrialde } \\
\text { zenbakia }\end{array}$ \\
\end{tabular} & $\begin{array}{l}\text { Oudin-en } \\
\text { sarrerak }\end{array}$ \\
\hline Bazcatcea. paistre. & Paistre. & 453 & Paistre. \\
\hline BIRITCHIA. pair. & Paire. & 453 & Pair. \\
\hline Baquetiarra. qui aime la paix. pacifique. & Paix. Qui aime paix. & 454 & \\
\hline Baquetsua, baquezcoa. paisible. & Paisible. & 454 & Paisible. \\
\hline Chatarra. paquet. & Paquet. & 456 & Pacquet. \\
\hline $\begin{array}{l}\text { CHICHITERA, chichitola, pimpirina, astoaren } \\
\text { arima. papillon. }\end{array}$ & Papillon. & 456 & Papillon. \\
\hline BARKATCEA. pardonner. (Voltoire) & Pardonner. & 457 & Pardonner. \\
\hline Barka diaçadaçu. pardonnez moy. & $\begin{array}{l}\text { Pardonner. Pardonne moy } \\
\text { cette faut. }\end{array}$ & 457 & \\
\hline Barkacinoa, barkamendua. pardon. & Pardon. & 457 & Pardon. \\
\hline Barkaquiçuna. digne de pardon. & Pardonnable. & 457 & Pardonnable. \\
\hline BRAGAMIOA. parchemin. & Parchemin. & 457 & Parchemin. \\
\hline Vrrindatcea, vrrinztatcea. parfumer. & Parfumer. & 458 & Parfumer. \\
\hline Parra-choria, eliça choria. passer, passerculus. & $\begin{array}{l}\text { Passereau, Passer, Passer- } \\
\text { culus. }\end{array}$ & 467 & \\
\hline $\begin{array}{l}\text { Les passereaux crient, paxaros que pian, pipi- } \\
\text { lant passeres. }\end{array}$ & $\begin{array}{l}\text { Passereau. Les passereaux } \\
\text { crient, Pipilant passeres. }\end{array}$ & 467 & \\
\hline BAZCA. pasture. & Pasture. & 468 & Pasture. \\
\hline Calsada. paué. & Paué. & 468 & Paué. \\
\hline BeKatua. peché. & Peché. & 469 & Peché. \\
\hline Bekatorea. pecheur. & Pecheur. & 469 & Pecheur. \\
\hline Bekatorezza. pecheresse. & Pecheresse. & 469 & Pecheresse. \\
\hline Bekatu eguitea. & Pecher. & 469 & Pecher. \\
\hline BETHAÇALA, bethespala, bethilleac. paupieres. & Paulpieres. & 469 & Paulpieres. \\
\hline $\begin{array}{l}\text { ÇAHAGUIA. peau de cuir a mettre vin ou huile. } \\
\text { outre. }\end{array}$ & $\begin{array}{l}\text { Peau. Peau de bouc ou de } \\
\text { cheure cuir a mettre vin ou } \\
\text { huile. }\end{array}$ & 469 & \\
\hline Calsadatcea. pauer. & Pauer. & 469 & Pauer. \\
\hline Irakaztunlaria. pedant. & Pedante. & 470 & Pedant. \\
\hline Vrkatcea. pendre. & Pendre. & 471 & Pendre. \\
\hline VSTEA. opinion. penser. & Penser. & 472 & Penser. \\
\hline Vste gabe, vste gabez, vste gaberic. sans y penser. & Penser. Sans y penser. & 472 & \\
\hline IoITEA. frapper. percer. pousser. (Voltoire) & Percer. & 473 & Percer. \\
\hline Ioçaçu barrika. percez la barrique. & $\begin{array}{l}\text { Percer. Percer de muiz, Do- } \\
\text { lia terebrare. }\end{array}$ & 473 & \\
\hline CHIPIA, chiquia. petit. & Petit. & 477 & Petit. \\
\hline Chipitasuna. petitesse. & Petitesse. & 477 & Petitesse. \\
\hline
\end{tabular}




\begin{tabular}{|c|c|c|c|}
\hline $\begin{array}{l}\text { A eskuizkribuko } \\
\text { sarrerak }\end{array}$ & $\begin{array}{l}\text { Nicot-en } \\
\text { sarrerak }\end{array}$ & $\begin{array}{c}\text { Nicot-en } \\
\text { orrialde } \\
\text { zenbakia }\end{array}$ & $\begin{array}{c}\text { Oudin-en } \\
\text { sarrerak }\end{array}$ \\
\hline IÇURRIA. peste. (Voltoire) & Peste. & 477 & Peste. \\
\hline Içurritea. pestilence. & Pestilence. & 477 & Pestilence. \\
\hline APPURRA. petit. peu. & Peu. & 478 & Peu. \\
\hline Appurca. peu a peu. & Peu à peu. & 478 & Peu à peu. \\
\hline ICIALDURA, icidura. peur. & Peur. & 478 & Peur. \\
\hline Icitcea. faire peur. auoir peur. & Peur. Auoir peur. Faire peur. & 478 & \\
\hline ChimicatCEA, cimicatcea. pinser. & Pincer. & 481 & Pinser. \\
\hline VssoA. 2. vrsoa. pigeon. palomme. (Voltoire) & Pigeon. & 481 & Pigeon. \\
\hline Vssocumea. pigeonneau. & Pigeonneau. & 481 & Pigeonneau. \\
\hline Vssoteguia. pigeonnier. & Pigeonnier ou Colombier. & 481 & Pigeonnier. \\
\hline Vsso dorrea. colombier. & Pigeonnier ou Colombier. & 481 & Colombier. \\
\hline Vrricalmendua. compassion. pitié. (VRRICALTCEA) & Pitié. & 483 & Pitié. \\
\hline Vrricalmendutsua. compassif. pitoyable. & Pitoyable. & 483 & Pitoyable. \\
\hline ARRENCURA. plainte. & Plainte. & 485 & Plainte. \\
\hline Arrencuratcea. se plaindre. & $\begin{array}{l}\text { Se plaindre ou complain- } \\
\text { dre. }\end{array}$ & 485 & Se plaindre. \\
\hline Arrencuratia. plaintif. qui se plaint toujours. & Plainte ou plaintif. & 485 & Plaintif. \\
\hline Atseguina. plaisir. delice. contentement. & Plaisir. & 486 & Plaisir. \\
\hline Atseguintsua. & [Plaisant]. & 486 & [Plaisant]. \\
\hline Atseguintasuna & [Plaisanteries]. & 486 & [Plaisanterie]. \\
\hline ARTINA belharra. plant[a]in. & Plantain. & 487 & Plantain. \\
\hline IFINTCEA, landatcea. planter. piquer. ficher. attacher. & Planter. & 487 & Planter. \\
\hline Ifinia. mis. planté. & Planté. & 487 & \\
\hline Ifintça. plantatio. & Plantement. Plantatio. & 488 & \\
\hline IGUELSUA, guilsua e. plastre. & Plastre. & 488 & Plastre. \\
\hline Iguelsuztatcea, guilsatcea. plastrer. & Plastrer. & 488 & Plastrer. \\
\hline BERUNA. plomb. & Plomb. & 489 & Plomb. \\
\hline $\begin{array}{l}\text { Berunztatcea, beruneztatcea, berundatcea. } \\
\text { plomber. garnir de plomb. }\end{array}$ & Plomber. & 489 & Plomber. \\
\hline BussOA. plongeur. & Plongeur. & 489 & Plongeur. \\
\hline Bussotcea. plonger. & Plonger. & 489 & Plonger. \\
\hline $\begin{array}{l}\text { BaINo. est vne particule qui e[s]pliq[ue] la que } \\
\text { du comparatif. }\end{array}$ & Plus. Magis. & 490 & Plus. \\
\hline Hil biloac. poil folet. lanugo. & Poil. Poil folet [...]. Lanugo. & 490 & Poil folet. \\
\hline BipiltCEA. plumer. & Plumer. & 490 & Plumer. \\
\hline VDAREA. poire. (Voltoire) & Poire. & 492 & Poire. \\
\hline Vdareondoa. poirier. & Poirier. & 492 & Poirier. \\
\hline
\end{tabular}




\begin{tabular}{|c|c|c|c|}
\hline $\begin{array}{l}\text { A eskuizkribuko } \\
\text { sarrerak }\end{array}$ & $\begin{array}{l}\text { Nicot-en } \\
\text { sarrerak }\end{array}$ & $\begin{array}{c}\text { Nicot-en } \\
\text { orrialde } \\
\text { zenbakia }\end{array}$ & $\begin{array}{c}\text { Oudin-en } \\
\text { sarrerak }\end{array}$ \\
\hline VKaBILla. poing. & Poing. & 492 & Poing. \\
\hline Vkaraya. muineca O. le poignet. & Poignet. & 492 & Poignet. \\
\hline BiKeA. poix. & Poix. & 493 & Poix. \\
\hline Bikeztatcea. poisser. & Poisser. & 493 & Poisser. \\
\hline Piñu cia, meluis sagarra. pomme de pin. & Pomme. Pommes de pin. & 493 & Pomme de pin. \\
\hline Bassurdea. porc sanglier. aper. (Voltoire) & $\begin{array}{l}\text { Porc. Porc sanglier, Aper } \\
\text { apris. }\end{array}$ & 494 & Porc sanglier. \\
\hline VRDAINA. porcher. & Porcher. & 494 & Porcher. \\
\hline Vrdea. porc, porceau. (Voltoire) & Porc ou Porceau. & 494 & Porc. \\
\hline ATHEA, bortha. porte. (Voltoire) & Porte. & 495 & Porte. \\
\hline Athalçaina. portier. & Portier. & 495 & Portier. \\
\hline BortHA, 2. athea. porte. & Porte. & 495 & Port. \\
\hline Borthaçaina, athalçaina. portier. & Portier. & 495 & Portier. \\
\hline IABEA. maistre. possesseur. & Posseseur. & 496 & Posseseur. \\
\hline Iabetcea. posseder. entre en possession. & Posseder. & 496 & Posseder. \\
\hline Iabetasuna. & [Possession]. & 496 & [Possession]. \\
\hline Cutchua, oha eltcea. pot de chambre. matula. & Pot. Pot à pissser, Matula. & 497 & $\begin{array}{l}\text { Pot de chambre, \& Pot a } \\
\text { pisser. }\end{array}$ \\
\hline BIRIAC, hauscoac. poumons. & Poulmon. & 498 & Poumon. \\
\hline VRDINCHAC. potirons. & Potiron. & 498 & Potiron. \\
\hline BERDOGALA. pourpier. & Pourpier. & 501 & Pourpier. \\
\hline CAUARDIlla. pourpre. rougeole. & Pourpre. & 501 & Pourpre,maladie. \\
\hline $\begin{array}{l}\text { BusteltCEA, vsteltcea, pusteltcea, vmatcea. } \\
\text { pourrir. chopir. mollir. (Voltoire) }\end{array}$ & Pourrir. & 502 & Pourrir. \\
\hline Busteldua. pourri. & Pourri. & 502 & Pourry. \\
\hline Busteldura. pourriture. & Porriture. & 502 & Pourriture. \\
\hline BIPERRA. poiure. & Poyvre. & 503 & Poivre. \\
\hline Biperztatcea. poiurer. & Poyvrer. & 503 & Poivrer. \\
\hline ÇORHOA. preau. herbe verte. & Preau. & 504 & Preau. \\
\hline ÇAPATCEA. presser. enfoncer. entasser. & Presser. & 508 & Presser. \\
\hline AITÇAQUIA, atchaquia. excuse. pretexte. & Pretexte. & 509 & Pretexte. \\
\hline IRASTEA. pressurer. & Pressurer. & 509 & Pressurer. \\
\hline Belhartcea, belhastea. printemps. & Printemps. & 511 & Printemps. \\
\hline CARCELA, garcela. prison. & Prison. & 512 & Prison. \\
\hline ARAUA. proportion. & Proportion. & 520 & Proportion. \\
\hline Araueratcea. proportionner. & Proportioner. & 520 & Proportionner. \\
\hline ARANA. prune. (Voltoire) & Prune. & 524 & Prune. \\
\hline
\end{tabular}




\begin{tabular}{|c|c|c|c|}
\hline $\begin{array}{l}\text { A eskuizkribuko } \\
\text { sarrerak }\end{array}$ & $\begin{array}{l}\text { Nicot-en } \\
\text { sarrerak }\end{array}$ & $\begin{array}{c}\text { Nicot-en } \\
\text { orrialde } \\
\text { zenbakia }\end{array}$ & $\begin{array}{l}\text { Oudin-en } \\
\text { sarrerak }\end{array}$ \\
\hline Aranondoa. prunier. & Prunier. & 524 & Prunier. \\
\hline BOTHEREA. puissance. pouuoir. (Voltoire) & Puissance. & 525 & Puissance. \\
\hline Botheretsua. puissant. & Puissant. & 525 & Puissant. \\
\hline BERROGOY, berriz hogoy. quarante. & Quarante. & 528 & Quarante. \\
\hline Berrogoygarrena. quarantiéme. & Quarantieme. & 528 & Quarantiesme. \\
\hline Berrogoytan, berrogoy aldiz. quarante fois. & Quarant. Quarante fois. & 528 & \\
\hline BerRogoya O. gariçuma. caresme. & Quaresme. & 528 & Quaresme. \\
\hline Iharduquitçaillea. qui conteste. & Querelleux. & 530 & Querelleux. \\
\hline Iharduquitça. querelle. disension. & Querelle. & 530 & Querelle. \\
\hline Irulaga. quenoüille. & Quenoüille. & 530 & Quenoüille. \\
\hline ANTOLATCEA. accomoder. rabiller. & Rabiller. & 533 & Rabiller \\
\hline Antolatçaillea, antolaria. rabilleur. & Rabilleur. & 533 & Rabilleur \\
\hline ARRABOTA. rabot. & Rabot. & 533 & Rabot. \\
\hline BERREROzTEA, berriz erostea. racheter. & Racheter. & 534 & Rachepter. \\
\hline Berrerospena. rachat. & Rachapt. & 534 & Rachapt. \\
\hline ARRAÇOINA. raison. (Voltoire) & Raison. & 535 & Raison. \\
\hline Arraçoinamendua. raisonnement. & Raisonnement. & 536 & Raisonnement. \\
\hline Arraçoinezcoa. raissonable. & Raisonnable. & 536 & Raisonable. \\
\hline $\begin{array}{l}\text { Illarac çurkaitztatcea. ramer les pois. (ÇUR- } \\
\text { KAITZTATCEA) }\end{array}$ & Ramer. Ramer des poix. & 536 & \\
\hline ARRAMUA. rameau. & Rameau. & 537 & Rameau. \\
\hline ARRAÇATCEA. raser. & Raser. & 539 & Raser. \\
\hline ARRAPATCEA. rauir. emporter par force. & $\begin{array}{l}\text { Rauir. Rauir et emporter le } \\
\text { bien d'autruy. }\end{array}$ & 539 & Rauir. \\
\hline ARRASTELUA. rasteau. & Rasteau. & 539 & \\
\hline BAREA. la ratte. & Rate. La Rate. & 539 & Rate. \\
\hline Burdin arrastelua. rateau de fer. (BurdinA) & $\begin{array}{l}\text { Rasteau. Vne sorte de ras- } \\
\text { teau de fer. }\end{array}$ & 539 & \\
\hline Arrapaceria. & [Rauissement]. & 540 & [Rauissement]. \\
\hline Arraparia. & [Rauisseur]. & 540 & [Rauisseur]. \\
\hline ARRAYOA. rayon. & Rayons. & 540 & Rayon. \\
\hline COBERATCEA a. 167. cobratcea. recouurer. & Recouurer. & 544 & Recouurer. \\
\hline IKARTCEA. regarder. regard. & Regarder. Regard. & 548 & Regarder. \\
\hline DAMUA. douleur. regret. fascherie. & Regret. & 549 & Regret. \\
\hline Damugarria. & [Regretable]. & 549 & [Regretable]. \\
\hline Damutcea. & [Regretter]. & 549 & [Regretter]. \\
\hline BIR EZCONTCEA. remarier. & Remarier. & 552 & Remarier. \\
\hline
\end{tabular}




\begin{tabular}{|c|c|c|c|}
\hline $\begin{array}{l}\text { A eskuizkribuko } \\
\text { sarrerak }\end{array}$ & $\begin{array}{l}\text { Nicot-en } \\
\text { sarrerak }\end{array}$ & $\begin{array}{c}\text { Nicot-en } \\
\text { orrialde } \\
\text { zenbakia }\end{array}$ & $\begin{array}{l}\text { Oudin-en } \\
\text { sarrerak }\end{array}$ \\
\hline BRIYUA. reliquaire. & Reliquaire. & 552 & Reliquaire. \\
\hline Distiatcea. reluire. briller. & Reluire. & 552 & Reluire. \\
\hline INCONTRATCEA. rencontrer. & Rencontrer. & 555 & Rencontrer. \\
\hline Incontrua. rencontre. & Rencontre. & 555 & Rencontre. \\
\hline Incontru onez. par bon rencontre. & $\begin{array}{l}\text { Rencontre. Par bonne ren- } \\
\text { contre. }\end{array}$ & 555 & \\
\hline ARNEGATCEA. renier. & Renier. & 556 & Renier. \\
\hline Arnegaria, arnegatçaillea. renieur. & Renieur. & 556 & Renieur. \\
\hline Arnegua. reniement. & Reniement. & 556 & Reniement. \\
\hline ARRAMBERRITCEA. renouueler. & Renouueler. & 557 & Renouueller. \\
\hline VRRIQUITCEA. se repentir. (Voltoire) & Repentir. & 559 & Se repentir. \\
\hline VRRIQUIMENDUA. repentance. contrition. & Repentance. & 559 & Repentance. \\
\hline VRGOÏA. reproche. & Reproche. & 561 & Reproche. \\
\hline Deliberacionea. deliberation. resolution. & Resolution. & 563 & Resolution. \\
\hline Deliberatua. & [Resolu]. & 563 & [Resolu]. \\
\hline Guiçon deliberatua. & $\begin{array}{l}\text { [Resolu. Vn homme re- } \\
\text { solu]. }\end{array}$ & 563 & \\
\hline $\begin{array}{l}\text { IHARDETSTEA, inhardetstea. repondre a vne de- } \\
\text { mande. }\end{array}$ & Respondre. & 564 & Respondre. \\
\hline Ihardetspena O. reponse. & Response. & 564 & Response. \\
\hline Cimurra. ride. & Rides. & 570 & Ride. \\
\hline Cimurtcea. rider. soupir. & Rider. & 570 & Rider. \\
\hline Ezta deusic. il n'y a rien. (DeusA) & Rien. Il n'y a rien que. & 570 & \\
\hline Ezdeusa. le rien. & Rien. & 570 & Rien. \\
\hline Chirrixtatcea. rinsser. (CHIRRIXTA) & Rinser. & 571 & Rinser. \\
\hline IвауA. cours d'eau. riuiere. & Riuiere. & 571 & Riuiere. \\
\hline IRRIA. ris. & Ris. & 571 & Ris. \\
\hline Irri eguitea. rire. & Rire. & 571 & Rire. \\
\hline Irribera. & [Rieur]. & 571 & {$[$ Rieur $]$. } \\
\hline Galz vrrinac, asta corotzac. roignons. & Roignon. & 572 & Roignon. \\
\hline BIRIBILLA. rond. & Rond. & 573 & Rond. \\
\hline Biribiltasuna. rondeur. & Rondeur. & 573 & Rondeur. \\
\hline Biribilqui. rondem[ent]. en rond. & Rondement. & 573 & Rondement. \\
\hline CANABERA. roseau. & Roseau. & 573 & Roseau. \\
\hline IHINÇA. rosée. & Rosée. & 573 & Rosée. \\
\hline ChARRAMPIGNA. rougeole. & Rougeolle. & 574 & Rougeolle. \\
\hline ARRUTA. route. & Route. & 575 & Route. \\
\hline
\end{tabular}




\begin{tabular}{|c|c|c|c|}
\hline $\begin{array}{l}\text { A eskuizkribuko } \\
\text { sarrerak }\end{array}$ & $\begin{array}{l}\text { Nicot-en } \\
\text { sarrerak }\end{array}$ & \begin{tabular}{c|} 
Nicot-en \\
orrialde \\
zenbakia
\end{tabular} & $\begin{array}{c}\text { Oudin-en } \\
\text { sarrerak }\end{array}$ \\
\hline $\begin{array}{l}\text { AsNaUR eguitea. O. ruminer comme font les } \\
\text { bestes. }\end{array}$ & $\begin{array}{l}\text { Ruminer. Ruminer comme } \\
\text { quand les bestes remaschent } \\
\text { ce qu'elles ont ja mangé. }\end{array}$ & 576 & Ruminer. \\
\hline ChIrripa. ruisseau. & Ruisseau. & 576 & Ruisseau. \\
\hline ÇORROA. sac. poche. & Sac. & 577 & Sac. \\
\hline ÇuHurCia. sagesse. & Sagesse. & 578 & Sagesse. \\
\hline Çuhurra. sage. sobre. discret. & Sage. & 578 & Sage. \\
\hline Çuhurqui. sagem[ent]. & Sagement. & 578 & Sagement. \\
\hline AROA, sasoina. saison. & Saison. & 579 & Saison. \\
\hline Citthala, liçuna. sale, vilain. & Sale. & 579 & Sale. \\
\hline Cithalqueria. & [Saleté]. & 579 & [Saleté]. \\
\hline ITsusia. sale. vilain. laid. jnfame. & Sale. & 579 & Sale. \\
\hline Itsustasuna. saleté. deformité. & Saleté. & 579 & Saleté. \\
\hline Itsustea. salir. deuenir sale, laid. & Salir. & 579 & Salir. \\
\hline CHInCHINBAREA, 2. jtçaina. sansuë. & Sansuë. & 580 & Sansuë. \\
\hline ITCHAINA, chinchinbarea. sangsuë. & Sansue. & 580 & Sangsuë. \\
\hline AsEA. saoul. remply. & Saoul. & 581 & Saoul. \\
\hline Asetcea. saouler. remplir. (Voltoire) & Saouler. & 581 & Saouler. \\
\hline BAHEA. sas. tamis. crible. van. & Sas. & 581 & Sas. \\
\hline Bahatcea. sasser. tamiser. cribler. vanner. & Sasser. & 581 & Sasser. \\
\hline BEBERINA. sariette. & Sarriette. & 581 & Sarriette. \\
\hline ICEYA. sapin. & Sapin. & 581 & Sapin. \\
\hline Iorralea. sarcleur. (IORRA) & Sarcleur. & 581 & Sarcleur. \\
\hline Iorratcea, jorran haritcea. sarcler. & Sarcler. & 581 & Sarcler. \\
\hline Iorraya. sarclet. & Sarclet. & 581 & Sarclet. \\
\hline ÇAPPOREA. a. saueur. goust. & Saueur. & 582 & Saueur. \\
\hline Çapporatcea. sauourer. gouster. & Sauourer. & 582 & Sauourer. \\
\hline IAUSIA. saut. & Sault. & 582 & Sault. \\
\hline Iausi eguitea. sauter. & Saulter. & 582 & Saulter. \\
\hline Iausica. & [Saulter. En saultant]. & 582 & \\
\hline Iautzcalaria, iautscaria. sauteur. & Saulteur. & 582 & Saulteur. \\
\hline IÇOKINA. saumon. & Salmon. & 582 & Saumon. \\
\hline IAQUITEA. sçauoir. & Sçauoir. & 583 & Sçauoir. \\
\hline Iaquinsuna. sçauant. & Sçauant. & 584 & Sçaüant. \\
\hline Iaquintasuna. science. & Science. & 584 & Science. \\
\hline Bigarrena. deuxiéme. second. (BIA) & Second. & 585 & Second. \\
\hline Bigarrenean. secondement. & Secondement. & 585 & Secondement. \\
\hline
\end{tabular}




\begin{tabular}{|c|c|c|c|}
\hline $\begin{array}{l}\text { A eskuizkribuko } \\
\text { sarrerak }\end{array}$ & $\begin{array}{l}\text { Nicot-en } \\
\text { sarrerak }\end{array}$ & \begin{tabular}{|c|}
$\begin{array}{c}\text { Nicot-en } \\
\text { orrialde } \\
\text { zenbakia }\end{array}$ \\
\end{tabular} & $\begin{array}{c}\text { Oudin-en } \\
\text { sarrerak }\end{array}$ \\
\hline Bigarrenecotz. pour la second fois. & $\begin{array}{l}\text { Second. Consul pour la se- } \\
\text { cond fois. }\end{array}$ & 585 & \\
\hline Bigarrentcea. secundare, ari. & Seconder. & 585 & Seconder. \\
\hline Chiperaillua. seche, poisson. & Seche. & 585 & Seche. \\
\hline Ciguillua, cigulua, sagetta. 2. sceau. & Seau. & 585 & Sceau. \\
\hline IHARROZTEA, inharroztea. secouer. ebranler. & Secouer. & 585 & Secoüer. \\
\hline IDORRA. sec. & Sec. & 586 & Sec. \\
\hline Idortcea. secher. (Voltoire) & Seicher. & 586 & Secher. \\
\hline Idortea. secheresse. & Seicheresse. & 586 & Secheresse. \\
\hline Idorqui. & [Seichement]. & 586 & Sechement. \\
\hline IHARTCEA, eihartcea. deuenir sec, aride. & Sec. denenir sec, et se seicher. & 586 & \\
\hline ICHAKA, jxeka. sillon pour faire ecouler l'eau. & $\begin{array}{l}\text { Seillon. Vn seillon ou rayon } \\
\text { pour esgoutter l'eauë. }\end{array}$ & 587 & \\
\hline VGATZA, bulharra. laict de femme. le sein. & Sein. & 587 & Sein. \\
\hline IDURIA, jrudia. 2. semblant. semblance. (Voltoire) & Semblant. Semblance. & 588 & Semblant. Semblance. \\
\hline $\begin{array}{l}\text { Ez jcusi iduri eguitea. faire semblant de ne voir } \\
\text { pas. }\end{array}$ & $\begin{array}{l}\text { Semblant. Faire semblant } \\
\text { de ne veoir ou apperceuoir } \\
\text { point quelque chose. }\end{array}$ & 588 & \\
\hline Iduriz. a la semblance. & $\begin{array}{l}\text { Semblance. A la semblance, } \\
\text { ou à la façon et maniere. }\end{array}$ & 588 & \\
\hline BEREZTEA, berecitcea. separer. distinguer. & Separer. & 590 & Separer. \\
\hline Elkar ganic bereztea. separer l'vn de l'autre. & $\begin{array}{l}\text { Separer. Separer l'vn auec } \\
\text { dél'autre. }\end{array}$ & 590 & \\
\hline VRRINA. senteur. graisse. & Senteur. & 590 & Senteur. \\
\hline Berecia. separé. distingué. & Separer. Separé. & 591 & \\
\hline CHARRANTCHa. seran. & Seran. & 591 & Seran. \\
\hline Charrantchatcea. & [Serancer]. & 591 & [Serancer]. \\
\hline СHARPOTA. serpoulet. thym. & Serpolet. & 592 & Serpolet, serpoulet. \\
\hline ArRatSa. le soir. & Soir. le soir. & 596 & Soir. \\
\hline Arratsean. au soir. & Soir. Au soir. & 596 & \\
\hline Arratsaldea. soirée. & Soirée. & 596 & Soirée. \\
\hline BAICEN. sinon. postponitur. & Sinon. & 596 & Sinon. \\
\hline СHimignua. singe. & Singe. & 596 & Singe. \\
\hline ANSIA, artha, coaita. soin. soucy. & Soing. & 597 & Soing. \\
\hline ARTHA, ansia, achola. soin. soucy. & Soing. & 597 & Soing. \\
\hline Arthatsua. soigneux & Soigneux. & 597 & Soigneux. \\
\hline Ansiatcea. & [Soigner]. & 598 & [Soigner]. \\
\hline Ansiatsua. soigneux. soucieux. & Soigneux. & 598 & Soigneux. \\
\hline
\end{tabular}




\begin{tabular}{|c|c|c|c|}
\hline $\begin{array}{l}\text { A eskuizkribuko } \\
\text { sarrerak }\end{array}$ & $\begin{array}{l}\text { Nicot-en } \\
\text { sarrerak }\end{array}$ & $\begin{array}{c}\text { Nicot-en } \\
\text { orrialde } \\
\text { zenbakia }\end{array}$ & $\begin{array}{c}\text { Oudin-en } \\
\text { sarrerak }\end{array}$ \\
\hline IGUZQUIA, ekia. soleil. & Soleil. & 598 & Soleil. \\
\hline Iguzqui jlkitea. l'orient. & Soleil leuant, Oriens sol. & 598 & Soleil leuant. \\
\hline Iguzqui sartcea. l'occident. & $\begin{array}{l}\text { Soleil couchant, Occidens } \\
\text { sol }\end{array}$ & 598 & Soleil couchant. \\
\hline Iguzqui mina. soleil ardent. & $\begin{array}{l}\text { Soleil. Le soleil est fort ar- } \\
\text { dant. }\end{array}$ & 598 & \\
\hline Iguzquiztatcea. mettre, etendre au soleil. & Soleil. Mettre au soleil. & 598 & \\
\hline ÇORTHEA. sort. & Sort. & 601 & Sort. \\
\hline IALGUITEA 2, ilkitcea. sortir. mettre dehors. & Sortir. & 601 & Sortir. \\
\hline ÇALUA, çaluya. souple. & Soupple. & 606 & Soupple. \\
\hline BEHACUNA. e. spectacle. & Spectacle. & 607 & Spectacle. \\
\hline Distia handiaz. & Splendeur. & 608 & Splendeur. \\
\hline Assucrea. sucre. & Succre. & 609 & Sucre. \\
\hline ICERDIA. sueur. qui suë. & Sueur. Sueur, Qui sue. & 610 & Sueur. \\
\hline Icerditcea, icertcea. suer. & Suer. & 610 & Suer. \\
\hline Icengoitia. surnom, sobriquet. & Surnom. & 612 & Surnom. \\
\hline Icenguillatcea. surnommer. & $\begin{array}{l}\text { Surnommer. Estre sur- } \\
\text { nommé et auoir vn sotbri- } \\
\text { quet. }\end{array}$ & 612 & Surnommer. \\
\hline IARRAIQUITCEA. suiure. (Voltoire) & Suyure. & 613 & Suiure. \\
\hline Iarraiquitça. suite. poursuite. & Suite. & 613 & Suitte. \\
\hline VRTZA, 2. taula. aix. table. & Table. & 614 & Table. \\
\hline Cutsua. tache. & Tache. & 615 & Tache. \\
\hline Cutsatcea. tacher. & Tacher. & 615 & Tacher. \\
\hline ICHILLA. & [Taire. Qui se taist]. & 616 & \\
\hline Ichiltcea. se taire, faire taire. & Taire. Se taire. Faire taire. & 616 & Taire. Se taire. \\
\hline CARPETA, 2. tapisseria. tapisserie. & Tapisserie. & 617 & Tapisserie. \\
\hline ICEBA. tante. & Tante. & 617 & Tante. \\
\hline ÇAKARRA. crouste de gale. teigne. & Teigne. & 619 & Teigne. \\
\hline Çakartsua. teigneux. & Teigneux. & 619 & Teigneux. \\
\hline Cecena. taureau. & Taureau. & 619 & Taureau. \\
\hline ITCHEQUITCEA. tenir. & Tenir. & 623 & Tenir. \\
\hline $\begin{array}{l}\text { Burua. teste, chef, bout, commencem[ent]. } \\
\text { (Voltoire) }\end{array}$ & Teste. & 627 & Teste. \\
\hline Buruz buru. teste a teste. & Teste à teste. & 627 & Teste à teste. \\
\hline Iaquilegoa $\mathrm{O}$, lecucotasuna. temoignage. & Tesmoinage. & 627 & Tesmoinage. \\
\hline Erle belharra. thym. & Thym. & 629 & Thim. \\
\hline IAITSTEA. tirer. pressurer. & Tirer. & 630 & Tirer. \\
\hline
\end{tabular}




\begin{tabular}{|c|c|c|c|}
\hline $\begin{array}{l}\text { A eskuizkribuko } \\
\text { sarrerak }\end{array}$ & $\begin{array}{l}\text { Nicot-en } \\
\text { sarrerak }\end{array}$ & $\begin{array}{c}\text { Nicot-en } \\
\text { orrialde } \\
\text { zenbakia }\end{array}$ & $\begin{array}{c}\text { Oudin-en } \\
\text { sarrerak }\end{array}$ \\
\hline Esnearen jaitstea. tirer du laict. & $\begin{array}{l}\text { Tirer. Tirer le laict d'vne } \\
\text { mamelle. }\end{array}$ & 630 & \\
\hline ItCHENDiA, 2. jlhetia. tison de feu. & Tison. & 631 & Tison. \\
\hline IGORÇURIA, ihorciria, durunda S. tonnerre. & Tonnairre. & 633 & Tonnerre. \\
\hline VQuitceA, hunquitcea. 2. toucher. & Toucher. & 634 & Toucher. \\
\hline VRÇAPALA. O, vsso apala, vsso tortoilla. tourterelle. & Tourte ou Tourterelle. & 637 & Tourterelle. \\
\hline Behiaren iaitstea. traire vne vache. & Traire. Traire vne vache [...] & 639 & \\
\hline Birlandatcea. transplanter. (BIRLANDA) & Transplanter. & 640 & Transplanter. \\
\hline $\begin{array}{l}\text { Begui ceiharrez behatcea, ceihar behatcea nor- } \\
\text { baiti. de trauers. (CEIHARRA) }\end{array}$ & $\begin{array}{l}\text { Trauers. Regarder de } \\
\text { trauers. }\end{array}$ & 641 & \\
\hline IELOSIAC. treillis. & Treillis. & 641 & Treillis. \\
\hline IKARA. tremblement. & Tremblement. & 641 & Tremblement. \\
\hline Ikaratcea. trembler. (Voltoire) & Trembler. & 641 & Trembler. \\
\hline BETHALDEA, acienda. troupeau de bestail. & $\begin{array}{l}\text { Trouppeau. Troupean de } \\
\text { bestiail. }\end{array}$ & 646 & \\
\hline $\begin{array}{l}\text { IsTRAGALATCEA, jstelgatcea, jstragaltcea. trous- } \\
\text { ser sa robe. }\end{array}$ & Trousser. Trousser sa robe. & 647 & \\
\hline Istragala eguitea. se trousser. & Trousser. Se trousser. & 647 & \\
\hline VNHAIA, vnhaina. vacher. & Vachier. & 649 & Vacher. \\
\hline Valiatcea. se seruir. faire valoir. & $\begin{array}{l}\text { Valoir. Valoir et seruir de } \\
\text { ce qu'vn autre chose sert. }\end{array}$ & 650 & \\
\hline Valio içaitea. valoir. & Valoir. & 650 & Valoir. \\
\hline Vbeldura. meurtrisseure. (VBELA) & Meurtrissure. & 650 & Meurtrisseure. \\
\hline VALENTA. vaillant, valereux. & $\begin{array}{l}\text { Valereux. Valereux id est } \\
\text { Vaillant. }\end{array}$ & 651 & Vaillant. \\
\hline Valentia. vaillantise. & Vaillantise & 651 & Vaillantise. \\
\hline Valioa. valeur. prix. & Valeur. & 651 & Valeur. \\
\hline AlHARgUNA. veuf ou veufue. & Vefue. & 652 & Veuf. veufue \\
\hline Alharguntasuna. veuuage. & Vefuage. & 652 & Veufuage. \\
\hline ARETZEA. veau. & Veau. & 652 & Veau. \\
\hline BeLOSA. velours. & Veloux. & 652 & Velours, vee veloux. \\
\hline BERUINA. vendange. & Vendenge. & 652 & Vendange. \\
\hline Beruinatcea. vendanger. & Vendenger. & 652 & Vendanger. \\
\hline VeILLA. veille qu'on fait dans l'eglise. & Veilla. & 652 & Veilla. \\
\hline Veillatcea. veiller. & Veiller. & 652 & Veiller. \\
\hline Beruinsalea. vendangeur. & Vendangeur. & 653 & Vendangeur. \\
\hline IAUGUITEA, 2. ethortcea. venir. & Venir. & 653 & Venir. \\
\hline Bista. la veuë. & Veue. & 656 & Veuë. \\
\hline
\end{tabular}




\begin{tabular}{|c|c|c|c|}
\hline $\begin{array}{l}\text { A eskuizkribuko } \\
\text { sarrerak }\end{array}$ & $\begin{array}{l}\text { Nicot-en } \\
\text { sarrerak }\end{array}$ & $\begin{array}{c}\text { Nicot-en } \\
\text { orrialde } \\
\text { zenbakia }\end{array}$ & $\begin{array}{l}\text { Oudin-en } \\
\text { sarrerak }\end{array}$ \\
\hline BEIRA. verre. & Verre. & 657 & Verre. \\
\hline BuA. grosse verole. & Verole. La grosse verole. & 657 & grosse Verole. \\
\hline CALITCHA, marroca. verruë. & Verrüe. & 657 & Verrüe. \\
\hline VERNIÇA. vernis. fard. & Vernis. & 657 & Vernis. \\
\hline Verniztatcea, verniçatcea. farder. & [Vernisser]. & 657 & [Vernisser]. \\
\hline IAUNSTEA. vestir. & Vestir. & 658 & Vestir. \\
\hline IsURTCEA. verser. & Verser. & 658 & Verser. \\
\hline Isuria. versé. & Verser. Versé. & 658 & \\
\hline VeRTUTEA. vertu. force. & Vertu. & 658 & Vertu. \\
\hline Vertutetsua. vertueux. & Vertueux. & 658 & Vertueux. \\
\hline VESPERA. vespre. veille. & Vespre. & 658 & Vespre. \\
\hline Vestitcea. vestir. (Voltoire) & Vestir. & 658 & Vestir. \\
\hline Vestidura. & [Vesture]. & 658 & [Vesture]. \\
\hline VIANDA, iaquia, ianharia. viande. mangeaille. & Viande. & 659 & Viande. \\
\hline VICIOA. vice. & Vice. & 659 & Vice. \\
\hline Viciosa, viciotsua. vicieux. & Vicieux. & 659 & Vicieux. \\
\hline ÇAHARRA. vieil. ancien. (Voltoire) & Vieil. & 660 & Vieil. \\
\hline Çahartasuna. vieillesse. & Vieillesse. & 660 & Vieillese. \\
\hline VICIA, bicia. vie. vif. & Vie. Vif. & 660 & Vie. Vif. \\
\hline VIGILIA. vigile de feste. jour de jeusne. & Vigile. & 660 & Vigile. \\
\hline VIRGINA. & [Vierge]. & 660 & [Vierge]. \\
\hline BeguitARTEA. visage. accueil. carresse. & Visage. & 663 & Visage. \\
\hline $\begin{array}{l}\text { Beguitarte eguitea. faire beau visage, bon accueil. } \\
\text { carresser. }\end{array}$ & Visage. Faire bon visage. & 663 & \\
\hline CHIRIBIRIA. violon. & Violles, Viollons. & 663 & Violon. \\
\hline VHARREA, vholdea. torrent, impetuosité d'eaux. & Torrent. & 663 & Torrent. \\
\hline Violeta. & [Violette]. & 663 & [Violette]. \\
\hline VIRATCEA, itçultcea. virer. & \begin{tabular}{|l|} 
Virer. \\
\end{tabular} & 663 & \begin{tabular}{|l} 
Virer. \\
\end{tabular} \\
\hline VISAYA, beguitartea. visage. & \begin{tabular}{|l|} 
Visage. \\
\end{tabular} & 663 & \begin{tabular}{|l|} 
Visage. \\
\end{tabular} \\
\hline Autemaitea. a. visiter. & Visiter. & 664 & Visiter. \\
\hline Autemaillea. qui visite. & \begin{tabular}{|l|} 
Visiteurs. \\
\end{tabular} & 664 & Visiteur. \\
\hline Visitatcea. visiter. & \begin{tabular}{|l|} 
Visiter. \\
\end{tabular} & 664 & Visiter. \\
\hline BeLA. voile. & \begin{tabular}{|l|} 
Voile. \\
\end{tabular} & 666 & Voile de nauir. \\
\hline ARROGACERIA. volerie. pillerie. rapine. & Volerie & 667 & Volerie. \\
\hline Arrogaria, arrogatçaillea. voleur, pilleur. & Voleur. & 667 & Voleur. \\
\hline Arrogatcea. voler. piller. & Voler. & 667 & Voler. \\
\hline BoçA, voça. voix. & Voix. & 667 & Voix. \\
\hline
\end{tabular}




\begin{tabular}{|l|l|c|l|}
\hline \multicolumn{1}{|c|}{$\begin{array}{c}\text { A eskuizkribuko } \\
\text { sarrerak }\end{array}$} & \multicolumn{1}{|c|}{$\begin{array}{c}\text { Nicot-en } \\
\text { sarrerak }\end{array}$} & $\begin{array}{c}\text { Nicot-en } \\
\text { orrialde } \\
\text { zenbakia }\end{array}$ & \multicolumn{1}{|c|}{$\begin{array}{c}\text { Oudin-en } \\
\text { sarrerak }\end{array}$} \\
\hline BOLATCEA. voler. emporter la vole. & Voler. & 667 & Voler. \\
\hline Volondrezcoa, borondatezcoa. volontaire. & Voluntaire. & 668 & Volontaire. \\
\hline BoRONDATEA. volonté. & Volonté. & 669 & Volonté. \\
\hline Borondatez, borondatezqui. volontairement. & Volontairement. & 669 & Volontairement. \\
\hline ÇU, çuc. vous. & Vous. & 669 & Vous. \\
\hline VOLONDREz, borondatez. volontairement. & Volontairement. & 669 & Volontairement. \\
\hline IHETCEA, higatua. vsé. & Vsé. & 670 & Vsé. \\
\hline Ihetcetcea. vser. & Vser. & 670 & Vser. \\
\hline
\end{tabular}

Javier Etxagibel

HEIS, Micaela Portilla Ikergunea,

Nieves Cano 27, 01006 Gasteiz

jetxagibel@outlook.es 